\title{
Field observations of the early-age behavior of jointed plain concrete pavements
}

\author{
Troy Haden Schell \\ West Virginia University
}

Follow this and additional works at: https://researchrepository.wvu.edu/etd

\section{Recommended Citation}

Schell, Troy Haden, "Field observations of the early-age behavior of jointed plain concrete pavements" (2001). Graduate Theses, Dissertations, and Problem Reports. 1185.

https://researchrepository.wvu.edu/etd/1185

This Thesis is protected by copyright and/or related rights. It has been brought to you by the The Research Repository @ WVU with permission from the rights-holder(s). You are free to use this Thesis in any way that is permitted by the copyright and related rights legislation that applies to your use. For other uses you must obtain permission from the rights-holder(s) directly, unless additional rights are indicated by a Creative Commons license in the record and/ or on the work itself. This Thesis has been accepted for inclusion in WVU Graduate Theses, Dissertations, and Problem Reports collection by an authorized administrator of The Research Repository @ WVU. For more information, please contact researchrepository@mail.wvu.edu. 


\title{
Field Observations of the Early-age Behavior of Jointed Plain Concrete Pavements
}

\author{
Troy H. Schell
}

Thesis submitted to the College of Engineering and Mineral Resources

at West Virginia University in partial fulfillment of the requirements

for the degree of
Master of Science
in
Civil Engineering

\author{
Roger H.L. Chen, Ph.D., Chair \\ Hota V.S. GangaRao, Ph.D. \\ Hema Siriwardane, Ph.D.
}

Department of Civil and Environmental Engineering

Morgantown, West Virginia

2001

Keywords: Concrete, cracking, early-age properties, concrete pavement, highways 


\section{ABSTRACT \\ Field Observations of the Early-age Behavior of Jointed Plain Concrete Pavements}

\section{Troy H. Schell}

Newly constructed rigid PCC highway pavements with open graded stabilized base courses have been found to develop non-uniform, transverse saw-cut joint-crack developments and extensive slab movement behaviors, which cause unwanted premature joint failures. Phase I of this study determined the variables associated with the sporadic, large joint opening development by literature review, laboratory tests and some field collected data. The large joints were believed to develop at early-ages of the slabs curing (within the first 48 hours). The early-age stress developments were found controlled by slab temperature history, material property development and frictional resistance. Minimal recommendations for corrects to the behavior were suggested.

The scope of the Phase II investigation was to perform extensive, continuous monitoring of the behaviors of newly constructed slab sections examining concrete temperature behaviors by slab depth and location, joint-crack developments by location, width and growth during the first 72 hours from initial placement. Re-evaluation of the Phase I theoretical pavement analysis and early-age concrete material property developments were also required by additional laboratory testing, slab behavior and actual strain measurement data collection.

The results of the field investigations and re-evaluations were that the analysis required time, location and concrete maturity dependency along the slab lengths. Crack developments were found to consist of primary and secondary formations. The primary cracking was found to be progressive, propagating development behavior dictated by the region of slab end movements determined by the slab to base course interaction, material property developments and slab temperature behaviors. Controlled primary crack development by increasing crack frequencies would reduce the average crack widths and restrict the extensive slab movements. Possible solutions have been examined and will be verified and tested during Phase III of the project. 
This Thesis is dedicated to my parents

Gerald A. and

Brenda J. Schell 


\section{ACKNOWLEDGEMENTS}

I am very grateful to my advisor, Dr. Roger H.L. Chen, for his understanding, assistance and guidance throughout the course of this work. I would also like to express my gratitude to the members of my committee, Dr. Hota V.S. GangaRao and Dr. Hema Siriwardane, for reviewing this work and for their helpful suggestions.

I would also like to thank Mr. Paul Frum and Mr. Dana Humberson for their assistance with laboratory test preparations and with the field investigation instrumentation designs and fabrications.

I would like to thank Joseph Sweet, Clifford Carnes, Jeong Choi, Ryan Harbert, Ricardo Kiriakidis and Cheng Lok Hing for their assistance in laboratory tests and site investigations.

My deep appreciation goes to my parents for all of their encouragement, support, and motivation throughout my life. Without their help, this would never have been possible.

I sincerely thank the Department of Civil and Environmental Engineering, and the Constructed Facilities Center, West Virginia University, Morgantown, WV and also the West Virginia Department of Transportation for facilitating this work and for supporting me financially by offering research assistantships under the research project, RP \# 149. I would also like to thank the Pennsylvania Department of Transportation for locating, permitting and assisting me in the instrumentation and investigations of new PCC slab section constructions. Also, the assistance and comments provided by Mr. Gary Robson, ACPA, and Mr. Arron Gillespie, Project Monitor, are greatly appreciated. 


\section{TABLE OF CONTENTS}

ABSTRACT

DEDICATION

ACKNOWLEDGEMENTS iv

TABLE OF CONTENTS $\quad$ v

LIST OF FIGURES viii

LIST OF TABLES $\quad$ XV

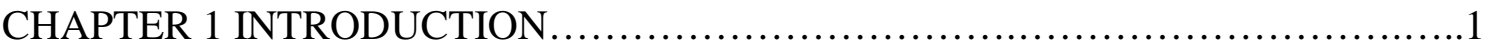

1.1 Problem Statement 1

1.2 Background 2

1.3 Phase I Accomplishments 4

1.4 Objectives

1.5 Significance of Work 6

$\begin{array}{ll}1.6 \text { Scopes } & 6\end{array}$

CHAPTER 2 LITERATURE and PAVEMENT ANALYSIS REVIEW ................9

2.1 Introduction 9

2.2 Early Age Concrete and Behavioral Properties 11

2.3 Phase II Investigated Pavement Design Variations 15

$\begin{array}{ll}2.4 \text { Summary } & 17\end{array}$

CHAPTER 3 EXPERIMENTAL PROGRAM/SPECIMEN PREPARATION.........21

$\begin{array}{ll}3.1 \text { General } & 21\end{array}$

3.2 CONCRETE MIX SPECIFICATIONS 23

A. General 23

B. Phase I Mix Design 24

C. Danville Mix Design 25

D. Elkins Mix Design 26

3.3 BASE COURSE SPECIFICATIONS 28

A. General 28

B. Marianna, PA: Lean Base Course 29

C. Danville, PA: ATPBC 31

D. Elkins, WV: Free Drain Base $\quad 33$

$\begin{array}{ll}\text { 3.4 INSTRUMENTATIONS } & 34\end{array}$

A. Temperature 34

B. Crack Width Measurements 37 
C. Strain Gages and Readout Units 39

D. Strain Gage Placement Techniques 44

E. Modulus Testing Frame 47

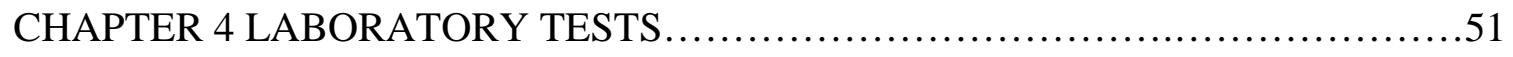

4.1 General 51

4.2 July 1999 Compression Tests 54

A. Procedure 54

B. Tests 56

C. Modulus Test Results 58

D. Early Age Modulus of Elasticity Tests - Discussion 60

E. 28 Day Compression Tests - Discussion 62

4.3 Field and Laboratory Cylinder Tests $\quad 72$

A. October and November 1999 Compression Tests Procedure 72

B. Tests 73

C. Early Age Modulus Test Results - Discussion 75

D. 7,14 and 28 Day Test Results - Discussion 77

$\begin{array}{ll}\text { 4.4 TEMPERATURE TESTS } & 87\end{array}$

A. General - Discussion 87

B. I-80 Danville, PA Concrete Thermal Coefficient Test and Results 89

CHAPTER 5 PCC SLAB CONSTRUCTION INVESTIGATIONS................... 95

$\begin{array}{ll}5.1 \text { General } & 95\end{array}$

5.2 Site Investigation Preparations 97

A. Compatible PCC Construction 97

B. Personnel and Investigation Time Frames 99

$\begin{array}{ll}5.3 \text { Investigated PCC Slabs Introduction } & 101\end{array}$

A. June 1998 PCC Slab Observation 101

B. Monitored Site Introduction 102

CHAPTER 6 I-79 Investigation near MARIANNA, PA October 9,1998_..............109

6.1 Introduction and Site Description 109

6.2 Temperature Data, I-79 Marianna 113

6.3 Cracking Behavior, I-79 Marianna 133

$\begin{array}{ll}\text { 6.4 Discussion, I-79 Marianna } & 140\end{array}$

CHAPTER 7 I-80 Investigation near DANVILLE, PA October 16, 1998..............143

7.1 Introduction and Site Description 146

7.2 Temperature Data, I-80 Danville 196

7.3 Cracking Behavior, I-80 Danville 160

A. 16 October 1998 slab section (Instrumented) 160

B. 12 October 1998 slab section (Non-instrumented) 162 
CHAPTER 8 Corridor H Investigation near ELKINS, WV October 12, 1999..........171

$\begin{array}{ll}\text { 8.1 Introduction and Site Description } & 171\end{array}$

$\begin{array}{ll}\text { 8.2 Temperature Data, Corridor H Elkins } & 179\end{array}$

8.3 Cracking Behavior, Corridor H Elkins 206

A. 12 October 1999 slab section (Instrumented) 206

B. 13 October 1999 slab section (Non-instrumented) 208

8.4 Strain Gage Data, Corridor H Elkins 214

8.5 Discussion, Corridor H Elkins 230

CHAPTER 9 COMPARISONS OF PROJECT OBSERVATIONS ...................233

9.1 PCC Pavement Slab Behavior Similarities $\quad 233$

A. Introduction 233

B. Temperature behavior 234

C. Joint crack development 237

9.2 Concrete Slab to Base Course Interaction 249

9.3 Generalized observations of concrete slab behavior 253

CHAPTER 10 MODIFICAITON OF STRESS ANALYSIS ......................257

$\begin{array}{ll}\text { 10.1 Introduction } & 257\end{array}$

10.2 Modified Discrete Regional Analysis $\quad 260$

10.3 Material and Behavioral Properties for Modified Regional Analysis 267

10.4 Corridor H Theoretical Analysis Results 277

10.5 Analysis Comparison to Investigation Observations and Discussion 289

CHAPTER 11 DISCUSSION, CONCLUSIONS AND RECOMMENDATIONS.....292

11.1 Discussion $\quad 292$

$\begin{array}{ll}11.2 \text { Conclusions } & 296\end{array}$

$\begin{array}{ll}11.3 \text { Recommendations } & 298\end{array}$

$\begin{array}{ll}\text { REFERENCES } & 301\end{array}$

APPENDIX A: Example of Compression Tests Stress-Strain Relationships 305

Committee Approval Signature Page 314 


\section{LIST OF FIGURES}

1.1 Modulus of Elasticity Development (Channel, 1998) 8

1.2 US 119 section Crack Development (Channel, 1998) 8

2.1 Coefficient of Friction (Channel, 1998) 18

$2.2 \quad$ Split Tensile Strength (Channel, 1998) 18

2.3 Dowel Bar Pull-out Stress (Channel, 1998) 18

$2.4 \quad$ Thermal Coefficient (Channel, 1998) 18

2.5 Modulus of Elasticity Development (Okamoto, 1994) 19

2.6 Split Tensile Strength (Okamoto, 1994) 19

2.7a. Transverse Joint Saw-cut 20

2.7b. Skewed Transverse Joint 20

2.7c. Perpendicular Transverse Joint 20

$3.1 \quad$ Typical Thermocouple Group Layout 48

3.2a. Standard EM-5 Strain Gage 49

3.2b. Modified Flange EM-5 Strain Gage 49

3.3. Picture: Corridor H slab, EM-5 Strain Gage Suspension System 50

4.1 Early-age Modulus of Elasticity, Cylinder 1W EM-5 Results (July 1999) 64

4.2 Early-age Modulus of Elasticity, Cylinder 1W Dial Gage Results (July 1999) 65

4.3 Early-age Modulus of Elasticity, Cylinder 2W (July 1999) 66

4.4 Early-age Modulus of Elasticity, Cylinder 4W (July 1999)

4.5 Early-age Modulus of Elasticity, Cylinder 6A (July 1999) 
4.6 Early-age Modulus of Elasticity, Cylinder 8A (July 1999)

4.7 28-Day Modulus of Elasticity Results (July 1999) 70

4.8 28-Day Compressive Strength Results (July 1999) 71

4.9 Early-age Modulus of Elasticity, Lab Specimen \#1 (Corridor H)

4.10 Early-age Modulus of Elasticity, Lab Specimen \#2 (Corridor H)

4.11 Early-age Modulus of Elasticity, Lab Specimen \#3 (Corridor H)

4.12 28-Day Modulus of Elasticity Developments, All Lab Specimens (Corridor H)

4.14 Lab and Field Specimen 28-Day Compressive Strengths, (Corridor $\mathrm{H}$ )

4.15 Hi-Way Paving, Inc., Compressive Strength Results (Corridor H) 86

4.16 Temperature Test Results (July 1999) 92

4.17 Ambient and Air-dry Cured Cylinder Temperature Behavior Compared (July 1999)

4.18 Temperature Behavior Comparison: EM-5 gage and Thermocouple \#1 (July 1999)

5.1 Crack Development, North Bound Outside Lane Joint-cracks (I-79 Marianna, PA: 15 June 1999)

5.2 Crack Development, North Bound Inside Lane Joint-cracks (I-79 Marianna, PA: 15 June 1999)

5.3 Ambient Temperature History (June 1998 I-79 Observation) 107

5.4a. I-79 Marianna, PA Pavement Design Cross-section 108 
5.4b. I-80 Danville, PA Pavement Design Cross-section 108

5.4c. Corridor H near Elkins, WV Pavement Design Cross-section 108

6.1a. Group Thermocouple Layout: I-79 Marianna, PA

9 October 1998 Investigation

6.1b. Group Thermocouple Layout: I-80 Danville, PA

16 October 1998 Investigation

6.2 Group \#1 Thermocouple Readings (I-79 Marianna, PA)

6.3 Group \#2 Thermocouple Readings (I-79 Marianna, PA)

6.4 Group \#3 Thermocouple Readings (I-79 Marianna, PA)

6.5 Group \#4 Thermocouple Readings (I-79 Marianna, PA)

6.6 Group \#5 Thermocouple Readings (I-79 Marianna, PA)

6.7 Maximum Core Temperatures by Location and Time (I-79 Marianna, PA)

6.8 Time Maximum Core Temperatures Reached by Location (I-79 Marianna, PA)

6.9 Slab Temperature Profile by depth at 11.5 hours (I-79 Marianna, PA)

6.10 Slab Temperature Profile by depth at 17.5 hours (I-79 Marianna, PA)

6.11 Slab Temperature Profile by depth at 23.5 hours (I-79 Marianna, PA)

6.12 Slab Temperature Profile by depth at 27 hours

(I-79 Marianna, PA)

6.13 Slab Temperature Profile by depth at 31 hours (I-79 Marianna, PA)

6.14 Slab Temperature Profile by depth at 38 hours

(I-79 Marianna, PA) 
6.15 Slab Temperature Profile by depth at 42.5 hours (I-79 Marianna, PA)

6.16 Field and Airport Ambient Temperature Histories

(I-79 Marianna, PA: 9 October 1998)

6.17 Lean Base and Ambient Temperature Readings

(I-79 Marianna, PA: 9 October 1998)

6.18 Concrete Age by Slab Location (I-79: 9 October 1998) 136

6.19 Crack Development up to 30 hours (I-79: 9 October 1998) 137

6.20 Crack Development after 30 hours (I-79: 9 October 1998) 138

6.21 Crack Development at Selected Times (I-79: 9 October 1998) 139

7.1 Group \#1 Thermocouple Readings (I-80 Danville, PA) 152

7.2 Group \#2 Thermocouple Readings (I-80 Danville, PA) 153

7.3 Group \#3 Thermocouple Readings (I-80 Danville, PA) 154

7.4 Group \#4 Thermocouple Readings (I-80 Danville, PA) 155

7.5 Group \#5 Thermocouple Readings (I-80 Danville, PA) 156

7.6 Group \#6 Thermocouple Readings (I-80 Danville, PA) 157

7.7 Ambient Temperatures (I-80: 16 October 1998) 158

7.8 ATPBC and Ambient Temperatures (I-80: 16 October 1998) 159

7.9 Crack Development at 26 hours (I-80: 16 October 1998) 164

7.10 Crack Development at 51.25 hours (I-80: 16 October 1998) 165

7.11 Crack Development at Selected Times (I-80: 16 October 1998) 166

7.12 Crack Development at 147 hours

Non-instrumented Section (I-80: 12 October 1998) 167

8.1a. Thermocouple Group Locations (Corridor H) 178

8.1b. Modified EM-5 Strain Gage Locations (Corridor H) 178 
8.2 Group \#1 Thermocouple Readings (Corridor H) 186

8.3 Group \#2 Thermocouple Readings (Corridor H) 187

8.4 Group \#3 Thermocouple Readings (Corridor H) 188

8.5 Group \#4 Thermocouple Readings (Corridor H) 189

8.6 Group \#5 Thermocouple Readings (Corridor H) 190

8.7 Group \#6 Thermocouple Readings (Corridor H) 191

8.8 Group \#7 Thermocouple Readings (Corridor H) 192

8.9 Ambient Temperature History (Corridor H) 193

8.10 Group \#1 Temperature Behavior by Concrete Age (Corridor H) 194

8.11 Group \#2 Temperature Behavior by Concrete Age (Corridor H) 195

8.12 Group \#3 Temperature Behavior by Concrete Age (Corridor H) 196

8.13 Group \#4 Temperature Behavior by Concrete Age (Corridor H) 197

8.14 Group \#5 Temperature Behavior by Concrete Age (Corridor H) 198

8.15 Group \#6 Temperature Behavior by Concrete Age (Corridor H) 199

8.16 Group \#7 Temperature Behavior by Concrete Age (Corridor H) 200

8.17 Maximum Core Temperature Reached by Location (Corridor H) 201

8.18 Time Concrete Placed and Time Maximum Core Temperature Reached (Corridor H) 202

8.19 Total Time to Reach Maximum Core Temperature By Location (Corridor H) 203

8.20 FDB and Ambient Temperatures by Location (Corridor H) 204

8.21 FDB and Ambient Temperature at Varying Times (Corridor H) 205

8.22 Concrete Age by Location (Corridor H) 209

8.23 Crack Development during first 24 hours (Corridor H: 12 October 1999) 210 
8.24 Crack Development after 24 hours (Corridor H: 12 October 1999)

8.25 Crack Development at Selected Times (Corridor H: 12 October 1999)

8.26 $2^{\text {nd }}$ Section Crack Development History (13 October 1999)

8.27 Concrete Thermal Coefficient Results \#1 (Corridor H)

8.28 Concrete Thermal Coefficient Results \#2 (Corridor H)

8.29 Total Strain by Time varying $\alpha_{C}$, EM-5 Gage \#4 (Corridor H) 225

8.30 Real Strain by Time, All Field Gages (Corridor H) 226

8.31 Gage \#1 Total Strain by Time varying $\alpha_{C}($ Corridor $H)$

8.32 Gage \#2 Total Strain by Time varying $\alpha_{C}($ Corridor $H)$

8.33 Gage \#3 Total Strain by Time varying $\alpha_{\mathrm{C}}($ Corridor $\mathrm{H})$

9.1 Ambient Temperature Histories by Site Investigation 243

9.2 Group Core Temperature Histories (I-79 Marianna, PA) 244

9.3 Group Core Temperature Histories (I-80 Danville, PA) 245

9.4 Group Core Temperature Histories (Corridor H) 246

9.5a. Joint-crack Measurement Locations 247

9.5b. Daytime Joint-crack Detail 247

9.5c. Nighttime Joint-crack Detail 247

9.6 Slab Section and Frictional Interaction Detail 252

10.1 Linearly Approximated Analysis Age by Location (Corridor H) 272

10.2 Modified Analysis $\Delta \mathrm{T}_{1}$ Values by Group versus Time (Corridor $\mathrm{H}$ ) 273

10.3 Modified Analysis $\Delta \mathrm{T}_{2}$ Values by Group versus Time (Corridor $\mathrm{H}$ ) 274

A1. July 1999 early-age EM-5 Gage Tests 306

A2. July 1999 early-age Dial Gage Tests 307 
A3. July 1999 28-Day Dial Gage tests 308

A4. July 1999 28-Day Dial Gage tests, example 2

A5. Corridor H Mix, early-age EM-5 tests 310

A6. Corridor H Mix, early-age Dial Gage tests 311

A7. Corridor H Mix, 7, 14 and 28 day EM-5 tests 312

A8. Corridor H Mix, 7, 14 and 28 day Dial Gage tests 313 


\section{LIST OF TABLES}

3.1 Phase I, Concrete Mix Design 24

3.2 Danville, PA Concrete Mix Specifications 26

3.3 Elkins, WV Corridor H Concrete Mix Specifications 27

3.4 CTPBC (Lean Base Course) Specifications 30

3.5 CTPBC Course Aggregate Specifications 30

3.6 ATPBC (Asphalt Base) Danville, PA Specifications 32

4.1 Concrete Cylinder Designations July 1999 Tests 55

4.2 Field and Lab Specimen Designation, Corridor H Cylinders 73

5.1 Approximate Pavement Specifications and Mix Designs for Investigations 98

6.1 Transverse Joint Saw Cutting, I-79 Marianna, PA 110

6.2 Converted Time Chart, I-79 Marianna, PA Investigation 116

7.1 Thermocouple Calibrations, I-80 Danville, PA 150

7.2 Converted Time Chart, I-80 Danville, PA 151

8.1 Converted Time Chart, Corridor H near Elkins, WV 177

8.2 Thermocouple Calibrations, Corridor H near Elkins, WV 185

8.3 Modified Strain Gage \#1 Data Sheet (Corridor H) 219

8.4 Modified Strain Gage \#2 Data Sheet (Corridor H) 220

8.5 Modified Strain Gage \#3 Data Sheet (Corridor H) 221

8.6 Modified Strain Gage \#4 Data Sheet (Corridor H) 222

9.1 Estimated Thermal Strains and Thermal Coefficients
By Site Investigation

10.1 Concrete Age by Slab Region 275

10.2 $\Delta \mathrm{T}_{1}$ by Region versus Time 275 
$10.3 \Delta \mathrm{T}_{2}$ by Region versus Time $\quad 276$

10.4 Example Table 1 of Stress Analysis 282

10.5 Example Table 2 of Stress Analysis 283

10.6 Modified Theoretical Analysis Results, Example Trial \#1 284-286

10.7 Critical Times of Example Trial \#1 Results 287

10.8 Approximate Transverse Crack Spacing by Number of Joints (Trial \#1) 288 


\section{Chapter 1: INTRODUCTION}

\section{$\underline{\text { 1.1 Problem Statement }}$}

In the recent years, newly constructed concrete highway pavements have been found to experience peculiar joint movements. These highways were constructed of rigid concrete pavement slabs of $254 \mathrm{~mm}$ to $304.8 \mathrm{~mm}$ (10 in to 12 in) thickness with no wire mesh or reinforcement. The slabs were saw-cut at a spacing of 4.57-m (15 ft) shortly after placement (within 24 hours). The purpose of the saw cutting is to control where cracks will occur in the pavement and to relieve the shrinkage stresses in the concrete. Large, joint-crack opening's were observed by field engineers at sporadic intervals along the slab. The 4.57-m (15-ft) section pavements were originally designed to allow cracking at the joints, and uniform crack openings were anticipated at each joint for thermal contraction. However based on current observations, non-uniform crack openings have occurred with some joints opening much wider than others.

In WVDOT design, these concrete pavements are typically constructed on top of a $152.4 \mathrm{~mm}$ (6 in) thick open-graded, free-draining base. The free-draining base material is a mixture of $2 \%$ asphalt and $98 \%$ aggregate (\#57 crushed limestone) that is placed and compacted on site. A layer of synthetic, separation/filter fabric is placed beneath the base course to prevent contamination of the free-draining base by fines from the sub-grade. The pavement sections are constructed using slip form paving. All joints are connected with $457.2 \mathrm{~mm}$ (18 in) length, $38.1 \mathrm{~mm}$ (1.5 in) diameter, epoxy coated dowel bars. The dowel bars are coated with a specially formulated grease compound (Tectyl Bondbreaker 506) so that there is no bond between the concrete and the dowel bar. Low modulus silicon sealant is used to seal the joints. Further observation by the field 
engineers notes that the sealant experienced extensive wrinkles at the large joint openings. This suggests that the joints were experiencing large openings and closings. These joint movements and their unique locations have raised interest and concern from engineers.

Research was conducted to determine "why" and "how" these joints behave differently than anticipated. The scope of Phase II was to verify laboratory results and to test hypotheses of how to correct the problem in an actual construction process. Phase II study also investigated the joint behavior in field experiments and re-evaluated the Phase I theoretical analysis and results compared to actual field constructed slab behavior.

\subsection{Background}

Through laboratory experiments and an extensive literature review of the topic, a hypothesis was generated during Phase I work. The ambient temperature and concrete temperature were found to be important factors in the resulting hypothesis. It is known that concrete expands and contracts as a result of temperature fluctuations. The effect of the sub-grade on the movement of the slab has a direct relation to the stresses generated in the concrete. Concrete pavement shrinkage is resisted by friction between the pavement and the base course interaction. This creates an internal tensile stress in the concrete, during contraction, which in turn causes the concrete slab to crack. The crack occurs at a pre-designated area, being a saw-cut joint, and releases the stress.

When the concrete slab is placed in the morning hours, the ambient temperature rises and the heat of hydration adds to the internal concrete temperature. This creates high temperatures in the concrete. During the late afternoon and evening, solar radiation 
begins to dissipate and the ambient temperature falls. In addition to this, the heat of hydration begins to decrease during the same period of time. This creates a large temperature drop from the maximum temperature to the minimum temperature during this period. The large temperature drop creates large tensile stress values from the thermal shrinkage of the concrete.

The hypothesis states that the high stress developed in the concrete, from the temperature change, causes the slab to crack. The cracking will not be uniform in width or be at every joint. The reasons for this are:

- The bond and friction force from slab to base course interaction may not be strong enough to keep the slab from moving when the crack occurs. This would create a large joint opening at that particular joint.

- Because of the large opening of the cracked joint, the joints around it may not crack at all. This is because the slabs will be able to shift. This will only be able to occur at a few joints because the stress will be building up, over a series of slab lengths, and another large crack will occur starting the process over again.

A coefficient of friction value was determined for the free draining base and the concrete interface during Phase I testing. The cracking would occur in the slab at young ages, 12 to 48-hours, because of the high friction coefficient. The cracking occurred when the modulus of elasticity of the concrete was at a low value. Because of the low modulus of elasticity of the concrete, large joint openings formed at the cracked joints. This was because the concrete had low resistance to deformation at this age.

The sporadic behavior of the joint cracks is a result of the friction force, concrete stress, dowel bar bond stress, and material properties of the early age concrete. When the 
slab cracks, it releases a large amount of stress thereby possibly breaking the bond between the slab and the base course allowing enhanced shifting. The slab deforms to relieve the stress build up and the cycle begins over.

The hypothesis generated deals with the slab/base-course interaction and temperature fluctuations. There is a bond formed between the concrete and the free-draining base as a result of a bleed zone between the two materials. The bleed zone is the area where concrete paste bleeds into the free-draining base material and creates a bond. The bond and friction forces develop over time along with the modulus of elasticity of the concrete. (See Figure 1.1: Channel, 1998)

\subsection{Phase I Accomplishments}

During Phase I, an extensive literature review was conducted and the results revealed that the temperature variations play a key role in the stress build up in the slabs. From the literature review it was also determined that there is a great need for methods for testing concrete slabs at this very delicate age. Field trips were made to five locations. (Channel, 1998) Accomplishments from these field trips include:

1. Collecting evidence of uneven crack movements and distributions.

2. Implementing strain measurements, thermal measurements and crack size determination procedures.

From data collection, it can be seen that smaller crack widths result when crack spacing is small (Figure 1.2: Channel, 1998). From Figure 1.2 it can also be seen that the slabs cast during evening hours, when solar radiation is low, experience more evenly spaced joint cracks with smaller joint openings. It should be noted that the large joints 
create a weak area in the pavement, which will cause unnecessary deterioration and reduce operational efficiency of the highway.

Laboratory experiments to measure the development of strain and temperature in concrete slabs have been done. In addition, material property tests were done on the same concrete mix used for the construction. These tests included:

- The determination's of the modulus of elasticity, the compressive strength and tensile strength of the concrete mix over time.

Two additional tests were conducted in the laboratory. One of these tests determined the coefficient of friction between the concrete and the free-draining base at different times. The other series of tests determined the bond stresses developed between the smooth dowel bars and the concrete over time. Using the results from the above mentioned tests and current equations for stress modeling, theoretical equations were developed to model the stress development in the concrete. These equations aided in the construction process investigations entailed in Phase II of the project.

\section{$\underline{1.4 \text { Objectives }}$}

The objective of this research was to verify results obtained from laboratory tests in actual construction processes and to test hypotheses of how to correct the joint movement problem. This study was to further understand why and how the pavement would behave in such a peculiar manner. Using this knowledge, this study would propose a solution for pavement design/construction to correct the joint movement problem. 


\section{$\underline{1.5 \text { Significance of Work }}$}

The pavement problem demonstrates a need for more advanced techniques in design and construction of highway concrete pavements. The sporadic cracking at joints and large openings may increase the maintenance cost, reduce the operational efficiency of the highway, and may create a driving hazard. The proposed testing scheme will verify laboratory results and propose new construction procedures to create a better pavement. This knowledge is needed to create better driving terrain and to reduce future costs by requiring less maintenance.

\subsection{Scopes}

The research plan was focused on field experiments. Testing of full-scale concrete slabs was crucial to the verification of laboratory experiments and to test the hypotheses of how to correct the cracking problem. Experimentation on actual construction projects where slip form paving was used with free-draining base as the base course material would be the most effective. Construction of new pavement's investigated were conducted by West Virginia Division of Highways and Pennsylvania Department of Highways.

The research plan proposed consisted of six major tasks:

1. Development of field monitoring techniques to evaluate the thermal behaviors, the strain and maturity of the concrete pavement.

2. Monitoring of the specimen to establish the rate, size, and position of cracked joints.

3. Comparison of field data to theoretical values from calculations.

4. Monitoring of slab using corrected construction technique and testing to verify validity of proposed technique.

5. Continue literature review and laboratory experiments.

6. Report preparation 
Phase II investigation was to perform extensive, continuous monitoring of the behaviors of newly constructed slab sections examining concrete temperature behaviors by slab depth and location, joint-crack developments by location, width and growth during the first 72 hours from initial placement. Re-evaluation of the Phase I theoretical pavement analysis and early-age concrete material property developments were also required by additional laboratory testing, slab behavior and actual strain measurement data collection.

In the following text, a thorough re-evaluation of the joint movement/cracking behavior is described. Chapter 2 gives literature review on past investigations and theory into this subject. Chapter 3 describes the experimental program. Chapter 4 investigates material property developments associated with concrete at early ages. Chapter 5 introduces the field investigations and continuous monitoring of newly constructed PCC slabs conducted during this study. Chapters 6,7 and 8 contain the three different slab investigations collected data and results. Chapter 6 is the I-79 slab section near Marianna, PA, Chapter 7 is the I- 80 section near Danville, PA, and Chapter 8 is the slab section of Corridor H near Elkins, WV. Chapter 9 compares the results and behaviors found during the investigations. Chapter 10 is the discrete regional theoretical analysis of the stress developments of newly constructed PCC pavement sections and Chapter 11 contains final discussions, conclusions and recommendations. 
Figure 1.1: Modulus Of Elasticity vs Time Air Dried Concrete

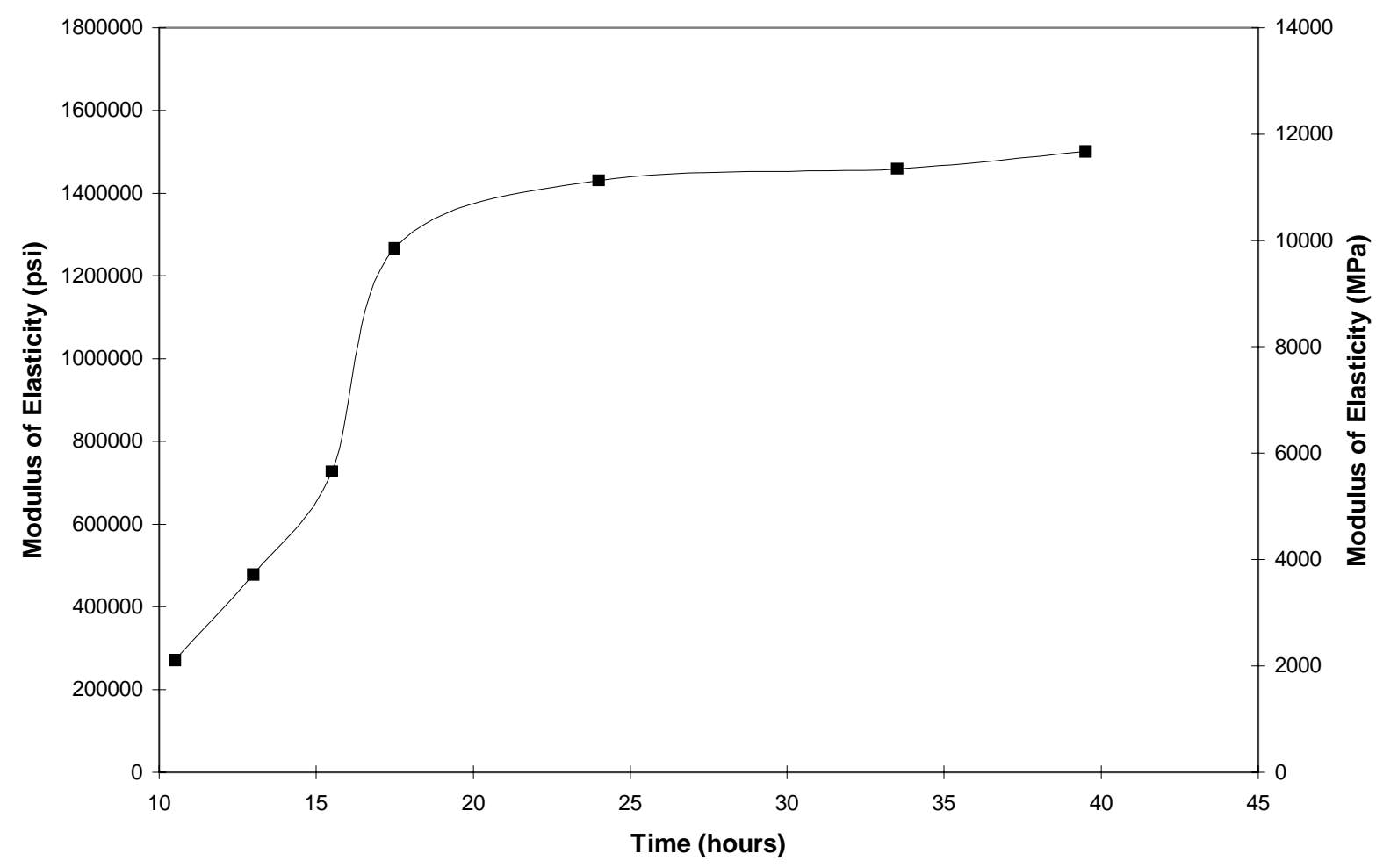

Figure 1.2: Crack Width From US Route \#119

Compared to the Joint Number

(Taken at 100 hours after placement)

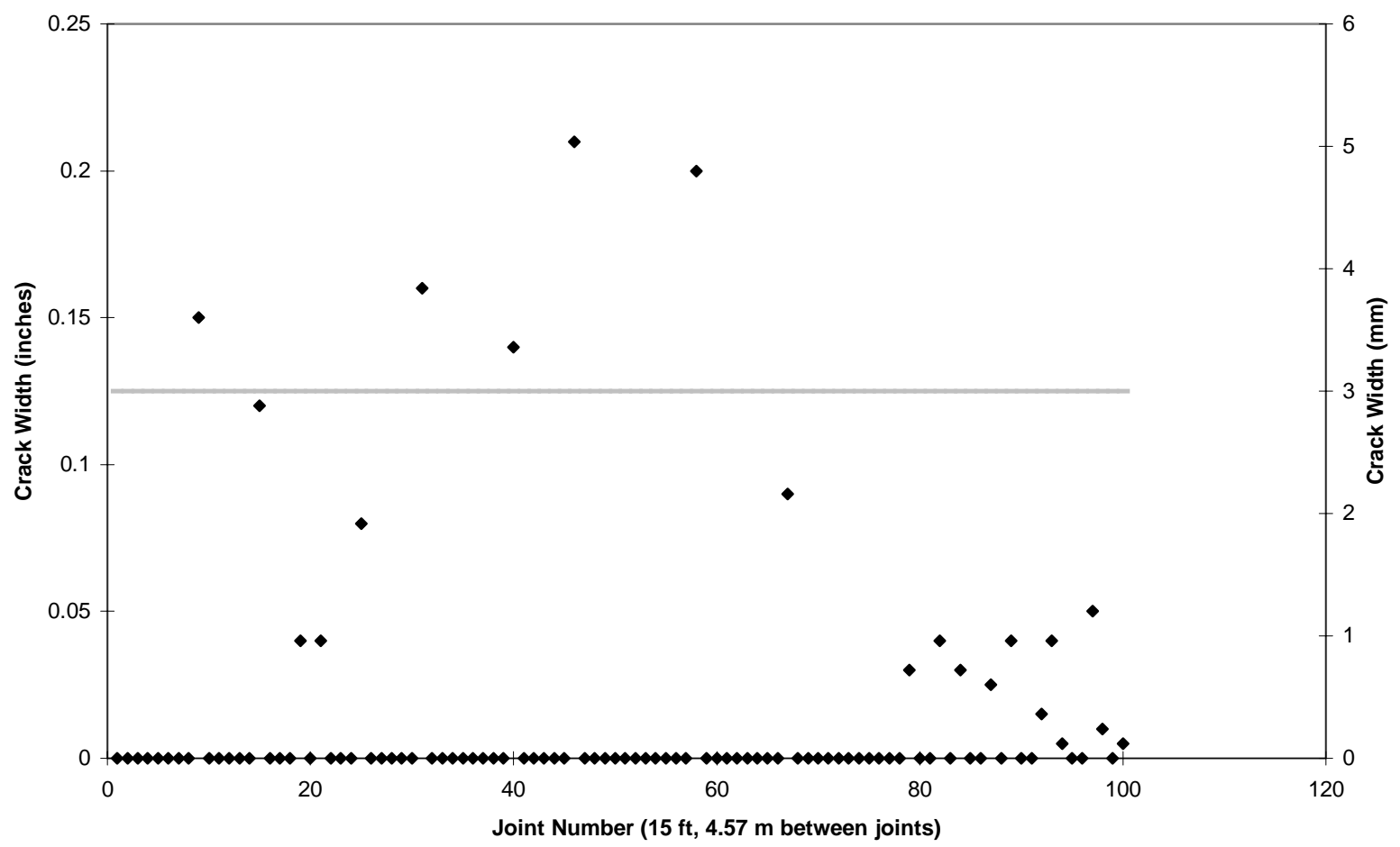

Figures 1.1: Modulus of Elasticity Development and

Figure 1.2: US 119 section Crack Development (Channel et. al. 1998) 


\section{CHAPTER 2: LITERATURE AND PAVEMENT ANALYSIS REVIEW:}

\section{$\underline{2.1 \text { Introduction }}$}

Phase I theoretical analysis was based upon equations developed during another research investigation performed by Okamoto in 1994, "Guidelines for Timing Contraction Joint Sawing and Earliest Loading for Concrete Pavements", report number FHWA-RD-91-079 (volumes 1 and 2). Initial analysis predicted the slab behavior primarily due to temperature fluctuations and early-age concrete material property development. Phase I analysis was based on the assumption that the entire concrete slab length consisted of identical material and behavioral properties. This assumption was believed to be true for only sufficiently short slab sections.

The theoretical analysis performed in Appendix A of the Phase I report showed possible transverse saw-cut joint crack behavior. The analysis did not compare greatly to the observed crack behavior. The actual joint-crack sequencing was not recorded sufficiently to compare it to the new theoretical prediction. The data inadequacy was understood at that time and thus requests of further investigations.

The time and location dependence on the theoretical analysis drastically complicated initial analysis time prediction. But, this was believed to be the correct method to produce an accurate theoretical modeling.

Literature review continued during Phase II research. Documented works of other researchers and companies as well as verbal conversations to various concrete specialized personnel were obtained. Several different states' highway construction officials and designers were contacted during this study. Early-age concrete material and behavior property tests and/or results were discussed. Various early-age concrete pavement 
studies are being performed nation-wide. The most comparable study to the joint movement study is being performed by Transtec, Inc., in affiliation with the Federal Highway Administration. They have developed a computerized design aide called HIPERPAV. (Transtec, 1997) The software, although utilizing similar equation analyses, revealed results of maximum saw-cut joint spacing but not comparing actual initial jointcrack formation. The HIPERPAV software was found possibly useful for additional long-term evaluation of the intermediate joint-crack formations, or slab subsection analysis. The software analyses was performed as time, or concrete age, dependent analyses only, like the Phase I analysis. The time and location dependent, early-age analysis is not considered in the software. The software is believed fundamentally and theoretically comparable, but for sufficiently short slab sections only and also only for long-term maximum behavior. The software may be of use in the long-term effects, or evaluation, of theoretical solutions determined from the Phase II joint-crack movement study. (Rasmussen, 1998) 


\subsection{Early Age Concrete and Behavioral Properties}

Early-age concrete material properties and concrete slab behavioral properties were tested or evaluated during Phase I research. The stress and strength development factors dictated what early-age properties were required for the theoretical analysis. The Phase I report detailed these factors when describing the initial pavement analysis in Chapter 2, Chapter 9 and Appendix A.1. The basic factors of the analysis were not changed during Phase II modifications adapting to time and location dependency. The early-age property developments throughout the first 72-hours were required but varied only by location and concrete age in the modification. Various property developments were determined for the specific concrete mix design utilized during Phase I. Some developments were assumed or estimated from previous works found during literature review.

The material and behavioral properties tested for, or approximated from literature review, during Phase I were described and documented. (Channel, 1998) For reference, these graphical results are presented and can be seen in Figures 1.1 and Figures 2.1 through 2.4. The Phase I tested properties were the modulus of elasticity in Figure 1.1, the coefficient of friction in Figure 2.1, the split tensile strength in Figure 2.2 and the dowel bar pullout stress in Figure 2.3. The concrete thermal coefficient was not determined from laboratory tests, but from literature review, and is in Figure 2.4. The age dependent developments of each property were determined for a specific concrete mix design and may not be representative of various mixes. Phase I referenced material, of the early-age developments of the modulus of elasticity and the split tensile strength of concrete from Okamoto in 1997, showed similar development shape but varied in value and time of development. The Okamoto material development graphs can be seen in 
Figures 2.5 and 2.6. The specific concrete mix designs and testing procedures varied between the laboratory tests. Comparison of the tests is restricted to the property value variations over the short time frames which initial property growth was seen. The variations of the developments would produce radically different results in theoretical analysis. Therefore, all material property and slab behavioral properties were suspect to verification of development during Phase II re-evaluations.

Phase II re-evaluations of the material and behavioral properties, and the laboratory testing procedures where questionable techniques and/or results were distinguished. Phase II analysis required that varying concrete mix and pavement designs' be investigated. The property developments for each would be different requiring independent tests for each. Re-performing all of the tests performed during Phase I for varying concrete mix designs was not practical. Therefore, specific critical, or most suspicious, properties were determined for re-testing.

The estimation of the development of the thermal coefficient of concrete was questioned first. This was because it was not laboratory tested for development in Phase I. From the literature review of Phase I, determination of the thermal coefficient of concrete at any age has been arguable. Phase I estimation of the thermal coefficient of concrete was believed within reason but needed testing verification. During Phase II, laboratory and field tests were performed to determine concrete thermal coefficients at varying ages. Testing procedures and results of Phase II tests can be seen in Chapter $4.5 \mathrm{~b}$ and Chapter 8.4. The results from the Phase II tests verified the suspicion that the coefficients development over time documented for Phase I analysis was not correct. The Phase I estimation of the thermal coefficient being around 5 to $6 \mathrm{in} / \mathrm{in} /{ }^{\circ} \mathrm{F}$ is believed a 
reasonable approximation, but the drastic development from zero at time equal to zero is not. Two concrete mix designs were tested for thermal coefficient development, which resulted in two different values. Testing was not extensive, but showed results that the coefficient remains nearly constant after initial concrete set. Prior to initial concrete set, the determination of the thermal coefficient is arguable at this time. It is not believed to be zero and should have a value possibly even higher when tested prior to concrete set. Prior to set, concrete is fluid-like in behavior, which typically have larger thermal coefficient values than solid materials. (Serway, 1990) The pavement behavior is believed not be effected by the very early thermal coefficient development, because critical behavior was not seen until well after initial set time. Therefore, the resulting tested, nearly constant, thermal coefficient value obtained will be utilized in the modified theoretical analysis. (See also Chapter 10)

The other properties early-age developments were initially believed reasonable for the specific concrete mix design. Some of the property developments were believed to be useful for Phase II analysis because of the probability of value similarity from varying the concrete mix designs. The developments of the coefficient of friction and the dowel bar pullout stresses are predicted to remain reasonably similar in growth and value. The split tensile strength development is believed to be similar between concrete mixes. Prior tests have given means of approximation of the tensile strength. ACI equations show tensile strength in terms of the $28^{\text {th }}$ day compressive strength. If it is assumed that the tensile strength of the concrete is similarly defined as a function of the early-age compressive strengths', then estimated tensile strength values and growths could be developed. These 
compressive strength values are readily obtained and could reveal reasonable values for theoretical use.

The last material property determined for development variation during theoretical analysis is the modulus of elasticity development. Referencing Phase I and Okamoto's modulus of elasticity test results, Figures 1.1 and 2.5, variation of early-age results is believed critical. Variation of testing procedure, concrete mix design and curing techniques proved important characteristics in modulus developments obtained. The variation in the concrete mix designs observed during the Phase II investigations required that the modulus of elasticity developments for each concrete mix design be determined for each theoretical analysis. Many considerations were accounted for during the Phase II laboratory modulus of elasticity tests performed. The results again proved different for varying concrete mixes. Phase II tests results and conclusions can be seen in Chapter 4 . 


\section{$\underline{\text { 2.3 Phase II Investigated Pavement Design Variations: }}$}

At the onset of the Phase II project, WVDOT Division of Highways was not expecting any newly constructed pavement on free-drain base course. As was found during Phase I, the asphalt treated base courses are not widely used in practice as of yet. Therefore, the search from state to state for a compatible type of construction design to investigate was performed. Many states transportation departments were contacted to see what type (or types) of base courses they were using in their new concrete highway construction. Few were using asphalt-stabilized bases and only Pennsylvania expected any construction to occur in the fall of 1998 or spring 1999. PennDOT officials were eager to assist us in locating a compatible construction to investigate. There were two new concrete pavement constructions that were to be completed during the late 1998 construction season. One was a section of I-79 southbound lanes near Marianna, PA and the other was a section of I-80 eastbound lanes near Danville, PA. Other than those two, no other new concrete pavement construction was to be performed in the remaining 1998 construction season. The Marianna, PA design utilized a lean base course, which is a concrete stabilized base. For comparative purposes of the slab behavior on varying bases, both sites were investigated.

The concrete mix designs differed for each site, which was not considered during the Phase I study. This required that further laboratory tests needed performed to evaluate the different mix designs. Minimizing the number of tests needing re-performed was a priority in Phase II to optimize available time. The concrete slab thickness and curing technique was also site specific. The transverse saw-cut depths, spacing and orientations were other variables. The transverse saw-cuts were described in Phase I showing the 
initial cut by width and depth and also described a later, wider secondary cut for uniformity. The initial transverse saw-cuts made were designed at a depth of one-third or one-fourth the slab depths and one eighth to three sixteenths wide, project specific. The initial orientation of the transverse joints was either perpendicular or skewed to the direction of travel. The PennDOT designs utilized the skewed orientation and the WVDOT utilized the perpendicular joints. The skewed joints were set at a six-to-one skew, which is mainly for tire ride and not for slab behavior corrections. The variation of transverse joint design can be seen in Figures $2.7 \mathrm{a}, \mathrm{b}$ and $\mathrm{c}$. The secondary cuts are made after shoulders have been constructed and cured along the 24-feet wide main slabs being investigated. The secondary cuts uniform the crack openings at the surface only. The non-uniform crack widths are not corrected. Extensive expansion and contraction will still occur at the larger joint cracks, which will wear out and fail the low modulus silicon sealant seals causing joint failures.

Further discussion on the variations in slab and material designs for the investigated slab constructions will be presented Chapters 3 and 5. Chapter 3 contains additional comments on the mix and design variations and Chapter 5 shows cross-sectional design differences. The individual site investigation chapters also describe additional design, behavioral and site specific information needed for a complete theoretical analysis. 


\section{$\underline{\text { 2.4 Summary }}$}

The majority of Phase II work was based on the Phase I report and the referenced papers and personnel from which the initial pavement analysis was developed.

Additional, Phase II field investigation's contribution was actual data, which was obtained during this study and has little referencing required. To date, no evidence of investigations or publications exist evaluating initial saw-cut joint-crack developments in newly constructed PCC highway pavements considering time and location dependency. Therefore, limited reference material exists about early-age slab behavior in this aspect. Minimal early-age concrete material property tests and coefficient of friction tests have been performed and documented. Further investigation into documented early-age concrete material property developments and other behavioral aspects should continue.

Early-age concrete material properties and concrete slab behavioral properties were studied, tested and/or evaluated during the theoretical analysis process. The properties used in the analysis are critical to the overall theoretical results and consequentially the recommended solutions or modifications to correct the joint movement problem. Some analysis value uncertainties resulted from Phase I study were re-evaluated during this study. Re-evaluations, additional testing and/or value estimations were performed. Further investigation and theoretical analysis should cautiously evaluate required assumptions. Actual theoretical analysis, required material property approximations and results can be seen in Chapter 10 . 

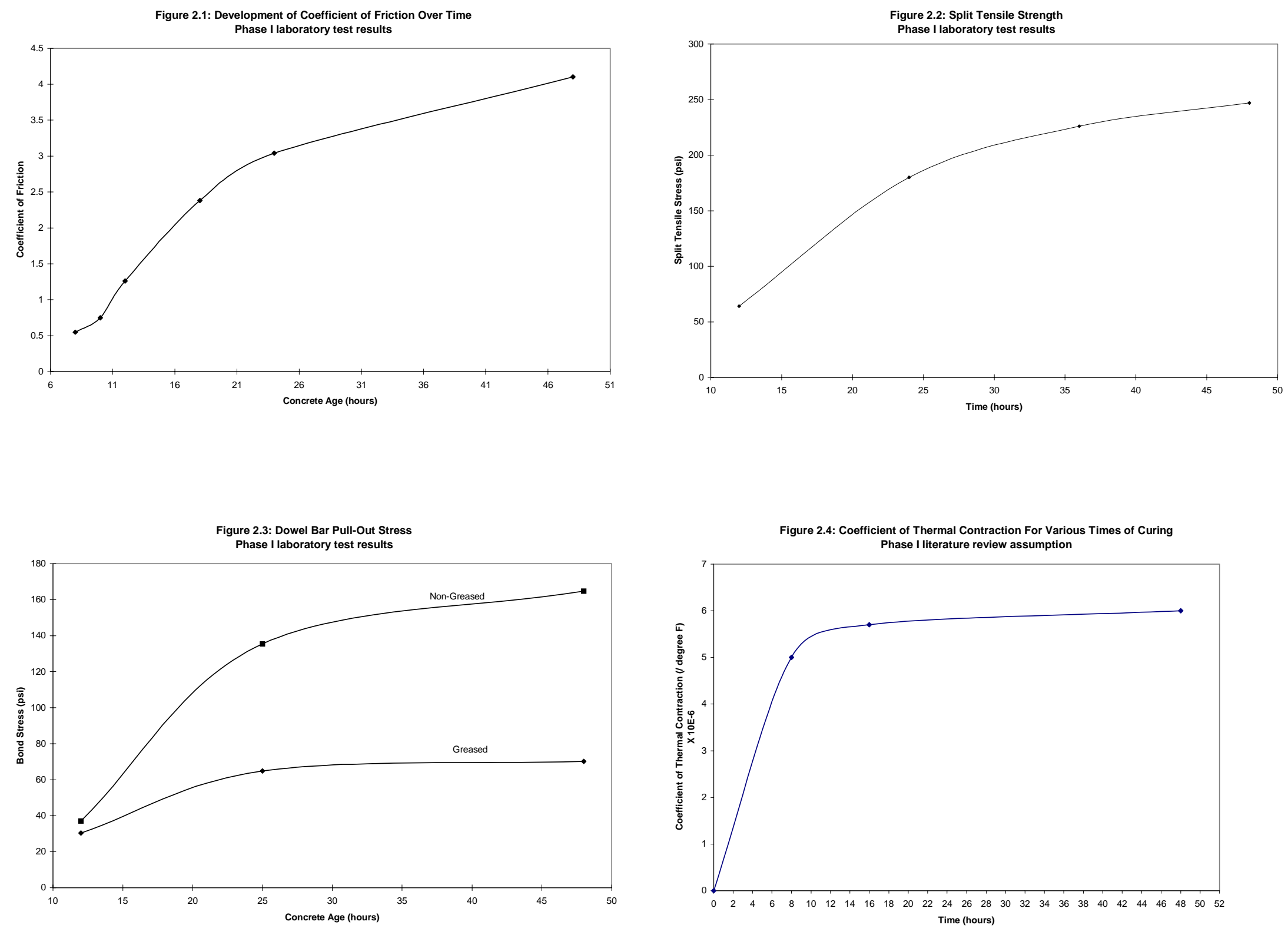

Figure 2.1 through 2.4: Phase I Material Properties (Channel, 1998) 
Figure 2.5: Modulus of Elasticity vs. Time

(Okamoto et.al, 1994)

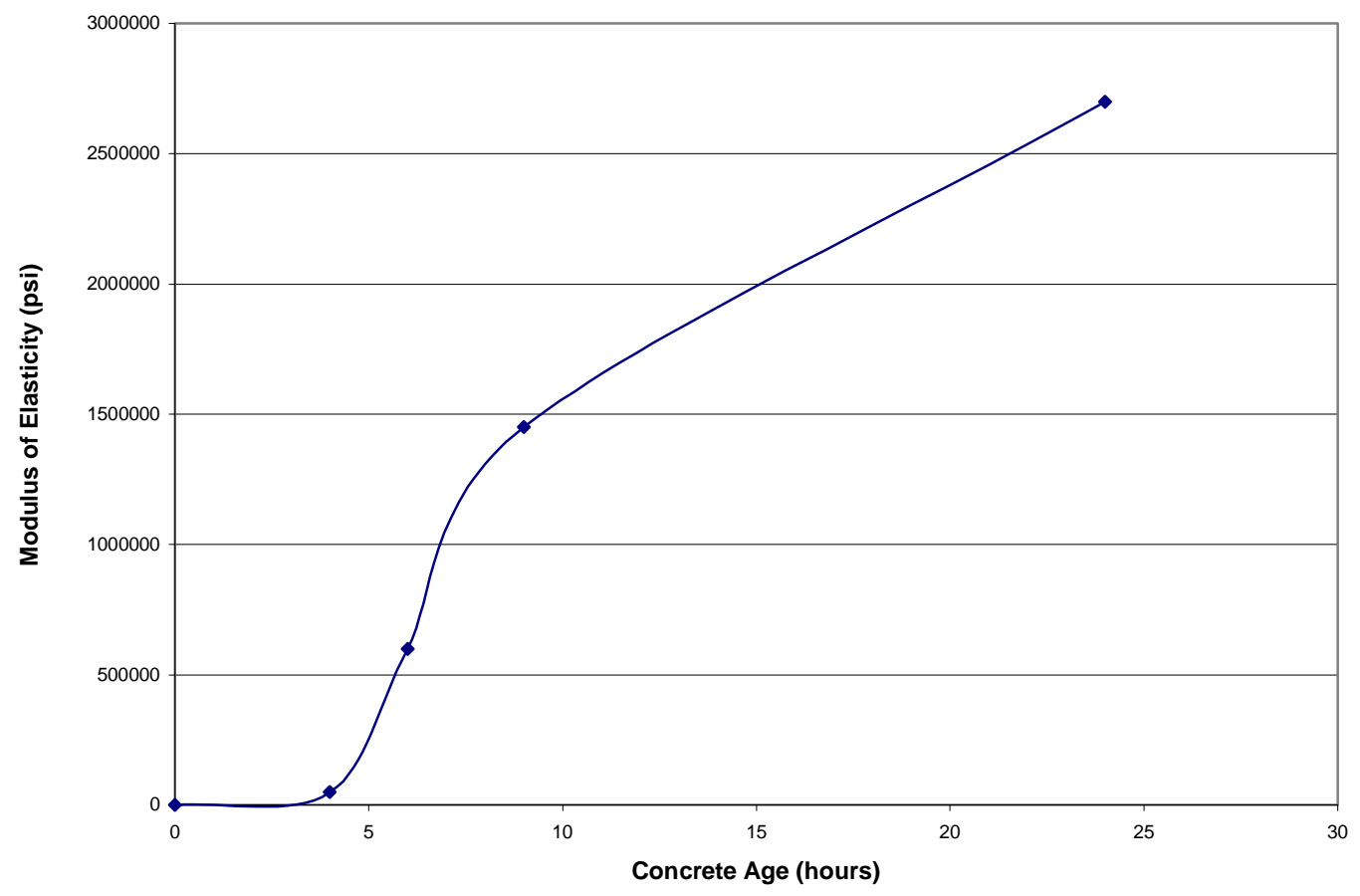

Figure 2.6: Concrete Split Tensile Strength Development (Okamoto et.al, 1994)

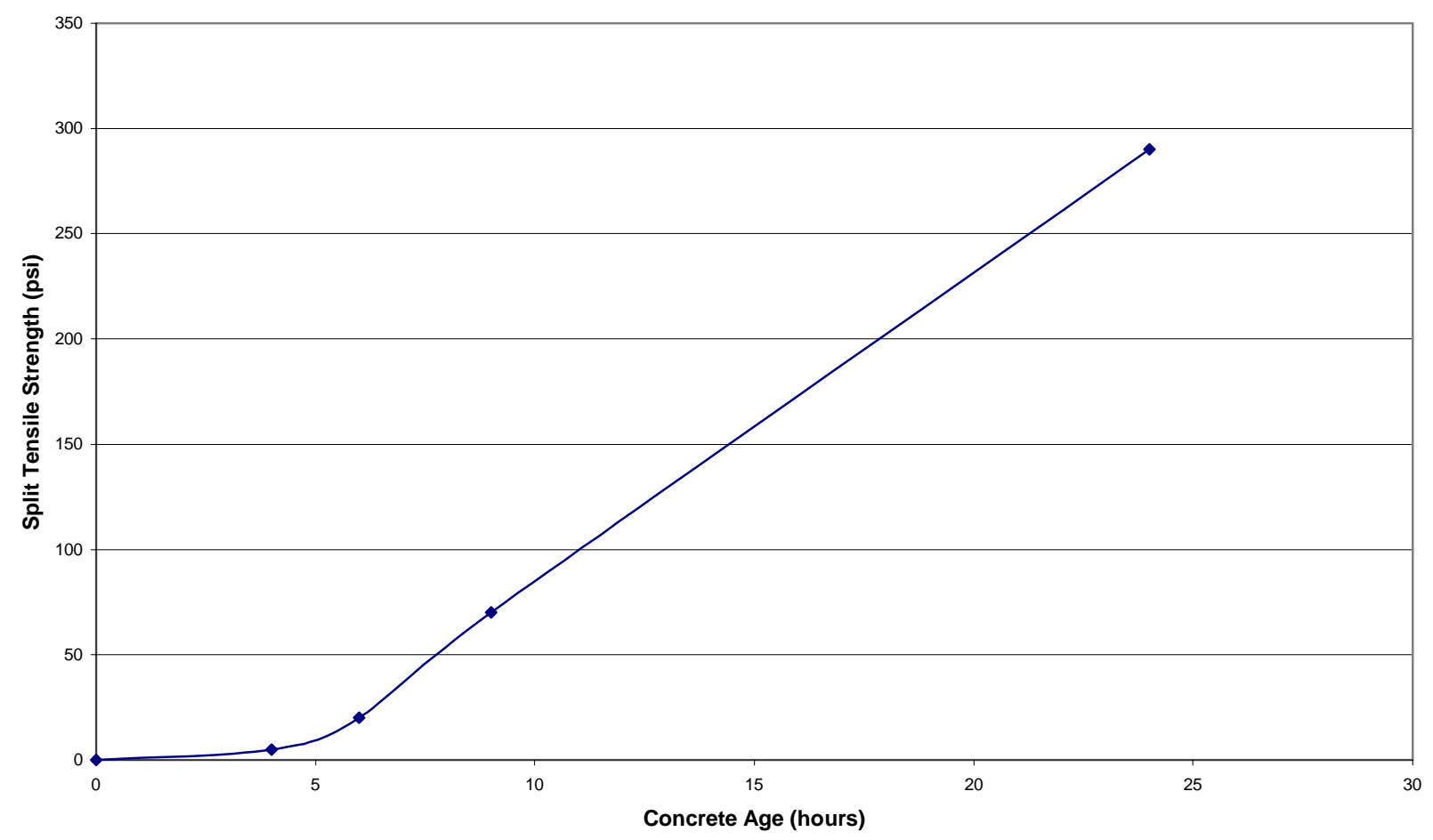

Figures 2.5 and 2.6: Material Property Developments (Okamoto et. al. 1994) 


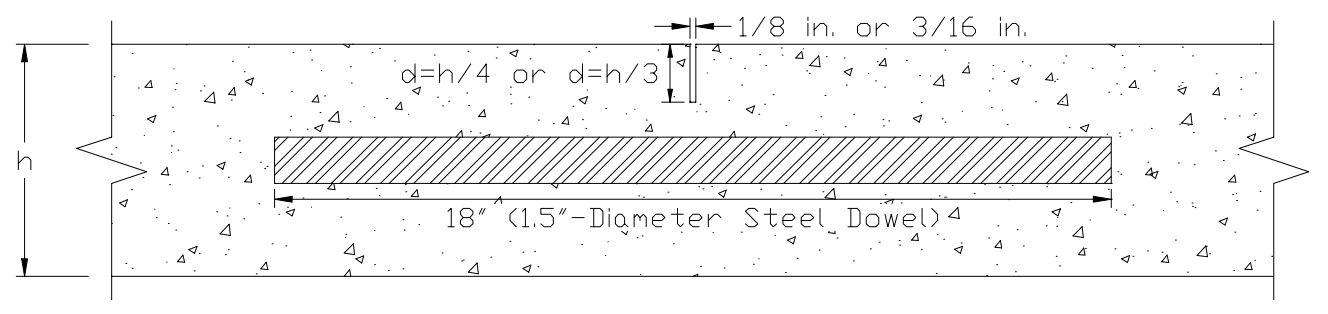

(a)

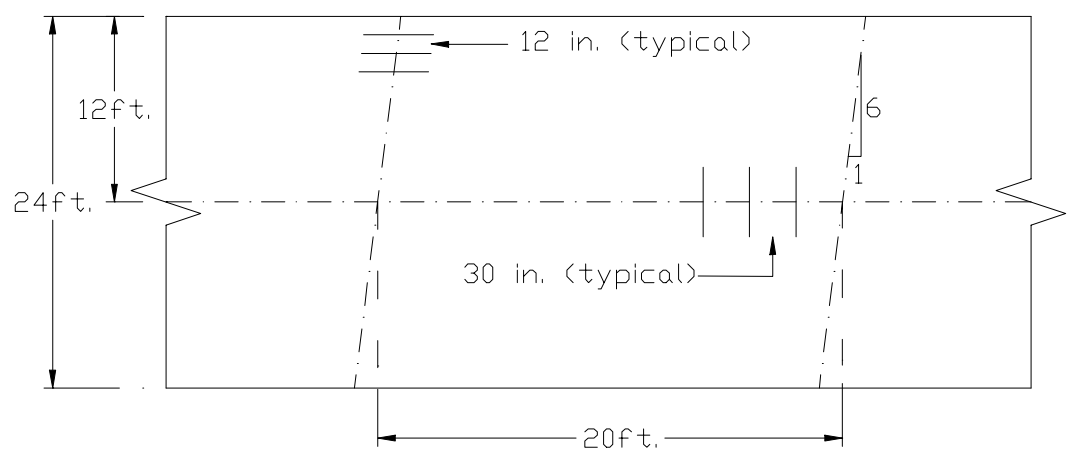

(b)

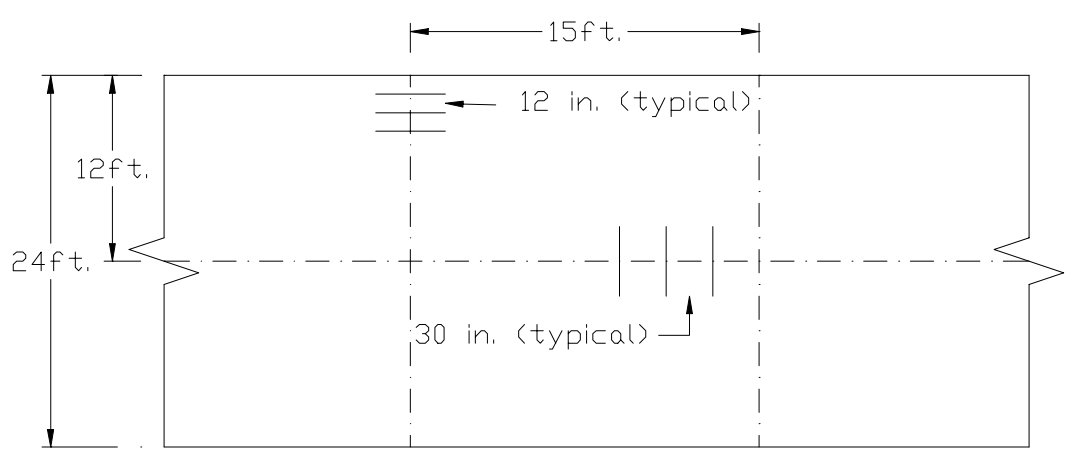

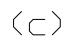

Figure 2.7a, b and c: Transverse saw-cut joint design variations. 


\section{CHAPTER 3: EXPERIMENTAL PROGRAM/SPECIMEN PREPARATION}

\section{$\underline{3.1 \text { General }}$}

The experiments to be conducted during this study were mainly determined by what Phase I did not encompass. To study the 4.57-m (15-ft) rigid concrete pavement joint cracking behavior, newly placed segments were instrumented and analyzed over an extended period of time. The instrumentation consisted of thermocouples and embedded strain gages. The thermocouples were inserted at various depths over the cross section of the slab and throughout the slab lengths. This was done so that the temperature profile of the slabs could be determined. By using the temperature profiles, axial restraint and curling stresses could be calculated. This data was needed from newly constructed slabs to evaluate the analysis equations developed during Phase I. In the previous study, the pavements were assumed to have the same growths in material property values and changes in temperature throughout the slab length. Yet, the construction process continued for 10 to 12 hours or more, which allows for substantial lengths of pavement to be placed. Phase I results showed that the analysis procedure as written can take into account changing properties with time, but not changing properties with time and location. Another aspect not considered during Phase I was that different concrete mix designs might be encountered at different sites. Also, the strain gage tested during Phase I proved to be an insufficient gage for the purposes of this analysis. Therefore, another type of strain gage would need to be found for the investigation.

The newly constructed PCC continuous slab investigations were to collect specific types of data. The data needed were:

1. The slab temperature profiles at different slab depths; 
2. The transverse joint crack formations;

3. The climatic data during construction of a pavement (including ambient temperature histories)

4. Longitudinal stain values for comparison to theoretical calculations.

Also, detailed information of the concrete pavements had to be acquired prior to monitoring their construction to ensure any differences between investigations were considered. These details include:

1. The pavement design containing the cross-section;

2. The mix designs and thickness of all courses;

3. The width of the pavement;

4. The type of transverse joint design;

5. The method of transverse joint cutting with the width, depth, and orientation;

6. The method of curing;

7. The type of shear transfer at joint locations.

The data collected must be taken at time and location intervals, which are relevant to the applications they are to be used for in an analysis situation. The slab temperature profiles histories; environmental exposures and the growth of the specific concrete material properties of a given construction must be checked closely for evaluation and are shown in Chapter 10. The collected data from the various investigations can be seen in Chapter 5, 6, 7 and 8 . 


\subsection{CONCRETE MIX SPECIFICATIONS:}

\section{2a. General}

The concrete mix design that was tested during the Phase I laboratory tests was obtained from the WVDOT Department of Highways. At that time, it was assumed to be the only mix design utilized for the type of construction in question for this state. That assumption was incorrect. The mix designs vary from project to project. Each contracting company makes their own designs, including the materials and admixtures as long as they meet the current state and federal guidelines, standards, such as ASTM, AASHTO, etc., for concrete mixture specifications.

Three different concrete mix designs were observed in three separate pavement constructions. It was almost a certainty that the concrete pavements would behave slightly differently even if every aspect of the project design were identical, because there are many other variables to consider.

The first two sites monitored were located in Pennsylvania and monitored in October of 1998. One site was on a section of I-79 northbound lanes near Marianna, PA and the other was on I-80 eastbound lanes near Danville, PA. For the ease in describing the different mix designs, they will further be recognized by their relative location (Marianna or Danville).

As previously stated, three mix designs were observed. The last site was a section of Corridor H in October 1999. The section of Corridor H constructed was near Elkins, WV. The concrete mix design used in the Corridor $\mathrm{H}$ construction, again varied from the mix design laboratory tested during Phase I. 
In the following sections are detailed tables of the different concrete mix designs. The first mix design shown is that used in the Phase I tests (Section 3.2b). The second is the Danville mix design used in the July 1999 compression tests, (Section 3.2c) and the final shown is the Elkins mix design (Section 3.2d).

\section{2b. Phase I Mix Design}

The concrete mix design was consistently used for every test performed during Phase I of this research. The mix proportioning was approximately 1:2:3 (cement: fine aggregate: coarse aggregate). The target compressive strength, $\mathrm{f}_{\mathrm{c}}{ }^{\prime}$, was $3,000 \mathrm{psi}$. The following table gives a representation of one cubic yard $(1 \mathrm{CY})$ of concrete mix proportioning and the corresponding absolute volumes.

TABLE: 3.1

PHASE I, RP \#107 CONCRETE MIX SPECIFICATION

\begin{tabular}{|c|c|c|c|}
\hline & & Amout/1yd ${ }^{3}$ & s. Vol - 1yd ${ }^{3}$ \\
\hline \multicolumn{2}{|c|}{ Portland Cement- sacks 6.0} & 564 LB & $2.87 \mathrm{cf}$ \\
\hline \multicolumn{2}{|c|}{ Flyash- sacks equivalent 0.0} & $0 \mathrm{LB}$ & $0 \mathrm{cf}$ \\
\hline \multicolumn{2}{|c|}{\begin{tabular}{|lll} 
Water- & 30.49 & Gallons \\
\end{tabular}} & $254 \mathrm{LB}$ & $4.07 \mathrm{cf}$ \\
\hline \multicolumn{2}{|c|}{ Air Content, by volume } & $7 \%$ & $1.89 \mathrm{cf}$ \\
\hline \multicolumn{2}{|c|}{ Coarse Aggregate- \#57 SSD } & 1782 LB & $10.62 \mathrm{cf}$ \\
\hline \multicolumn{2}{|c|}{ Fine Aggregate- river sand SSD } & 1230 LB & $7.55 \mathrm{cf}$ \\
\hline \multicolumn{2}{|r|}{ TOTAL } & 3830 LB & $27.00 \mathrm{ft}^{3}$ \\
\hline \multicolumn{2}{|l|}{ Air-Entraining- } & $2.01 \mathrm{oz} / \mathrm{Cwt}$ & 11.34 fl. oz. \\
\hline \multicolumn{2}{|l|}{ Water Reducer- } & $0 \mathrm{oz} / \mathrm{Cwt}$ & 0.0 fl. oz. \\
\hline \multicolumn{2}{|l|}{ Superplasticizer- } & $0 \mathrm{oz} / \mathrm{Cwt}$ & $0.0 \mathrm{fl} .0 \mathrm{z}$. \\
\hline \multicolumn{2}{|c|}{ Design Fresh unit weight } & $141.85 \mathrm{LB} / \mathrm{ft}^{3}$ & \\
\hline \multicolumn{2}{|c|}{$\frac{1}{\text { Water/Cement Ratio (w/c) }}$} & 0.45 & \\
\hline
\end{tabular}


The previous concrete mix proportioning was scaled to the amount of concrete needed for a give test to be performed. There were several different types of tests performed and were documented in the phase I report. The graphical results obtained from those tests are again documented in this report for reference purposes. These graphs include:

- Figure 1.1: Modulus of Elasticity v/s Time

- Figure 2.1: Coefficient of Friction v/s Time

- Figure 2.2: Split Tensile Strength v/s Time

- Figure 2.3: Dowel Bar Pull-out Stress v/s Time

These graphs represent the tests performed on this specific concrete mix design.

\section{2c. Danville Mix Design}

The Danville concrete mix design was utilized for the first set of compression tests performed in Phase II in July 1999. These proportions were obtained from the actual batch mixer slips written for the day of construction of the section of I-80 eastbound lanes near Danville, PA investigated on October 16, 1998. An abundance of information was supplied from the PennDOT personnel and the contracting company, New Enterprises Stone and Lime Co., Inc. Both were helpful, cooperative and interested in the work we were performing.

At the time of the investigation, obtaining some of the actual concrete materials from the batch plant for laboratory tests was not done, because no laboratory tests were scheduled yet. When it was decided to test the Danville mix design, a sample of the actual aggregates used was unattainable because construction there was complete. Although, the actual brands and types of admixtures used in the concrete mix were 
obtained from the respective companies for the laboratory tests. The aggregate gradations were listed on the batch sheets supplied to us, but exactly matching the aggregates was not practical. The aggregates used were obtained from the WVU concrete lab's aggregate bins. These aggregates are similar in type and in gradation, but not identical to those used in the Danville concrete mix. The following table lists the mix proportioning for one cubic yard of concrete and the scaled down mix amounts used during the July 1999 compression test cylinder concrete.

TABLE: 3.2

DANVILLE, PA MIX DESIGN CONCRETE MIX SPECIFICATION

PennDOT concrete class AA525 and mix 2-AA-2

\begin{tabular}{|c|c|c|c|}
\hline & Amout/1yd ${ }^{3}$ & $\begin{array}{r}\text { July } 1999 \text { Lab Mix/ } \\
0.0963 \text { CY(2.6CF) }\end{array}$ \\
\hline \multicolumn{2}{|c|}{ Portland Cement- sacks- 6.57} & $2525 \mathrm{LB}$ & $50.558 \mathrm{LB}$ \\
\hline Flyash- $\quad$ Pozzolan- & & $93 \mathrm{LB}$ & $8.956 \mathrm{LB}$ \\
\hline Water- & Gallons & $248 \mathrm{LB}$ & $23.786 \mathrm{LB}$ \\
\hline \multicolumn{2}{|l|}{ Air Content, by volume } & $6 \%$ & Actual $4.5 \%$ \\
\hline \multicolumn{2}{|c|}{ Coarse Aggregate- \#57 SSD } & 1776 LB & $171.029 \mathrm{LB}$ \\
\hline \multicolumn{2}{|c|}{ Fine Aggregate- sand A- SSD } & 1249 LB & $120.279 \mathrm{LB}$ \\
\hline & TOTAL & $3891 \mathrm{LB}$ & $374.608 \mathrm{LB}$ \\
\hline \multicolumn{2}{|l|}{ Air Entraining- MBVR } & $8 \mathrm{oz} / \mathrm{CY}$ & actual $22.783 \mathrm{~mL}$ \\
\hline \multicolumn{2}{|l|}{ Water Reducer- 220-N } & $19 \mathrm{oz} / \mathrm{CY}$ & actual $54.111 \mathrm{~mL}$ \\
\hline Superplasticizer- & & $0 \mathrm{oz} / \mathrm{Cwt}$ & 0 \\
\hline \multicolumn{2}{|c|}{ Design Fresh unit weight } & $144.1 \mathrm{LB} / \mathrm{ft}^{3}$ & $144.1 \mathrm{LB} / \mathrm{ft}^{3}$ \\
\hline Slump & & 1.5 inch & actual $1.0 \mathrm{inch}$ \\
\hline \multicolumn{2}{|c|}{ Water/Cement Ratio (w/c) } & 0.40 & 0.40 \\
\hline
\end{tabular}

Note: Surface moisture tests performed on field SSD aggregates.

\section{2d. Elkins Mix Design}

This concrete mix design was used in the construction of the section of Corridor $\mathrm{H}$ westbound lanes near Elkins, WV that was investigated on October 12, 1999. The field cylinders tested were made from the actual concrete being placed at the construction site. 
The materials for the laboratory tests were requested and obtained from the contractors on site batch plant. WVDOT project personnel and HI-WAY PAVING, Inc. were very helpful and cooperative in every aspect of the requests of the materials needed for these tests. All of the materials for the laboratory test, except water, were obtained directly from the contractor's stockpiles and storage tanks. The mix proportioning for one cubic yard and that used for the mentioned laboratory compression tests are listed in the following table.

TABLE: 3.3

ELKINS, WV MIX DESIGN CONCRETE MIX SPECIFICATION

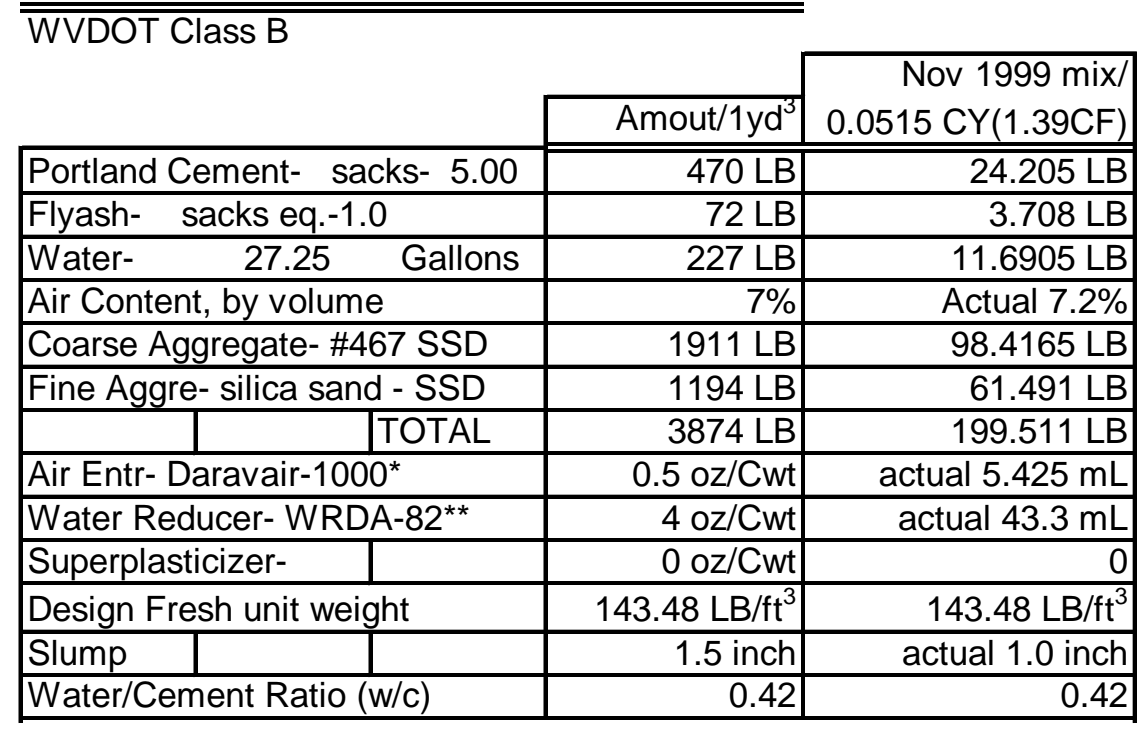

The specific means of concrete mixture specimen preparations of the previously listed concrete mixes are discussed in Chapter 3.4 Specimen Preparation. 


\subsection{BASE COURSE SPECIFICATIONS:}

\section{3a. General}

The issue of understanding the behavior of newly constructed concrete highway pavement, not only includes the concrete behavior itself, but also includes the boundary conditions the concrete is exposed too. The concrete slabs are constructed on base courses. These base courses are normally placed on separation/filter fabric on graded sub-base material made up either of soil, sand, stone or previous highway rubblized concrete. Several types of base courses are used in current construction practices across the country. This study was primarily focused on a WVDOT base course design of asphalt stabilized open graded aggregate material, or free drain base (FDB). To study the friction behavior, two different types of base courses had been utilized during the investigations performed in this study. One base course was the asphalt treated permeable base course, ATPBC, (also known as free drain base, FDB), and the other was a concrete treated permeable base course (CTPBC or Lean base course). The three sites investigated were as follows: Sections of I-79 and I-80 in October 1998 in Pennsylvania and a section of Corridor H in October 1999 in West Virginia.

The ATPBC and the CTPBC are designed to function in similar manner. The base course is a stabilized aggregate course that is to improve drainage capabilities and improve the surface in which the new concrete highway pavement is placed. To this point, there has been little documentation on which type of base performs better in practice. Therefore, the choice of which type of base is to be used is the designing engineer's preference. In several observed construction designs, it was left up to the construction contractors which type of base course they proposed. 


\section{3b. Marianna, PA: Lean Base Course}

The base course material used at the Marianna, PA I-79 highway construction site was a lean base course. A lean base course is a composite mix of cement paste and coarse aggregates. This minimum 4-inch thick base course was being used to enhance the support and drainage of the new concrete highway. The material was referred to as "popcorn", by the construction personnel, because of the texture and color after the curing compound was applied. (Wiley, PennDOT, 1998) The course is placed with a belt spreader, consolidated with a vibratory screed and thinly surface coated with white curing compound. This material is not designed for strength, but as a drainage layer for the highway. The lean base was placed on a 7-inch thick sub-base course. The sub-base material was rolled crushed limestone, Pennsylvania class 2A aggregate. The following table shows the lean base mix specifications for the newly constructed section of I-79. 
Table 3.4:

CONCRETE TREATED PERMEABLE BASE COURSE

(CTPBC, or Lean Base)

Marianna, PA Base Course Mix Design

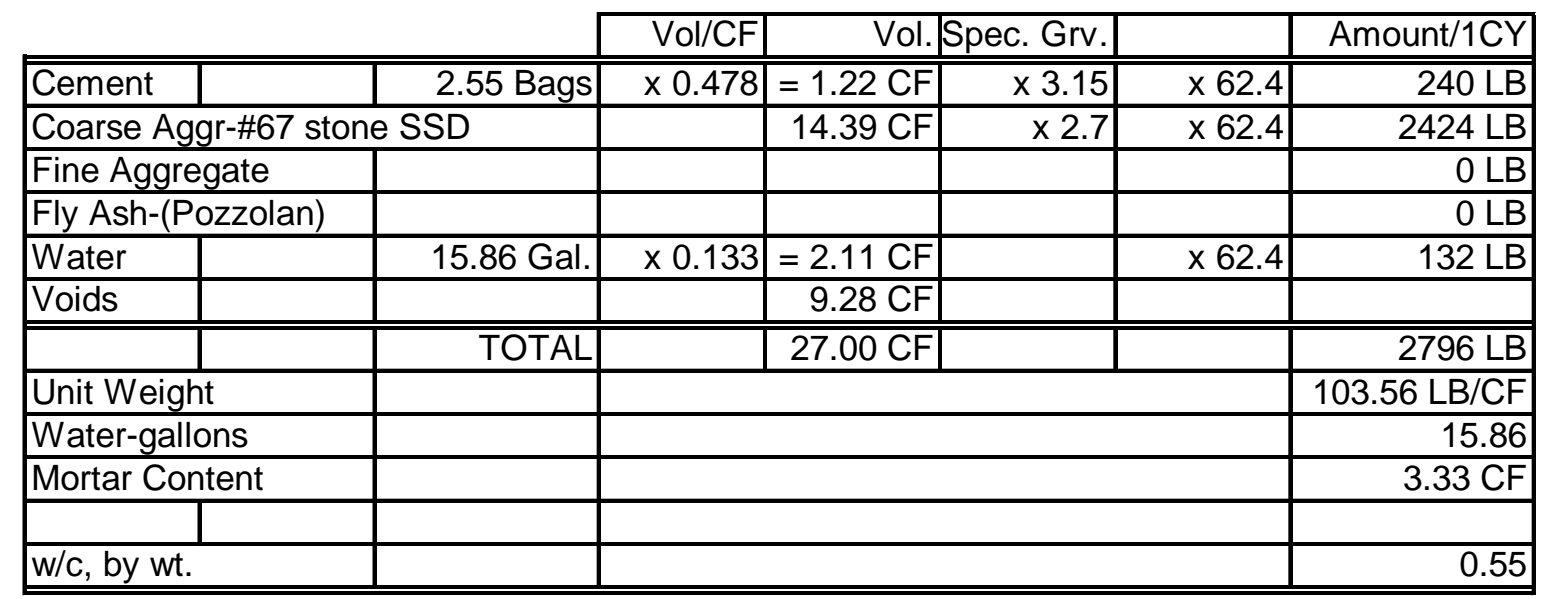

Notes:

1. Coarse Aggregate, \#67 stone, Greer Stone-W. Virginia (Supplier code: GRCWVA14)

The type of coarse aggregate used in the lean base mix was \#67 crushed limestone

obtained from Greer Limestone Co., W. Virginia. The actual gradation of the coarse aggregate used for the Marianna construction site is shown in the following table.

\section{Table 3.5:}

I-79 Marianna, PA

CTPBC (lean base) Coarse Aggregate

\section{Square Screen Analysis \%}

Passing

\begin{tabular}{|l|c|c|c|c|c|c|c|c|c|c|c|}
\hline Screen Sizes & $.11 / 2$ & .1 & $.1 / 2$ & $.3 / 8$ & $\# 4$ & $\# 8$ & $\# 16$ & $\# 30$ & $\# 50$ & $\# 100$ \\
\hline \hline F.A. & & & & 100 & 99 & 85 & 69 & 48 & 14 & 2 \\
\hline
\end{tabular}

\begin{tabular}{|l|c|c|c|c|c|c|}
\hline \multicolumn{2}{|l|}{ Screen Sizes } & .1 & $.3 / 4$ & $.3 / 8$ & $\# 4$ & $\# 8$ \\
\hline \hline$\# 67$ Stone & & 100 & 100 & 27 & 2 & 1 \\
\hline
\end{tabular}

Maximum Density $\quad 89.78$ P.C.F. $\quad$ Volume of C.A. 14.39 C.F.

The previous tables were obtained directly from the PennDOT mix design forms and worksheets for this project. These materials were mixed and placed by the construction contractors, A \& L Inc. The tables show the project specific values and not the 
Pennsylvania Standards and Specifications acceptable ranges. Typically the construction practices in Pennsylvania have similar standards and specifications as in West Virginia. For further details on the construction techniques, mix design standards, etc. refer to the PennDOT Standards and Specifications Manual of Construction, 1995.

\section{3c. Danville, PA: Asphalt Treated Permeable Base Course}

A section of I-80 eastbound lanes near Danville, PA was the second new concrete highway pavement construction fully investigated. A minimum 2.5-inch ATPBC was utilized during this construction, although much of the course placed was typically over 4-inches thick due to the unevenness of the sub-base course. The sub-base in this construction was rubblized concrete from the existing concrete highway. The ATPBC was used to provide adequate drainage and to grade the surface for the new concrete pavement. The base course was placed with a standard bituminous paver with sufficient width that the paver did not ride on the new base course. One major difference was the consolidation technique between the course types. A single pass of a tandem 10 ton steelwheel roller was used to consolidate the ATPBC and a vibratory screed was used on the lean base course. The other difference was the ATPBC was placed hot, above $250^{\circ} \mathrm{F}$. The roller was required to allow the ATPBC too sufficiently cool, (around $140^{\circ} \mathrm{F}$ ), and set in such a way that no seams, depressions or pushing formed. Separation/filter fabric was not utilized in this construction because the exiting layers of rubblized concrete, the original bases and the addition of edge drains were assumed to be a sufficient barrier to prevent the integration of fines in the drainage system. 
ATPBC is a mixture of bituminous material and coarse aggregates. The proportioning of the materials was $2.5 \%$ bitumen to $97.5 \%$ open graded stone (by weight). The aggregate was crushed \#57 limestone with the gradation specifications listed in the following table.

\section{Table 3.6:}

\section{Danville, PA}

ATPBC mix specifications

Total Percent Passing

\begin{tabular}{|l|c|c|c|c|c|}
\hline Square Sieve Size & $11 / 2 "$ & $1 "$ & $1 / 2 "$ & $\# 4$ & $\# 8$ \\
\hline Aggregate, \#57 stone & 100 & 99 & 27 & 2 & 1 \\
\hline
\end{tabular}

Bituminous material $-2.5 \%$ by weight.

It was assumed that the coarse aggregates used for the ATPBC were from the same stockpile that the coarse aggregates for the mainline concrete came from. The actual field sample sieve results for the ATPBC gradation tests were not obtained for the \#57 stone gradations. Therefore, the above table lists the results obtained for the \#57 stone gradations performed for the concrete mix. The gradation of the \#57 stone is in compliance with the AASHTO square sieve analysis requirements. These should reveal similar results because all of the stone obtained for the project came from the same supplier. 


\section{3d. Elkins, WV: Free Drain Base}

WVDOT refers to the asphalt stabilized permeable base course as Free Drain Base, (FDB), different than the ATPBC reference by PennDOT. Both refer to a mixture of bituminous material and open graded coarse aggregate. The mix procedures, compositions and construction processes are identical in nature.

The mix proportioning that was utilized for the Phase I testing composed of $2 \%$ bitumen to $98 \%$ AASHTO \#57 open graded stone (by weight). The aggregate was heated to between $275^{\circ}$ and $325^{\circ} \mathrm{F}$ and mixed with the bitumen to form a homogeneous mix. A course was then placed hot from a typical asphalt paver and rolled to consolidate to a 4inch depth.

The design used for the section of Corridor $\mathrm{H}$ near Elkins, WV was of the same mix proportioning of bitumen to aggregate as the phase I test: $2 \%$ to $98 \%$, respectively. The difference in them was the depth of the base course. The Elkins base course was 6 inches in depth and was under-wrapped by separation/filter fabric. 


\subsection{INSTRUMENTATIONS:}

\section{4a. Temperature}

The temperature data collected for this research was performed by the use of thermocouples with a hand-held digital portable thermometer and the use of a digital infrared thermal meter (thermal gun). The thermal gun was used to measure the surface temperatures of the concrete slabs at the group thermocouple locations and to measure the base course temperatures directly in front of the concrete paver's. The thermocouples, used for measuring the concrete and ambient temperatures, were made of thermal-grade wire of the same type used during Phase I, type K (See also Ch.5.4 Phase I report). The type $\mathrm{K}$ wire was made of two dissimilar metals, Nickel-Chromium on the positive lead and Nickel-Aluminum on the negative lead. The wire has a measurable temperature range from $32^{\circ} \mathrm{F}$ to a maximum of $392^{\circ} \mathrm{F}$. The percent error for the wire was $+/-1^{\circ} \mathrm{F}$. The wire was capable of reading lower and higher temperatures but the percent error increased out of that temperature range. (Omega, Inc., 1998) For the purpose of temperature measurement of this project, the temperature reading range and the percent error for the wire was acceptable.

The thermocouple wire was Teflon coated. The wire could be ordered at specified lengths with one end factory bedded tipped or could be ordered by the spool which were cut to specified lengths and silver-solder tipped. It was determined that the factory bedded tipped wires were more consistent in readout values by repetitive tests and from wire to wire tests. Also, the process of silver-solder tipping many thermocouples would be very time consuming and it would be difficult to precisely connect the wire leads with 
our available equipment. Therefore, factory bedded tipped wire was used for the majority of this research.

A new hand-held thermometer was purchased to take the readings from the thermocouples. The readouts of both are accurate to $+/-1^{\circ} \mathrm{F}$, (the precision of the wire), and the thermometer was smaller which was most desirable for the field investigations.

The thermocouples were inserted 8 or 12-inches from the outside edge at three different depths into the side of the concrete slab, depending on the construction site (see individual site investigations in Chapters 6, 7 and 8). The depths were distinguished as top, middle and bottom. The depths correspond to 2 -inches down from the surface, $1 / 2$ the slab thickness and 1-inch up from the bottom (or base course surface), respectively. (See Figure 3.1 Thermocouple layout) Each location of three thermocouples is referred to as a group. The groups for each concrete slab investigation were designated in increasing number from the beginning of each slab.

The thermocouples for each group were required to be placed directly after the paving equipment had passed and prior to the concrete finisher's, the texturing equipment and the curing compound applied. A new method of inserting the thermocouples into the slab was needed because of the increased distance of the thermocouple placement inside the slab edge. The insertion of the wire was required to cause as minimal of a disturbance to the concrete slab as possible. A handled insertion rod was designed for this task. The rod was made in the WVU structures laboratory of 1/4-inch steel rod and a wooden handle. The end of the rod was grooved so that small 1-inch long steel-wire hooks could be attached and easily slip off at the desired depth. The wire hook was attached to the thermocouple wire 1-inch from the bedded tipped where the temperature is measured. 
The rod was of sufficient length to allow each thermocouple to be precisely placed to 8 or 12-inch depth in the side of the specific pavement section.

The temperature readings for each thermocouple by group were taken at designated intervals, as often as possible, with the portable thermometer. At the time of each group's thermocouple checks, the thermal gun was used to obtain the surface slab temperature at the corresponding group locations. Therefore, the data was collected at the four depths for each group location and time checked.

The ambient temperature readings for the investigations were taken from thermocouples suspended in the air. These thermocouples were placed no less than ten feet away from the slab so that radiant heat from the curing slab would not effect the temperature readings. The ambient temperature results were checked for accuracy by obtaining the climatic data logs of the closest recording location. The climatic data for a given location and time can be obtained from the National Climatic Data Center or the closest airport that monitors the weather conditions. For the construction sites that had relatively close climatic data records, the ambient temperature readings taken compared well to the NCDC recorded value's which shows that the thermocouples were performing as desired. The figures showing these results can be seen in the temperature sections of the investigated site chapters. (Chapter 6, 7 and 8)

All of the thermocouples used were numbered and calibrated prior to their use. The precision of $+/-1^{\circ} \mathrm{F}$ was acceptable for our purposes. The thermocouple calibration technique was implemented to equalize the thermocouples readings to a calibrated value, for all of the thermocouples, and not for precise temperature measurements. 
The calibration tests were performed with a large insulated container, filled with room temperature water and a typical submergible temperature thermometer, as a reference. The thermocouple tips were secured and suspended near the centroid of the container to avoid variation in water temperature by depth or proximity. Each thermocouple was read in number sequence and then the process was repeated. The temperature readings by thermocouple revealed that different thermocouples consistently gave a similar value. The errors from the variation in thermocouple readings, $+/-1^{\circ} \mathrm{F}$, compared to the error from other sources, were minimal. Therefore at this time the temperature readings have not been calibration corrected from the actual field investigation readings.

\section{4b. Crack Width Measurements}

The field investigation's data collection required that the transverse joint crack formations be evaluated by location and time of initial crack formation and the respective joint crack growth during the investigation timelines. For consistency in the measurements taken and due to the rigidity of the joint cracks themselves, the joint crack widths were measured at approximately one inch below the bottom of the transverse saw cut and one inch up from the base course surface, as allowable. This was done because it was observed in June 1998 that the tops of the joints were opening wider than the bottoms. This behavior can be contributed to the bond between the concrete slab to the base course and the temperature and shrinkage effects in the concrete slab. Therefore, all of the investigated concrete slab's joint crack formations were consistently measured at top and bottom locations. 
The joint crack widths were measured using joint crack width comparators obtained from Avonguard, Inc. These comparators were identical to those used during Phase I investigations. The joint crack comparators were small transparent plastic cards with various size labeled line marks. The cards were held by the joint crack's to obtain the corresponding crack sizes. The precision of the measurements for the smaller widths, (less than $1 \mathrm{~mm}$ ), was better than the precision of the cracks larger than $1 \mathrm{~mm}$, (up to 10 $\mathrm{mm})$.

At the time of the first two field investigations, the Avonguard joint crack width comparators were the only available measurement devices used. For the section of Corridor H near Elkins, WV, another type of measuring device was obtained to more precisely measure the joint crack width greater than $1.5 \mathrm{~mm}$. The measuring device was a calibrated, digital caliper. The caliper was only capable of measuring the joint crack widths after $1.5 \mathrm{~mm}$ because of its design. For the joint cracks smaller than $1.5 \mathrm{~mm}$, the Avonguard joint crack comparators were utilized.

The frequency in which the joint crack widths were taken was site investigation dependent. The concrete slab's curing method and availability of personnel were important factors in determining how often the joint cracks were measured. For the first two slab constructions investigated, (Marianna and Danville, PA), the curing techniques, coating of white curing compound or polyethylene sheet covering, affected the ability to observe the crack formations. In Pennsylvania, after a specific date the concrete slabs are cured with a minimum of approximately $1 / 32$-inch thick polyethylene sheeting in 20 -feet sections with 12-inch overlap and no curing compound due to the drop in nighttime temperatures during the fall. Curing compound was used on the Marianna slab 
construction but the Danville slab was covered with polyethylene sheeting. The sheeting covered the surface and sides of the slab. Verbal requests to slice the sides of the sheeting at the joint locations throughout the slab length were given to the construction contractor and the PennDOT officials. The requests were approved for the sheeting to be sliced. The sheeting could not be sliced until after the transverse joints were saw cut and the sheeting placed in the final positions for the early curing. The saw cut personnel recovered the slab sections after the joints were cut. The sheeting slicing was performed early in the morning hours nearing daylight. The slicing and re-securing of the sheeting was time consuming. Therefore, the joint crack formation over time, for the beginning section, was not obtained during the Danville slab investigation.

The Marianna and Elkins concrete slabs were both cured with white curing compound. The coating allowed for the joint crack formations to be more easily accessible and more visible at initiation of the crack formations. Because of the application of the curing compound, the connector's for the thermocouples had to be protected. This was achieved by placing the individual group connector's inside of plastic zip-lock bags and placed away from the slab as construction equipment permitted.

The results from the transverse joint crack investigations for each site investigation are included in the respective site investigation chapters. (See Chapter 6, 7 and 8)

\section{4c. Strain Gages and Readout Units}

The strain gage utilized during Phase I was determined to be insufficient for the purposes of this project due to the modulus of elasticity of the gage being designed for hardened concrete and not early age curing concrete. (Phase I report, Ch.5.7, pg. 55) 
During Phase II, a search for a compatible strain gage to evaluate early age concrete was performed. Most embedded concrete strain gage manufacturer's designs are for hardened concrete only and have not been early age tested. There were two possible types of strain measuring techniques currently in practice that could achieve strain readings in early age concrete. These gages utilized different mechanical techniques to evaluate strain. The most accurate method discussed was a laser displacement measurement system. This system was an external system, which would not be effected by the developing stiffness and temperature fluctuation in the curing concrete. The laser displacement system was very expensive and bulky, thus not ideally suited for the applications of this research. The other type of strain gage measurement was another type of embeddment strain gage. These types of strain gages utilize vibrating wire technology. There has not been documentation, to date, that verifies that the gages are sensitive enough or capable of producing accurate strain measurements in the early age concrete environment, although, some studies have documented early age concrete strain reading results.

The vibrating wire embeddment strain gage used for the early age strain measurements was made by Roctest Inc., model EM-5. The standard model EM-5 was used for the July 1999 compression tests. Additional laboratory and field tests performed utilized modified flange EM-5 strain gages. A total of six EM-5 gages were purchased.

The vibrating wire technology used in the development of these gages is based on the change of vibration frequency due to external loading on the flanges. The main difference in the gage types is the gage design itself (See Figures 3.2a. Standard EM-5 Strain Gage). The vibrating wire gages utilize end flanges connected by a thin wire that is excited by electrical stimulation to detect changes in vibration frequency. The flanges 
allow for a low relative stiffness to be obtained when placed in concrete. An external force of less than $2.9 \mathrm{~kg}(6.4 \mathrm{lbs}$.) can stretch the wire 3,300 $\mu$ strain. (Roctest, Inc., 1999) The stress applied to the diameter of the wire alone would show a modulus value of the material the gage wire is made of. But in the design of these gages, the loads are transferred from the end flange areas and transmitting that stress to the gage wire. Because of this, calculations of the effective transmitted stress from the end flanges reveal a relative modulus of elasticity of approximately 3,225 psi. This value is much less than the modulus of elasticity values determined for concrete even at early ages, (E=300,000psi at 10 hours). (Channel, 1998)

The EM-5 vibrating wire strain gages are monitored with readout units. They produce a range of readouts from data acquisition systems with remote capabilities to standard portable readout units. The portable units were chosen for the earlier stated expense reasons. The readout unit used for this study was the Roctest Inc., model MB-6T. The university was loaned a demonstration unit that was used for all strain evaluations during this project. The company loaned the demo-unit because they were unsure whether their product was useful for the purpose intended. After the completion of all strain tests, the MB-6T readout unit was returned to the Roctest offices in Plattsburg, NY.

A standard model EM-5 gage was used during the July 1999 compression tests. It was seen from the results of these tests that the gage may not be responding in concrete of age less than 16-hours. Since only one gage was used during those tests, the verification of the responsiveness of the standard EM-5 was uncertain. The stress versus strain curves obtained from the EM-5 gages compression tests were linear after the $16^{\text {th }}$ hour. 
Assuming that the unresponsiveness of the gage for early age (less than 16-hours) was true, the possibility of modifying the gage to allow it to be more sensitive was done. The EM-5 gage end flange diameters were modified from their standard design by increasing them from 0.875-inch to 2.00-inch (See Figure 3.2b. Modified EM-5 gage design).

Modification of the flange diameters provided a larger contact surface to the concrete for load transfer, which should decrease the effective modulus of the gage.

Five modified EM-5 strain gages were ordered from Roctest, Inc. Three were for the investigation of the section of Corridor $\mathrm{H}$ concrete slab strain monitoring and two were for the use in compression test cylinders, one field and one laboratory. The concept was to check the response of the modified EM-5 strain gages in the curing concrete slab, for comparison of theoretical analysis strain values, and in the determination and comparison of the modulus of elasticity growths from the Elkins concrete mix design.

The MB-6T was equipped with a liquid crystal display, LCD, screen with back lighting capability which made night time data collection easier during our field tests. The LCD screen displayed four types of values. They are a NORMAL (N) reading, a LINEAR (L) reading and temperature values in degrees Fahrenheit and Centigrade. The $\mathrm{N}$ reading is the period of the wire, displayed in $\mu$ seconds $\left(1 \mu \mathrm{sec}=10^{-6}\right.$ seconds $)$ and the $\mathrm{L}$ reading is the linearized reading. The linearized reading can be calculated from the normal reading. The conversions from $\mathrm{N}$ to $\mathrm{L}$ readings are performed inside the $\mathrm{MB}-6 \mathrm{~T}$ unit. The change in strain, $\varepsilon=\varepsilon_{1}-\varepsilon_{0}$, can simply be determine from consecutive $L$ values or from a base $\mathrm{L}_{0}$ value to a current $\mathrm{L}_{1}$ value. A conversion equation developed by Roctest for their EM-5 strain gage uses a K conversion factor of 4.0624 for the EM-5 gage and an equation that reveals the changes in strains. 


$$
\varepsilon=\varepsilon_{1}-\varepsilon_{0}=\left(\mathrm{L}_{1}-\mathrm{L}_{0}\right)=\mathrm{K} \times 10^{9} \times\left[\left(1 / \mathrm{N}_{1}^{2}\right)-\left(1 / \mathrm{N}_{0}^{2}\right)\right]
$$

The N, L and temperature data values collected from the Corridor H project and the laboratory tests are manipulated to give the desired strains and then checked for their accuracy and reliability.

The process of interpreting the readings obtained from the MB-6T readout unit is complex for the early age analysis. Temperature changes in the concrete and gage cause added strain to be seen due to the differences in the materials coefficient's of thermal expansion/contraction. When interpreting the readings to determine the total strain, assuming there are no other influence on the gage or concrete, temperature fluctuation strain may be removed. Theoretically, the reliable readings are attainable when the concrete stiffness becomes greater than the stiffness of the EM-5 gage. To calculate the total strain being imposed on an EM-5 vibrating wire strain gage the coefficients of thermal expansion/contraction must be known of the concrete at any age. The coefficient of thermal expansion is known for any EM-5 gage being $11.5 \mu \mathrm{m} / \mathrm{m} /{ }^{\circ} \mathrm{C}$ or $6.4 \mu \mathrm{in} / \mathrm{in} /{ }^{\circ} \mathrm{F}$. The equation used is that shown in the EM-5 instruction manual for the Total Strain at Constant Temperature $\varepsilon_{\mathrm{to}}$.

$$
\varepsilon_{\mathrm{to}}=\left(\varepsilon_{1}-\varepsilon_{0}\right)+(\alpha-\eta \beta)\left(\mathrm{T}_{1}-\mathrm{T}_{0}\right)
$$

It can be seen in the above equation that the total strain is the change of strain plus the product of the difference of the coefficient of thermal expansions of the EM-5 gage $(\alpha)$ and the concrete at any given time or maturity $(\eta \beta)$ times the change in temperature.

If the coefficient of thermal expansion of the concrete is unknown for any given point, a trial and error or an iterative process may be utilized to narrow down the approximate value for the coefficient. This procedures requires the selection of a set of data that 
would generally have the same value for the coefficient of thermal expansion of concrete (an age grouping: example, the first six hours and then six hours to twelve hours, etc.). Then plug that assumed value into the equation and begin a loop process. The looping process is continued until the change in real strain from the value assumed previously was within a predetermined percent difference. Once that occurs, the approximate values of real strain and the approximate value of the coefficient of thermal expansion of the concrete within that maturity range are known. This should work if the assumed values of the coefficient of thermal expansion are alternating from higher than estimated values to lower estimated values.

The procedure can be discretized to analyze from one reading to the next and perform the above process for each reading individually. The later individualization, instead of a group, may reveal when the real strain has converged, by comparing the values obtained for the coefficient of thermal expansion of the concrete. If the values of the coefficient are near similar then the values shown for the real strain are also quite similar to the actual real strain. (Roctest Inc., 1999)

The process discussed is a possible solution to determine the total real strain from the readings obtained from the EM-5 gages and MB-6T readout unit.

\section{$\underline{\text { 3.5d. Strain Gage Placement Techniques }}$}

During this study, the gages were used for two types of strain data collection. The two types were to suspend an EM-5 strain gage inside of a 6 by 12-inch plastic concrete cylinder mold and to place EM-5 gages in newly constructed PCC highway pavement. New suspension and placement techniques were developed during this phase. 
The task of suspending the EM-5 gage in the plastic concrete cylinder was evaluated first. The orientation of the gage was parallel to the cylinder length and centered within the cylinder depth and the gage wire run out the side of the cylinder mold wall. This was accomplished using two techniques. One utilized 50-LB test monofilament fishing line, (used for the July 1999 cylinder), and the other utilized straight pieces of thick coat hanger wire, (used for the Elkins field and laboratory cylinders). Both suspension materials were used to secure the EM-5 gages in position and orientation.

The plastic cylinders were measured and marked to ensure precise placement of the gages. Holes were made in specific locations on the cylinders for the fishing line to be threaded. Two tightly wrapped layers of line secured the EM-5 gage in the cylinder mold.

The fishing line technique was not usable with the modified flange EM-5 gages. The straight coat-hanger sections were used for these gages because they could be placed through the plastic cylinder requiring no assistance from inside the cylinder. The modified gage flanges could not be easily maneuvered around inside the cylinder without possibly damaging the gage itself. The stiff coat-hanger pieces were heated at the tip and pressed through the plastic cylinder wall in precise locations. A series of eight pieces of rod were placed through the plastic cylinder mold, which securely supported the modified EM-5 strain gage in the correct position.

Three modified EM-5 gages were placed in various locations along the slab length of the new PCC pavement construction of a section of Corridor H near Elkins, WV. Simply placing the gages in the concrete after placement was not an option because of the amount of concrete disturbance that would cause. Therefore, a suspension or support 
technique for the embeddment gage was developed such that the concrete slab could be placed around the gage. The task was not easily performed because of the desired constant orientation but free longitudinal movement of the gage in the slab. A simple yet viable solution was required. A suspension technique developed included the use of the following materials for each strain gage: four 5/8-inch 12-inch long stainless steel stakes, a 1/4-inch diameter steel chair, 50-LB test monofilament fishing line and plastic quickties. The stainless steel stakes were drilled 1/2-inch down from the tops to allow the fishing line to by threaded through. The stakes were to be hammered into the base course in a square formation. Centered in the square would be the steel chair with the modified EM-5 strain gage resting on it at the desired mid-depth level monitoring level. The fishing line would be continuously wrapped between the stakes and around the gage until it was secured in the correct orientation. Since the gage was not secured to the chair or the chair to the base course, the free longitudinal movement was permitted. The chairs made in the structure's laboratory at WVU were insufficient for the purpose they were designed for. The chairs did not provide the stability needed. Therefore, the modified EM-5 strain gages that were used during the Elkins investigation were suspended and supported. From other researchers strain placement techniques obtained, a direct quicktie to a stake technique used was modified on in the field. An example picture of the actual gage suspension system can be seen in Pictures 3.1. The differing systems, although not pleasing in appearance, securely held the gages in the desired locations and orientation. Precautionary measures were taken to support the gages with fresh concrete directly before the concrete pavement equipment passed over the individual gage locations. 


\section{4e. Modulus Testing Frame}

The modulus-testing frame is an apparatus that is secured around 6-inch concrete cylinders to measure the deformation of the cylinder under compressive load. The frame is made of two rigid steel rings six inches apart that are connected by a stabilizer bar, dial gage assembly and two rigid support bars. The frame is approximately centered on the cylinder and mounted by six screws, three in each steel ring. The screws are tightened snuggly against the concrete but not to the extent of damaging the concrete. Once the frame is securely fastened, the two rigid frame supports are removed. The modulus frame is then zeroed at that time. The concrete cylinders were then compressive loaded and the corresponding dial gage readings were recorded. Pictures of a concrete cylinder with the mounted modulus testing frame and the compression testing machine can be seen the Phase I report. (Channel, 1998)

There were three sets of concrete cylinder specimens tested using the modulus frame. The recorded loads to deformations were then converted to stress versus strain graphs. The slopes of these graphs are the modulus of elasticity values for the concrete at the given time of testing. The addition of the EM-5 strain gages inside concrete cylinders allowed for comparisons to be made between the two types of deflection measuring methods. The specifics of each set of tests and results can be found in Chapter 4. 


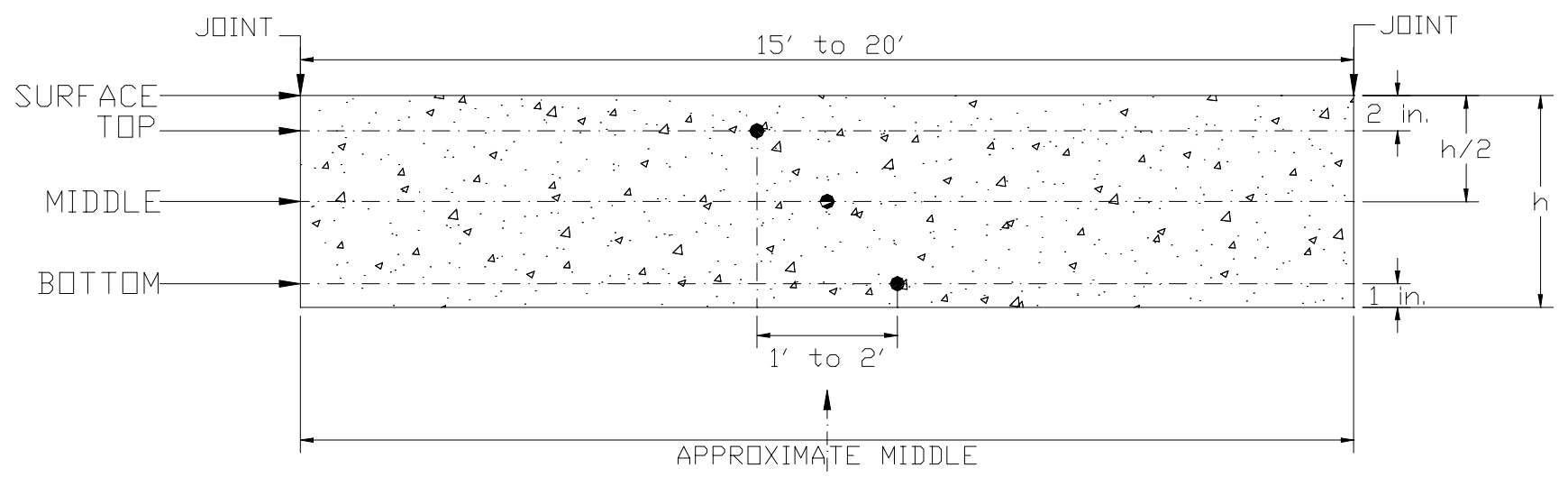

Figure 3.1: Typical Group Thermocouple Layout 


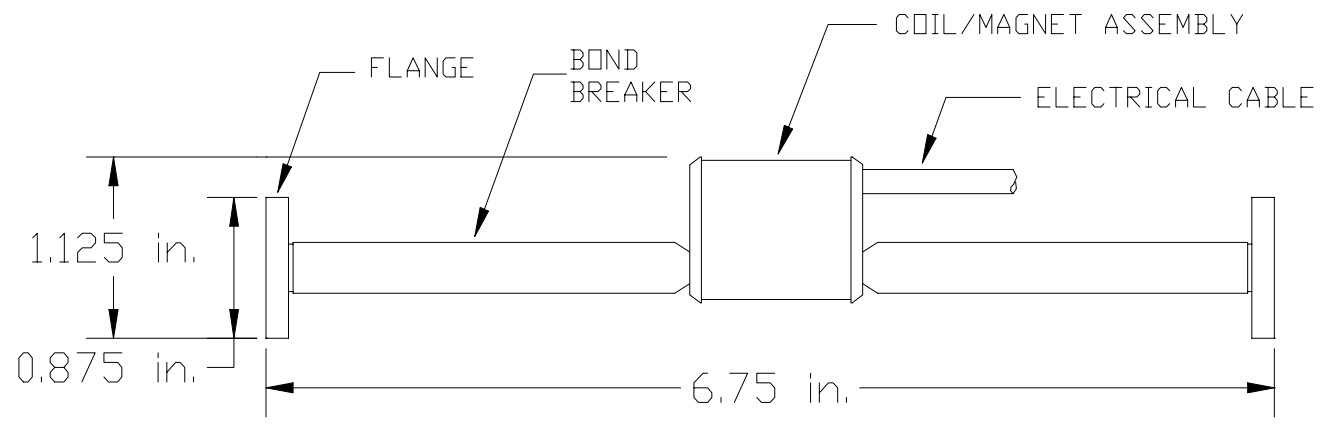

INDIVIDUAL GR RQSETTE MDUNTING HQLES
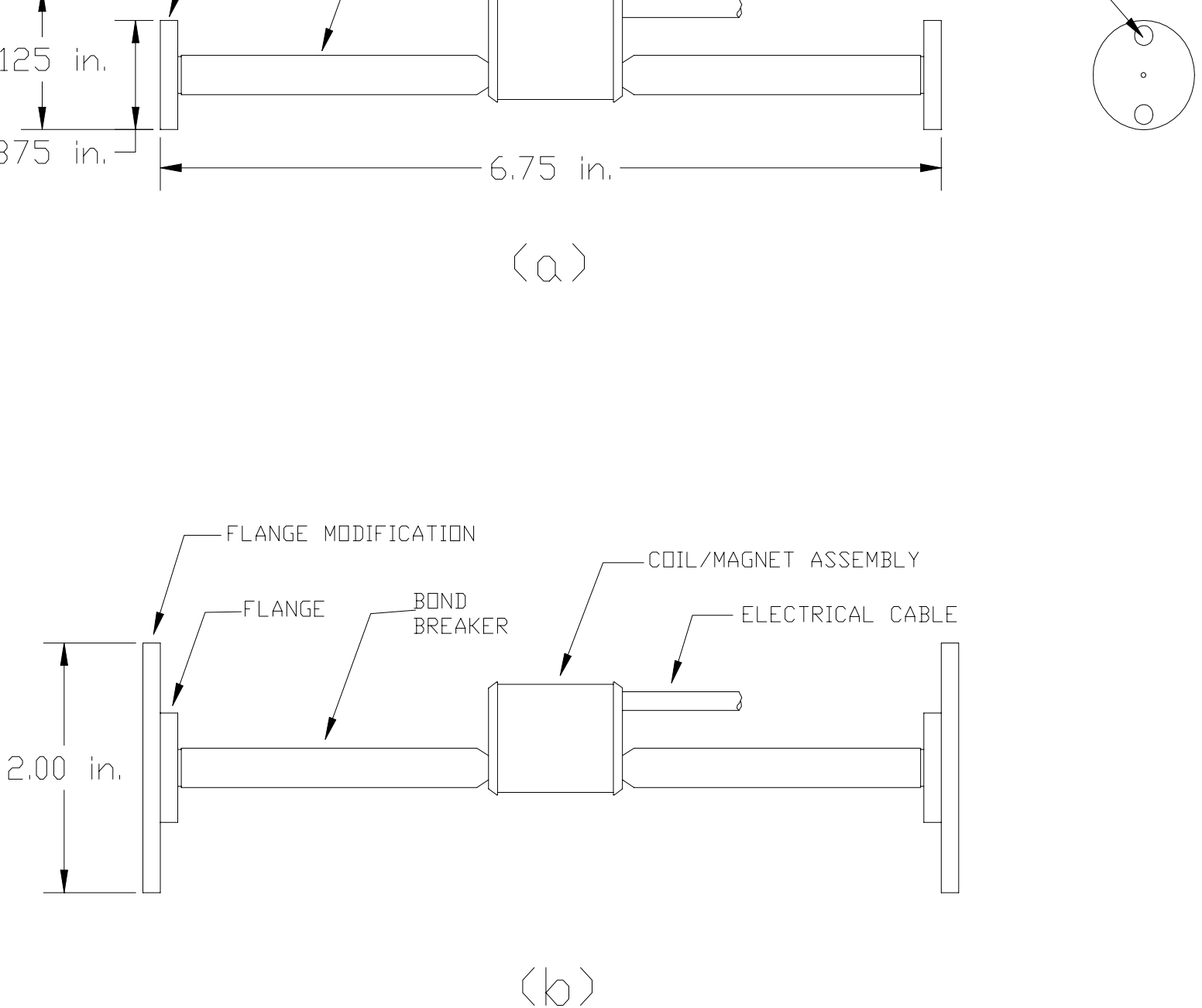

Figure 3.2: EM-5 Vibrating Wire Strain Gages: a. Standard, b. Modified 


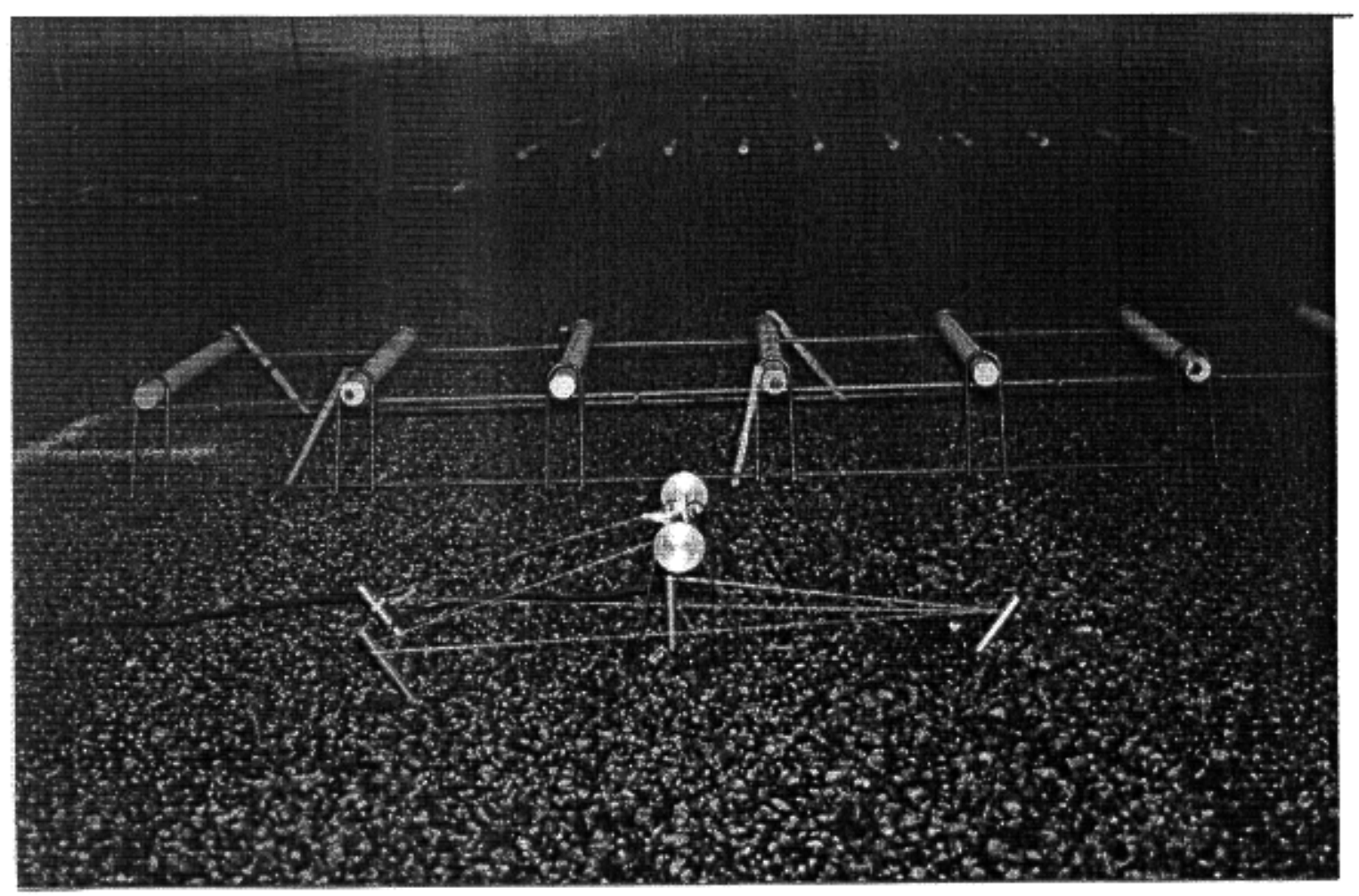

Figure 3.3: Example Picture EM-5 Strain Gage Suspension System 


\section{CHAPTER 4: LABORATORY TESTS}

\subsection{General:}

The early-age concrete material property growth was determined to have a direct relationship in the strength and stress development of a concrete slab. The early-age developments of the modulus of elasticity, split tensile strength and the coefficient of thermal contraction were determined for the WVDOT concrete mix design. Other time dependent factors, such as the coefficient of friction between the slab and the base course and the bond strength or stress between the transverse dowel bars and the concrete, were also tested and determined for the given mix and pavement design.

For the proposed analysis of the early-age stress and crack behavior developments to be validated, the correct material property growths over time must be used for each. Some material property developments must be assumed or estimated because standardized testing methods to determine them do not exist for early-age concrete, as of yet. Some new, modified testing procedures were attempted during Phase I of this research. Although all of the earlier tests have their individual importance, some of the variables have a greater effect on the over-all results. From inspecting the revised analysis, the growth of the modulus of elasticity is one of the most influential factors. The results from compression tests during Phase I were documented to have varied from other documented tests of early age concrete modulus of elasticity growth. The growth curves were comparable in shape but not in value. Possible explanations for the variable growth of modulus values may be variations of mixes, differing curing techniques, and numerous other factors. Because of these uncertainties on a critical variable in this analysis, more compression tests were performed. 
A suitable strain gage to be utilized in the early age monitoring of new PCC construction was required for this project. Since very little testing has been attempted on very young concrete, no gage had been specifically designed for this purpose. A particular type of strain gage, using vibrating wire technology (which was discussed Chapter 3), could possibly be used for early age testing. The overall gage stiffness was determined to be low enough to possibly give reliable readings of strain after approximately five to six hours after being embedded into the concrete, the time at which the concrete reached a stiffness greater than that of the gage. To optimize and minimize the amount of laboratory tests required in this Field Investigation phase of research, a modified modulus of elasticity testing scheme was developed.

Standard, 6-inch by 12-inch concrete cylinders under compression were utilized in the early age modulus tests done during Phase I. The basic concept of this procedure was again used in Phase II, but with some added modifications. It was decided that modifying the early age compression tests to evaluate these several factors would be an optimal test. These factors included: the types of curing methods, loading damage of the cylinder due to early age tests, and the early age response of an embeddment strain gage.

The mix design chosen for the July 1999 tests was that of the Danville, PA I-80 pavement mix. This mix design was chosen because the modulus growth over time needed to be known for the analysis and there was more data collected from that field investigation than the Marianna, PA field investigation.

The tests performed on the Danville, PA mix design are discussed in Section 4.2 and the tests performed on the Elkins, WV mix design are discussed in Section 4.3. 
Two different, smaller types of tests were also performed during this phase of the project. They were cylinder temperature tests and coefficient of thermal expansion/contraction tests. They were both performed in conjunction with the July 1999 compression test cylinders and will be discussed in Section 4.4. 


\subsection{JULY 1999 COMPRESSION TESTS:}

\section{2a. PROCEDURE:}

The early age growth of the modulus of elasticity is very important to the calculations of the stress development. Values determined for the modulus of elasticity versus time for the WVDOT concrete mix design found during Phase I of this research varied drastically from those obtained from other testing sources (Okamoto, 1994). Since the values of the modulus of elasticity can vary a lot among different mix designs, it is very important to obtain the modulus of elasticity development over time for any mix design which is being analyzed. The curing method was a major difference along with the difference in the mix designs for the two tests. The differences in test procedures and mix designs made the comparison of the two tests inconclusive. Therefore, a more thorough test procedure was developed so that the same mix design and batch of concrete was used for different curing methods. It was determined that ten 6-inch by 12 -inch concrete cylinder molds be filled with concrete of the same batch mix. These cylinders were distinguishable by the labels that they were given. Cylinders numbered 1 through 5 were to be water bath cured and were given a designation W. Cylinders numbered 6 through 9 were to be air cured and were given the designation A. Cylinder number 10 was to be cast, covered with a plastic cap, wrapped in a plastic sheet and was to be undisturbed until the 28 day compressive strength test was performed. The five cylinders which were tested for early age modulus of elasticity were designated *, and the other five were not tested early. Therefore, the cylinder designations tell how each was to be tested, as shown in Table 4.1 Concrete Cylinder Designations. 
Table 4.1

Concrete Cylinder

Designations

Danville, PA mix design

Cylinders cast 07 July 1999 at 1100 hrs

Early age modulus of elasticity testing

\begin{tabular}{|c|c|c|c|c|c|c|}
\hline \multirow[b]{3}{*}{ Cylinder Designation } & & & \multicolumn{3}{|c|}{ Tests Performed } & \multirow{3}{*}{$\begin{array}{c}\text { Contained } \\
\text { Thermocouple } \\
\end{array}$} \\
\hline & \multicolumn{2}{|c|}{ Curing Method } & \multirow{2}{*}{$\begin{array}{c}\text { Early } \\
\text { Modulus }\end{array}$} & \multicolumn{2}{|c|}{28 day } & \\
\hline & Water-bath & Air & & Modulus & $f_{c^{\prime}}^{\prime}$ & \\
\hline $1 W^{*}$ & $\mathrm{x}$ & & $\mathrm{x}$ & $\mathrm{x}$ & & $\mathrm{X}$ \\
\hline $2 \mathrm{~W}^{*}$ & $x$ & & $\mathrm{x}$ & $\mathrm{x}$ & $\mathrm{x}$ & $\mathrm{x}$ \\
\hline $3 W$ & $\mathrm{x}$ & & & $\mathrm{x}$ & $\mathrm{x}$ & $x$ \\
\hline $4 W^{*}$ & $\mathrm{x}$ & & $\mathrm{x}$ & $\mathrm{x}$ & $\mathrm{x}$ & \\
\hline $5 W$ & $x$ & & & & $x$ & \\
\hline $6 \mathrm{~A}^{*}$ & & $x$ & $\mathrm{x}$ & $\mathrm{X}$ & $\mathrm{x}$ & $\mathrm{X}$ \\
\hline $7 \mathrm{~A}$ & & $x$ & & $x$ & $x$ & $x$ \\
\hline $8 A^{*}$ & & $\mathrm{x}$ & $\mathrm{x}$ & $\mathrm{x}$ & $\mathrm{x}$ & \\
\hline $9 \mathrm{~A}$ & & $\mathrm{x}$ & & $\mathrm{x}$ & $\mathrm{x}$ & \\
\hline 10 & & & & & $\mathrm{x}$ & \\
\hline
\end{tabular}

The cylinder test scheme was designed to allow value verifications and comparisons to be made. If cylinders $1 \mathrm{~W}^{*}$ (the one containing the strain gage and a thermocouple) and cylinder 10 (the one which was undisturbed) are temporarily put to the side, there are four of each type of curing methods (water bath and air curing) remaining to be tested. Out of the eight cylinders, four thermocouples were embedded inside; two of which are placed in either of the two types of curing methods. (Two in water bath cylinders and two in air cylinders) From the two thermocouples in each type of curing, one thermocouple 
was placed in a cylinder, which was tested for early age modulus of elasticity

development, and one thermocouple was placed in a cylinder, which was not tested until the 28th day.

The aforementioned test scheme allows certain aspects to be evaluated and/or compared. First, the early age growth (the first 72 hours) of the modulus of elasticity for the Danville, PA concrete mix design was constructed. This was performed using two different deflection systems: one using the modulus frame dial gage and the other using an EM-5 embeddment strain gage. The second aspect was the evaluation and comparison of the modulus growth curves of the water-bath curing to air-dry curing of the same mix. Third, the 28th day modulus values and the 28th day compressive strengths, $\mathrm{f}_{\mathrm{c}}$ ', for the early age and the non-early age tested cylinders could be compared to see if any damage

was caused due to the early age loading. The fourth aspect was to check the temperature behavior in the different types of curing cylinders and to check the thermocouple response in the EM-5 strain gage (See section 4.4). The last aspect to be tested was the response of the EM-5 gage embedded in a concrete cylinder to temperature fluctuations. This would be an attempt to find the coefficient of thermal expansion/contraction of the Danville, PA mix design (See section 4.4).

\section{2b. TESTS:}

The concrete cylinders were made as described in Chapter 3.2a and 3.4. The ten cylinders were prepared and labeled prior to filling with concrete. Cylinder $1 \mathrm{~W}^{*}$ had the EM-5 strain gage suspended by mono-filament 50 pound test fishing line with it's axis parallel and mid-point coinciding with the plastic concrete cylinder. This cylinder could 
not be made in accordance with the standard rod technique because damaging the gage could be a possibility when inserting the rod. Great caution was used not to disturb the gage. The thermocouples were placed in the designated cylinders near the cylinder centroid. After all ten of the cylinders were made, they were wrapped in a large sheet of plastic and left to cure and set enough for the plastic molds to be removed.

The plastic concrete cylinder molds were removed at around 10 hours. This was after the concrete was mature, or set enough, not to be damaged when the mold was removed. The cylinders were relabeled for identification with a charcoal pencil. The cylinders labeled for water-bath curing were then placed inside the temperature controlled isolation room water-bath and kept between 70 to $80^{\circ} \mathrm{F}$. The cylinders labeled for air-dry curing were then permitted to cure in the air, at 70 to $80^{\circ} \mathrm{F}$, at low humidity, inside the WVU concrete lab.

The compression testing then began on the cylinders. The five early age testing cylinders, $(1 \mathrm{~W}, 2 \mathrm{~W}, 4 \mathrm{~W}, 6 \mathrm{~A}$ and $8 \mathrm{~A})$ were prepared and loaded in rapid succession. Each cylinder was fitted with the modulus frame as discussed in Chapter 3.4. They were each capped on both ends using nine-inch square pieces of 1/2-inch regular sheathing board (See Chapter 3.4d). This material works better than the standard steel ring and rubber membrane caps because it minimizes cylinder edge damage and distributes the load more evenly to the cylinders. (Frum, 1999) This technique, instead of silicon capping, had to be utilized because the silicon capping under repeated loads fails and would give unreliable and non-reproducible values. The cylinder compression loads and corresponding deformations were recorded at varying times within a 72-hour period for each cylinder. Cylinder $1 \mathrm{~W}^{*}$ deformation was checked with the modulus frame but also 
contained the embedded EM-5 strain gage. For that cylinder both the modulus frame dial gage and the strain gage deformation values were recorded for each given load. The cylinders were not to be tested beyond their elastic limits at any time so that they could be tested repeatedly.

\section{2c. MODULUS TEST RESULTS:}

The compression test data, the compressive loads and their corresponding deflection values, were used to develop stress versus strain graphs for the given time of testing. The stress, $\sigma$ (psi) values were calculated, as in Phase I, by using:

$\sigma=\mathrm{P} / \mathrm{A} \quad$ where;

$\mathrm{P}=$ Compressive load (pounds)

$\mathrm{A}=$ Area of concrete cylinder $\left(\mathrm{in}^{2}\right)=\pi \mathrm{r}^{2}$

The strain, $\varepsilon$ (in/in), was calculated for the modulus frame tested cylinders by using:

$\varepsilon=\Delta \mathrm{L} / \mathrm{L} \quad$ where

$\Delta \mathrm{L}=$ Dial gage reading

$\mathrm{L}=$ Distance between frame rings (in)

For the modulus frame used the distance between testing rings, L, was $152.4 \mathrm{~mm}$ (6in).

The strain, $\varepsilon$ (in/in) for the EM-5 strain gage was determined by using the equation;

$\varepsilon=\varepsilon_{1}-\varepsilon_{0}=\left(\mathrm{L}_{1}-\mathrm{L}_{0}\right) \quad$ where

$\mathrm{L}_{0}=$ Initial LINEAR Reading, in linear units, equivalent to $\varepsilon_{0}$

$\mathrm{L}_{1}=$ Current LINEAR Reading, in linear units, equivalent to $\varepsilon_{1}$

Each of which directly proportional to the fundamental vibration square of the gage wire.

Positive values of $\varepsilon$ represent tensile strains and negative values of $\varepsilon$ represent 
compressive strains. In this case, all the values were known to be negative and compressive, so for graphically purposes they are converted to positive values.

Stress versus strain graphs were constructed for each compression test performed and the best-fit straight lines were placed with the corresponding equations on each graph. The slopes of the stress versus strain graphs are equivalent to the modulus of elasticity values obtained for the given cylinder at the given time. Five cylinders were early age compression tested (first 72-hours). Examples of the July 1999 early-age compression test data graphs can be seen in Figures A.1 and A.2 of Appendix A. The determined modulus of elasticity values for each cylinder specimen and time of testing were combined into individual cylinder specimens graphs of the development of modulus of elasticity versus time. These results for the July 1999 early-age compression testing, modulus of elasticity development graphs can be seen in Figures 4.1 through 4.6.

- Cylinder 1W EM-5 Gage results in Figures 4.1.

- Cylinder 1W Dial Gage results in Figures 4.2.

- Cylinder 2W Dial Gage results in Figures 4.3.

- Cylinder 4W Dial Gage results in Figures 4.4.

- Cylinder 6A Dial Gage results in Figures 4.5.

- Cylinder 8A Dial Gage results in Figures 4.6. 


\section{2d. EARLY AGE MODULUS OF ELASTICITY TESTS - Discussion:}

The compression tests performed in Phase II were performed quite similar to the tests performed during Phase I in procedure except for the addition of the embedded EM-5 gage, additional curing methods and total number of test cylinders.

After examining these graphs, it was seen that a gradual growth of the modulus of elasticity occurred in the first 72 hours. The initial drastic, increase from very low values to more typical values the modulus of elasticity was not seen during these tests, as expected. The Danville, PA mix design differed from that tested during Phase I. Unfortunately, the critical time to begin the test was missed in this case. Gradual increases in modulus values were obtained by all compression tested cylinders. The initial rapid growth was seen to have occurred prior to the initial time of testing at 10 hours of cure time. The rapid growth, although fundamentally important, may not be of great importance to the analysis because the slabs found in the field were not failing until well after 12 hours in most cases as the heat of hydration dissipated. It was seen that the heat of hydration was near a maximum at the same time as the onset of the testing. The heat is generated from the cement and water reaction during curing. The strength development of the concrete is a direct result of the reaction. During our tests, the concrete cured more quickly and thus strengthened more quickly than the concrete tested during Phase I. For this reason, the rapid growth rate was undetermined. The gradual modulus growth rate after the concrete has reached a cure surpassing the time of the maximum value of the heat of hydration is important for this analysis because it is still increasing in value. Thus, the modulus of elasticity value at the beginning of the concrete 
slab differs from the value at the end of the slab, because the concrete at the end of the slab is 10 to 12 hours, or more, younger.

The results from the EM-5 vibrating wire embedded strain gage were greater in value than the modulus frame dial gages, although they both showed a similar gradually increasing modulus of elasticity curve. During the first 72 hours of curing, the EM-5 gage resulted in a modulus of elasticity that ranged from $2.5\left(10^{6}\right)$ psi at 10 hours, to around $4.0\left(10^{6}\right)$ psi at 72 hours. The modulus frame resulted in values ranging from 1.5 to almost $2.5\left(10^{6}\right)$ psi in the same time span, respectively. The exact reason for the discrepancy is unknown at this time but many fundamental, mechanical and procedural variations and/or errors could be justifiably concluded. All five of the modulus growth versus time graphs made from the dial gage test results showed a similar development trend. The water-bath cured cylinders all showed a growth from around $1.5\left(10^{6}\right)$ psi to around $2.5\left(10^{6}\right)$ psi, from 10 to 72 hours, respectively. While the air-dry cured cylinders both showed a growth from $1.5\left(10^{6}\right)$ psi to only around $2.0\left(10^{6}\right)$ psi, at the same time frame. The slight drop in value of the modulus of elasticity growth in the air-dry cured cylinders could be due to the curing technique or could be due to the early age compression loading or both. The early age cylinders were tested again at an age of 28 days along with non-early age tested cylinders. These results are discussed in Chapter 4.2e. 28 Day Compression Tests - Discussion.

During the early age compression testing some imperfections, or flaws, were found in the experimental technique being used. First, the modulus frame dial gage incremental scale is not sufficiently small to give the most accurate of results. Thus in some cases during the analysis, some test results were discarded. It was seen that multiple tests 
should be performed on each cylinder for any given time to give a more reliable value. Other situations will be later discussed.

\section{2e. 28 DAY COMPRESSION TESTS - Discussion:}

The early age compression tests and the resulting modulus of elasticity growth curves can only be used if the integrity of the specimens were not compromised. If the cylinders are shown to have been damage in any way, the results might be unreliable. This is why another comparative scheme was implemented in this test. Non-early tested concrete cylinders were made and cured in the same manner as the early age tested cylinders. The non-early age tested cylinders were shown in Table 4.1. The designated cylinders were then compression tested on the $28^{\text {th }}$ day of curing. The compression data was again converted into stress versus strain curves, as in the early age tests with the best-fit straight line drawn and labeled. The cylinders were compression tested as follows: cylinders $2 \mathrm{~W}^{*}, 3 \mathrm{~W}, 4 \mathrm{~W}^{*}, 6 \mathrm{~A}^{*}, 7 \mathrm{~A}, 8 \mathrm{~A}^{*}$ and $9 \mathrm{~A}$. The stress versus strain graph's developed from these tests were recorded in the order as previously listed and examples can be seen in Figures A.3 and A.4 in Appendix A. The slopes of the lines on the stress versus strain graphs are the 28-day modulus of elasticity values of the corresponding cylinders. The modulus of elasticity values versus cylinder designations that were determined from the stress versus strain relationships were graphically shown in Figure 4.7. It can be seen from these graphs that the modulus of elasticity values at 28 days for the early tested and non-early tested cylinders are respectively similar when considering the curing methods. The water-bath cured cylinders all revealed values around $2.4\left(10^{6}\right)$ psi and the air-dry cured cylinders revealed values around $2.0\left(10^{6}\right)$ psi. The discrepancy in values can be 
directly attributed to the curing method. Thus, verifying comments made in the Phase I report that the loss of moisture had a direct effect on the modulus of elasticity development.

The final comparative test was the 28 -day compressive strength, $\mathrm{f}_{\mathrm{c}}$. All of the cylinders were tested to failure, except for cylinder $1 \mathrm{~W}^{*}$. Cylinder $1 \mathrm{~W}^{*}$ was being used in another laboratory test for the thermal coefficient of the concrete (See Chapter 4.4b). The compressive strengths of the other nine remaining cylinders were shown graphically in Figure 4.8. It can be seen from this graph that the similar curing methods produced similar compressive strength values. The early age tested and non-early age tested water cured cylinders, $\left(2 \mathrm{~W}^{*}, 3 \mathrm{~W}, 4 \mathrm{~W}^{*}\right.$ and $\left.5 \mathrm{~W}\right)$, had a values of $\mathrm{f}_{\mathrm{c}}$ ' around 6,700 to $6,800 \mathrm{psi}$. However, with the air-dry cured cylinders, the early tested and the non-early tested showed drastically different values of $\mathrm{f}_{\mathrm{c}}$ '. The non-early age tested cylinders, (7A, 9A and 10$)$, had a $\mathrm{f}_{\mathrm{c}}$ ' of around $6,300 \mathrm{psi}$, but the early age test cylinders, $\left(6 \mathrm{~A}^{*}\right.$ and $\left.8 \mathrm{~A}^{*}\right)$, had values of $\mathrm{f}_{\mathrm{c}}$ ' around 4,200 to 4,300 psi. This drastic lose of compressive strength can be contributed to the curing method, air-dry cured, being early age tested.

It can be determined from these tests that the early age testing of the water cured concrete cylinders had little or no effect on the development of compressive strength or the modulus of elasticity value. It can also be determined that early age testing of air-dry cured concrete cylinders may have a drastic effect on the development of the compressive strength. Thus for early age compressive loading tests, it may be recommended to utilize water-bath curing to try to ensure specimen integrity. 
MODULUS OF ELASTICITY versus TIME

July 1999 Compression Tests

Cyl 1W EM-5 Results

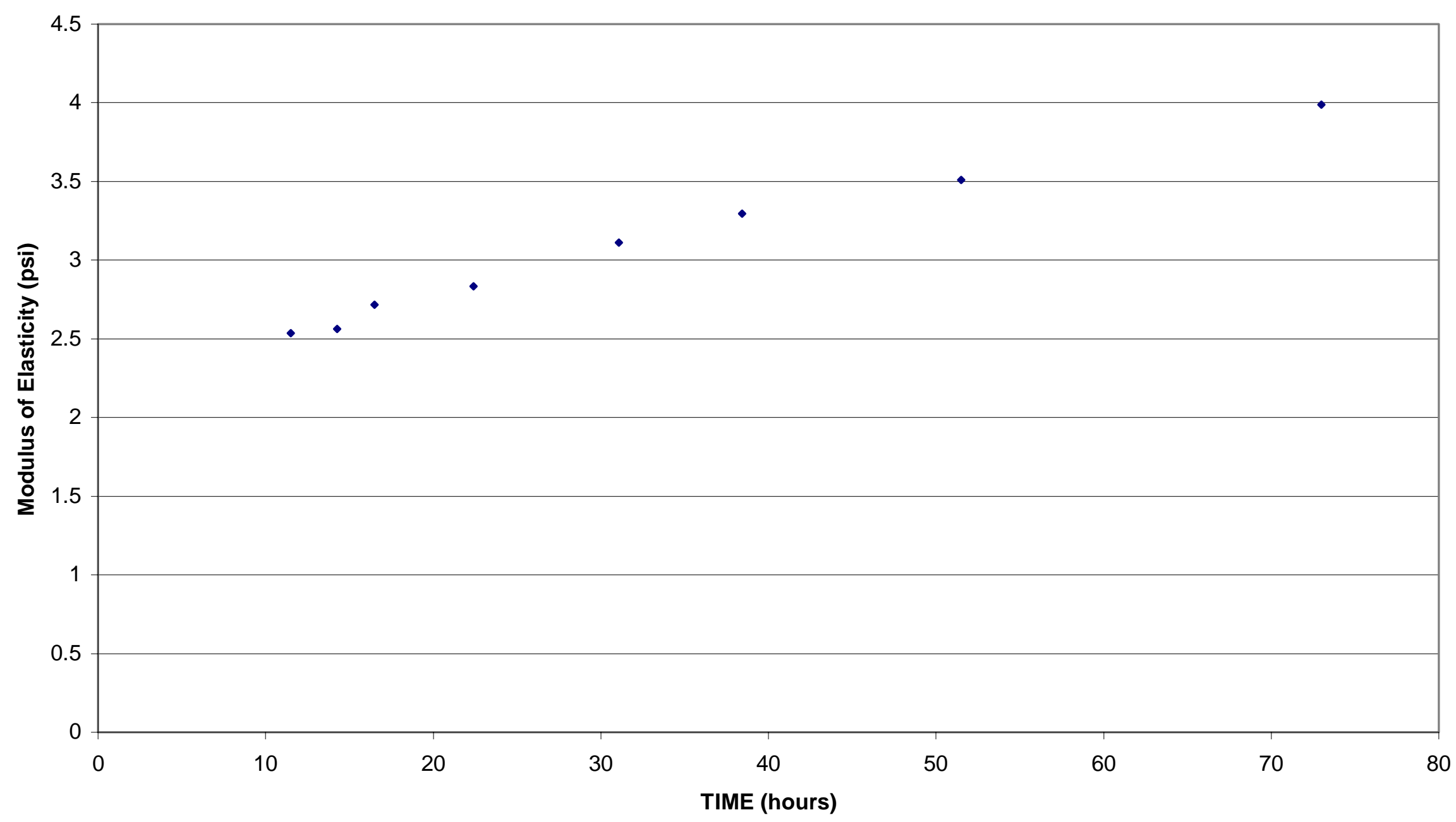

Figure 4.1: Modulus of Elasticity Development Cylinder 1W, EM-5 Gage Results 


\section{MODULUS OF ELASTICITY versus TIME July 1999 Compression Tests \\ Cyl 1W Dial Gage Results}

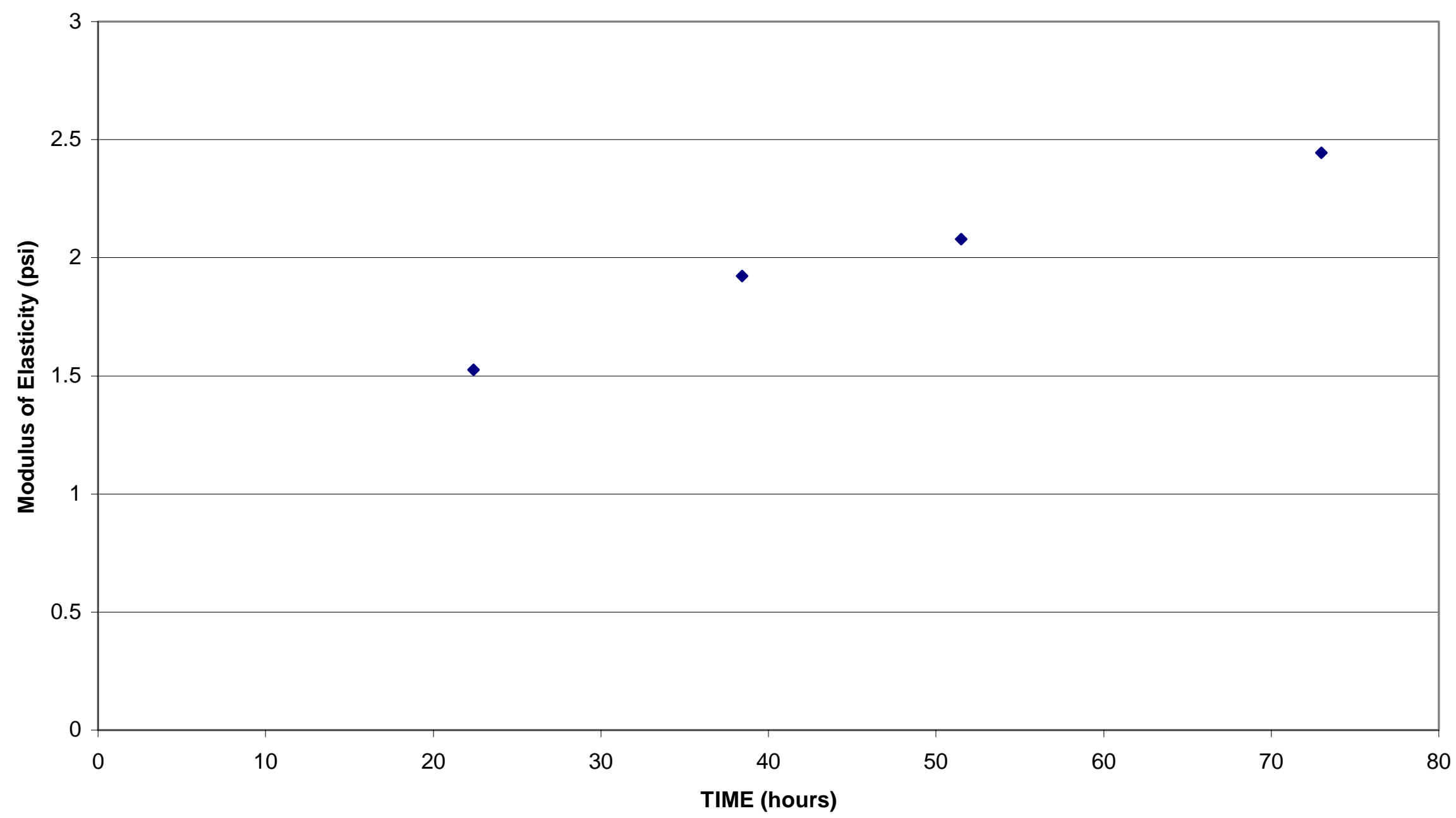


MODULUS OF ELASTICITY versus TIME

July 1999 Compression Tests

Cyl 2W Dial Gage Results

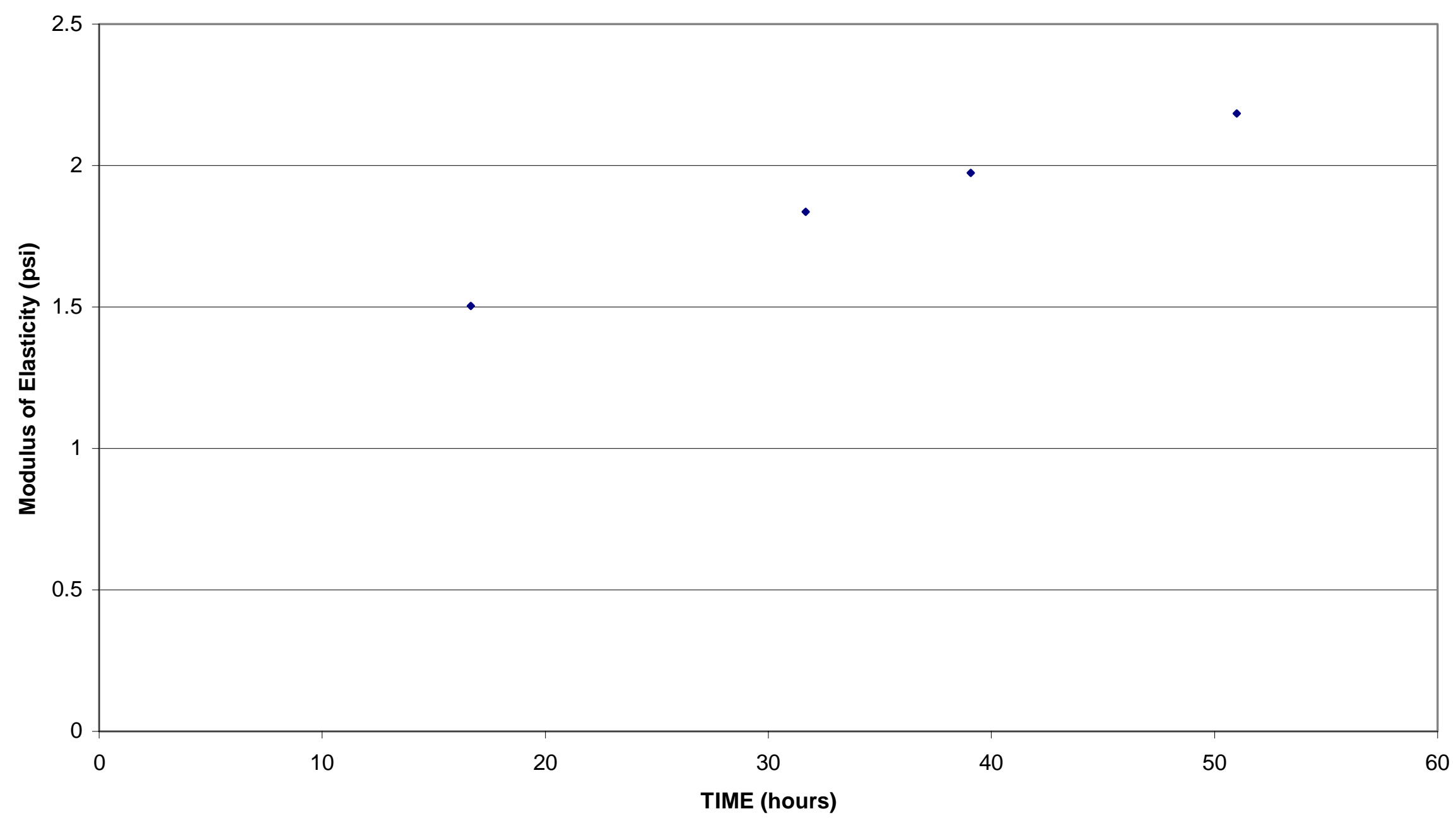

Figure 4.3: Modulus of Elasticity Development Cylinder 2W, Dial Gage Results 
MODULUS OF ELASTICITY versus TIME

July 1999 Compression Tests

Cyl 4W Dial Gage Results

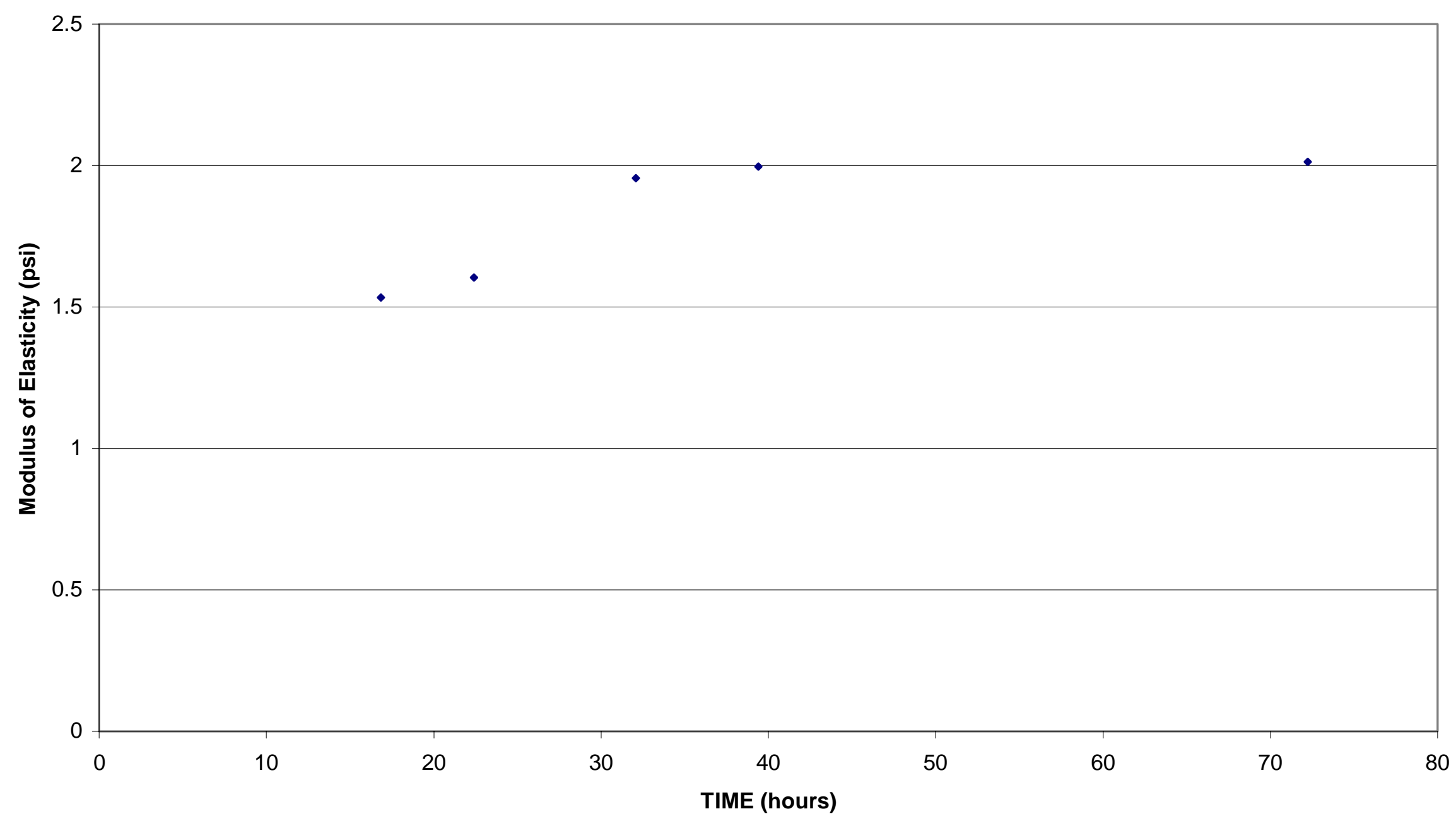




\section{MODULUS OF ELASTICITY versus TIME July 1999 Compression Tests \\ Cyl 6A Dial Gage Results}

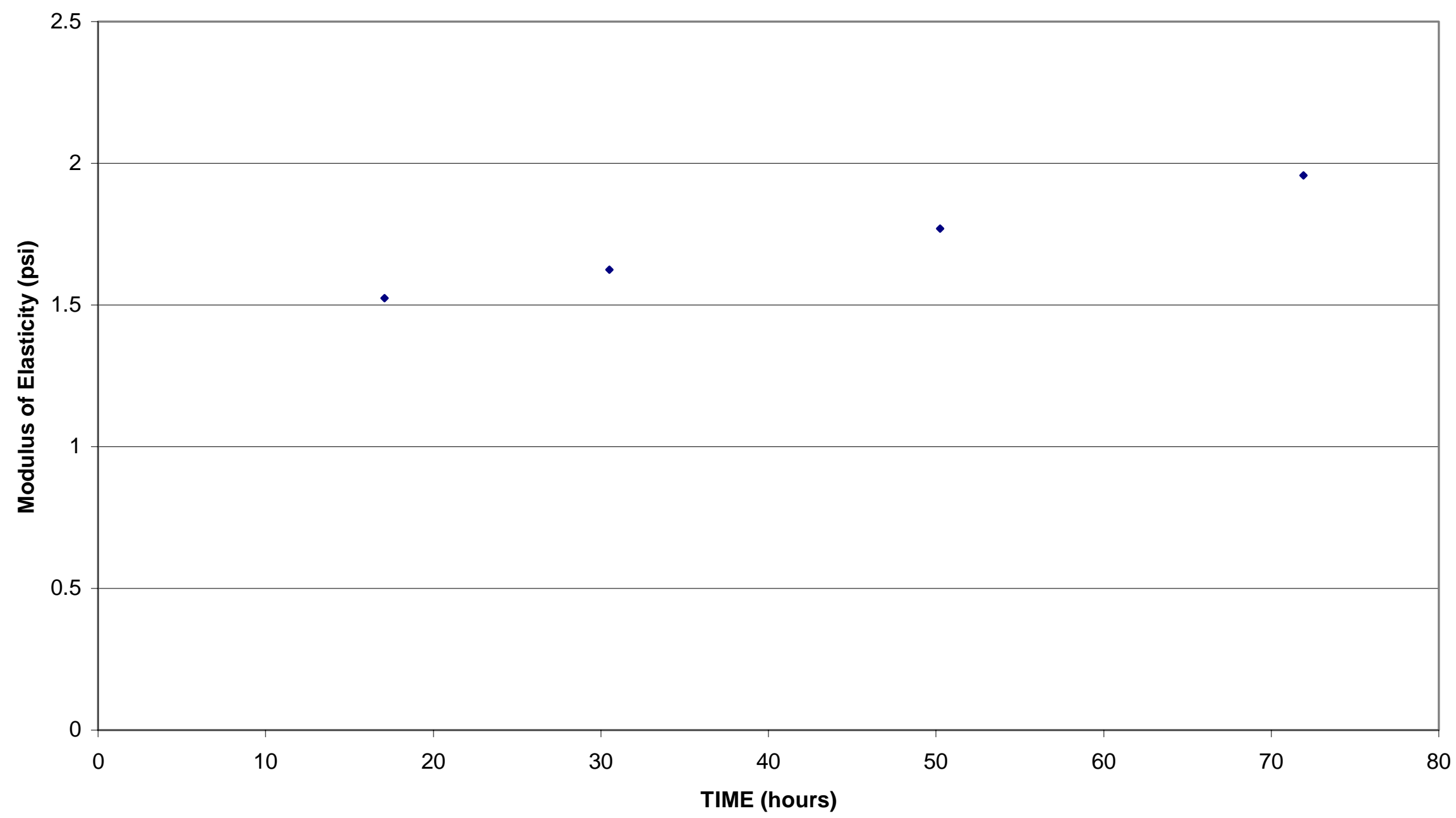




\section{MODULUS OF ELASTICITY versus TIME July 1999 Compression Tests \\ Cyl 8A Dial Gage Results}

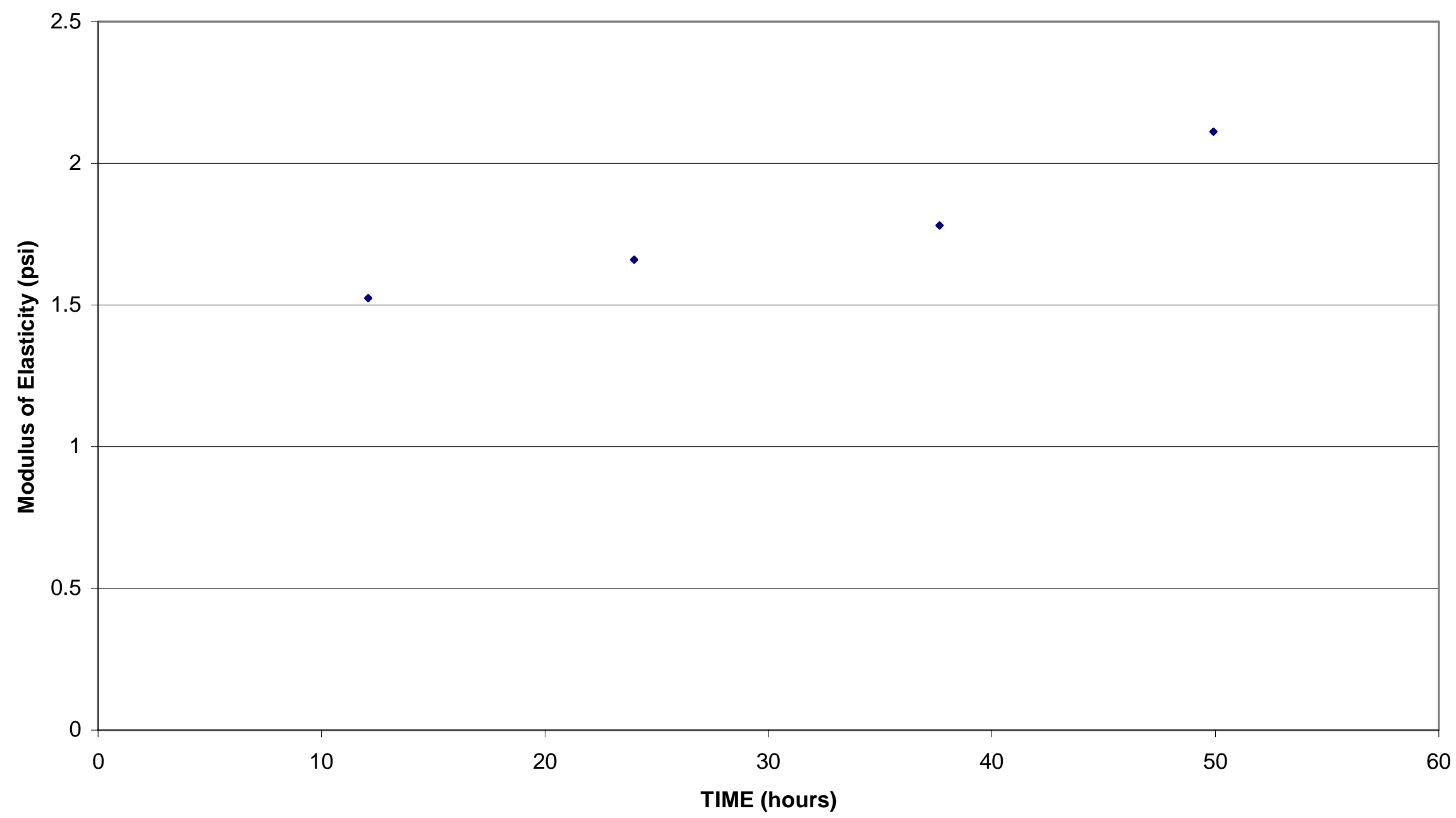


28 Day Modulus of Elasticity Values

Danville, PA Mix Design

07 July 1999 Mixed at 1100 HRS

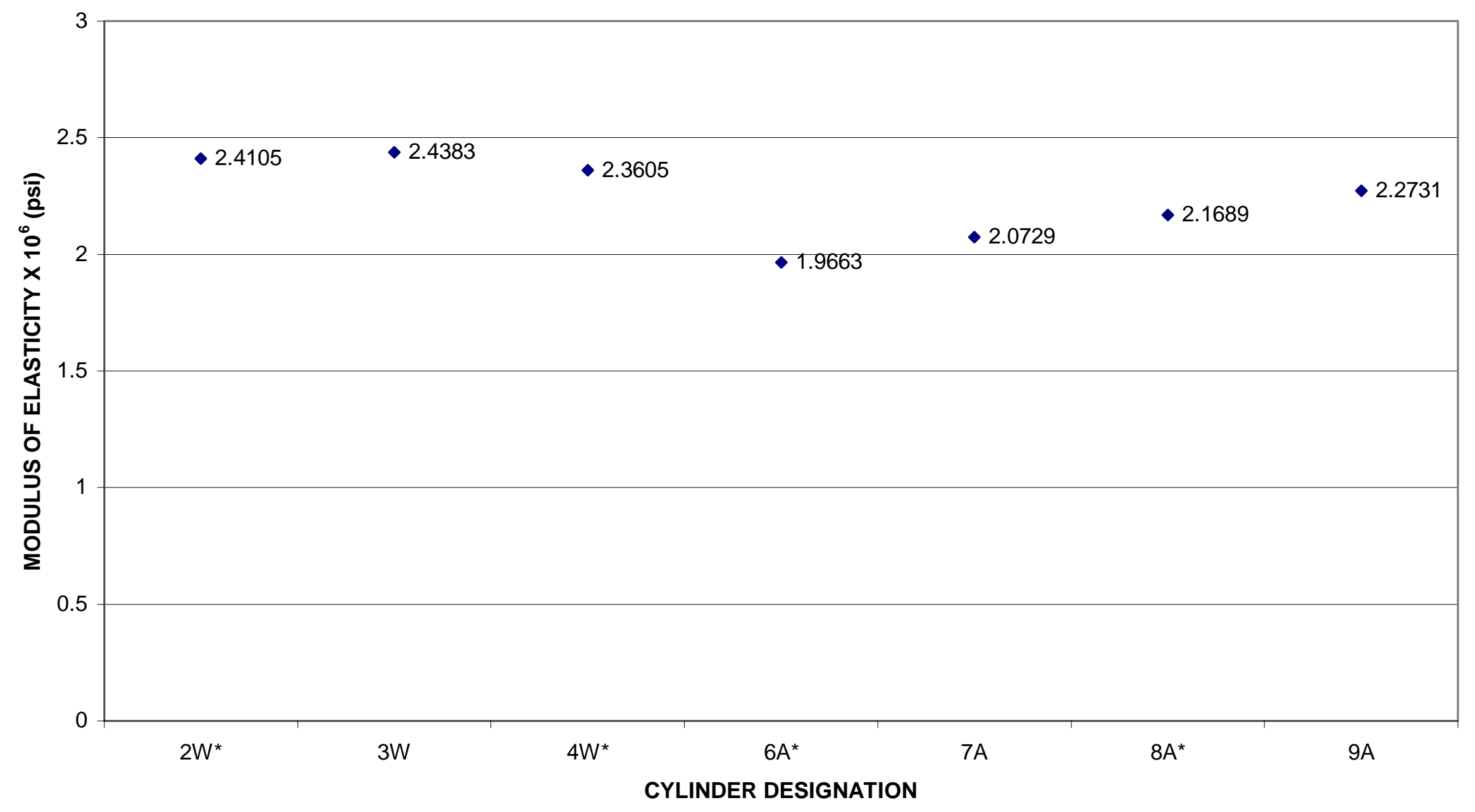

Figure 4.7: $28^{\text {th }}$ Day Modulus of Elasticity Values Danville Mix Cylinders, July 1999 
28 Day Compressive Strength, $f_{c}{ }^{\prime}(p s i)$ Testing Results

Danville, PA mix design mixed on 07 July 1999 at $1100 \mathrm{hrs}$

(see text notes)

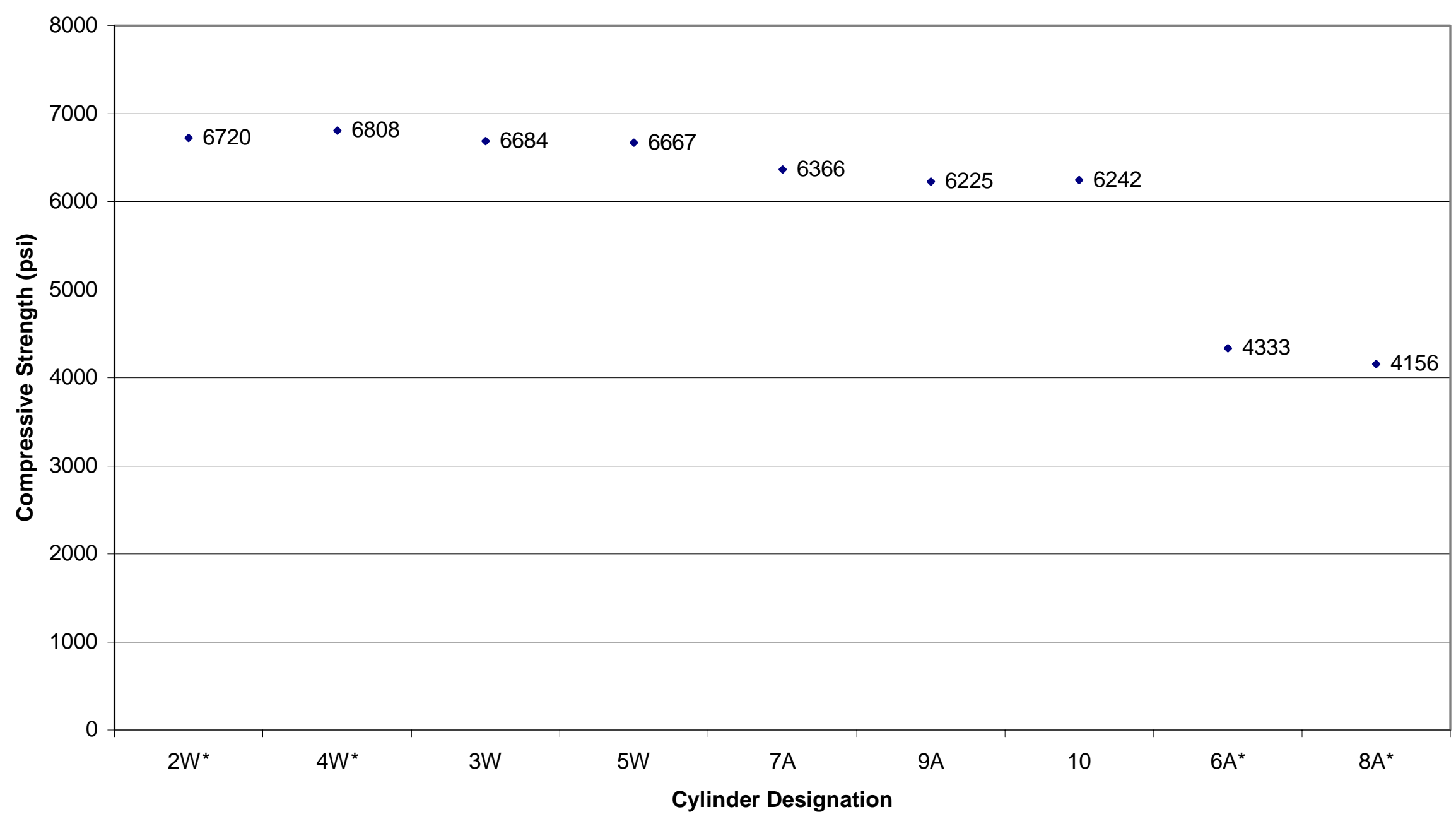

Figure 4.8: $28^{\text {th }}$ Day Compressive Strength, $\mathrm{fc}^{\prime}(\mathrm{psi})$, Danville Mix Cylinders July 1999 


\subsection{FIELD AND LABORATORY CYLINDER TESTS:}

\section{3a. October and November 1999 Compression Tests Procedure:}

A section of Corridor H, near Elkins, WV was to be fully investigated for early-age behavior. A specialized modulus of elasticity testing scheme was developed to assist in determining the modulus growth behavior for the Elkins, WV concrete mix design.

Results of the modulus of elasticity tests performed in July 1999 assisted in the development of a more reliable method. The same brand and type of concrete mix materials used near Danville were ordered and used in the respective quantities but the aggregates used were not. The University's aggregate stockpiles in the concrete laboratory were used for the mix at that time. Moisture contents were obtained but the differences in the aggregates greatly varied the strength development.

For the November 1999 tests, all of the materials used, except water, for the comparative modulus tests were requested and obtained directly from the construction site to eliminate any material variations. Standard 6 by 12 -inch plastic concrete cylinders were again used for the compression tests.

The testing procedure developed was simply a comparative scheme that allowed the actual concrete mix design placed to be evaluated to reveal if the early age modulus of elasticity growth curves found in laboratory tests could be assumed to be the same as in the field. Due to the modified strain gages suspended in two of the test cylinders, different consolidation techniques were used when making them. One method was the standard rod consolidation technique and the other was by simply hammering the outside of the cylinder to consolidate the concrete. To determine the effect that these consolidation techniques had on the values obtained from the compression tests, several 
types of cylinders were made for comparison; three in the field and five in the laboratory; some were rodded and some were hammered. (See the following Table 4.2)

\section{Table 4.2:}

\section{Field Specimen Cylinders:}

Field Specimen \#1: 1 hammered with a suspended modified EM-5 strain gage

Field Specimen \#2: 1 hammered

Field Specimen \#3: 1 rodded

\section{Laboratory Specimen Cylinders:}

Lab Specimen \#1: 1 hammered with a suspended modified EM-5 strain gage

Lab Specimen \#2, \#4: 2 hammered, one early age compression tested, one non-tested * Lab Specimen \#3, \#5: 2 rodded, one early age compression tested, one non-tested *

- Note: * The non-tested specimens were used in final compressive strength testing performed at a concrete age of 28 days only.

\section{3b. TESTS:}

The concrete cylinders made for these tests were done as specified in Chapters 3.2b. All of the specimens were water-bath cured after removal of the plastic cylinders and plastic caps. The early age laboratory test cylinders were then capped with particleboard, as discussed in Chapter 4.2b, prior to each compression test. All of the specimens, field and laboratory, were capped with silicon caps for the 7,14 and 28 day tests. The silicon capping distributed the applied load more evenly and also protected the specimens 
edging. The silicon capping could not be applied to the early age tested specimens because the young concrete specimens could be damaged during the silicon capping procedure. (Frum, 1999)

The test specimens from the field were compression tested at 7, 14 and 28 days to be compared to the values obtained in the laboratory specimens for their 7, 14 and 28 days compression test results. If the values for the developing modulus of elasticity as well as the 28th day compressive strength, $f_{c}$ ', compared, it could be deduced that the first 72 hour, early-age modulus of elasticity values could be used from the laboratory tests in the analysis of the concrete slab behavior.

The early age compression tests performed on the laboratory mix in November 1999 were improved from the tests performed in July 1999. Cylinders were tested three consecutive times so that an average could be used for consistency and reliability purposes during analysis. After each test, the dial gage compressometer was remounted to avoid slippage errors. The three compression tests on each cylinder were performed in rapid succession. The compression tests commenced as soon as the concrete cylinders were set enough to remove the plastic cylinder forms, (after about 10 hours). Seven rounds of three compression tests for each of the three different early age test cylinders (totaling 63 individual tests) were performed within the first 72 hour period of curing. These results in the predicted early-age modulus of elasticity growth curve are to be utilized in the pavement analysis. The compression tests were being performed for the 7 , 14, and 28-day field specimens during the same time frame as the early age tests on the laboratory specimens. The specimens that were tested at early ages, as well as the field specimens were tested in the same triplicate manner, totaling six specimen's tested three 
times on three different days (totaling 54 more tests). Also after all of the testing was

performed on the $28^{\text {th }}$ day, a final compressive strength test was performed on each of the cylinders, except the two containing the EM-5 modified embedment strain gages.

\section{3c. EARLY AGE MODULUS TEST RESULTS - Discussion:}

The compression test data for the Elkins, WV specimens were reduced in the same manner as the July 1999 test data. (See Chapter 4.2c.) The three consecutive compression tests performed on each specimen for a given time were plotted together for of each test of each specimen. The respective slopes of the three best-fit straight lines were then averaged to give an averaged modulus of elasticity value for a given specimen at a given time.

The specimens tested at early age were laboratory specimens \#1, \#2 and \#3.

Laboratory specimen \#1 utilized both the modulus frame dial gage and the modified EM5 strain gage to measure the corresponding deflections to a given load. (Or Lab Specimen \#1 EM-5 Gage and Lab Specimen \#1 Dial Gage) Each deflection test method was tested three times and at seven different ages within a 72-hour period, or 84 individual stressstrain relationships. Each specimen has a set of seven data stress-strain graphs containing the three consecutive tests. Examples of early-age stress-strain graphs for the Elkins mix laboratory cylinders can be seen in Appendix A, Figures A.5 and A.6.

The resulting modulus growth curves for each specimen are as follows:

- $\quad$ Lab Specimen \#1 EM-5 and Dial Gage in Figure 4.9.

- $\quad$ Lab Specimen \#2 Dial Gage in Figure 4.10.

- Lab Specimen \#3 Dial Gage in Figure 4.11. 
The first 72 hours of modulus growth were obtained for the Elkins, WV mix design. The Dial Gage results for all three specimens showed quite similar trends and values. At this point it would be hard to distinguish any distinct differences, based on these results in order to comment on whether or not the consolidation technique, hammering or rodding, had adverse effects. The Dial Gage modulus growth results have been found to increase steadily in value from around $1.0\left(10^{6}\right)$ psi to around 1.7 to $1.8\left(10^{6}\right)$ psi, at 12 hours to 72 hours, respectively. The EM-5 modified Gage revealed values increasing from around $1.4\left(10^{6}\right)$ psi to around $2.6\left(10^{6}\right)$ psi, in the same time frame. As in the July 1999 compression tests, the EM-5 gages revealed larger results. The modified EM-5 Gage results are nearly twice as large as the Dial Gage results. (Figure 4.9) The results obtained from the modulus frame being used in these tests compared to the EM-5 gages (standard in July 1999 and modified here) show that the modulus frame tests are detecting more deflection than the EM-5 gages at the same load. The sensitivity of the gages is different for each. The modulus frame dial gage has a readable increment of 0.0001 inch and a sensitivity of $+/-16.667\left(10^{6}\right)$ inch/inch. The EM-5 vibrating wire strain gage has an incremental digital readout sensitivity of $0.1\left(10^{6}\right)$ inch/inch.

Intermediate values were estimated with the modulus frame dial gage readout, but the MB-6T vibrating wire readout unit was digital and no estimations were needed. Regardless of the sensitivities, the modulus growth rates increase respectively between the two deflection reading techniques. This observation indicates that the deflection readings could both be correct. The value used for the original length, $\mathrm{L}$, in the strain calculation for the modulus frame is 6 inches, which could be a source of error. The 
determination of the more accurate gage is beyond the scope of this research and it is recommended that tests be performed on this matter more extensively.

\section{3d. 7, 14 and 28 DAY TEST RESULTS - Discussion:}

The 7, 14 and 28-day compression tests provide a comparative test scheme for the Field specimens and the Lab specimens. As stated earlier, if the modulus growth values from the Lab are comparable to the values from the Field then the early age lab compression tests may be assumed valid and can be utilized for the early age concrete pavement stress analysis.

The 7, 14 and 28 day compression tests were performed in the same manner as the early-age tests, (by performing three separate tests for a given specimen and time). The results of the compression test have been consolidated to 7,14 and 28-day tests for each specimen test type. Examples of the Laboratory and Field specimens 7, 14 and 28-day stress-strain graphs located in Appendix A, Figures A.7 and A.8. As with the early age Lab tests, a best-fit straight line was made for each individual test, three for each day tested. The three slopes are then averaged to reveal an average modulus of elasticity value for that day. The averaged modulus values were then assembled to show the average modulus development curves for each specimen. The Lab specimen results can be seen in Figures 4.12 and the Field specimen results in Figures 4.13.

It can be seen from these graphs that the rate of growth of modulus value has drastically decreased from that found during the first 72-hours. Generally, the specimens show gradually increasing trends in the modulus of elasticity after the seventh day, as 
expected. Again, the values obtained from the EM-5 gage are higher than the values from the dial gages. All of the results obtained for the dial gage testing for the Lab and Field specimens showed modulus values from $2.0\left(10^{6}\right)$ psi to under $2.5\left(10^{6}\right)$ psi. Also, both of the modified EM-5 gage specimens revealed modulus values from $3.0\left(10^{6}\right)$ psi to around $3.25\left(10^{6}\right)$ psi. All of the results are similar enough to assume that the development of the modulus of elasticity values from 7 to 28 days is consistent between the Field and Lab specimens. Thus, it may be assumed that the early age modulus developments are similar also and they may be utilized for the theoretical Elkins, WV pavement stress analysis.

There was one final test performed with these specimens. All of the specimens made in the field and the laboratory, except the ones containing modified EM-5 gages (specimens \#1 Field and Lab), were subjected to a 28-day compressive strength, $\mathrm{f}_{\mathrm{c}}^{\prime}$, test. The specimens tested were the Field specimens \#2 and 3, and the Lab specimens \#2,3,4 and 5. Recall that specimens \#4 and 5 were not compression tested at all and that one was hammer consolidated and the other was rod consolidated. The results of these compression strength tests can be seen in Figure 4.14. The comparison of values of $\mathrm{f}_{\mathrm{c}}$ ' for the different specimens reveal that the early age tested cylinders may have had their compressive strengths compromised. Nearly a twenty- percent drop in compressive strength is noted for the early age tested specimens from the non-tested and field cylinders. Although the compressive strengths might be compromised, the growth development of the modulus of elasticity did not show such a compromise. Thus, the permanent deflections caused from the early age loading do not drastically effect the stress-strain relationship when considering stress loading only reaching 20-30 percent of 
the compressive strength at any given time of concrete curing, so the results of these tests are believed valid.

The specimens tested at early ages showed possible damage coming from the earlyage loading. The non-early age tested specimens revealed a 28 -day compressive strength of around 5,200-psi. The contractor that placed the concrete slab, Hi-Way Paving Inc., performed independent testing on various concrete mix proportioning. They performed compressive strength tests for different concrete mixes and at maturity of 1, 3, 7, 14 and 28 days. The mix design used for the Corridor $\mathrm{H}$ investigated slab section called for a mix of 5 bags of cement plus one bag of flyash, with the other proportions as shown in Chapter 3.2d. Three different batches of the identical mix design had been tested and reproduced in Figure 4.15. The average 28-day compressive strength from their tests was around 5,000 psi. This average value is similar to the value obtained during this study's compression tests. Because of the comparative values of the multiple tests, the compressive strength development and the growth of modulus of elasticity values obtained from the early age study and the independent study may be used in the theoretical analysis. 
Average Experimental Modulus of Elasticity Values

Early-Age Compression Testing of WV Lab Specimen \#1

(Hammered; Cylinder Removed at 13 hrs.)

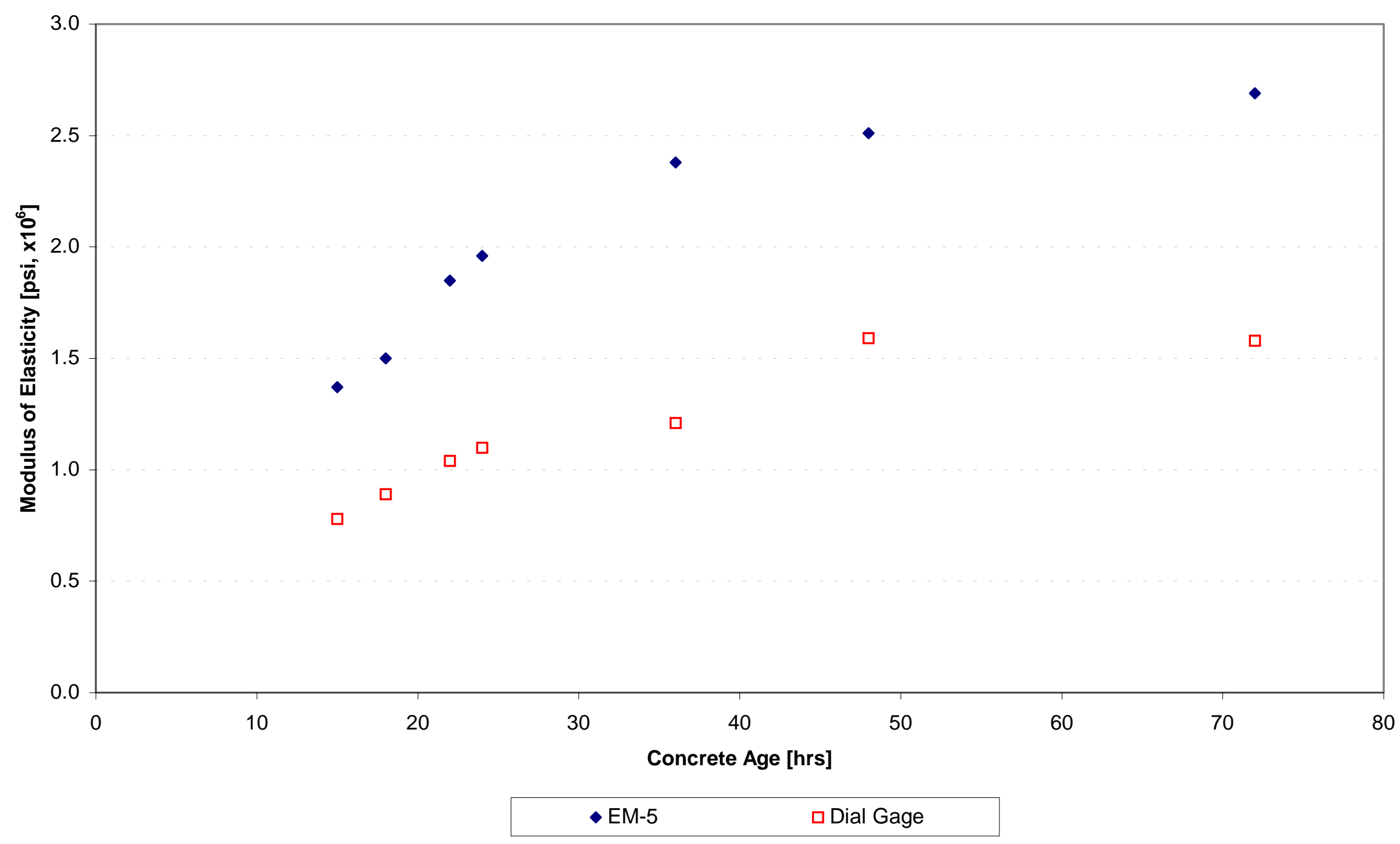

Figure 4.9: Early-age Modulus of Elasticity Development Lab Specimen \#1, Corridor H Mix 
Average Experimental Modulus of Elasticity Values

Compression Testing of WV Lab Specimen \#2

(Hammered; Cylinder Removed at 11 Hours)

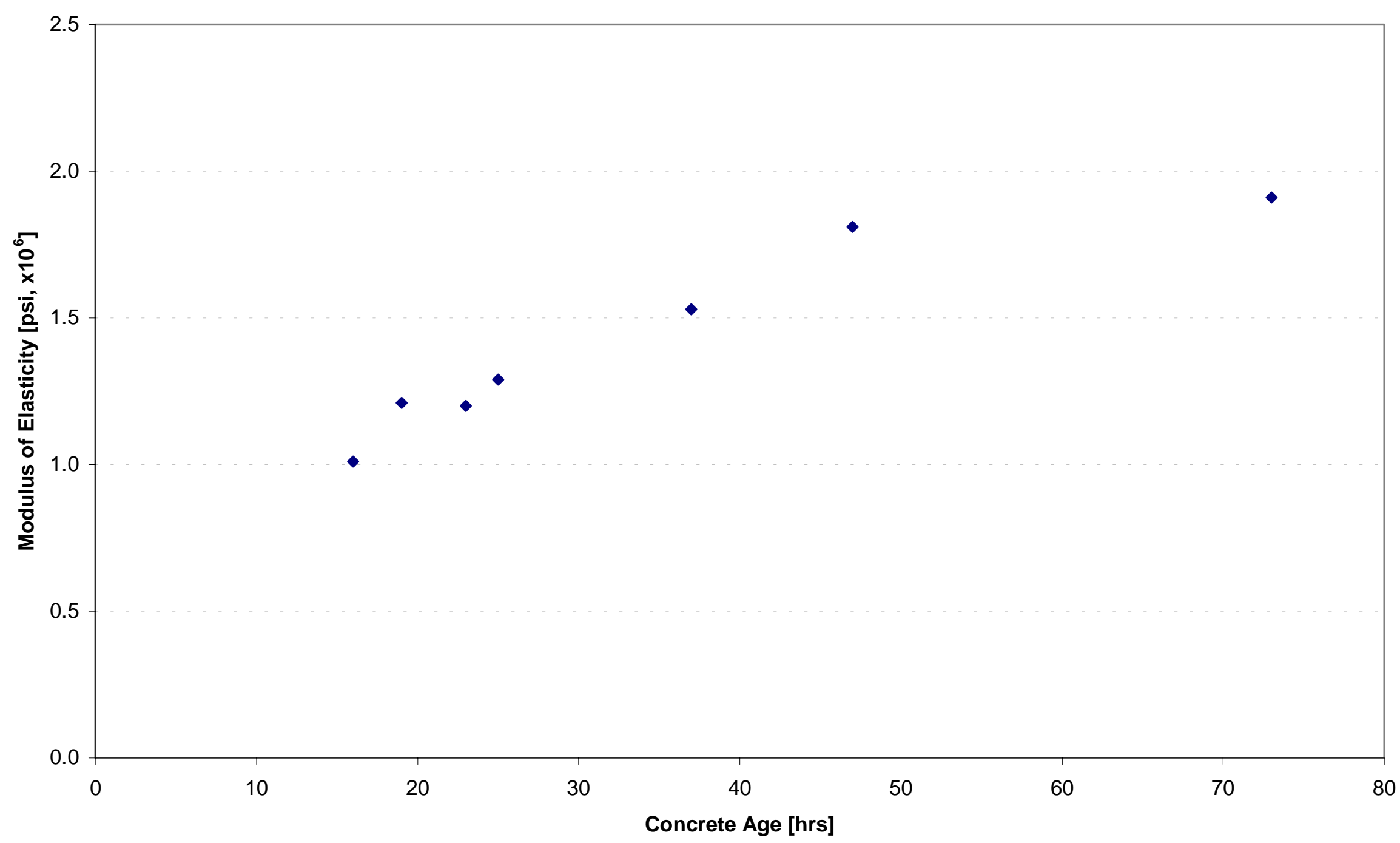




\section{Average Experimental Modulus of Elasticity Values}

Compression Testing of WV Lab Specimen \#3

(Rodded; Cylinder Removed at 9 hours)

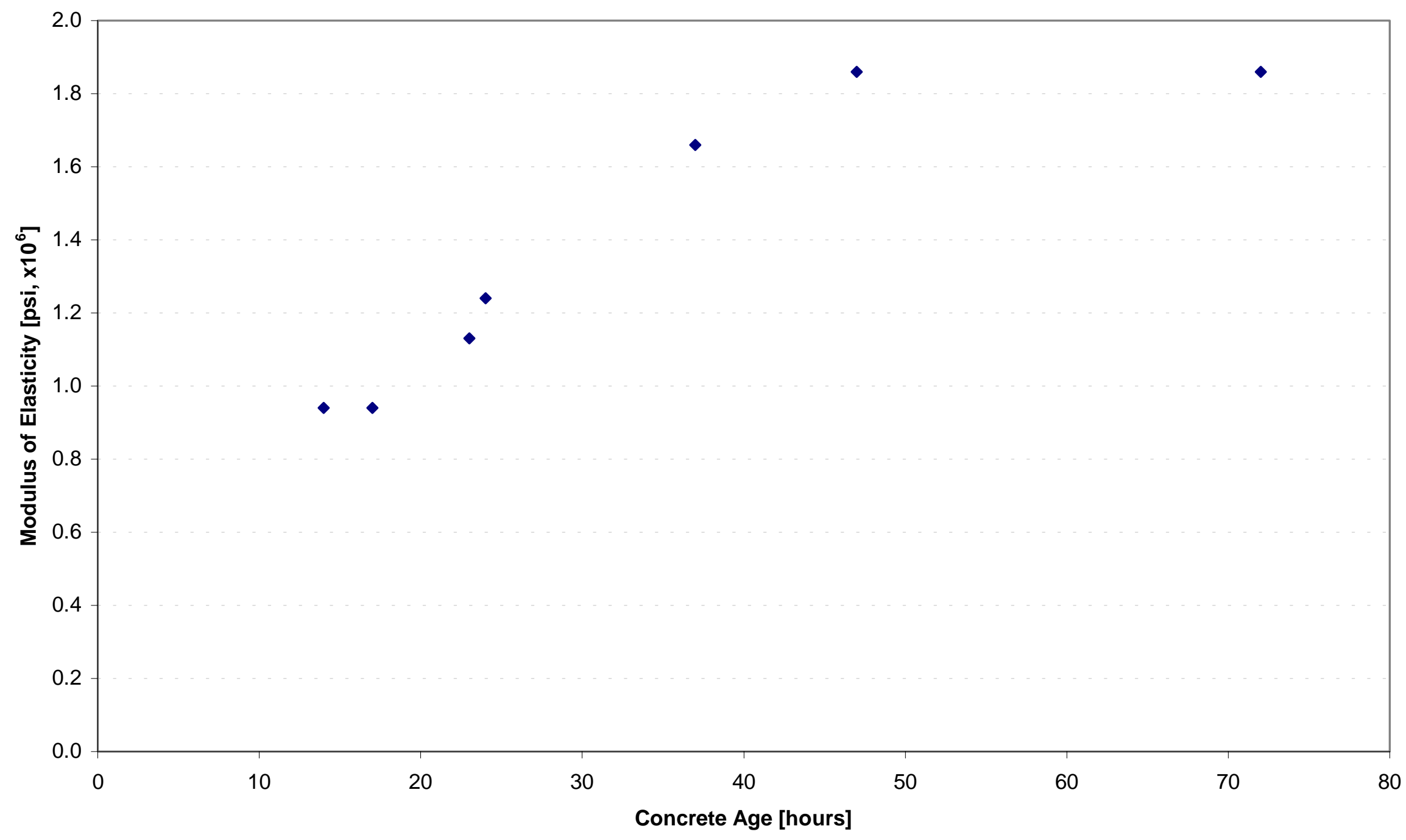


Average Modulus Development Curves

\section{Compression Testing of WV Lab Specimens}

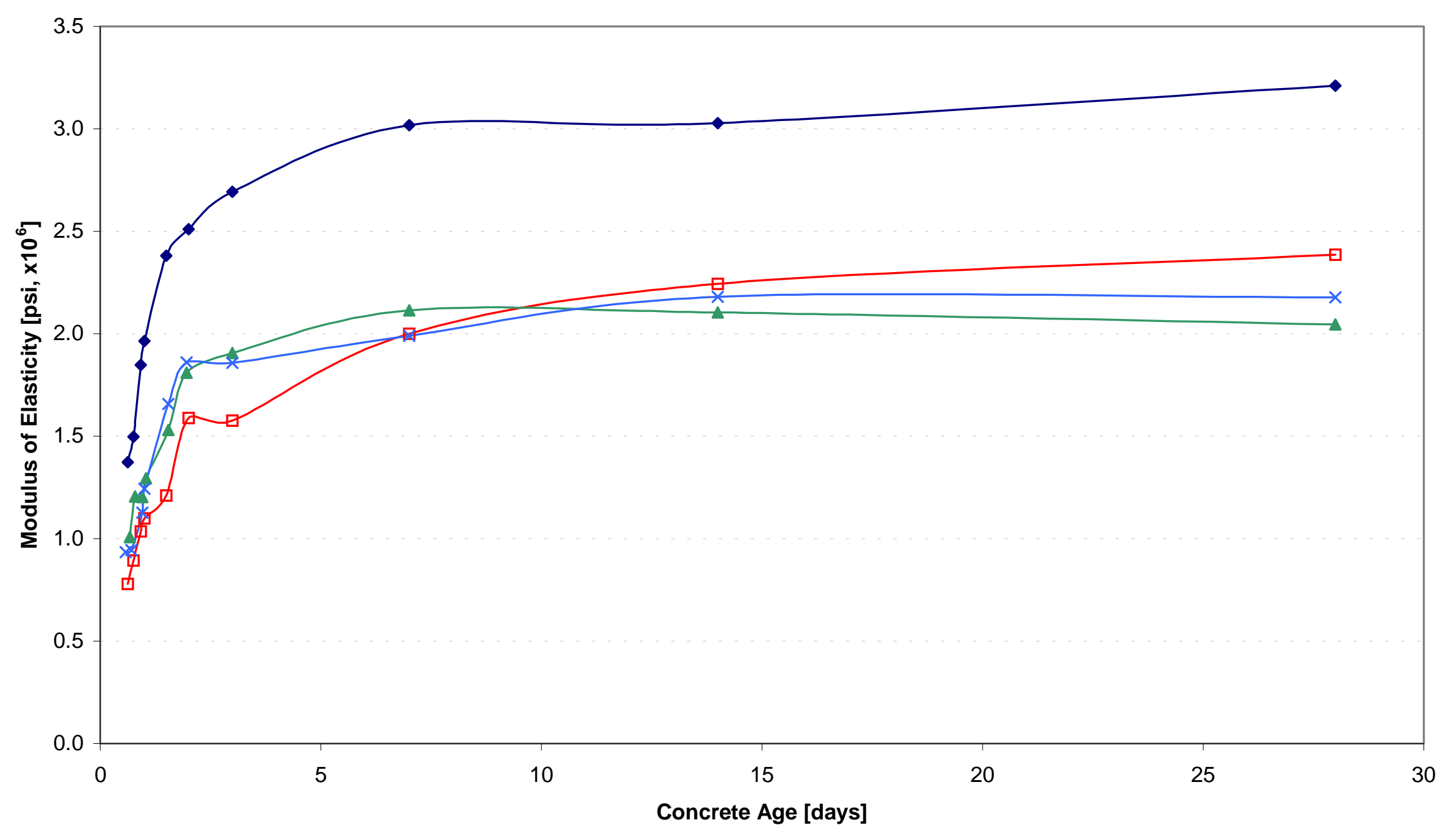

LAB CYL 1 (EM-5)

$\because$ LAB CYL 1 (DIAL)

$\multimap-\mathrm{LAB} C Y L 2$ (DIAL)

$*$ LAB CYL $3(\mathrm{DIAL})$

Figure 4.12: 7, 14 and 28-Day Modulus of Elasticity Values for all Lab Specimens, Corridor H Mix 
Average Modulus Growth Curves

Compression Testings of WV Field Specimens

Corridor H Westbound Lanes near Elkins, WV

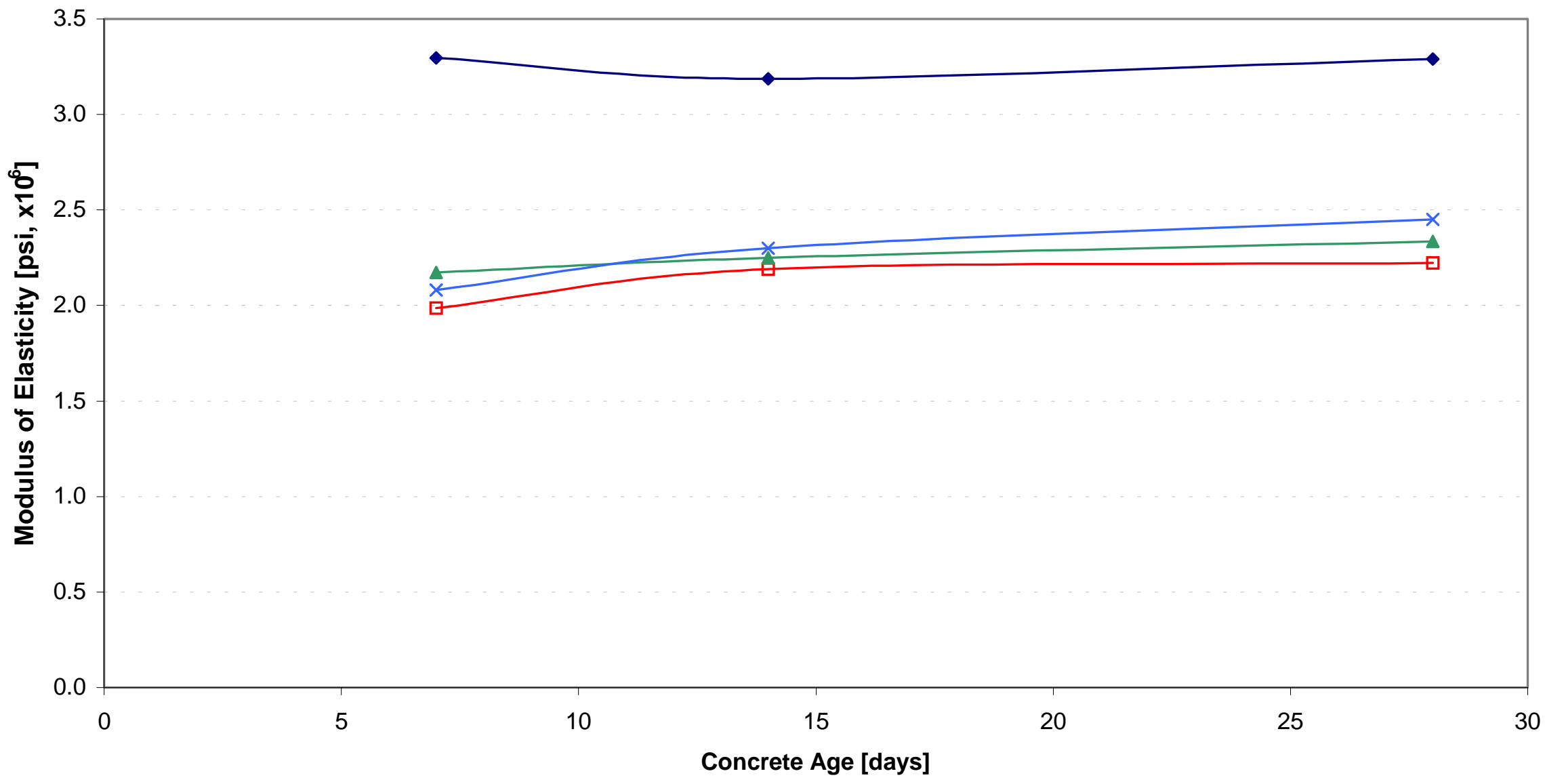

FIELD CYL. 1 (EM5) ๑FIELD CYL 1 (DIAL) —FIELD CYL 2 (DIAL) $\leftarrow$ FIELD CYL 3 (DIAL)

Figure 4.13: 7, 14 and 28-Day Modulus of Elasticity Values for all Field Specimens, Corridor H Mix 
28 Day Compressive Strength, $f_{c}{ }^{\prime}(p s i)$ Testing Results

Elkins, WV mix design, Field and Laboratory specimens

(Note: $\mathbf{H}=$ hammered, $\mathbf{R}=$ rodded, ${ }^{*}=$ early age tested)

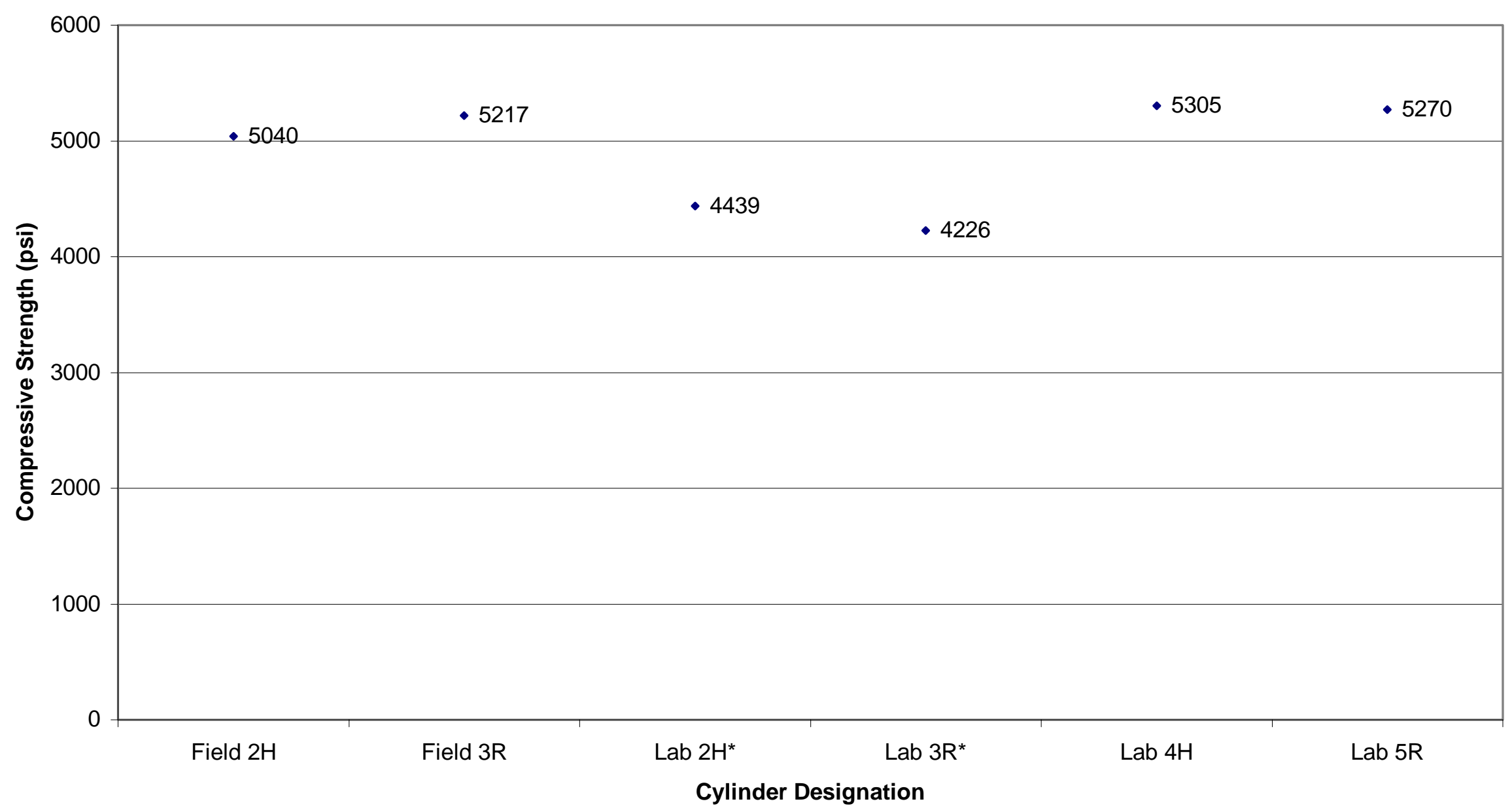

Figure 4.14: $28^{\text {th }}$ Day Compressive Strength, fc' (psi), for Corridor H Mix Specimens 


\section{STRENGTH DEVELOPMENT CURVES \\ Elkins, WV concrete mix design \\ Hi-Way Paving Inc. Results}

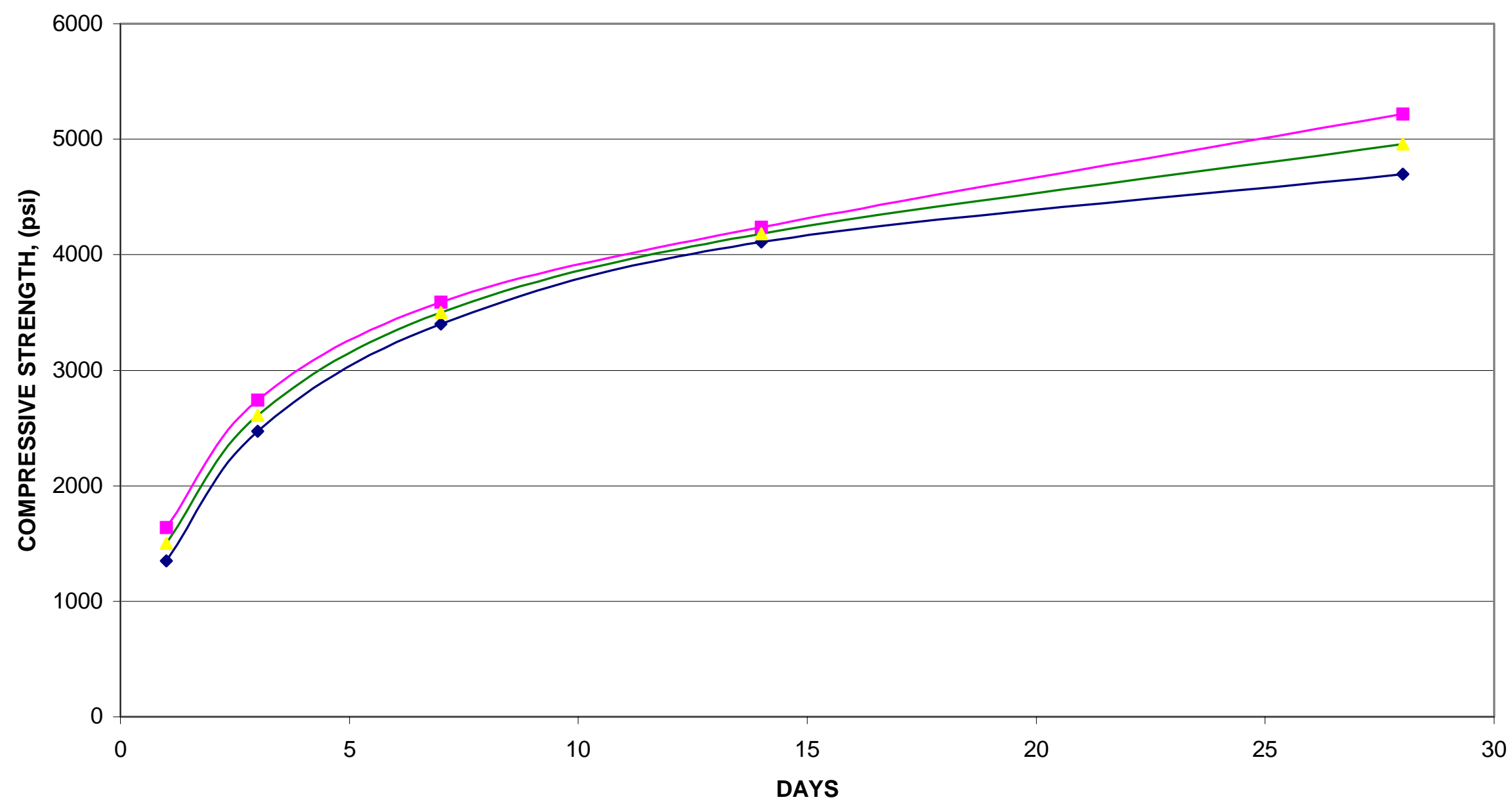

Batch $1-$ Batch $2--$ Batch 3

Figure 4.15: Hi-Way Paving, Inc., Concrete Compressive Strength, fc (psi), for Corridor H Mix 


\subsection{TEMPERATURE TESTS:}

\section{4a. General:}

A temperature-monitoring scheme consisting of six thermocouples and the curing concrete cylinders from the July 1999 compression tests was initiated. Five thermocouples were placed near the centriods of the plastic cylinders as the concrete was placed in them. The thermocouples were labeled $\mathrm{T} \# 1$ through $\mathrm{T} \# 6$, and put in predetermined cylinders as follows: (See also Table 4.1)

$\mathrm{T} \# 1$ - Cylinder $1 \mathrm{~W}^{*} \quad \mathrm{~T} \# 4$ - Cylinder $6 \mathrm{~A}^{*}$

T \#2 - Cylinder 2W* $\quad \mathrm{T} \# 5$ - Cylinder 7A

T \#3 - Cylinder 3W T \#6 - Ambient

The size of the concrete specimen should have an effect on the rate at which the heat dissipates from it after the initial heat of hydration is complete. The purpose of these tests are not to determine the actual amount of the heat of hydration, but to show how external temperatures changes can drastically increase the heat loss in a specimen. In the July 1999 lab compression tests, certain cylinders were to be water-bath cured, W, and others were to be air-dry cured, A. Also, an EM-5 vibrating wire strain gage was suspended inside of cylinder 1W. The EM-5 gage has an internal thermocouple and its response capability was being investigated. All of the concrete cylinders where plastic capped and covered with a plastic sheet until an age of around 10 hours. At that time the plastic cylinders were removed and the specimens were placed in their predetermined locations. Thus, thermocouples \#1 through \#3 cylinders were submerged in the temperature isolation rooms water-bath in the concrete research laboratory. The responses were seen and plotted in Figure 4.16. This figure shows the effect of the 
cylinders submerged in $80^{\circ} \mathrm{F}$ water, compared to the cylinders left in the ambient temperature. This effect can be further seen in Figure 4.17. The ambient temperature is not a truly constant value but gradually falls from around $90^{\circ} \mathrm{F}$ to below $70^{\circ} \mathrm{F}$. This allows those cylinders to cool more gradually than the water-bath cylinders. These effects are typical thermodynamic principles and definition of temperature transfer, but this is not the focus here. The system changes the cylinders were subjected to in these tests are examples of weather changes in the field concrete construction and the rapid change in temperature value. The concrete cylinders can be considered small compared to the water-bath and thus transfer the heat more quickly. The long, relatively thin newly constructed concrete slabs also can be considered small when considering introducing atmospheric weather conditions. It has been seen that a definite rise in temperature occurs during the heat of hydration process. It has also been seen that the rate of heat transfer directly relates to these tests. It can be assumed that after the initial heat of hydration, the concrete is susceptible to drastic changes in surrounding temperature. This can be very important when investigating the temperature behavior of a concrete slab. For instance, at the beginning of a new slab the concrete may have passed its maximum heat of hydration temperature while at the other end it is just beginning to cure as nighttime comes. The beginning end of the slab will be influenced by the much cooler temperatures for a longer period of time compared to the end of the slab, which reaches its maximum heat of hydration early in the morning hours and then is subjected to warmer daytime temperatures.

This is the key point of seeing when the heat of hydration reaches a maximum and how the concrete reacts to changes before and after the maximum is reached. The other 
purpose was to check the response of the EM-5 gages internal thermocouple compared to the ones used in these studies. Figure 4.18 shows that the thermocouples produce reasonably accurate results. Thus, the EM-5 temperature readings may be used in the analysis to correct thermal strains in the results from the differing modulus values and fluctuating temperatures.

\section{5b I-80 Danville, PA Concrete Thermal Coefficient Test and Results}

The embedded EM-5 strain gage was believed to react well in response to compression loading tests on early-age concrete cylinders. The concept of testing for the thermal coefficient of the concrete was believed to be possible with the vibrating wire gage technology. The thermal coefficient of the gage was obtained from the manufacture. Therefore, the change in strains measured and the thermal strain from the gage itself removed, revealing the change in strain of the concrete cylinder. The change in strain could then be divided by the change in temperature giving the approximate thermal coefficient of the concrete.

The gage design allows for the gage to relax or tighten changing the frequency, which changes the reported strain. The wire is not in contact with the concrete, but only with the end flanges. The flanges are secured by the concrete, which restricts any wire behavior strains to be transferred. The differential strain readings from the wire's thermal behavior could then be removed justifiably.

The concrete cylinder with the embedded EM-5 gage used in the July 1999 compression testing was used for these thermal tests. The specified cylinder was watercured after being made and removed only for compression tests. After the $28^{\text {th }}$ day 
compression testing was completed, the thermal testing was begun. A thermal test procedure was determined for the concrete cylinder and EM-5 gage. The test performed was not typical of standard, but was modified for the situation and type of specimen.

The concrete cylinder was transferred from the water-bath to a five-gallon plastic bucket filled with the water from the water-bath. The cylinder was non-loaded for all thermal tests to remove possible differential strain behavior. Temperature measurements were to be taken from inside the cylinder by an embedded thermocouple and the EM- 5 gage itself and the surrounding water in the bucket by another thermocouple. Variation in temperature behavior from the cylinder and the surrounding water could be checked and evaluated to see if differential temperature strains could effect final results.

The structure's laboratory at West Virginia University has a large refrigerator that could hold the five-gallon bucket. The bucket with the submerged cylinder was placed in the refrigerator over night so that a constant cooler temperature was achieved. The bucket was removed from the refrigerator and placed in the research laboratory. EM-5 gage readings were taken at varying times as the water and cylinder temperature rose toward the laboratory ambient temperature. The process was gradual because of the water behavior and thermodynamic properties.

The thermal coefficient could be determined also by cooling the specimen. This was performed in another non-typical way. The bucket needed gradually warmed, but again the thermal chamber was unavailable. The test was being performed in early August 1999. The daytime temperatures reached around $95^{\circ} \mathrm{F}$. Therefore, a hatchback vehicle was used as the heating chamber. The bucket was placed in the hatchback and covered from direct sunlight. The specimen was left for several hours to reach a near constant 
temperature throughout. The bucket was removed and again placed inside the research laboratory to gradually cool to room temperature. The EM-5 readings were checked periodically during the cooling process and recorded for later evaluation.

Data manipulation from the heating and cooling tests resulted in estimations of the thermal coefficient of the I- 80 mix. The results ranged from 4.05 to $4.35 \mu \mathrm{in} / \mathrm{in} /{ }^{\circ} \mathrm{F}$. The means of determining the coefficient values is questionable due to slight differential temperature behavior. Yet, the rate of change of temperature and corresponding strains determined do reveal consistent behavior. Results should be further evaluated, but the resulting thermal coefficient is believed to be representative of the I-80 Danville, PA concrete mix design. Additional thermal coefficient of concrete testing was performed in the field during the Corridor H near Elkins, WV slab investigation. These results can be seen in Chapter 8.4. 
CYLINDER TEMPERATURE TEST RESULTS

DURING COMPRESSION TESTING

07 July 1999 Time $=0$ at 1100 hrs

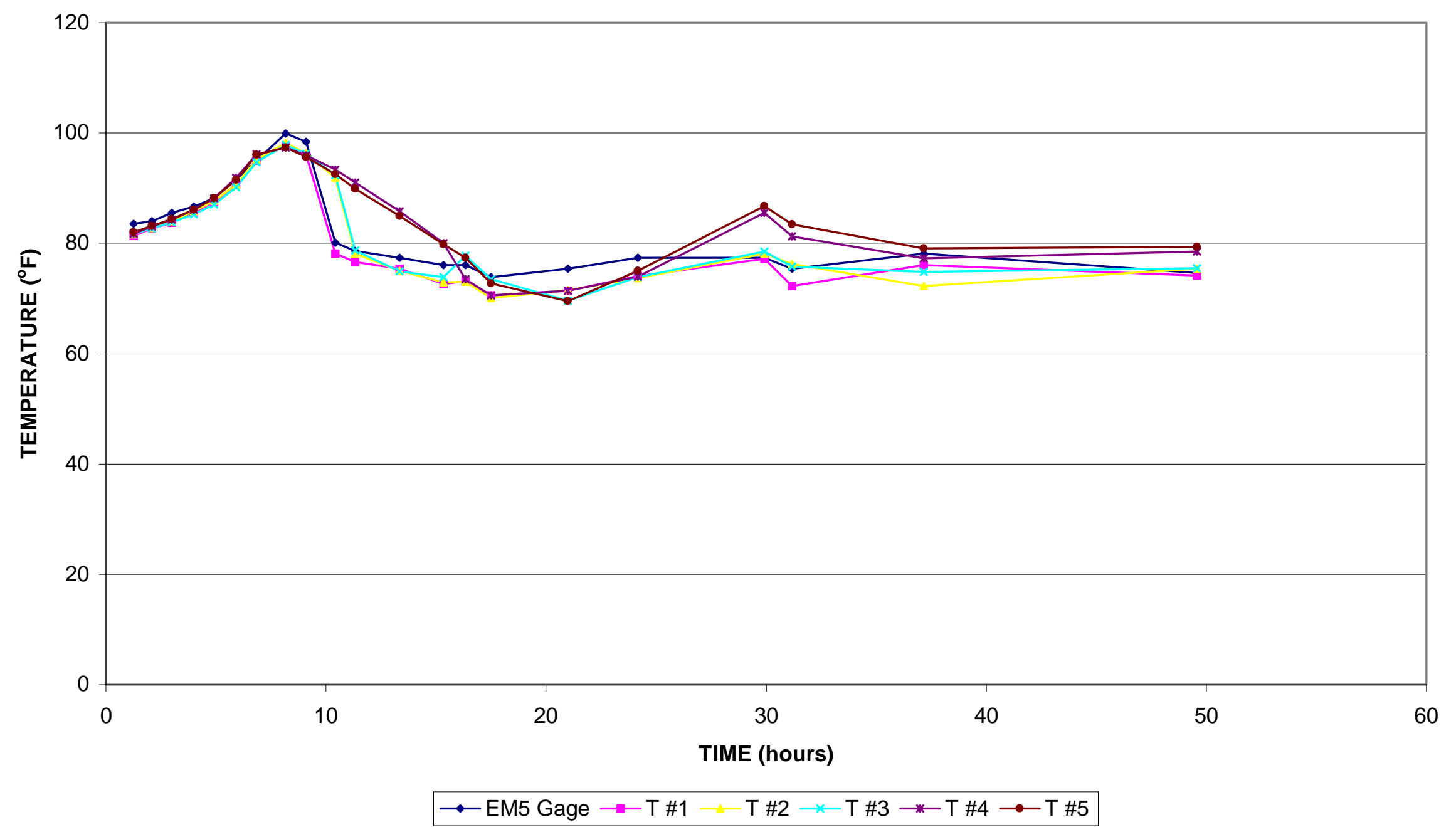

Figure 4.16: Temperature Test Results, July 1999 tests 
AMBIENT AND AIR-DRY CURED CYLINDER

TEMPERATURES versus TIME

07 July 1999 Time $=0$ at 1100 hrs

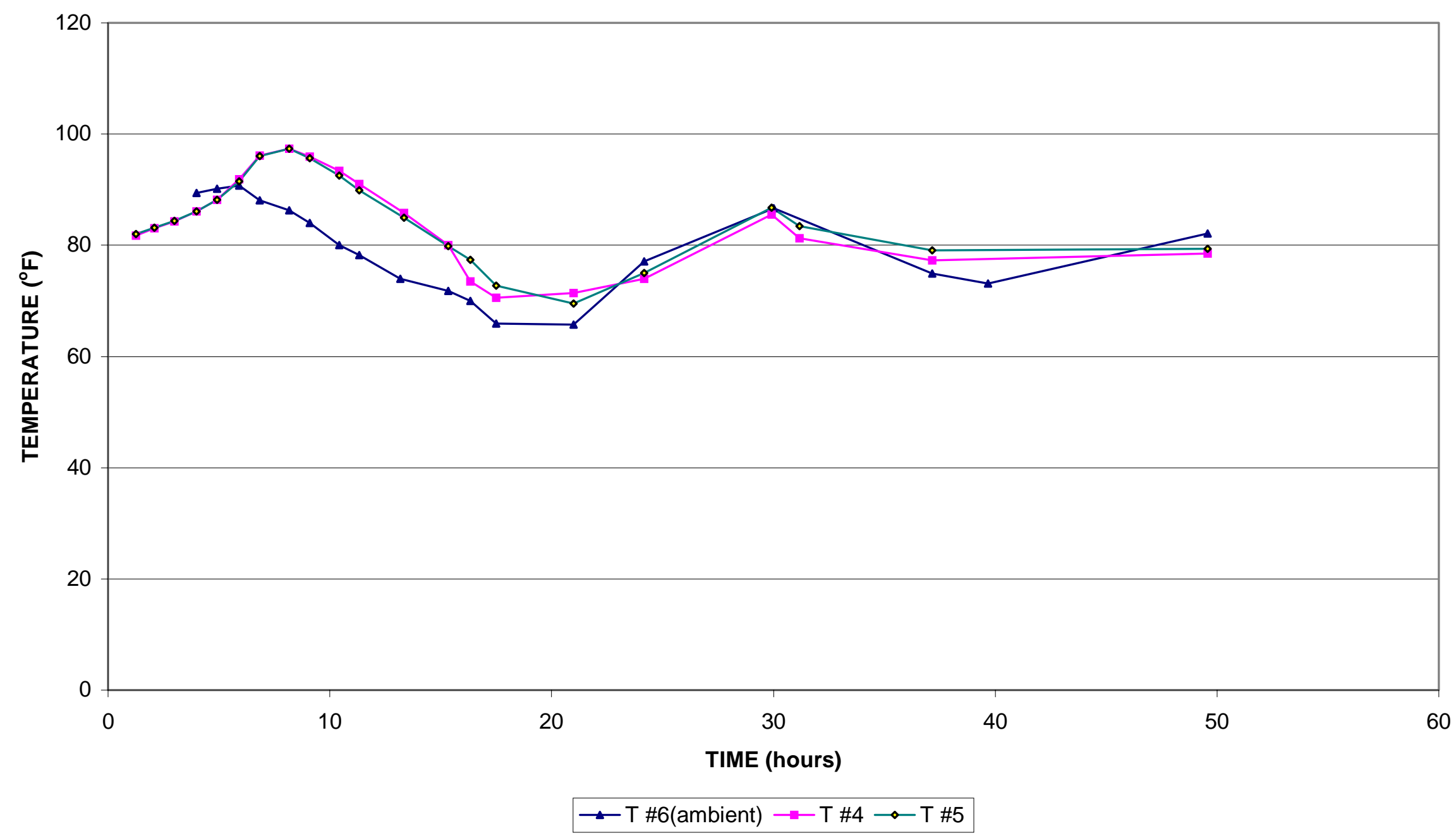

Figure 4.17: Ambient and Air-Dry Cured Cylinder Temperature Behavior Comparison 


\section{EM-5 GAGE AND THERMOCOUPLE \#1 versus TIME}

\section{July 1999 time $=0$ at $1100 \mathrm{hrs}$}

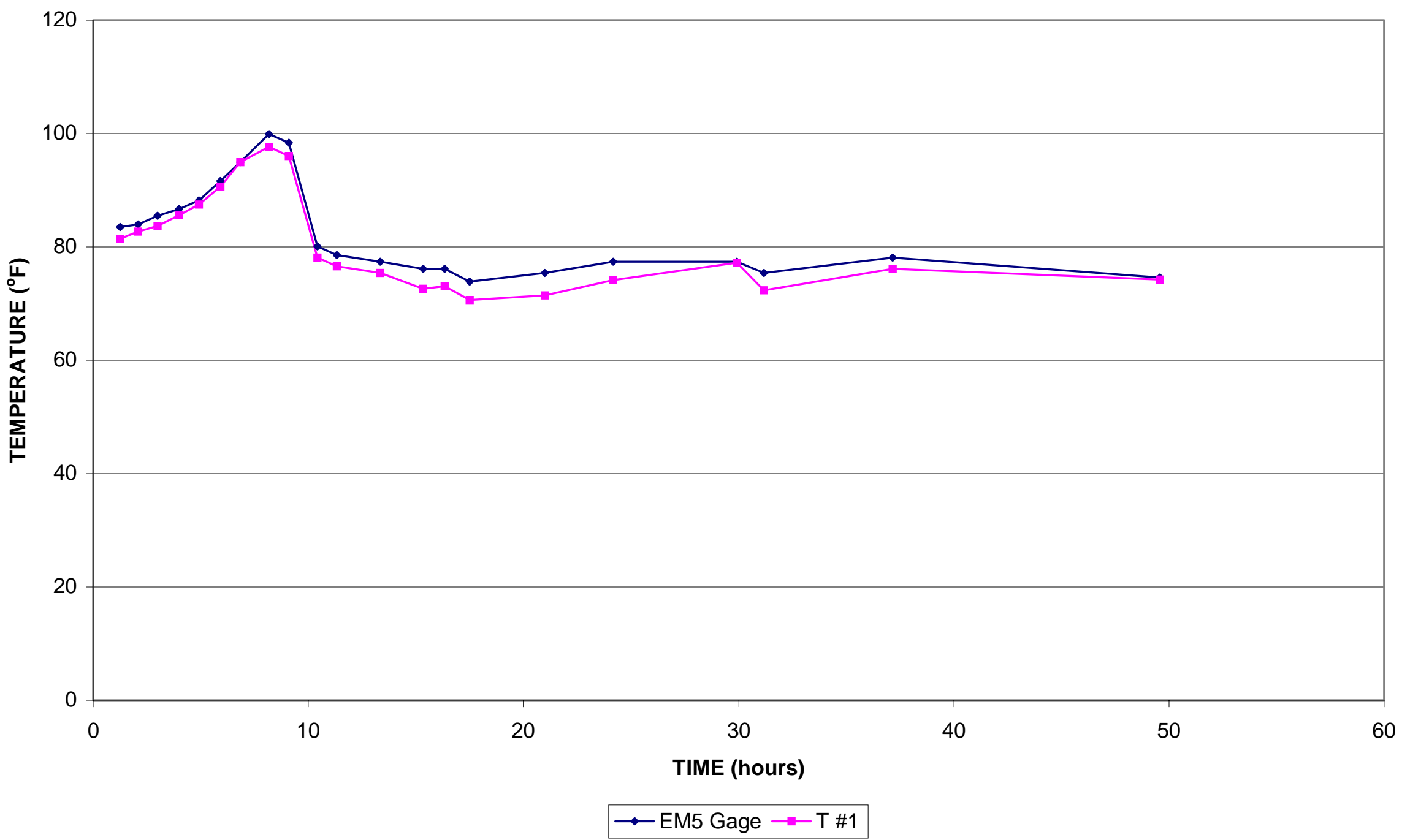

Figure 4.18: Temperature Behavior Comparisons of Embedded EM-5 Gage and Thermocouple \#1 


\section{CHAPTER 5: PCC SLAB CONSTRUCTION INVESTIGATIONS:}

\section{Chapter 5.1 General}

The crack formation history and detailed temperature profile histories of a newly constructed PCC pavement was required to visualize the slab behavior as well as modify the analysis procedure as needed. The field investigations performed utilized the varying characteristics by location concept in the revised data collection schemes. Many of the methods and equipment needed to obtain the data from field investigations was discussed in Chapter 3. The temperature, crack width and strain measurements equipment and operations are thoroughly discussed in that chapter.

The information obtained from the previous works gave a basic understanding of some of the behavioral characteristics of newly placed concrete pavements. It was believed that the early formation of joint cracks, less than 24-hours old, were opening wider than later crack formations, 48-hours on. All of the joint crack widths were shown to increase over time, which is reasonable due to shrinkage of the concrete. The shrinkage alone was not believed to create enough stress to cause the over-all frequency of cracking and crack sizes. Other stress developments in the concrete slab were evaluated and shown in the stress analysis documented in Phase I.

New pavement construction was to be monitored at least as long as the initial joint crack formation's occurred, 24 to 72-hours and the temperature histories from different locations converged. The investigation timeline was project-specific.

Each field site construction process was similar in technique. Slip-form pavement construction was a requirement for the construction method. The pavement process was investigated during June 1998 pavement construction near Marianna, PA. The 
observations made at that time allowed for detailed field investigation instrumentation and monitoring schemes to be developed for slip-form pavement construction. The types of instrumentation's and equipment needed to obtain the required data were determined by the specific construction. These details can be seen in Chapter 3 . 


\subsection{SITE INVESTIGATION PREPARATIONS:}

\section{2a. Compatible PCC Construction}

A search for new construction similar to that studied during Phase I was undertaken. A state by state search was performed to locate new PCC construction with compatible pavement design and construction technique. The initial search began in late summer 1998. The Phase II research was not approved until September 1998. Many state departments of transportation engineers were contacted during the search. Telephone conversations with other state engineers revealed which states were utilizing ATPBC in new PCC highway pavement construction, which were limited in number. Pennsylvania was the only state found during the 1998 search that had new construction of PCC pavement scheduled in the remaining 1998-construction season or into the mid 1999construction season. There were no other states found which had sufficiently compatible sites because the use of ATPBC is not widely used yet. The following characteristics were sent to any of the prospective states via e-mail to check the comparability of the construction designs. 


\section{Table 5.1}

\section{PAVEMENT SPECIFICATIONS}

Cross-section details:

Concrete Slab:

Thickness $=10$ to 12 inch (254 to $304.8 \mathrm{~mm}$ )

Width $=24 \mathrm{ft}$ (with longitudinal joint)

Note: Slip-form pavement with no wire mesh or reinforcement

Base Course:

Thickness $=6$ inch $(152.4 \mathrm{~mm}$, may vary $)$

Note: Asphalt stabilized, open-graded (permeable) free draining base Synthetic separation/filter fabric beneath base course

Transverse Thermal Contraction Joints:

Spacing $=15 \mathrm{ft}$ (may vary)

Shear transfer devices:

Dowel bars: Length $=18$ inch $(457.2 \mathrm{~mm})$

Diameter $=1.5$ inch $(38.1 \mathrm{~mm})$

Note: coating is formulated grease compound (Tectyl bond breaker 506)

(may vary)

Joint Sealer: Low modulus silicon sealant

\section{Mix Designs:}

Concrete, WVDOT classB:

WVDOT SI metric standard specifications, adopted 1994, section 601.3

Proportioning Table 601.3.1, page 275

28 day compressive strength $=21 \mathrm{Mpa}(3000 \mathrm{psi})$

Target cement factor $=335 \mathrm{~kg} / \mathrm{m}(21 \mathrm{pcf})$

Maximum water content $=0.48 \mathrm{~L} / \mathrm{kg}$ cement

Standard size of aggregate $=$ AASHTO \#57 or \#67 (limestone)

Entrained air $=7 \%$

Note: Our laboratory mix design

1:2:3 (cement: fine aggregate: coarse aggregate)

$\mathrm{w} / \mathrm{c}=0.45$

$7 \%$ air (by volume)

$\mathrm{f}_{\mathrm{c}}{ }^{\prime}=3000 \mathrm{psi}$

Asphalt stabilized, open-graded (permeable) free draining base:

98\% \#57 crushed limestone

$2 \%$ bitumen by weight

Note: Mixed at greater than $250^{\circ} \mathrm{F}$ 
The previous table was used as a baseline for the pavement design compatibility check. The variation of pavement design was taken into consideration during the search. The specifications and mix designs were only a reference for comparisons to be made and not to be strictly matched. Some states were located that did have some PCC construction scheduled. The base coarse used at those sites utilized non-stabilized stone base, or open graded material only. The base material stabilization was critical because better similarity in the coefficients of friction between the concrete slab and the base might be found. The stabilized base coarse could reveal similar pavement crack behavior, regardless of the stabilizing material, as long as they had similar strength and bonding characteristics.

The new PCC construction sites found during the search were not precise matches in design, but were sufficiently similar to allow behavioral characteristics and other conclusions to be made in varying site investigations. The sites investigated are further discussed in Chapters 6 through 9.

\section{2b. Personnel and Investigation Time Frames}

The first site investigation was done on a section of I-79 southbound lanes near Marianna, PA. The continuous monitoring was to be continued until sufficient crack formations had occurred. One personnel performed the instrumentation and continuous investigation. The crack formation was expected to occur more quickly because of the much lower nighttime forecast temperatures. The investigation of the Marianna concrete slab section was continuous for around 43 hours after the initiation of concrete placement. At that time, the initial joint crack formation was believed to be complete. It 
was determined at that point that the next investigation required more than one personnel or could not be continuously monitored. Details of the I-79 Marianna investigation can be seen in Chapter 6.

The second site investigation occurred less than one week after the Marianna investigation. It was located on a section of I-80 eastbound lanes near Danville, PA, which was a 5-hour one way drive. Two personnel were sent to perform the slab instrumentation and investigation. They were to continuously monitor the slab until sufficient cracking had occurred and not less than 48-hours. Details of the I-80 Danville investigation can be seen in Chapter 7.

The last of the three sites continuously investigated was a section of Corridor $\mathrm{H}$ near Elkins, WV in October of 1999. The preparation time for this site was slightly more than the other two investigations. Three personnel were sent to the site for the instrumentation and continuous investigation of the new PCC highway pavement construction. The section was investigated for around 72 continuous hours after initial concrete placement. Long overlapping shift work was used to optimize the data collection. The details of the Corridor $\mathrm{H}$ investigation can be found in Chapter 8 . 


\subsection{INVESTIGATED PCC SLABS INTRODUCTION:}

\section{3a. June 1998 PCC Slab Observation}

This pavement was placed on June 15, 1998 near the Marianna, PA exit of I-79 in the northbound lanes. This slab section was not continuously monitored, but only observed for the construction process and crack formation. The PCC pavement was 11 inches thick, 24 feet wide and was placed on a 4 inch thick lean base course on a 6 to 8 inch course of aggregate, PennDOT class $2 \mathrm{~A}$. The section placed was approximately 980 feet in length. The concrete slab was coated with white curing compound at the required application rate, after final texturing was applied to the pavement surface. The transverse saw joint spacing was 20 feet, which is typical in PennDOT construction. The saw cutting began when the pavement was set enough for raveling not to occur. All joints were cut prior to 24 hours after the start of the pavement construction. The initial cut was 3/16 inch wide and 4 inches deep. The joint was temporarily sealed with an elastic, Styrofoam cord to keep out debris. The joint was to be widened to $5 / 8$ inch cut 2 inches deep at a later date after the concrete shoulders were added. The joints were then filled with a permanent elastic V-shaped rubber seal, which was not observed. The sealant design was not the same as the design described in Phase I, but the cracking behavior was a concern for comparison. It was found that the transverse joint cracking on the inside and outside lanes were in the same joints and of similar size. This was mainly due to the fact that the longitudinal joint cracks formed at an age later than 120 hours, the total time observed, so the longitudinal joint was not affecting the early age transverse cracking behavior of the slab. Therefore, only one side of a slab's cracking behavior need recorded. The transverse joint crack formations were documented at 24, 78 and 120 
hours after placement for both the northbound inside and outside lanes, designated as NBIS and NBOS, respectively. The widths and sporadic behavior appeared to be consistent with the documented formations from Phase I (See Figures 5.1 and 5.2). The joint numbering sequence starts at zero at the very beginning of that day's construction. The figures show that the joint crack widths are of similar size and sporadic behavior as seen before, even though the slab was placed on a lean base course. The cracking behavior observed appeared to be similar to that of previously monitored pavements. This observation would possibly allow for the monitoring of pavements placed on other types of bases and still be able to get results that could be useful in understanding the cracking problem. To understand how to correct or manage the undesirable transverse joint crack movements being observed, it was crucial to monitor as many compatible sites as possible.

Some climatic data was obtained from the Washington County airport, which was approximately ten miles away from the Marianna slab construction site. Within reason because of the proximity of the locations, the obtained ambient history could be assumed to be similar (See Figure 5.3).

\section{3b. Monitored Site Introduction}

The information obtained from the June 1998 observation was instrumental in the development of preparation schemes needed for the complete site investigations that were performed during Phase II. Specific data to be collected from the site investigations were determined and obtained. Slab temperature histories needed to be known for each slab site so that detailed comparative analyses could be performed. Continuous monitoring 
with thermocouples was the only way to obtain this data. The transverse joint crack formations needed to be found by time and location of crack width growth. By knowing the crack development pattern by size and location, maximum stress developments within the slab by location may be visualized.

The climatic histories during the site investigations were obtained to evaluate any possible variations in the slab behavior. The complete climatic data effects on concrete was beyond the scope of this research, but the ambient temperature histories effect on the concrete slab temperature histories was important to the varying slab behaviors.

Three new PCC highway pavement constructions were continuously investigated during this study. Two PCC pavement constructions were monitored in October of 1998 and were found in Pennsylvania. One was again near the Marianna, PA exit on I-79, but this time in the southbound lanes. The other was near the Danville, PA exit on I-80 in the eastbound lanes. The third new PCC slab construction investigated was a section of Corridor H near Elkins, WV in October of 1999. The I-79 and I-80 highway constructions were on existing highway layouts where no additional earthwork was needed. The Corridor $\mathrm{H}$ construction was a completely new highway. The early-age, slab behavior may not be affected by the sub-grade compaction or stability, but the longterm behavior may.

The cross-sectional designs of the three investigated slabs can be seen in Figures 5.4a, $\mathrm{b}$ and c. Figure 5.4a is a representation of the I-79 Marianna, PA pavement design, Figure 5.4b is the I-80 Danville, PA pavement design and Figure 5.4c is the Corridor $\mathrm{H}$ near Elkins, WV pavement design. The investigations were of the 24 -feet wide concrete slab placement and behavior, not including the addition of shoulders or added lanes. 
Further discussion of the cross-sectional and overall pavement designs can be seen in each of the investigated site's chapters. 
NBOS JOINT CRACK FORMATION (PROJECT SR0079-Q10)

Placed 15 JUNE 1998, from 0700 hrs until 1200 hrs

Time for crack observation is hours after $1200 \mathrm{hrs}$

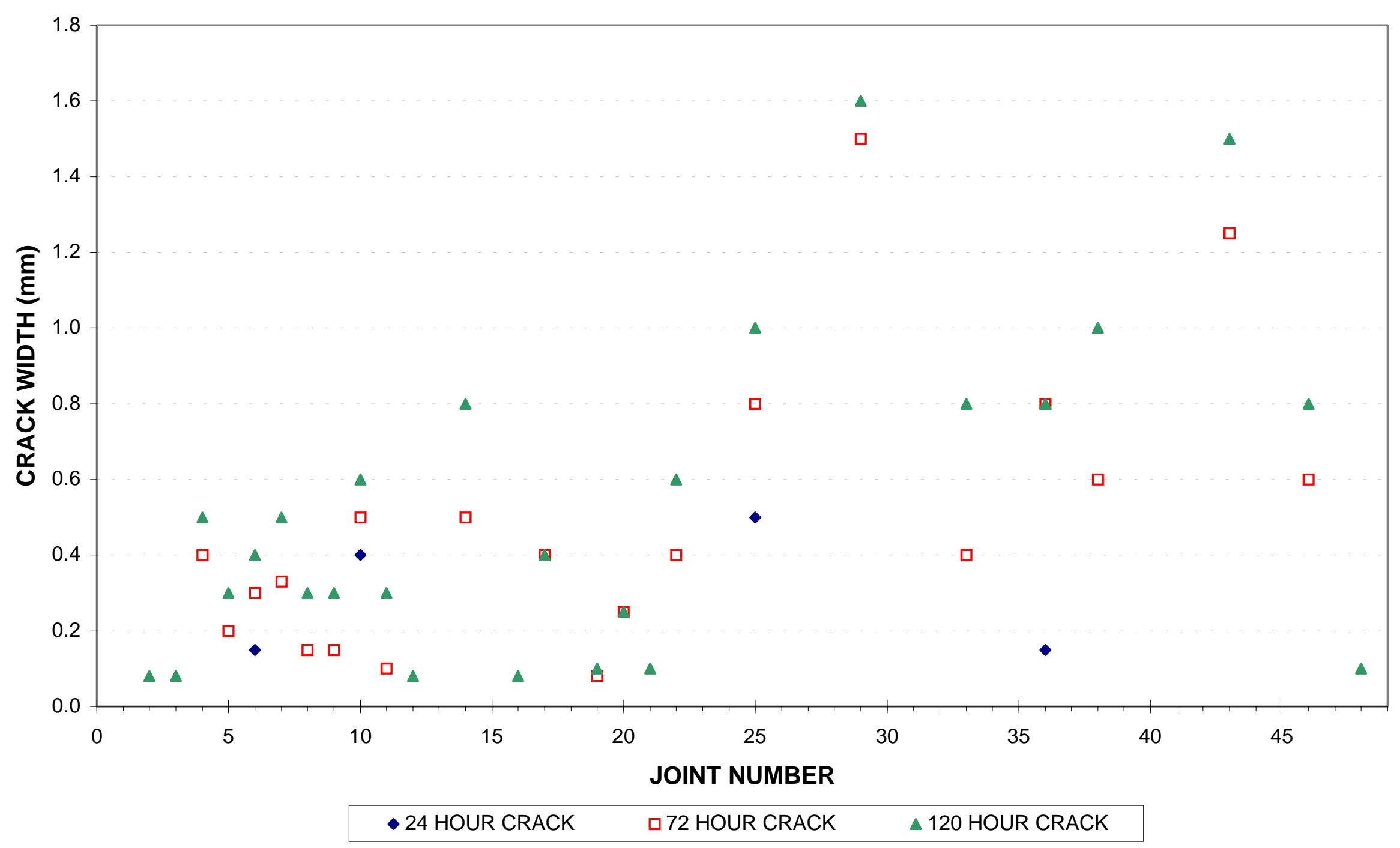

Figure 5.1: North Bound Outside Lane Joint-crack Formation, June 1998 I-79 Marianna, PA 


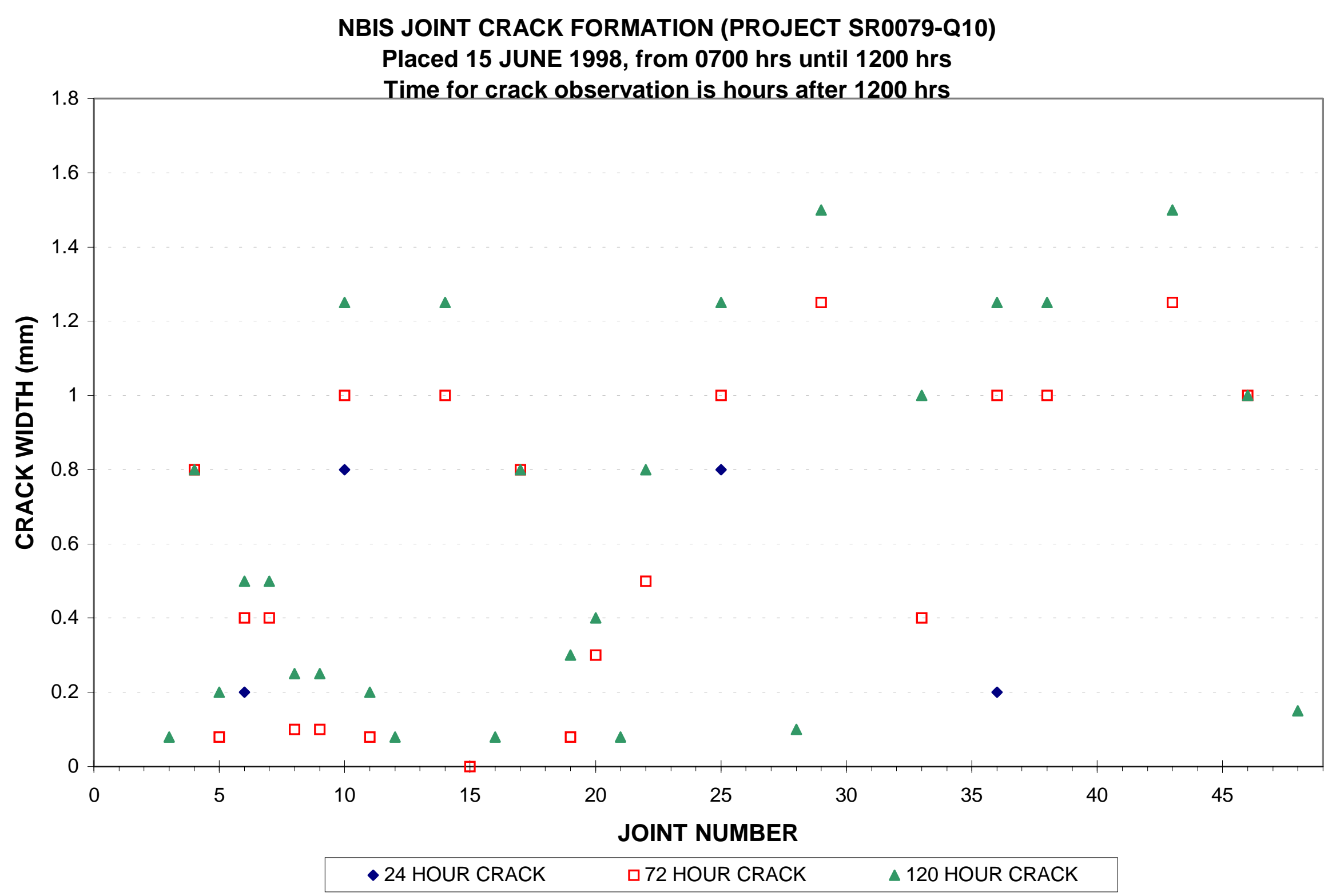

Figure 5.2: North Bound Inside Lane Joint-crack Formation, June 1998 I-79 Marianna, PA 


\section{Washington County Airport Ambient Temperature History \\ (Ten Miles from I-79 Marianna Site) \\ Time $=0$ at 1200 hrs 15 June 1998}

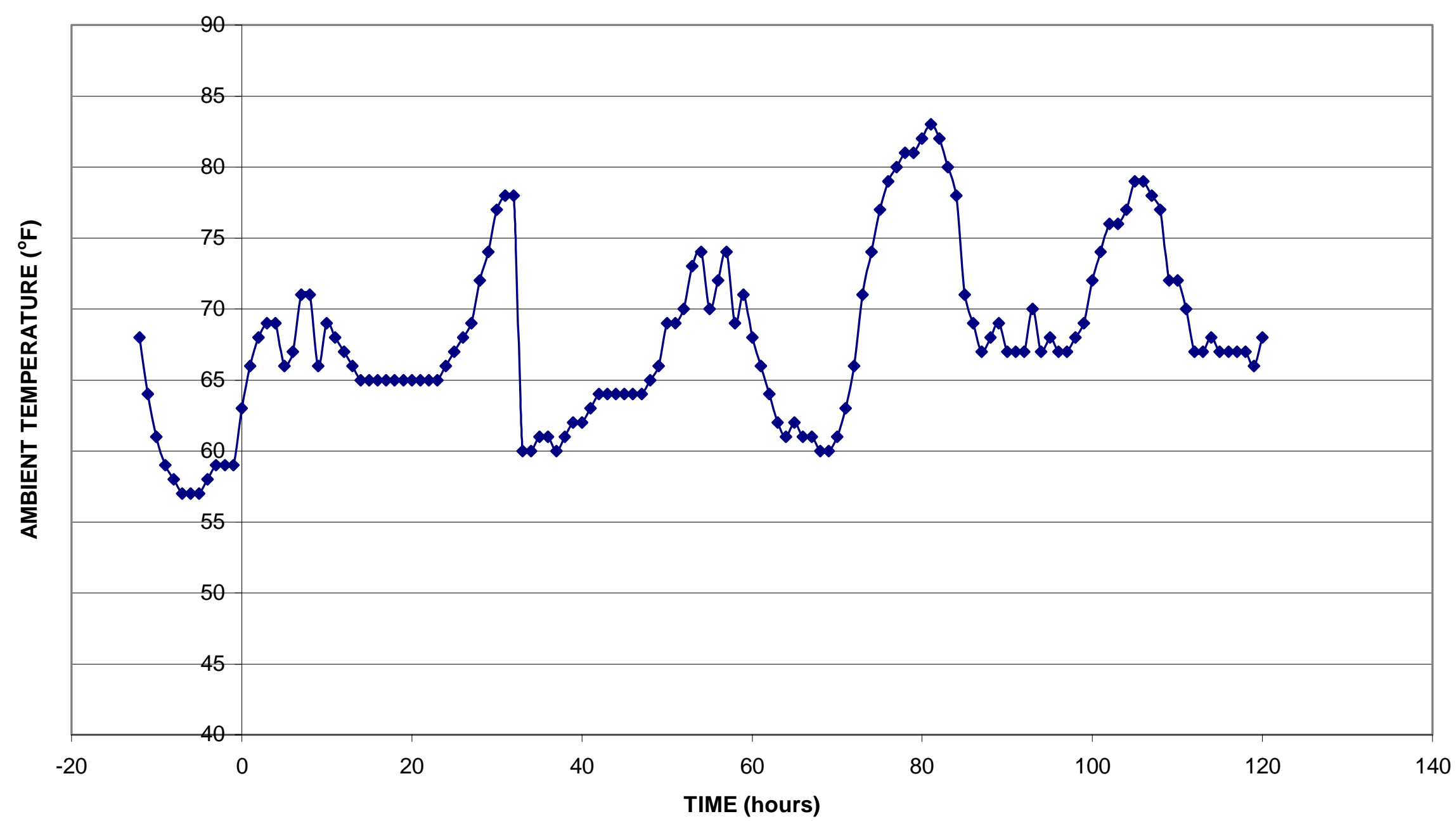



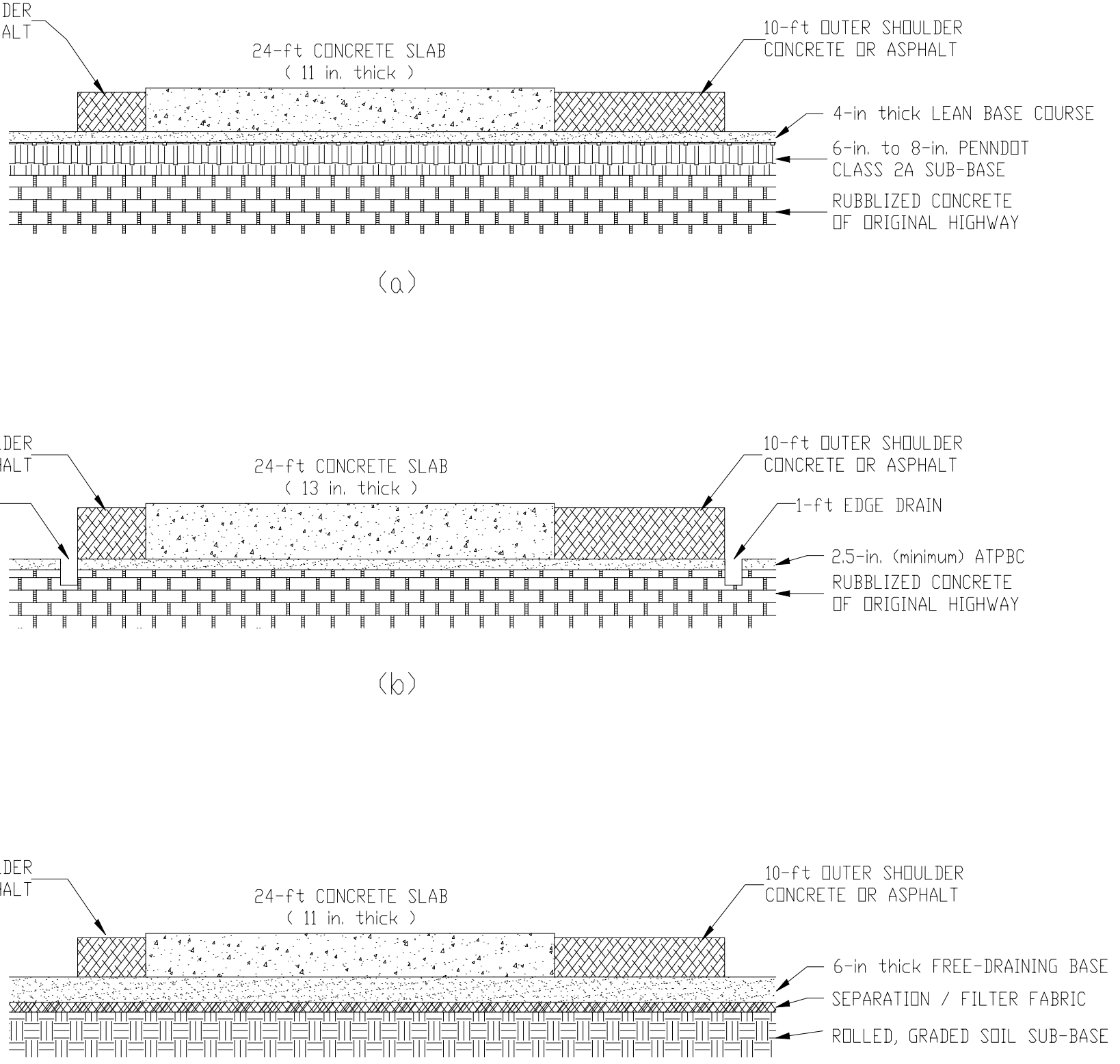

Figure 5.4: Pavement Cross-sections: a) I-79 Marianna, PA design, 


\section{CHAPTER 6: I-79 Investigation near Marianna,PA October 9, 1998:}

\subsection{Introduction and Site Description}

The first PCC concrete pavement construction instrumented and continuously monitored was a section of I-79 southbound lanes near the Marianna, PA exit (state project number SR0079-Q10, federal project numbers OAC-X124-185, OOF-X124184/OOF-Z124-184 and Pennsylvania contract 124203). The concrete slab section investigated was placed on October 9, 1998 beginning at 0730 hours. It was of the same design and general location as the pavement observed on June 15, 1998, discussed in Chapter 5.3a. This pavement section was approximately 2570 feet in length, which was much longer than the pavement observed in June 1998, (980 feet), and was being constructed in the opposite lanes. The slab was 11 inches thick, placed on a 4-inch thick lean base course on a graded 6 to 8 -inch aggregate sub-base course. Separation/filter fabric under the base course was not utilized in this design because of the additional subbase course over existing base courses from the previous highway pavement. (See chapter 3.2 and 3.3 for mix specifications.) The cross-section design can be seen in Figure 5.4a. The concrete slab was cured with white curing compound applied after the surface texturing was performed. After allowing sufficient time for the concrete set to avoid raveling, the transverse joints were saw-cut. The slab construction was performed by A \& L Inc.

The slab was monitored for 43 continuous hours. The thermocouples were placed into groups at different locations along the slab length. Temperature readings and transverse joint crack developments were monitored as often as physically possible. Slab temperatures were taken as near to hourly as possible and the crack width measurements 
by location and time were checked periodically throughout the investigation. The equipment used for the site investigation was discussed in chapter 3.5.

The transverse joint crack formations were monitored on the outside lane edge only. This was because of the similarity of crack formation found during the June 1998 observation. The transverse joints were all saw cut prior to 22 hours from the construction start time and only after the initial concrete set to avoid raveling. The initial saw cuts were of the same width and depth as the June 1998 section's, being 3/16 inch and 4 inches (approximately h/3), respectively. (See Table 6.1 Transverse joint saw cutting and Figure 2.7a, b and c Transverse saw-cut design) All concrete slab cracking observed occurred at saw cut locations, but not at every one joint as assumed and required by design. The cracks were checked for their location and size at different times during the investigation, as described in chapter 3.5c.

\section{Table 6.1}

TRANSVERSE JOINT SAW CUTTING 09 OCT 98 I-79 Southbound Lanes Investigation near Marianna, PA Depth of saw-cuts: 4 inch (approximately $\mathrm{h} / 3$ ) Time $=0$ at 0730 hours

\begin{tabular}{|c|c|c|c|c|c|}
\hline DATE & \multicolumn{1}{c}{$\begin{array}{c}\text { INITIAL } \\
\text { CUT }\end{array}$} & \multicolumn{1}{c}{$\begin{array}{c}\text { FINAL } \\
\text { CUT }\end{array}$} & $\begin{array}{c}\text { TOTAL } \\
\text { TIME }\end{array}$ & $\begin{array}{c}\text { NUMBER } \\
\text { of JOINTS }\end{array}$ & $\begin{array}{c}\text { RATE } \\
\text { (Joints/hr) }\end{array}$ \\
\hline \hline 09-Oct-98 & $1900 \mathrm{hrs}$ & & $10.5 \mathrm{hrs}$ & 132 & 12.57 \\
\hline 10-Oct-98 & & $0530 \mathrm{hrs}$ & \multicolumn{3}{|c}{} \\
\cline { 1 - 2 }
\end{tabular}

Note: The longitudinal joint was not cut within the observation time. But was to be cut within 72 hours after placement by PennDOT specification.

The slab temperature readings were taken at five different locations along the slab at $50,550,1050,1950$ and 2450 feet from the starting location of that day's construction. These different locations were being monitored to check the assumption from the Phase I analysis that the temperature histories could be assumed to be constant over the slab 
length. They were checked at four different depths at each location being at the surface, two inches down from the surface (top), the mid-depth 5.5 inches down (middle) and one inch up from the base course (bottom), as discussed in chapter 3.5b. Manufactured typeK thermocouples were inserted in the previously mentioned different slab depths' 8 inches into the outside edge of the pavement to measure the internal temperatures. Also, an infrared non-contact temperature gun was used to measure the slab surface temperature at the varying group locations.

The stresses in the slab are due to both the cooling of the slab or the change in uniform temperature and due to the temperature differences from the bottom to the surface of the slab which cause curling stress. The joint crack formations may be correlated to the location where the axial tensile stress development exceeds the tensile strength of the slab at various times. It was assumed during this study that the slopes of the highway pavements, typically $6 \%$ or less, have little to no effect on the joint crack formations of a slab section. The concrete slabs have been seen not to begin cracking until after complete initial concrete set. The long, relatively thin concrete slab's bond to the base course becomes strong by that time. Therefore, the internal self-weight stresses developed, or Slump-effect from the slab slope, are minimal compared to the stresses of thermal and shrinkage origin. Also, turns in the highway slabs were found to have little effect in the crack formation, as seen in the June 1998 observation. Curvatures of highway pavements are typically gradual which allows the inside and outside lane stress development over a given cross-section to be generally equal. Slopes and curvature in the pavement sections have been neglected in this study because of these reasons. The analysis of any slab may be performed assuming a level, straight section of concrete pavement. 
The next two sections include the temperature data and transverse joint crack data collected from the Marianna concrete slab investigation. Further discussion of the data collection and slab behavior can be seen in section 6.4 and chapter 9 . 


\subsection{Temperature Data, I-79 Marianna}

The five locations along the slab where temperature measurements were taken were designated into group numbers. Group \#1 was at the 50-foot location, Group \#2 at the 550-foot location, Group \#3 at the 1050-foot location, Group \#4 at the 1950-foot location and Group \#5 at the 2450 location. (See Figure 6.1a. Thermocouple-layout) The temperature readings collected at each location were at different times due to the length of the slab. A common time scale was required so that the information could be interpreted. The common scale was set at time equal to zero at the beginning time of the construction, 0730 hours. (See Table 6.2 Converted time) Using this time scale, group thermocouple readings versus time graphs were generated. (See Figures 6.2 through 6.6: Temperature readings for Group \#1 through Group \#5)

These graphs show important curing behaviors of the concrete. At different times within the maturing slab, the figures tell us when the maximum temperature at the middepth was reached at that location. (See Figure 6.7 and 6.8) The temperature differences from the bottom to the top of the slab and when they were the greatest at each location. How they vary from each location can also be determined and visualized in the group temperature figures.

To show that the different maturity levels in the concrete slab are very important along the slab length, the data was arranged in slab temperature profiles at various times. The data reduction analysis was being performed in a spreadsheet format. There were many readings of temperature data at various times and locations to utilize. Possible means of reducing the data were evaluated. At any given time, temperatures at the five different locations could be obtained or interpolated. This was accomplished by taking data from 
equivalent times at the different group locations and placing them in slab location versus temperature graphs in terms of slab depth at different times. The times that were chosen were 11.5 hours, 17.5 hours, 23.5 hours, 27 hours, 31 hours, 38 hours and 42.5 hours. (See Figures 6.9 through 6.15) These graphs show that there are definite differences in the temperature fluctuations by location at any given time. The incremented times were chosen as a representation of the slab temperature profile histories. This was not the ideal way to utilize or analyze the data collected because much data was being discarded in this reduction process.

The climatic data for the days the slab investigation was performed was obtained from the Washington County airport. Ambient temperatures were monitored at the construction location to be compared with those obtained from the airport, which was ten miles away from the site location. The temperature histories were compared and found to have the same general trends in temperature history. (See Figure 6.16)

The lean base temperatures were also recorded and compared to the ambient temperatures observed the day of the construction. It shows the effect of solar radiation on the temperature of the surface of the base course during different times of the day. (See Figure 6.17) This could effect the bond strength development between the concrete slab and the base course as well as change the possible temperature histories of various slab locations. 


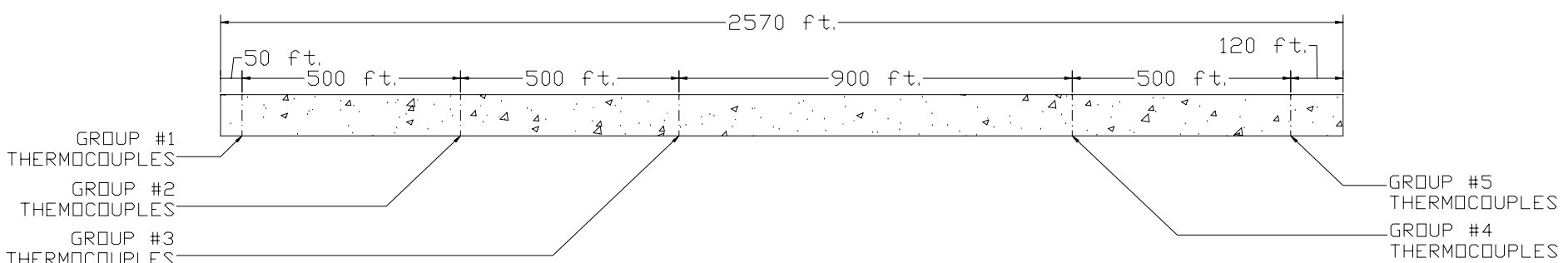

$\langle a\rangle$

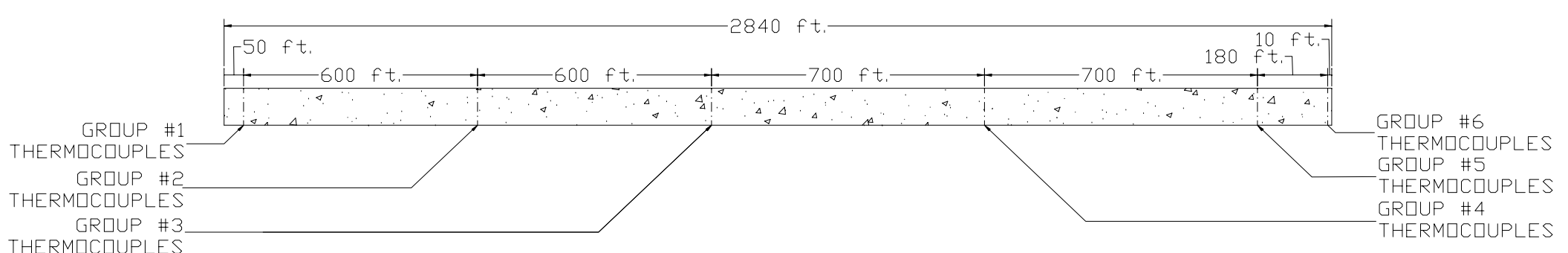

(b)

Figure 6.1: Thermocouple Group Locations for Slab Investigations:

a) I-79 Marianna, PA TC Layout, b) I-80 Danville, PA TC Layout. 
Table 6.2

Converted Time Chart

Equivalent Time Chart for Interpretation and Analysis

I-79 Marianna, PA October 9, 1998

(Time $=0$ at $0730 \mathrm{hrs}$ )

\begin{tabular}{|c|c|c|c|c|c|c|c|c|c|}
\hline Date & Hour & Mil Time & Act Time & AM/PM & Date & Hour & Mil Time & Act Time & AM/PM \\
\hline \multirow[t]{17}{*}{ 09-Oct-98 } & 0 & 730 & 730 & AM & 10-Oct-98 & 25 & 830 & 830 & \\
\hline & 1 & 830 & 830 & & & 26 & 930 & 930 & \\
\hline & 2 & 930 & 930 & & & 27 & 1030 & 1030 & \\
\hline & 3 & 1030 & 1030 & & & 28 & 1130 & 1130 & \\
\hline & 4 & 1130 & 1130 & & & 29 & 1230 & 1230 & PM \\
\hline & 5 & 1230 & 1230 & PM & & 30 & 1330 & 130 & \\
\hline & 6 & 1330 & 130 & & & 31 & 1430 & 230 & \\
\hline & 7 & 1430 & 230 & & & 32 & 1530 & 330 & \\
\hline & 8 & 1530 & 330 & & & 33 & 1630 & 430 & \\
\hline & 9 & 1630 & 430 & & & 34 & 1730 & 530 & \\
\hline & 10 & 1730 & 530 & & & 35 & 1830 & 630 & \\
\hline & 11 & 1830 & 630 & & & 36 & 1930 & 730 & \\
\hline & 12 & 1930 & 730 & & & 37 & 2030 & 830 & \\
\hline & 13 & 2030 & 830 & & & 38 & 2130 & 930 & \\
\hline & 14 & 2130 & 930 & & & 39 & 2230 & 1030 & \\
\hline & 15 & 2230 & 1030 & & & 40 & 2330 & 1130 & \\
\hline & 16 & 2330 & 1130 & & 11-Oct-98 & 41 & 30 & 1230 & AM \\
\hline \multirow[t]{8}{*}{ 10-Oct-98 } & 17 & 30 & 1230 & AM & & 42 & 130 & 130 & \\
\hline & 18 & 130 & 130 & & & 43 & 230 & 230 & \\
\hline & 19 & 230 & 230 & & & 44 & 330 & 330 & \\
\hline & 20 & 330 & 330 & & & 45 & 430 & 430 & \\
\hline & 21 & 430 & 430 & & & 46 & 530 & 530 & \\
\hline & 22 & 530 & 530 & & & 47 & 630 & 630 & \\
\hline & 23 & 630 & 630 & & & 48 & 730 & 730 & \\
\hline & 24 & 730 & 730 & & & & & & \\
\hline
\end{tabular}




\section{GROUP \#1 Thermocouple Readings (Location X=50 feet) \\ I-79 SOUTHBOUND LANES near Marianna, PA}

(October 9,1998 time $=0$ at 7:30 AM)

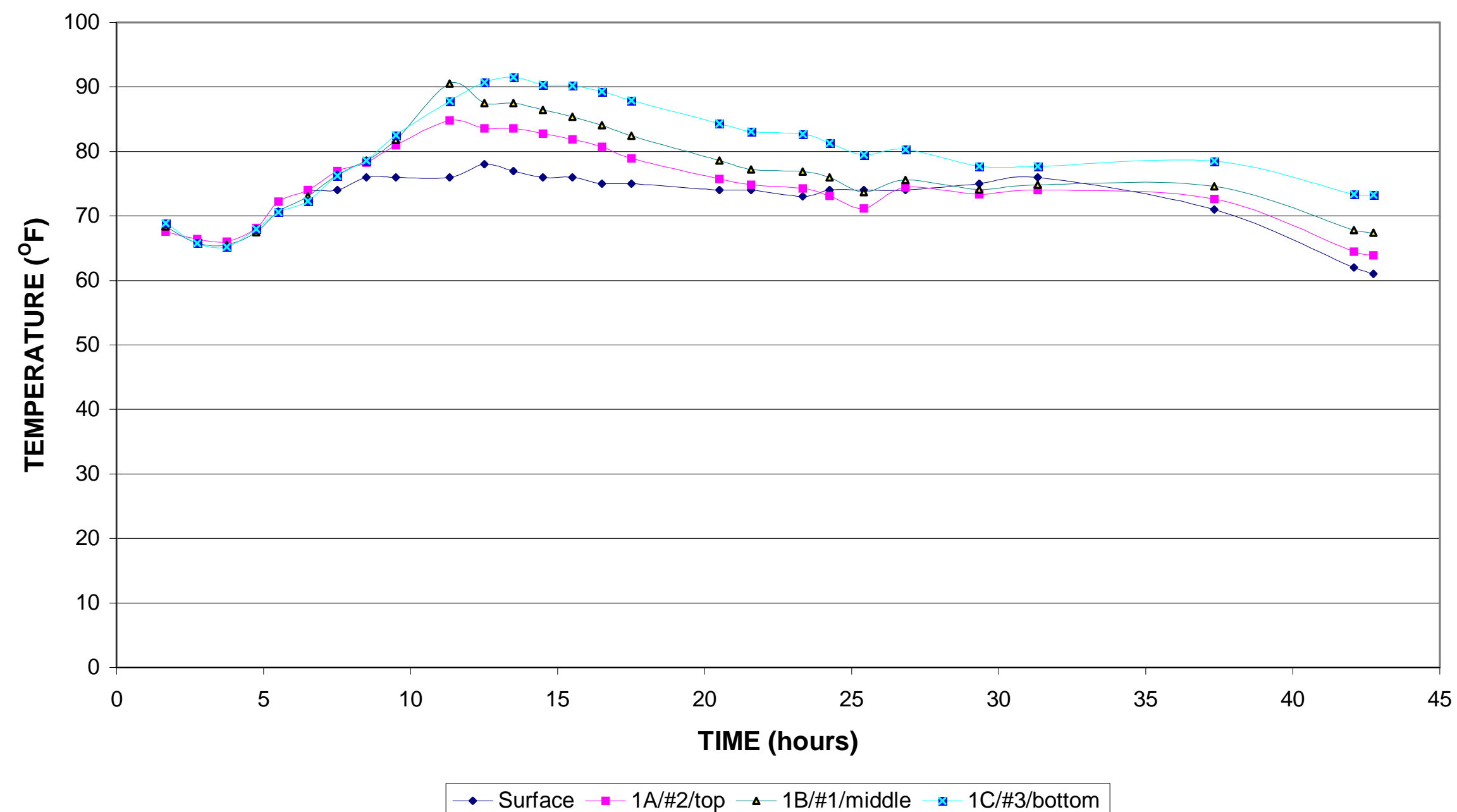




\section{GROUP \#2 Thermocouple Readings (Location X=550 feet)}

I-79 SOUTHBOUND LANES near Marianna, PA

(October 9,1998 time $=0$ at 7:30 AM)

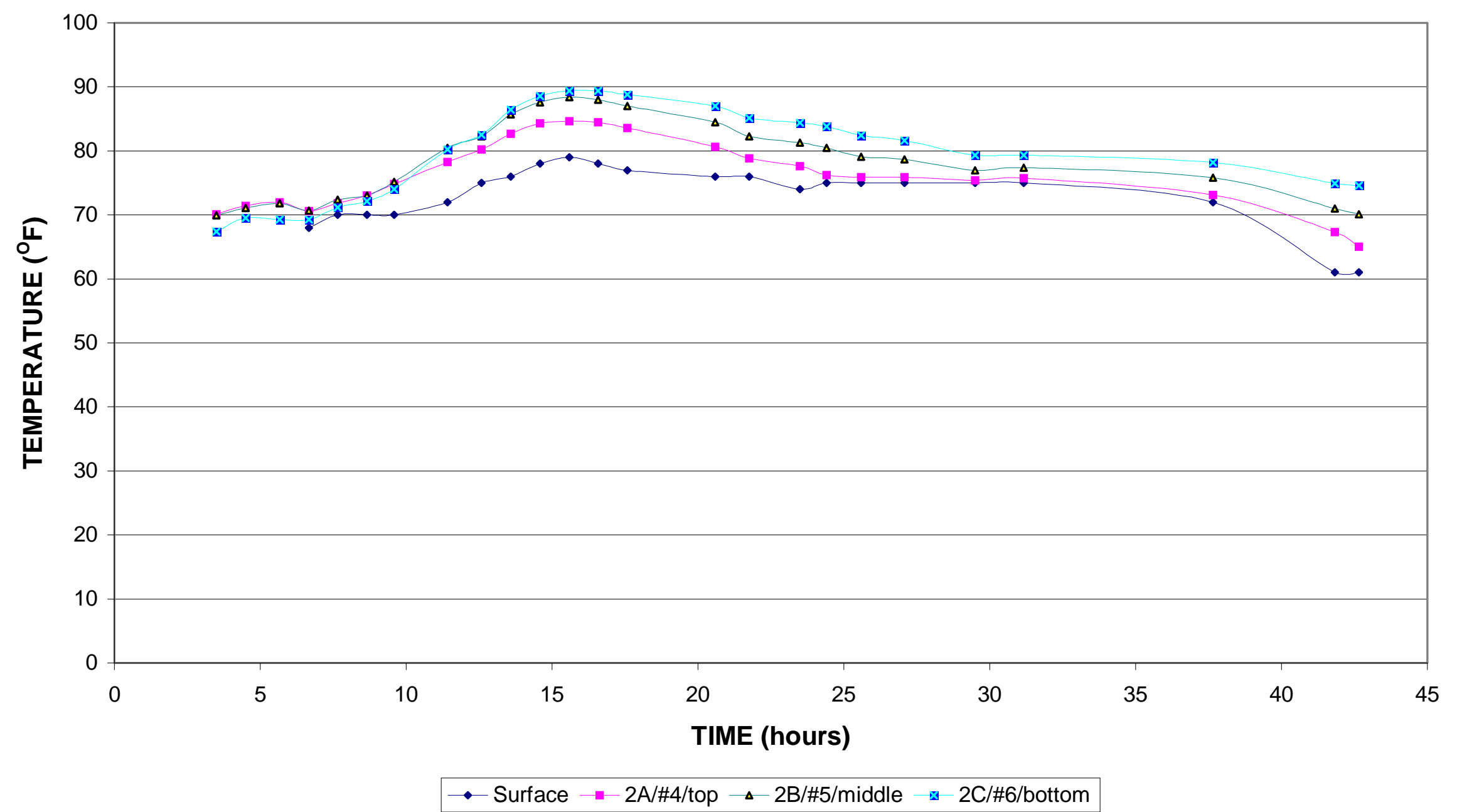




\section{GROUP \#3 Thermocouple Readings (Location $X=1100$ feet) \\ I-79 SOUTHBOUND LANES near Marianna, PA}

(October 9,1998 time $=0$ at 7:30 AM)

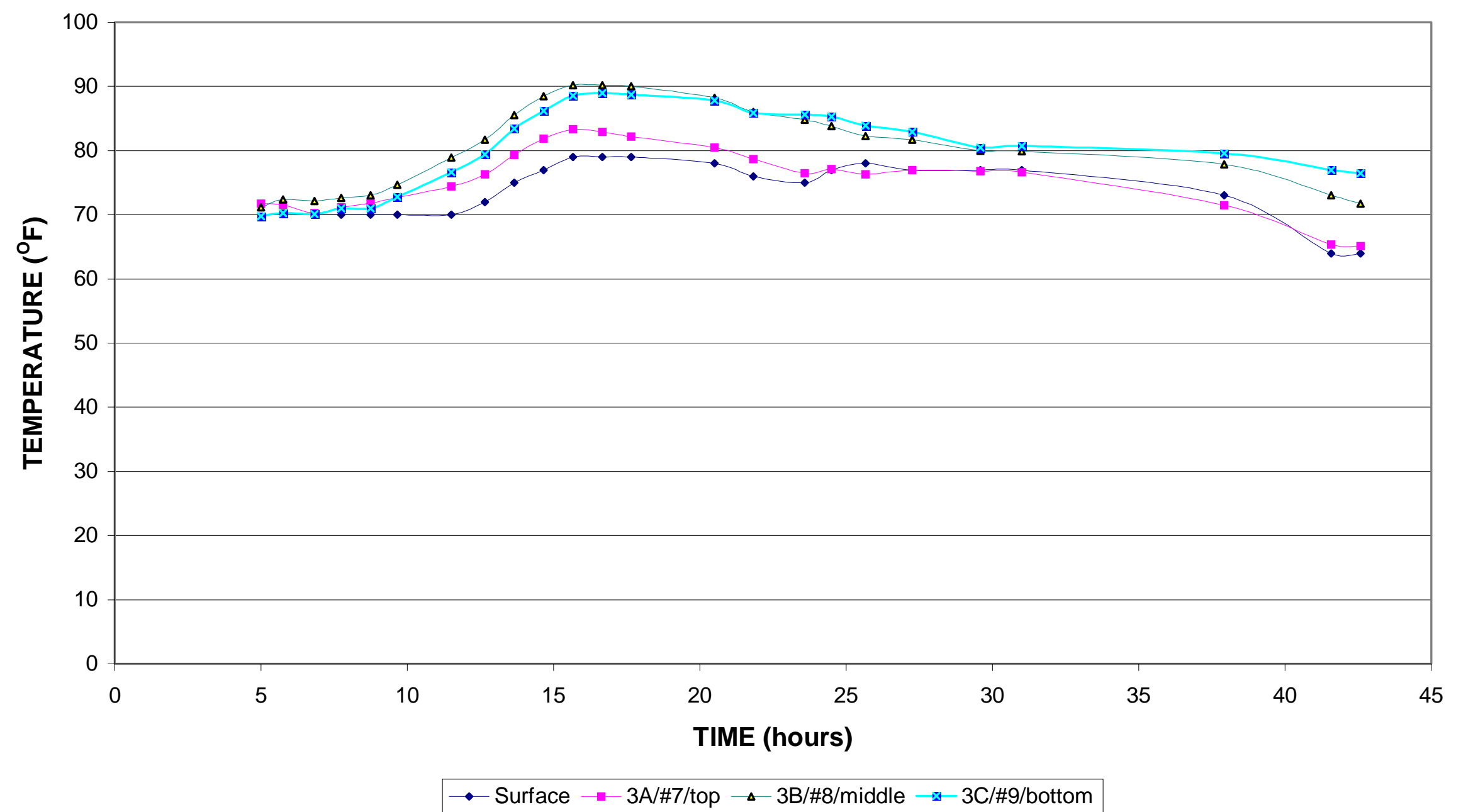




\section{GROUP \#4 Thermocouple Readings (Location X=1950 feet) \\ I-79 SOUTHBOUND LANES near Marianna, PA}

(October 9,1998 time $=0$ at 7:30 AM)

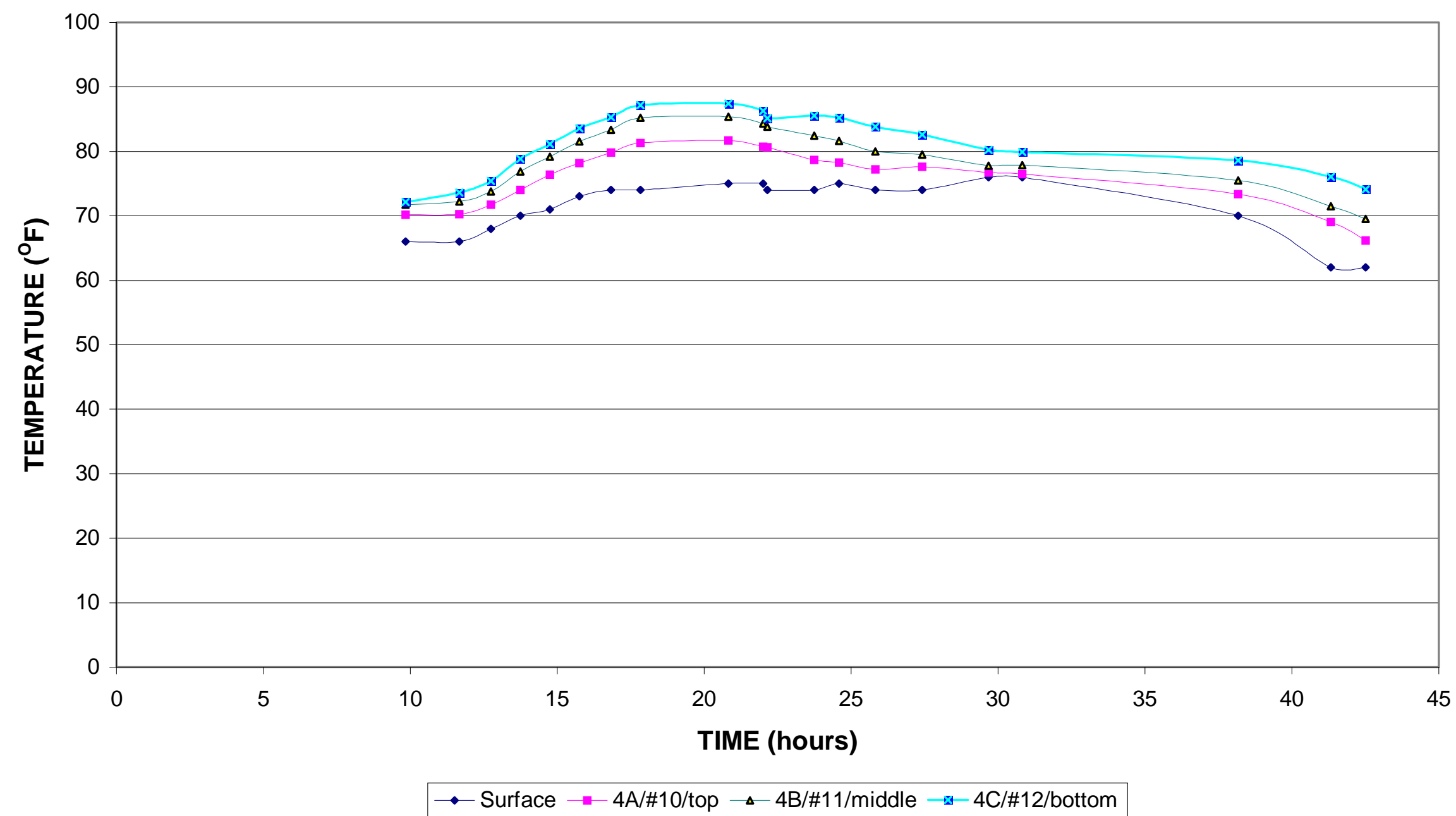




\section{GROUP \#5 Thermocouple Readings (Location $X=2450$ feet) \\ I-79 SOUTHBOUND LANES near Marianna, PA}

(October 9,1998 time $=0$ at 7:30 AM)

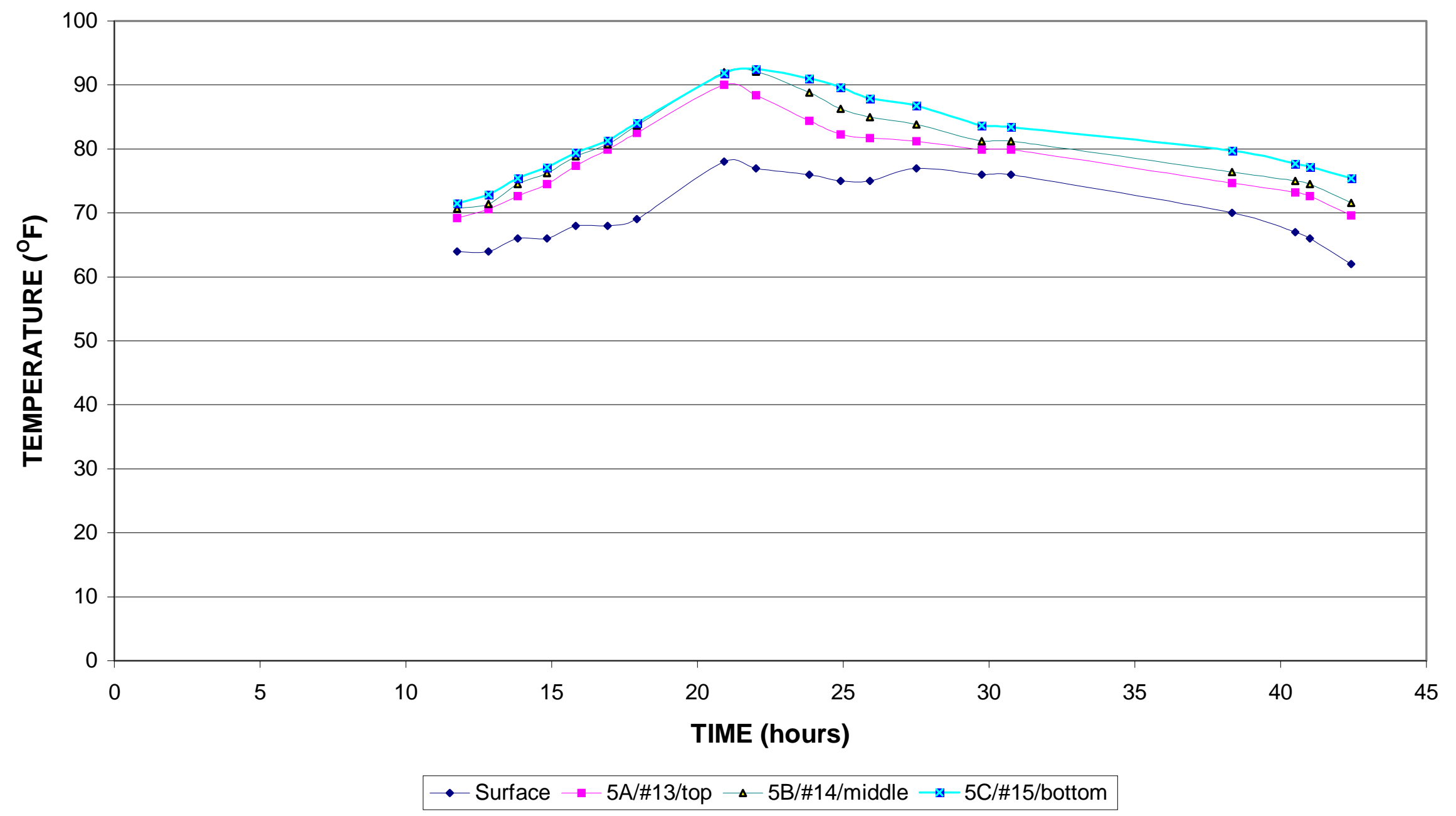


MAXIMUM CORE TEMPERATURE verSUS SLAB LOCATION AND TIME

I-79 near Marianna, PA SOUTHBOUND LANES

(October 9, 1998 time $=0$ at 7:30 AM)

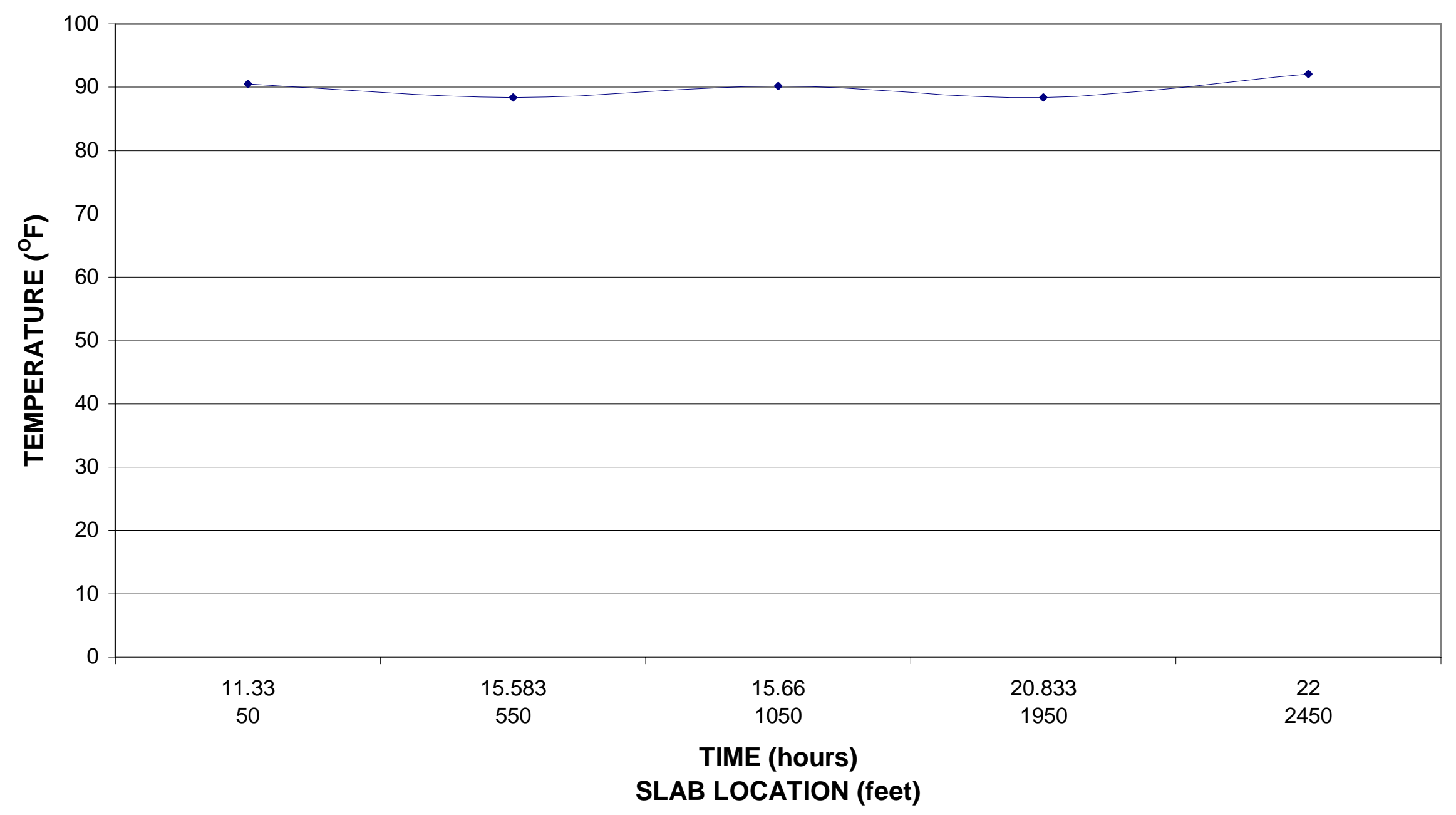


MAXIMUM SLAB TEMPERATURE REACHED versUs TIME

I-79 near Marianna, PA time $=0$ at 0730 hrs 09 October 1998

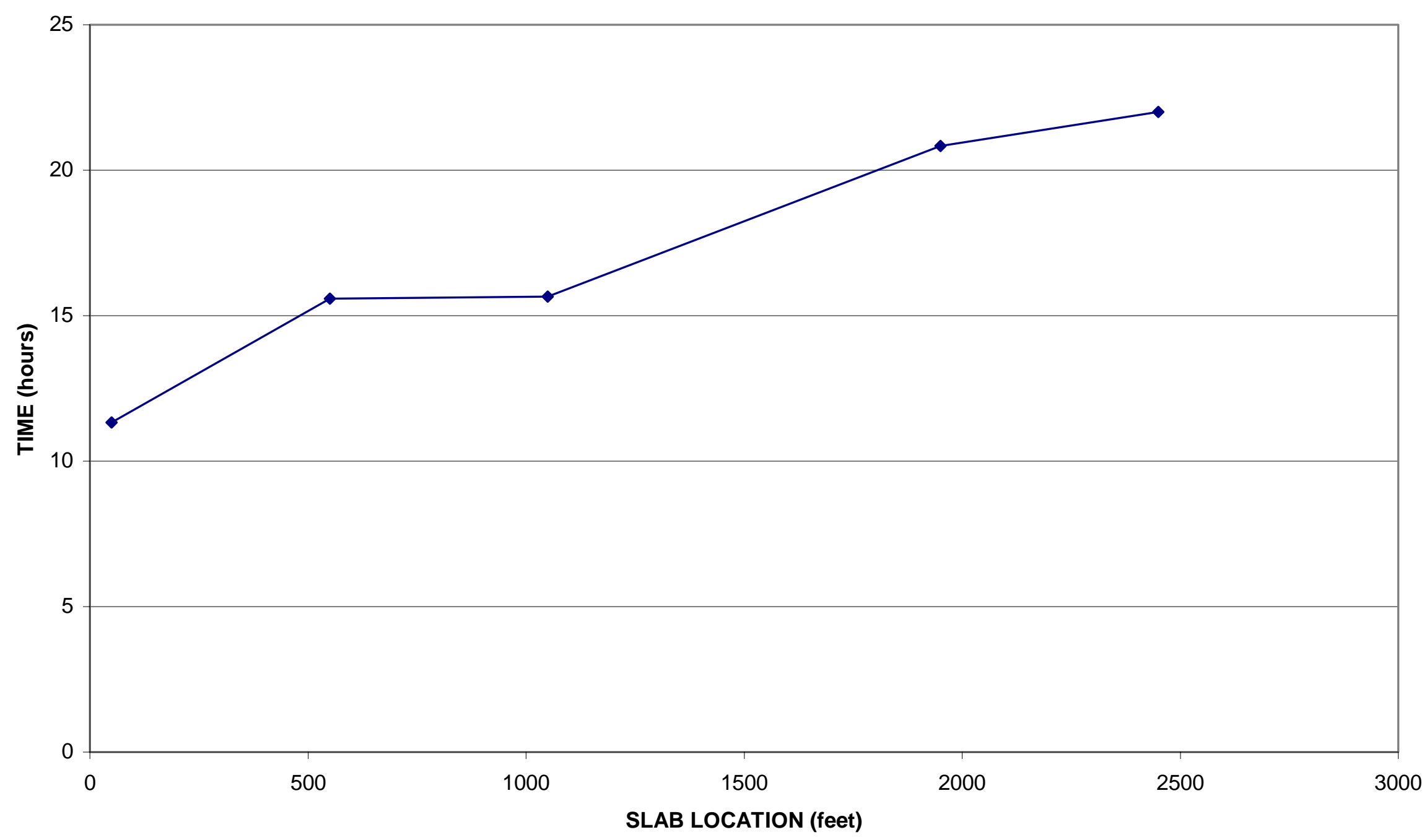

Figure 6.8: Time Maximum Core Temperature Reached by Location, I-79 Marianna, PA 


\section{SLAB TEMPERATURE PROFILE by depth as of 11.5 hours}

I-79 SOUTHBOUND LANES near Marianna, PA

(October 9, 1998 time $=0$ at 7:30 AM)

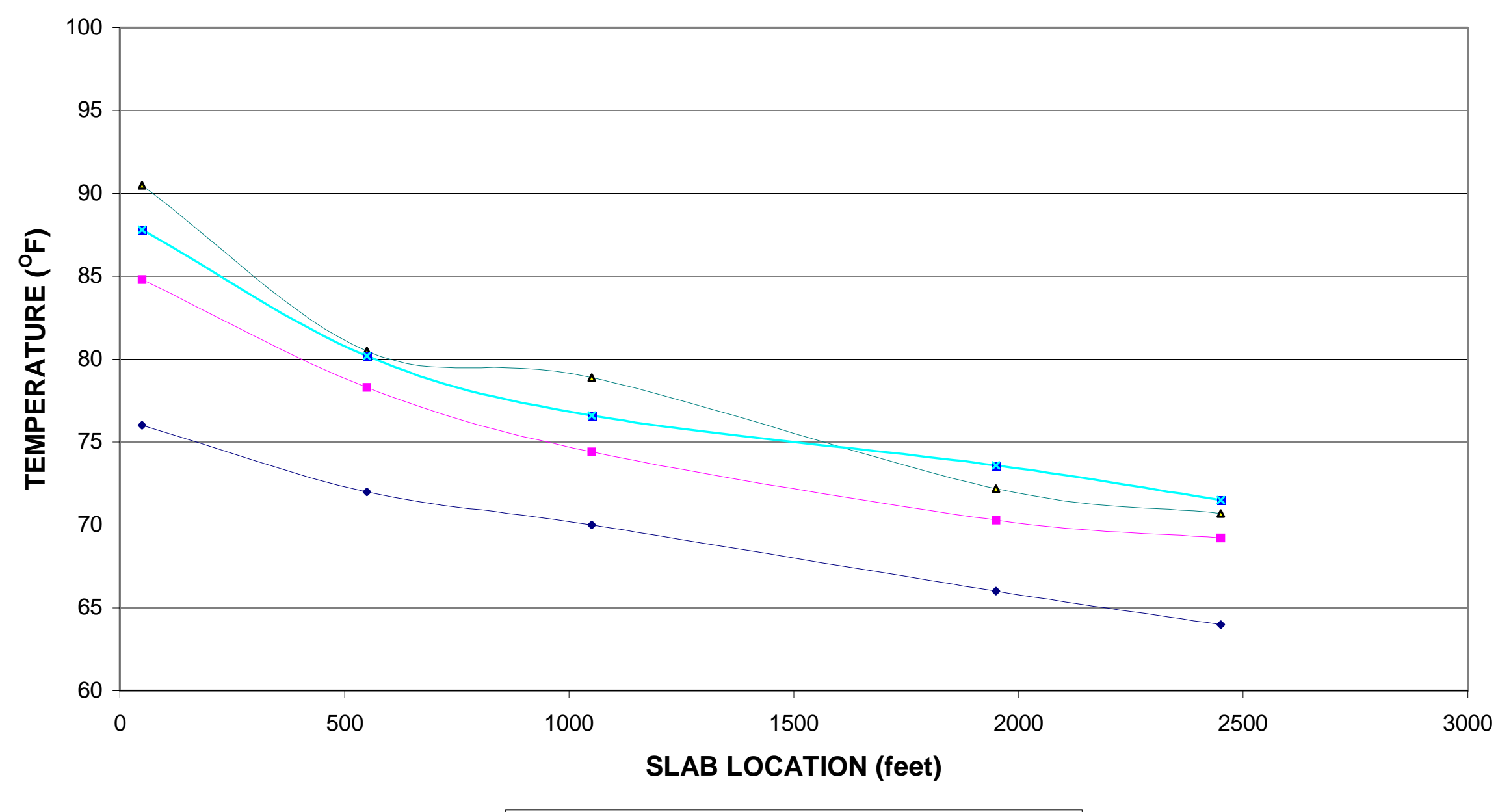




\section{SLAB TEMPERATURE PROFILE by depth as of 17.5 hours}

I-79 SOUTHBOUND LANES near Marianna, PA

(October 9, 1998 time $=0$ at 7:30 AM)

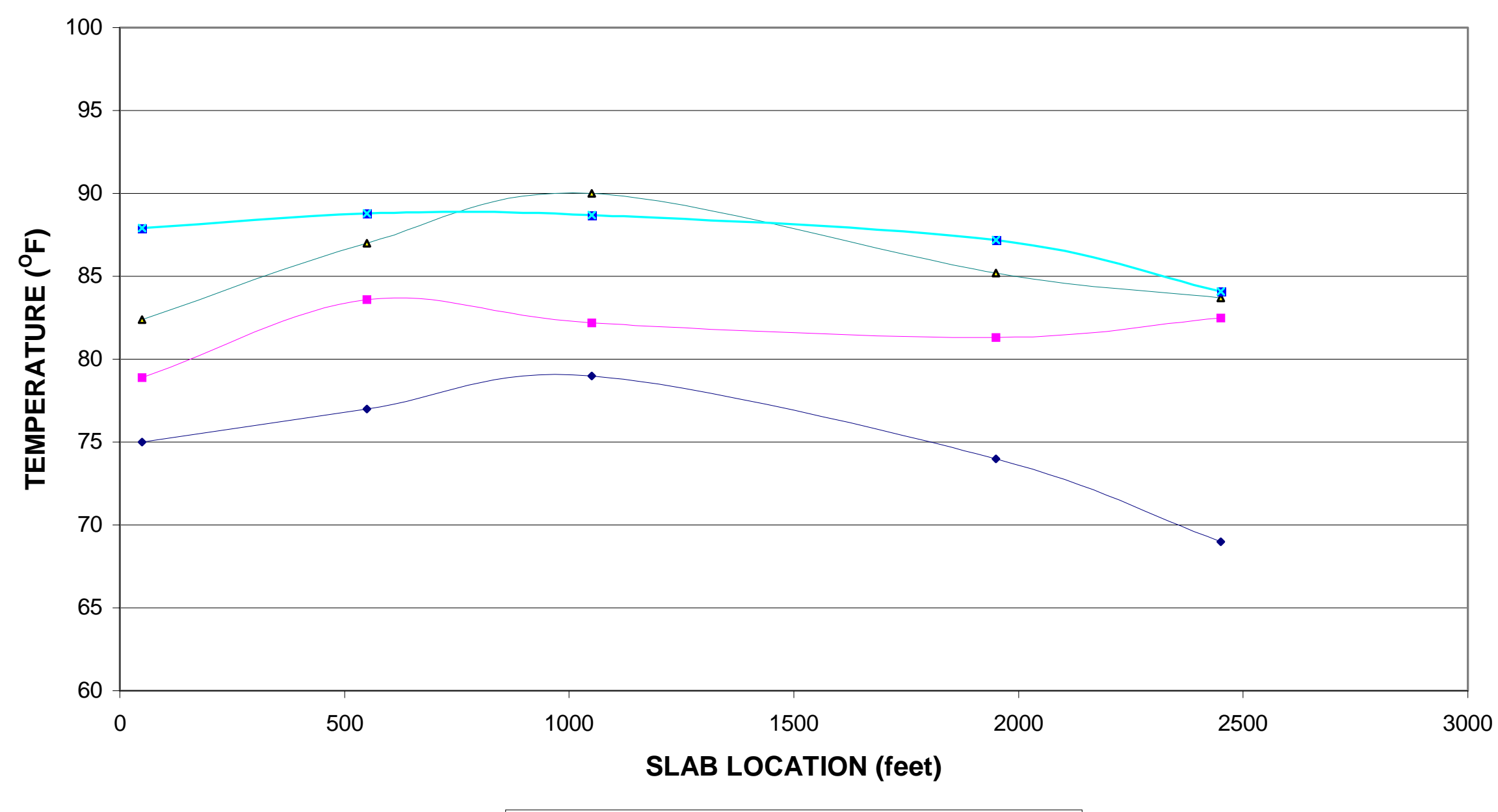




\section{SLAB TEMPERATURE PROFILE by depth as of 23.5 hours}

I-79 SOUTHBOUND LANES near Marianna, PA

(October 9, 1998 time $=0$ at 7:30 AM)

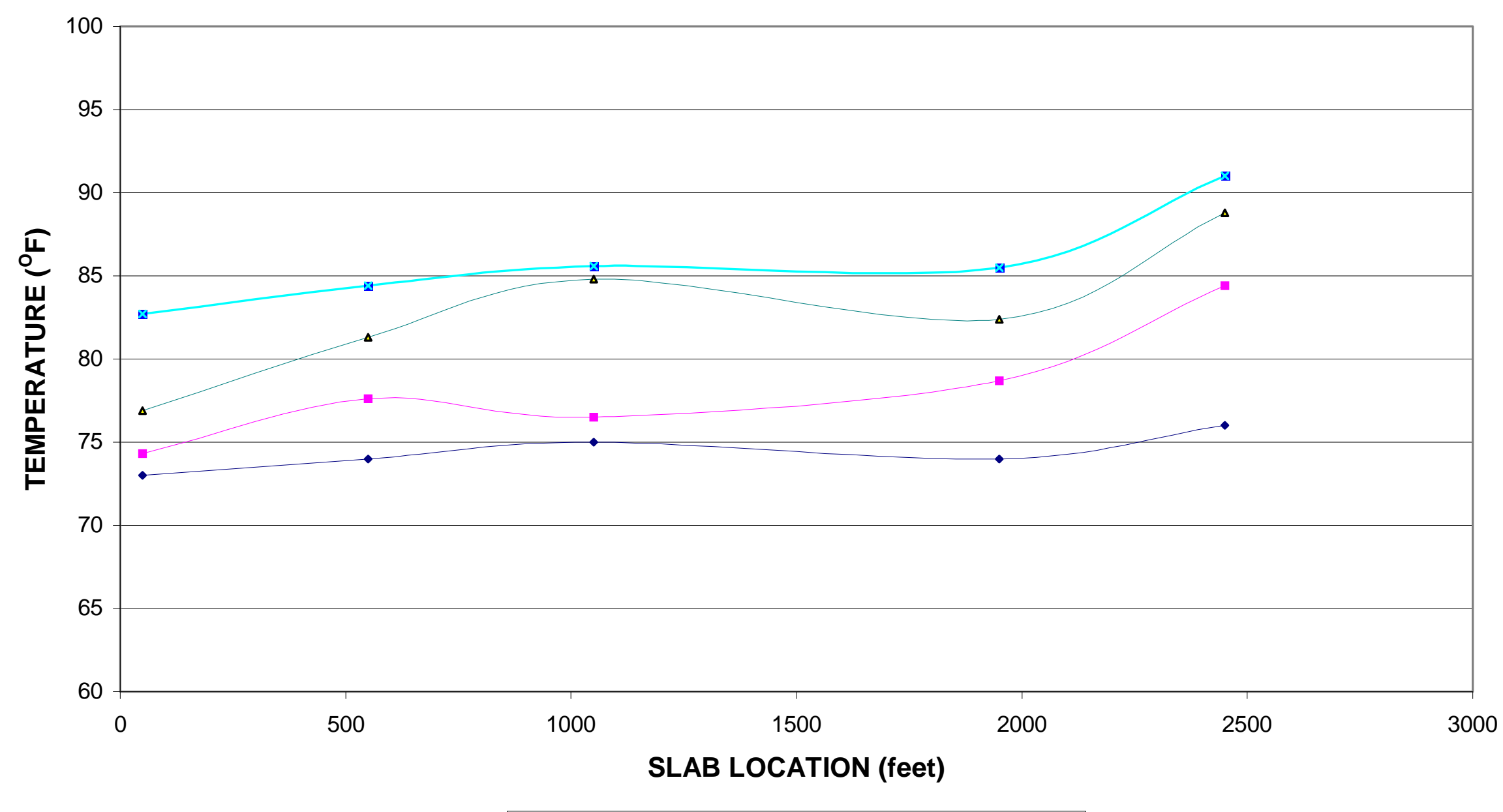




\section{SLAB TEMPERATURE PROFILE by depth as of 27 hours}

I-79 SOUTHBOUND LANES near Marianna, PA

(October 9, 1998 time $=0$ at 7:30 AM)

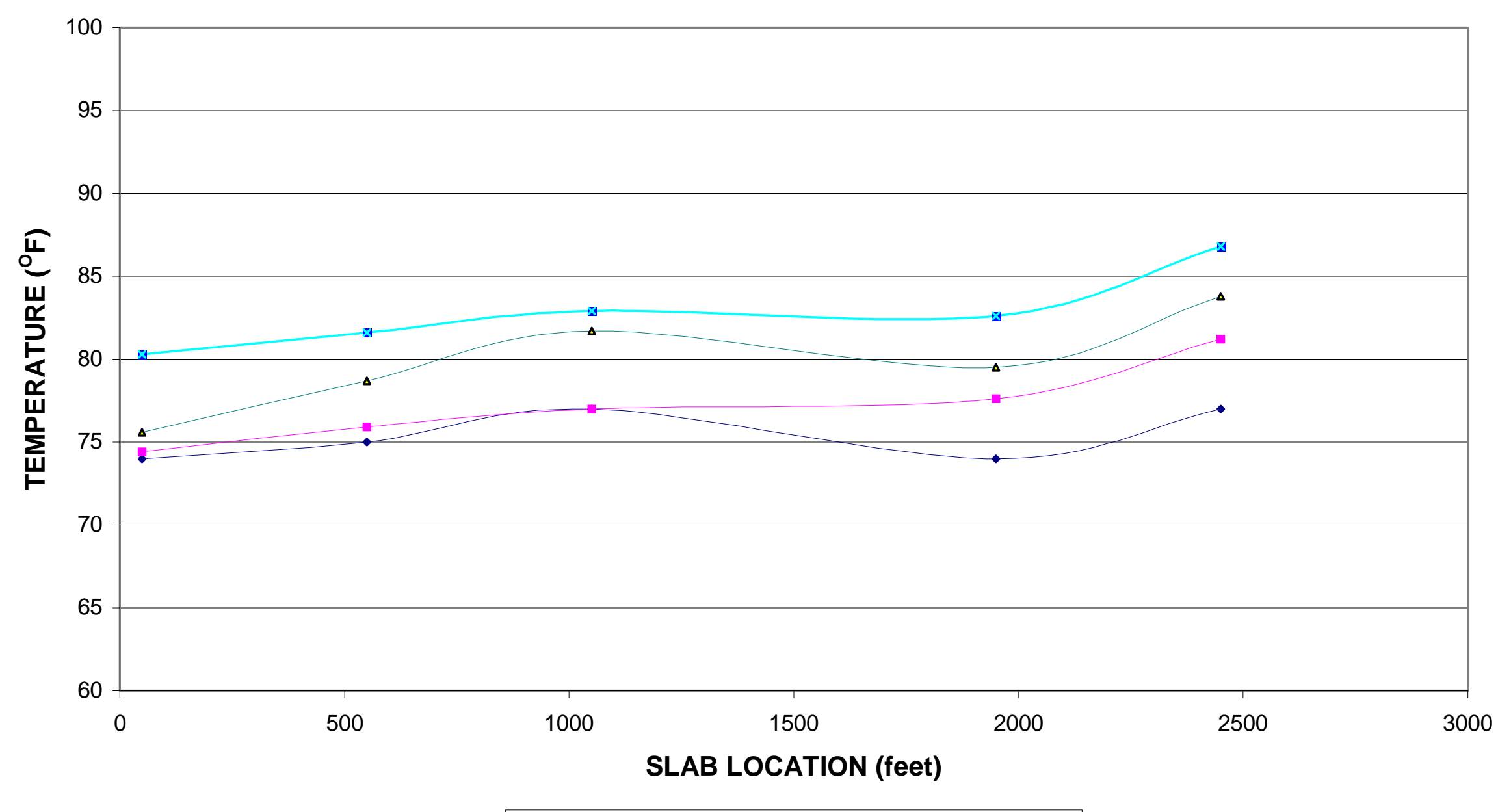




\section{SLAB TEMPERATURE PROFILE by depth as of 31 hours}

I-79 SOUTHBOUND LANES near Marianna, PA

(October 9, 1998 time $=0$ at 7:30 AM)

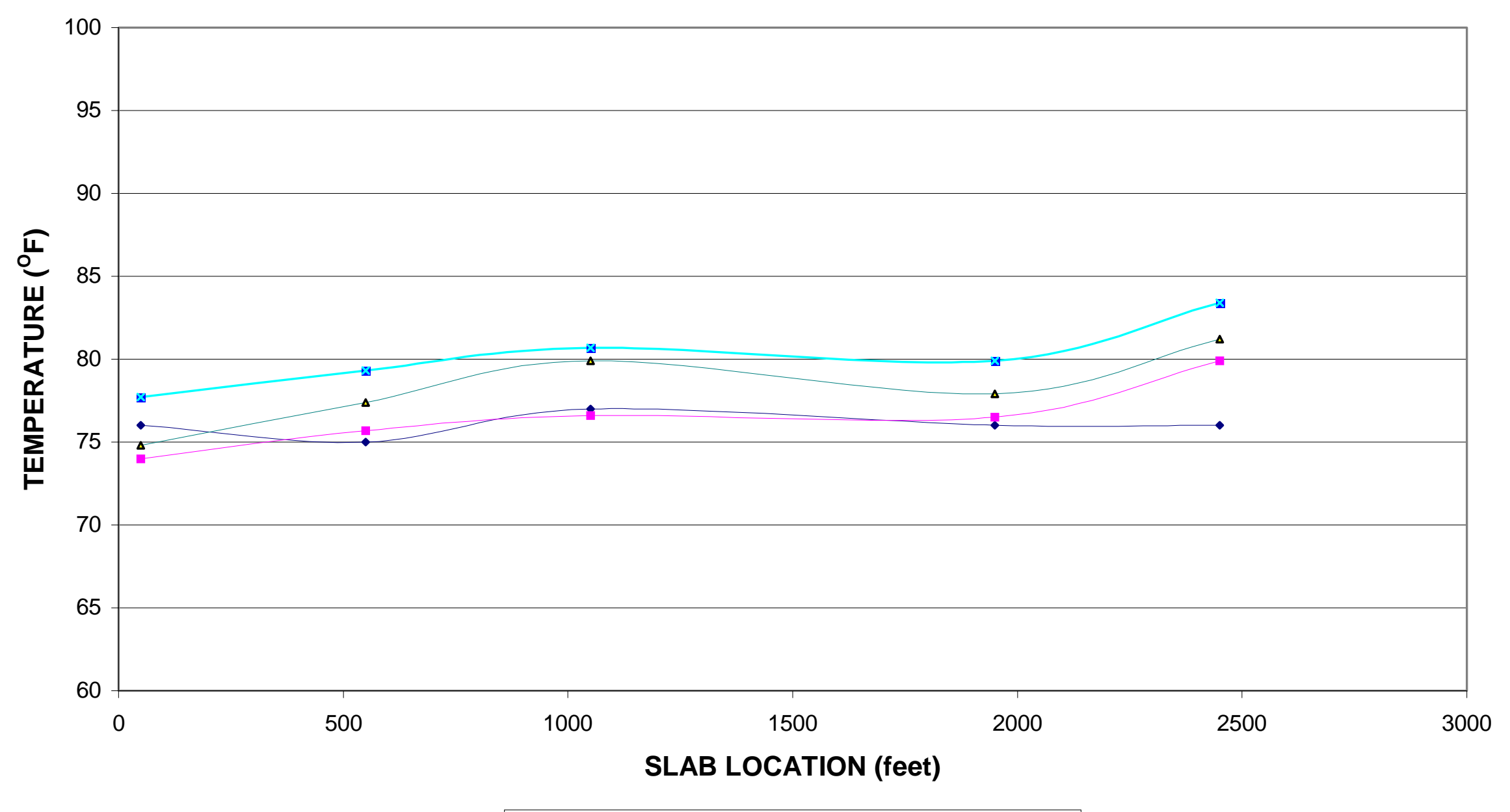




\section{SLAB TEMPERATURE PROFILE by depth as of 38 hours}

I-79 SOUTHBOUND LANES near Marianna, PA

(October 9, 1998 time $=0$ at 7:30 AM)

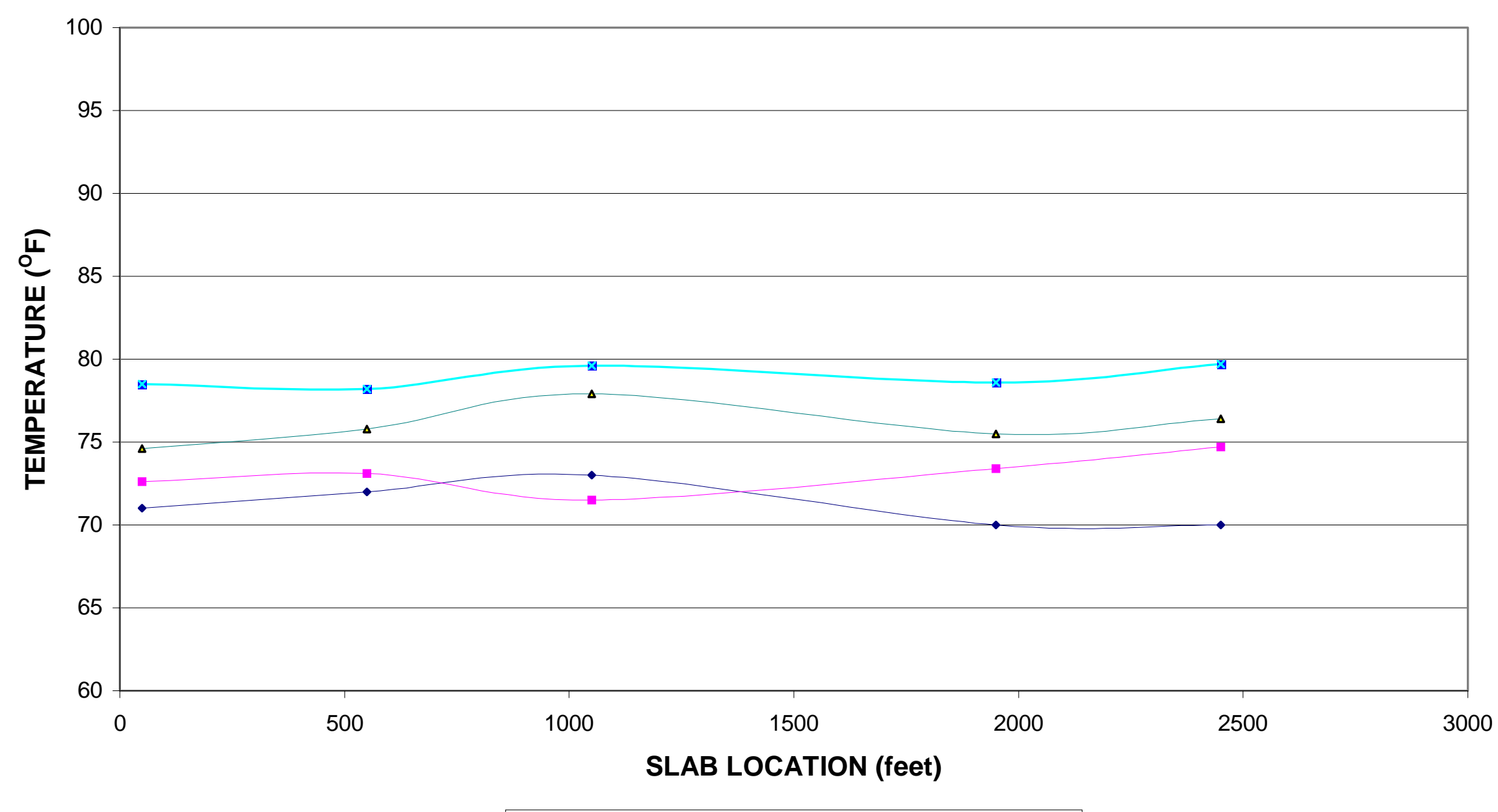




\section{SLAB TEMPERATURE PROFILE by depth as of 42.5 hours}

I-79 SOUTHBOUND LANES near Marianna, PA

(October 9, 1998 time $=0$ at 7:30 AM)

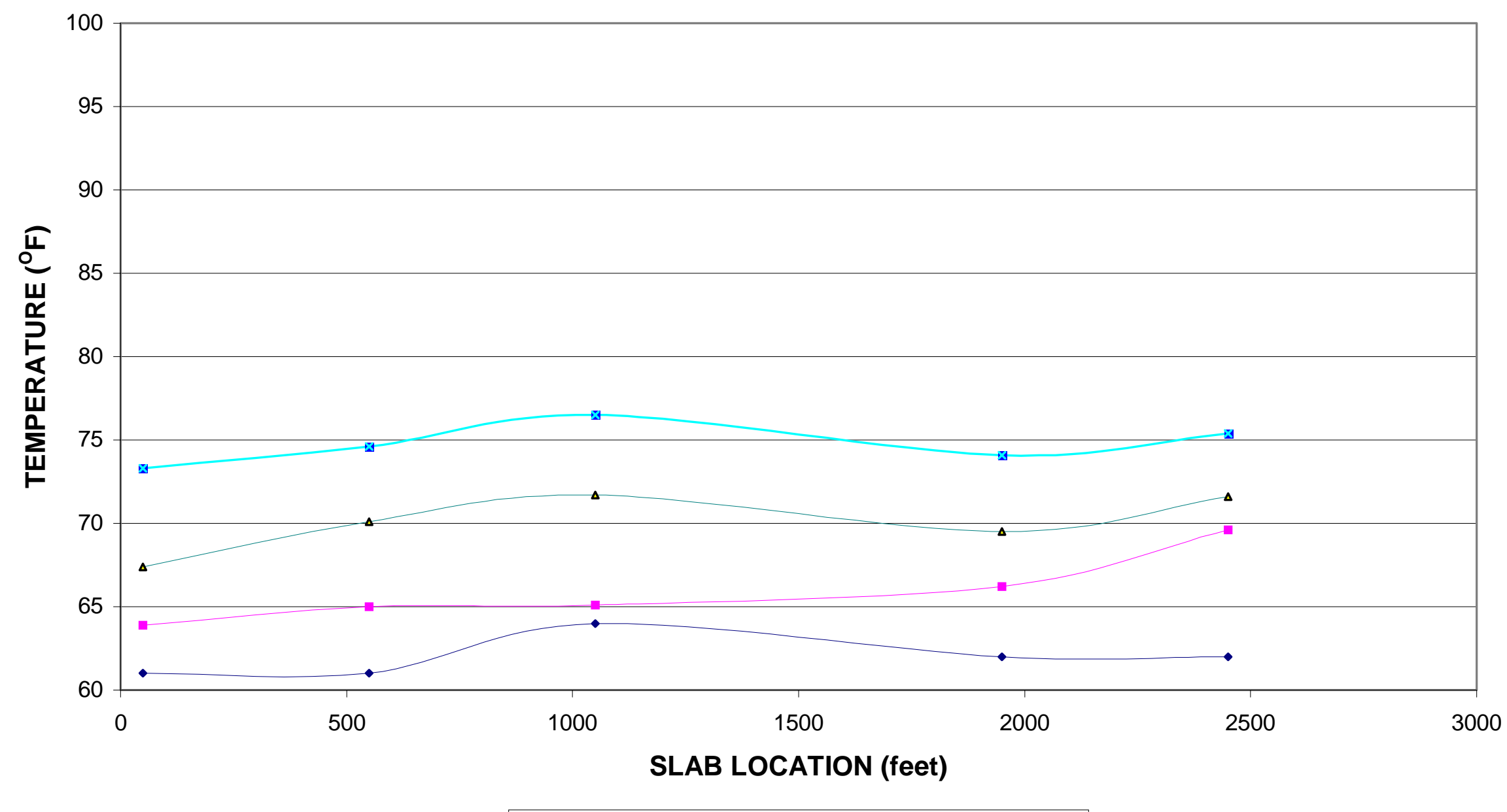


FIELD AMBIENT TEMPERATURE DATA versus

WASHINGTON COUNTY, PA Airport Temperature Data

Time $=0$ at 0730 hours 09 October 1998

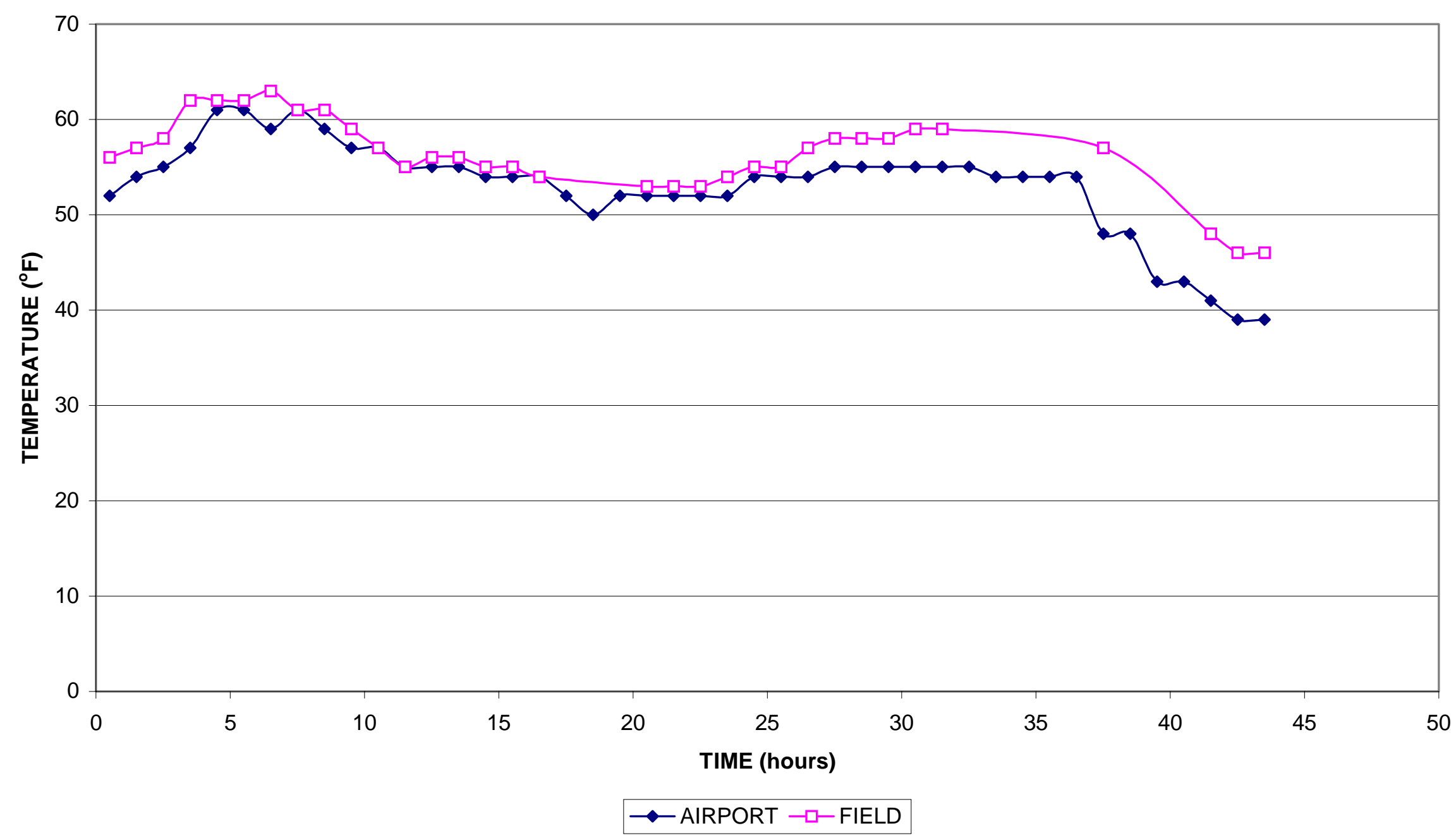

Figure 6.16: Field Thermocouple versus Local Airport Ambient Temperatures, I-79 Marianna, PA 
LEAN BASE AND FIELD AMBIENT TEMPERATURES versUS TIME AND LOCATION

I-79 SOUTHBOUND LANES near Marianna, PA

(October 9, 1998 time $=0$ at 7:30 AM)

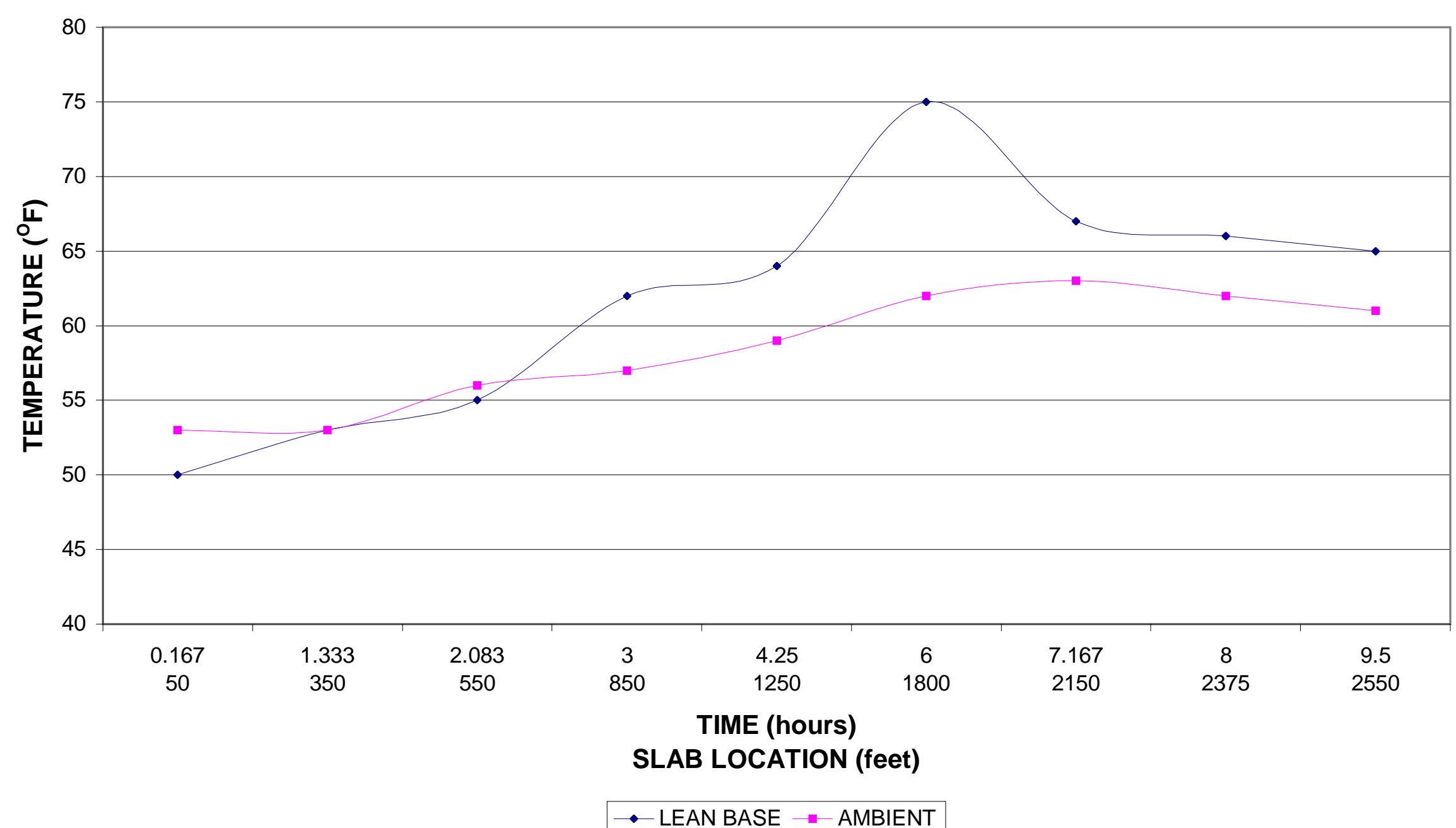

Figure 6.17: Lean Base and Corresponding Ambient Temperature Readings 


\subsection{Cracking Behavior, I-79 Marianna}

There are several very interesting behavioral aspects of the transverse joint cracking that were observed during the Marianna investigation. Not only did the slab crack in a non-uniform or sporadic manner, such as found in Phase I and other field engineers observations, but the locations and times that the cracking occurred were informative and interesting.

The concrete placement began at 0730 hours on October 9, 1998 and was stopped at 1630 hours that day. This showed that the concrete placed at 0730 was 9 hours more mature than that placed at the end. This can be seen graphically with a concrete age, from equivalent start time, versus the slab location graph (See Figure 6.18 Concrete age by Location).

The joint cracks were measured for size and location at seven different times. The joint numbering sequence starts at zero at the very beginning of that day's construction, as before. They were continued in numbering 1 through 132, either end being 0 and 133 which were the adjoining sections from the previous day and the next day's constructed slab, respectively. It was observed that cracking occurred initially at approximately every eighth to tenth joint or 160 to 200 feet. As the temperatures dropped even more, these sections cracked again at every third to fifth joint, or 60 to 100 feet. These intervals of joint cracking were consistent with observations from previously monitored crack formations. The total crack widths varied only slightly in size from the first nights to the second nights cracking, but the rate at which the cracks widened the second night was much quicker than the first night. The frequency of the crack spacing only slightly affected the crack widths. This could be due to the fact that when the cracking occurred 
the amount of stress developed and the maturity of the concrete at the time of cracking was greater the second night. (See Figures 6.19, 6.20 and 6.21: Crack data)

The joint cracking began in the beginning region, or starting point, of the constructed slab section. The crack progression continued from the older end of the slab toward the younger end. This observation depicts that the concrete maturity level is critical in determining crack initiation, unlike the Phase I description that the cracking would occur at the mid-lengths of slab sections. The joint cracking history revealed that the entire slab length did not crack during the first night after construction. The cracks were found to grow in width over time, as expected. After the first night, approximately one half the length of the slab had cracks. The crack widths were less than 1-mm and were generally equal in spacing. Crack formations stopped during the morning hours of October $10^{\text {th }}$ and recommenced in the early evening hours that day.

The second night's joint cracks formed more rapidly than the first night's. The approximate joint crack spacing continued throughout the entire length of the slab. The joints that cracked first were found to open wider than the additional intermediate cracking observed. The final crack formation of the slab was found to be at every third to fifth joint, or 60 to 100 feet. The crack widths ranged from less than $0.2 \mathrm{~mm}$ to $1.6 \mathrm{~mm}$ by 41.5 hours after initial concrete placement. It was believed at this time that the initial early age joint crack formation was complete. The adjoining section of the monitored slab was placed approximately one week prior to the investigated slab section. The joints of the investigated section were assumed to continue in width only and not frequency. The older slab section was observed to have cracked at every third to fifth joint (60 to 100 feet) and be around 4 to 5-mm in width. Thus, the decision to end the monitoring 
was made. (Note: The entire crack formation history of the adjoining section was not obtained, only general measurements were taken.)

The joint crack formation may be described as a progressive, repetitive sequence. The sequence is strictly dependent upon the concrete tensile strength development, location dependent temperature profile histories and tensile stress development within a given length of pavement. The concrete material property development is mainly dependent on the concrete age at a given location of the slab. The temperature history by location is dependent upon the ambient history that the concrete is exposed to during the first 12 to 24-hours of curing. The rate of temperature loss in concrete after the heat of hydration is directly attributed to the ambient temperatures. It was determined from the temperature readings that the concrete reached a maximum temperature of around $90^{\circ} \mathrm{F}$ during the heat of hydration at around twelve hours of maturity for each location at mid-depth, which is assumed as the set temperature. As the concrete slab cooled and reduced in size due to the temperature change, tensile axial restraint stresses began developing within the slab. Also, because the ambient temperatures at night were much cooler than the slab, large temperature differences developed from the cooler surface of the slab to the warmer bottom of the slab, which caused curling stresses. The combination of these two tensile stresses was enough to exceed the strength development and crack the slab, but only in particular regions. (Detailed discussion on the above mentioned stresses can be found in Chapter 10.) 
CONCRETE AGE, (from equivalent start time), versus SLAB LOCATION I-79 SOUTHBOUND LANES near Marianna, PA

(October 9, 1998 time $=0$ at 7:30 AM)

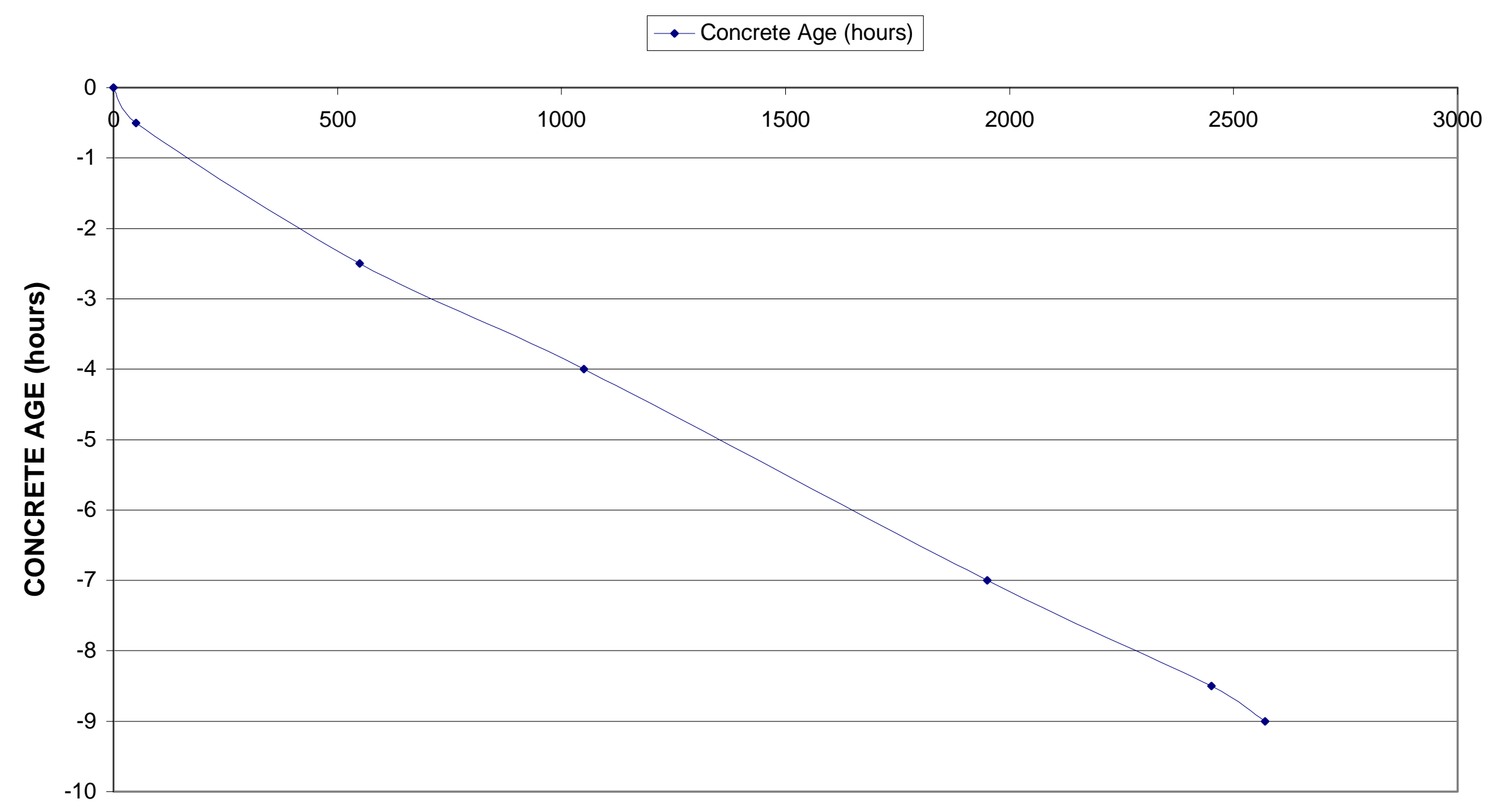

SLAB LOCATION (feet) 
Crack Width Development At Top of Slab (up to 30 hours)

I-79 Southbound Lanes near Marriana, PA

(Time $=0$ at 7:30 AM, October 9, 1998)

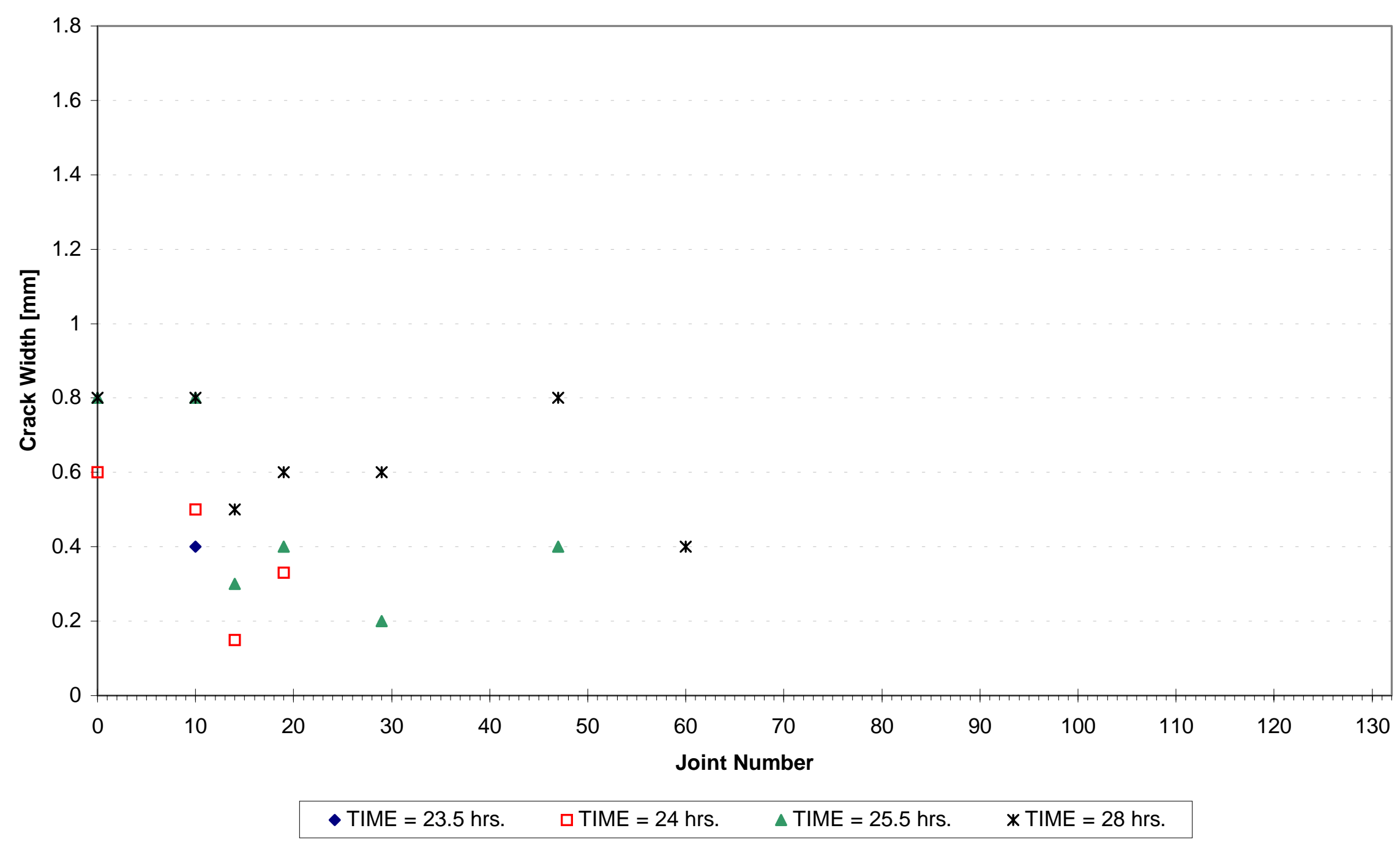

Figure 6.19: Crack Development up to 30 hours, I-79 Marianna, PA 


\section{Crack Width Development At Top of Slab (after 30 hours) \\ I-79 Southbound Lanes near Marriana, PA \\ (Time $=0$ at 7:30 AM, October 9, 1998)}

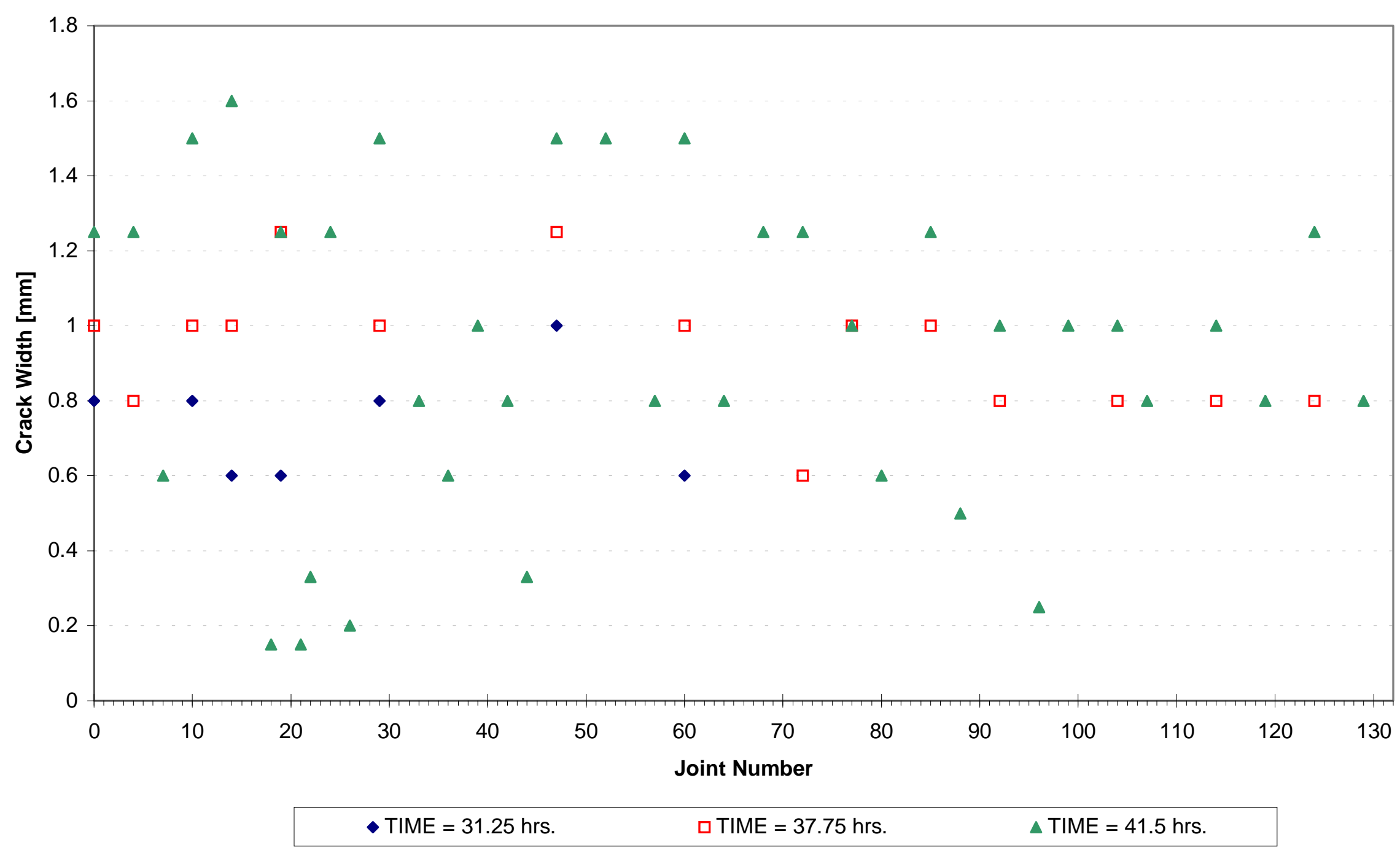

Figure 6.20: Crack Development after 30 hours, I-79 Marianna, PA 
Crack Width Development At Top of Slab

I-79 Southbound Lanes near Marriana, PA

(Time $=0$ at 7:30 AM, October 9, 1998)

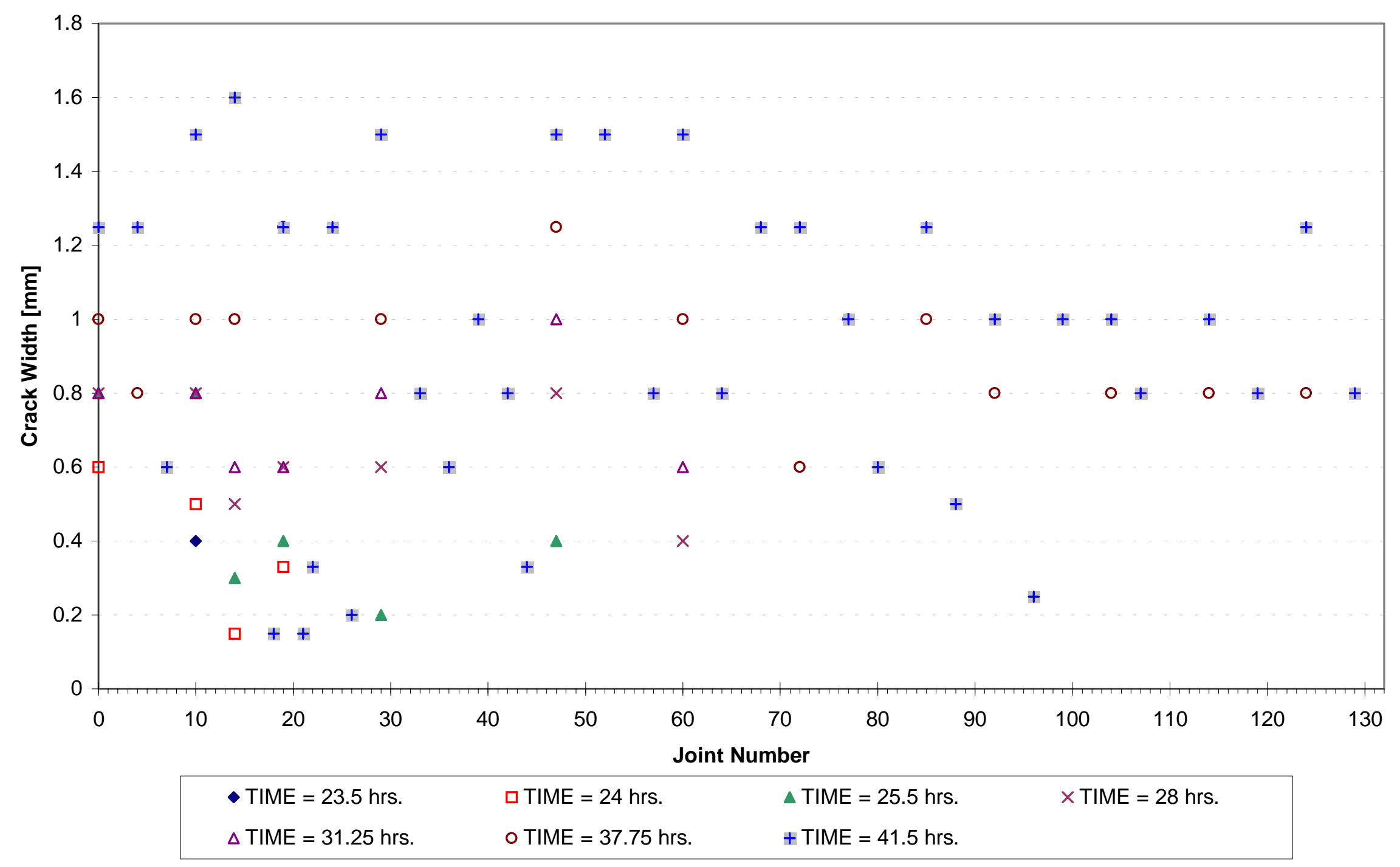

Figure 6.21: Crack Development at Selected Times, I-79 Marianna, PA 


\subsection{Discussion, I-79 Marianna}

It was observed in the field that the transverse joints would crack in a semi-predictable manner. Differing slab concrete maturity by location played a major role in the cracking potential of the slab. The concrete maturity is the extent to which the concrete material properties have developed, such as, the modulus of elasticity, the coefficient of thermal expansion/contraction, the coefficient of friction, etc. The cracking potential is a ratio or percentage of the concrete strength to the applied concrete stress. As the ratio approaches the value one, or one hundred percent, the cracking potential is considered to be high and the concrete will crack. The concrete placed in the morning hours had already surpassed the maximum temperature and was cooling as the evening hours approached and the ambient temperature dropped. This added to the cooling effect and the temperature gradient, which increased the stresses developed. In these areas the concrete was still very young and the strength was low, so these factors caused the slab to crack during the first night. The amount of drop in uniform temperature and the temperature gradient in the slab when cracking was observed were approximately $8^{\circ} \mathrm{F}$ and 10 to $15^{\circ} \mathrm{F}$, respectively. The cracking only occurred when a combination of both stresses developed. The cracking potential is much higher in the early evening and nighttime hours due to the curling stress's development.

In the younger end region of the slab, that which was placed in the afternoon hours, was still maturing and had only begun to cool from its maximum temperature reached in the early morning hours of October 10, 1998. Although a large temperature gradient was observed due to the cooler nighttime temperatures in the younger slab section, it was just beginning to cool in uniform temperature and the curling stress developed alone did not 
exceed the strength of the slab at that maturity level. As the ambient temperatures warmed during the early morning hours, the temperature gradients reduced and cracking was observed to stop during the daytime hours. After approximately 28 hours from the start of construction, or 11:30 AM on October 10, the slab did not crack again until the evening hours (after approximately 37 hours, or 8:30 PM on October 10). The slab continued to cool, but without a large temperature gradient and curling stress. The maturing slab strength was greater than the stresses being imposed due to the uniform cooling. Therefore, the cracking potential was low during the daytime hours.

As the second night approached and the ambient temperatures dropped again, the temperature gradients increased producing larger curling stresses. By that time the entire slab had surpassed its maximum temperature with a drop in uniform temperature ranging from 12 to $16^{\circ} \mathrm{F}$ and the restraint stresses were greater than the previous night. When the temperature gradients increased in the early evening hours, the stresses developed throughout the slab were much greater; therefore, high cracking potential was achieved and cracking occurred quickly along the total length of the slab. (See Figures 6.19 through 6.21) By 38 hours, the values of the changes in the drop of uniform temperature and the temperature gradients were nearly the same throughout the slab length, being 12 to $16^{\circ} \mathrm{F}$ and 6 to $10^{\circ} \mathrm{F}$, respectively. The developing concrete material properties were also converging in values throughout the length of the slab. Knowing these factors, the cracking potential was nearly the same along the slab. When the slab cracking resumed, the rate of crack formation dramatically increased, although the crack spacing and comparative widths did not. 
These explanations are only based upon the field data collected and the assumed development of the non-calculated predicted stress development, which were described in Phase I of this research project. The actual cracking behavior that was observed alone is not enough to recommend a solution. The possible correction explained in the Phase I recommendations that by paving in the evening hours could possibly control the cracking widths was not verified. The cracking widths and frequencies observed during the second night were comparable to those observed during the first night. These factors reveal that changing the time of construction alone may not correct the cracking problem because the different times of placement of concrete did not control the crack widths. These factors also explain that the cracking behavior will occur generally in the same frequency.

The non-uniform joint crack widths might be made more uniform by changing the concrete mix designs or the bond strengths between the slab and the base course, by controlling the temperature fluctuations, or by a combination of them all. Further analysis was needed and will be discussed in Chapter 10. 


\section{Chapter 7: I-80 Investigation near Danville, PA October 16, 1998:}

\section{$\underline{7.1 \text { Introduction and Site Description }}$}

The second, PCC highway pavement construction investigation was performed on a section of I-80 eastbound lanes near the Danville, PA exit (state project number SR0080056, district 3-0 Montour County PA, Liberty and Valley townships). The concrete slab section investigated was placed on October 16, 1998 beginning at 0800 hours. The construction was slip-form non-reinforced rigid pavement as required. The construction design was different than the I-79 construction design investigated on October 9, 1998, one week prior. The mix designs, base course material, various course depths and concrete curing technique were all different. The mix designs used for this construction are shown in Chapter 3. The base course material used was ATPBC, similar to that used in West Virginia, (WV FDB course). The cross-sectional design for the investigated pavement section can be seen in Figure 5.4b. Two sections' joint crack formations were obtained during this investigation; one from the instrumented investigated section placed October $16^{\text {th }}$ and one from a section placed on October $12^{\text {th }}$. The October $12^{\text {th }}$ section has a different cross-sectional design, length and crack behavior than the instrumented section. (Details of the October $12^{\text {th }}$ section are described in section $7.3 \mathrm{~b}$ with the section's cracking behavior discussion.) The October $16^{\text {th }}$ slab section was 24 feet wide with a minimum 13-inch thickness placed on a minimum 2.5-inch ATPBC on the existing highway's rubblized concrete. Separation/filter fabric was not used because of the addition of edge drains in the design. The investigated section was 2840 -feet long, the longest of all the investigated sites. PennDOT regulations on the curing method for the date of the construction and the expected low temperatures required that the concrete slab 
be cured with 1/32-inch thick polyethylene sheeting instead of curing compound. The sheeting was hindering to some of the work to be performed, as discussed in Chapter 3. The number of times the joint crack formations were observed was limited due to the time it took to slice the sheeting at all the joint locations. Requests and approvals to cut the sheeting were obtained verbally from the PennDOT engineers and the prime contractor, prior to being performed. The prime contractor which constructed the new sections of I-80 was New Enterprises Stone and Lime Co., Inc. The company and PennDOT personnel were very helpful with every aspect of the work that was performed.

The temperature data from the various slab depths were again placed into groups. Six groups of three thermocouples were inserted at three different depths in the outside lane edge of the slab. They were placed with the rod and hook assembly technique described in chapter 3.5b. The group thermocouples were placed after the paving equipment passed and before the concrete finishers, texturing machine and polyethylene sheet covering were performed. The hand held thermometer was used to take the temperature readings nearly hourly for the first 30-hours and during critical times. The thermal infrared gun was used to take the surface temperatures at the group locations and on the base course prior to concrete placement. After the sheeting was placed, it had to be lifted such that the gun could get a reading from the pavement surface and then replaced and secured. Two thermocouples were used to observe the ambient temperatures, one at either end of the pavement section.

The polyethylene sheeting was less than ideal for the observations to be performed. The sheeting was removed during the transverse joint saw cutting. The transverse saw joints were cut to the same specifications as the I-79 investigated slab. The cuts were 
made on a 1:6 skew at a 20-feet spacing. The cuts were made 3/16-inch wide and approximately $\mathrm{h} / 3$ depth (4.5-inch depth). The timing of the saw cutting was also similar to the I-79 slab saw cutting. Precise rate of saw cutting is irrelevant as long as no intermediate out of joint cracking occurs. 


\subsection{Temperature Data, I-80 Danville}

The instrumentation and continuous monitoring of thermocouples at different slab depths were recorded for approximately 52 hours after the initiation of concrete placement. The thermocouple insertion technique and monitoring equipment was identical. (See chapter 3.5b and chapter 6.1) Each type $\mathrm{K}$ thermocouple was calibrated prior to use. The calibrations can be seen in Table 7.1. The thermocouples were again placed at three different depths at various locations along the 13-inch thick concrete slab and labeled as different group numbers. They were designated by top, middle and bottom, where the top was 1-inch from the slab surface, the middle was 6.5 -inches from the surface and the base and bottom was 1-inch up from the base course. Slab surface temperatures were again taken with the infrared gun at the different group locations. Six groups of thermocouples were placed during this instrumentation. Group \#1 was at 50feet, Group \#2 was at 650-feet, Group \#3 was at 1250-feet, Group \#4 was at 1950-feet, Group \#5 was at 2650-feet and Group \#6 was at 2830-feet. The various locations can be seen in Figure 6.1b.

Group \#6 thermocouples were placed closely to Group \#5 thermocouples because a different type of concrete mix design was used in the last two to three 10-CY trucks (approximately 20 feet of pavement). The second mix had an accelerator admixture, Pozzutec 20. Instead of using bulkheads to end a days slab placement, "dummy baskets" were placed where the typical shear dowel bar baskets were located. The dummy baskets were made of PVC pipe sections 16-inches long. The PVC sections were located and spaced the same as the dowel transfer bars. Both ends of the pipe sections were ducttaped to keep out the concrete. The dummy baskets were used so that the end section 
could be cut and lifted out the next morning and then dowel bars slid inside the open PVC holes for the continuation of pavement construction, saving construction time. The increased rate of hydration, strength development and bond strength due to the accelerator was found to have minimal affect on the crack behavior of the overall slab. The temperature history of Group \#6 may be disregarded in the stress development analysis in this case, but may be useful in observing the temperature affects on concrete containing accelerator admixtures.

The slab temperature data collected from each group have been compiled into a time equal to zero scale, where time equals zero at 0800 hours on October $16^{\text {th }}$, 1998. (See Table 7.2 Converted Time Chart) Each group's temperature history by slab depth can be seen in Figures 7.1 through 7.6. Although the actual temperature readings observed during the I-79 Marianna investigation and I-80 Danville investigation were not the same, the temperature behavior observed by slab location and time was similar. The time that initial hydration concrete maximum temperature was reached was again around 10 to 12 hours after placement for each location. The varying maturity of the slab by location was again readily visible. The ambient temperature histories encountered by the different slab locations directly affected the slab temperature profiles seen. The stresses developed in a slab section, which cause cracking, are mainly temperature and concrete maturity material property related. The first two thirds of the slab section placed was observed to reach maximum hydration temperatures during the nighttime hours the first night. The ambient temperatures at that time were cool. The core slab temperatures dropped significantly and large surface-to-bottom temperature gradients were observed. The remaining third or so of the concrete slab section did not reach maximum hydration 
temperatures until the early morning hours of the $17^{\text {th }}$. The core temperatures along that slab section had not dropped much during the first night. Some surface-to-bottom temperature gradients were observed, but the combination of the two was not sufficient enough to cause cracking. During the daytime hours of the $17^{\text {th }}$, the slab temperatures were increased slightly due to solar radiation. Temperature gradients were reduced and core temperatures increased slightly. By the early evening hours of the $17^{\text {th }}$ around 36 hours after initial concrete placement, the temperature profiles along the slab length, or group locations, were quite similar in value. The temperature gradients and core temperature drop was nearly identical throughout the slab length during the remaining hours of the investigation.

Ambient temperature values were obtained at locations near either end of the monitored slab section. Climatic data including the ambient temperature history for the monitoring duration was also obtained from NCDC, (National Climatic Data Center), collected from an observation location at Williamsport, PA, approximately 15 miles away. The results of all three ambient data collects can be seen in Figure 7.7. The ambient histories obtained were nearly identical; thus any of the three could be used for analysis.

The ATPBC surface temperatures just prior to concrete placement were recorded along the slab length. The surface temperatures along with the ambient temperatures at the time the surface temperatures were taken can be graphically seen in Figure 7.8. It can be seen from the figure that the base course temperature becomes drastically higher than the ambient temperature due to solar radiation in afternoon hours of construction. This observation was also seen at the I-79 Marianna slab construction, but the use of the lean 
base course at that location did not absorb nearly as much radiation. (See also Figure 6.17) The solar radiation affect is much more pronounced on ATPBC because of the material color, black, which absorbs more energy than the Lean Base which is a light gray to white color. 
Table 7.1

THERMOCOUPLE CALIBRATIONS for Danville, PA

Tested in a Sealed Styrofoam Cooler on 15 Oct 98

\begin{tabular}{|c|c|c|c|c|c|c|c|c|}
\hline \multirow{3}{*}{$\begin{array}{l}\text { Calibration } \\
\text { Designation } \\
\text { Gage \# }\end{array}$} & \multirow[b]{2}{*}{ NEW } & \multicolumn{5}{|c|}{$\begin{array}{l}\text { Temperatures (degree F) by test series } \\
\text { and Thermometer used }\end{array}$} & \multirow[b]{2}{*}{ NEW } & \multirow{2}{*}{ OLD } \\
\hline & & OLD & NEW & OLD & NEW & OLD & & \\
\hline & 1 & 1 & 2 & 2 & 3 & 3 & 4 & 4 \\
\hline 1 & "66.7 & 67.5 & 66.9 & 67.9 & 67.1 & 68.1 & & \\
\hline 2 & 67.1 & 67.8 & 67 & 68 & 67.2 & 68.2 & & \\
\hline 3 & 66.8 & 67.4 & 67 & 68.1 & 66.9 & 68 & 66.8 & 67.8 \\
\hline 4 & 66.6 & 67.4 & 66.4 & 67.6 & 66.9 & 68.1 & 66.7 & 67.9 \\
\hline 5 & 66.7 & 67.4 & 66.6 & 67.7 & 67 & 68.2 & & \\
\hline 6 & 66.8 & 67.6 & 66.8 & 67.8 & 67.4 & 68.4 & $7.4,65.7]$ & $7.4,65.9]$ \\
\hline 7 & 66.4 & 67.3 & 66.3 & 67.4 & 66.1 & 67.5 & & \\
\hline 8 & 66.3 & 67.3 & 66.4 & 67.5 & 66.4 & 67.7 & 66.3 & 67.7 \\
\hline 9 & 66.5 & 67.3 & 66.6 & 67.6 & 66.4 & 67.6 & & \\
\hline 10 & 66.3 & 67.4 & 67.1 & 68 & 66.5 & 67.7 & 66.8 & 67.8 \\
\hline 11 & 66.6 & 67.6 & 67.1 & 68 & 66.6 & 67.8 & & \\
\hline 12 & 66.2 & 67.2 & 66.6 & 67.8 & 66.6 & 67.8 & 66.2 & 67.6 \\
\hline 13 & 66.4 & 67.5 & 66.6 & 67.6 & 66.6 & 67.7 & & \\
\hline 14 & 66.6 & 67.6 & 66.5 & 67.6 & 66.5 & 667.8 & & \\
\hline 15 & 66.5 & 67.5 & 66.5 & 67.5 & 66.4 & 67.6 & 66.3 & 67.6 \\
\hline $1 \mathrm{~s}$ & 65.9 & 67 & 65.9 & 67.2 & 66 & 67.4 & & \\
\hline $2 s$ & 66.1 & 67.1 & 66 & 67.3 & 66.2 & 67.5 & 66.2 & 67.5 \\
\hline $3 s$ & 65.8 & 67.1 & 65.8 & 67.2 & 66.1 & 67.4 & & \\
\hline $4 s$ & 65.7 & 67 & 65.8 & 67.2 & 65.9 & 67.3 & & \\
\hline $5 s$ & 65.8 & 66.9 & 65.6 & 67 & 65.8 & 67.3 & & \\
\hline
\end{tabular}

Note: Gages 1 thru 15 were 72 inch thermocouple wire and 1s thru 5s were 36 inch thermocouple wire, to be used as spares. Both sets of thermocouple wires were silver soldered in the lab. 
Table 7.2

Converted Time

Chart

Equivalent time chart for Interpretation and Analysis

I-80 Danville, PA Investigation 16 October 1998

(Time $=0$ at 0800 hours)

\begin{tabular}{|c|c|c|c|c|c|c|c|c|c|}
\hline Date & Mil Time & Act Time & AM/PM & Hour & Date & Mil Time & Act Time & AM/PM & Hour \\
\hline \hline 16-Oct-98 & 800 & 800 & AM & 0 & 17 -Oct-98 & 1200 & 1200 & PM & 28 \\
\hline & 900 & 900 & & 1 & & 1300 & 100 & & 29 \\
\hline & 1000 & 1000 & & 2 & & 1400 & 200 & & 30 \\
\hline & 1100 & 1100 & & 3 & & 1500 & 300 & & 31 \\
\hline & 1200 & 1200 & PM & 4 & & 1600 & 400 & & 32 \\
\hline & 1300 & 100 & & 5 & & 1700 & 500 & & 33 \\
\hline & 1400 & 200 & & 6 & & 1800 & 600 & & 34 \\
\hline & 1500 & 300 & & 7 & & 1900 & 700 & & 35 \\
\hline & 1600 & 400 & & 8 & & 2000 & 800 & & 36 \\
\hline & 1700 & 500 & & 9 & & 2100 & 900 & & 37 \\
\hline & 1800 & 600 & & 10 & & 2200 & 1000 & & 38 \\
\hline & 1900 & 700 & & 11 & & 2300 & 1100 & & 39 \\
\hline & 2000 & 800 & & 12 & $18-O c t-98$ & 0 & 1200 & AM & 40 \\
\hline & 2100 & 900 & & 13 & & 100 & 100 & & 41 \\
\hline & 2200 & 1000 & & 14 & & 200 & 200 & & 42 \\
\hline & 2300 & 1100 & & 15 & & 300 & 300 & & 43 \\
\hline $17-$ Oct-98 & 0 & 1200 & AM & 16 & & 400 & 400 & & 44 \\
\hline & 100 & 100 & & 17 & & 500 & 500 & & 45 \\
\hline & 200 & 200 & & 18 & & 600 & 600 & & 46 \\
\hline & 300 & 300 & & 19 & & 700 & 700 & & 47 \\
\hline & 400 & 400 & & 20 & & 800 & 800 & & 48 \\
\hline & 500 & 500 & & 21 & & 900 & 900 & & 49 \\
\hline & 600 & 600 & & 22 & & 1000 & 1000 & & 50 \\
\hline & 700 & 700 & & 23 & & 1100 & 1100 & & 51 \\
\hline & 800 & 800 & & 24 & & 1200 & 1200 & PM & 52 \\
\hline & 900 & 900 & & 25 & & 1300 & 100 & & 53 \\
\hline & 1000 & 1000 & & 26 & & 1400 & 200 & & 54 \\
\hline & 1100 & 1100 & & 27 & & & & & \\
\hline
\end{tabular}




\section{GROUP \#1 Thermocouple Readings (Location X=50 feet) \\ I-80 Eastbound Lanes near Danville, PA \\ (16 October 1998 time $=0$ at $0800 \mathrm{hrs}$ )}

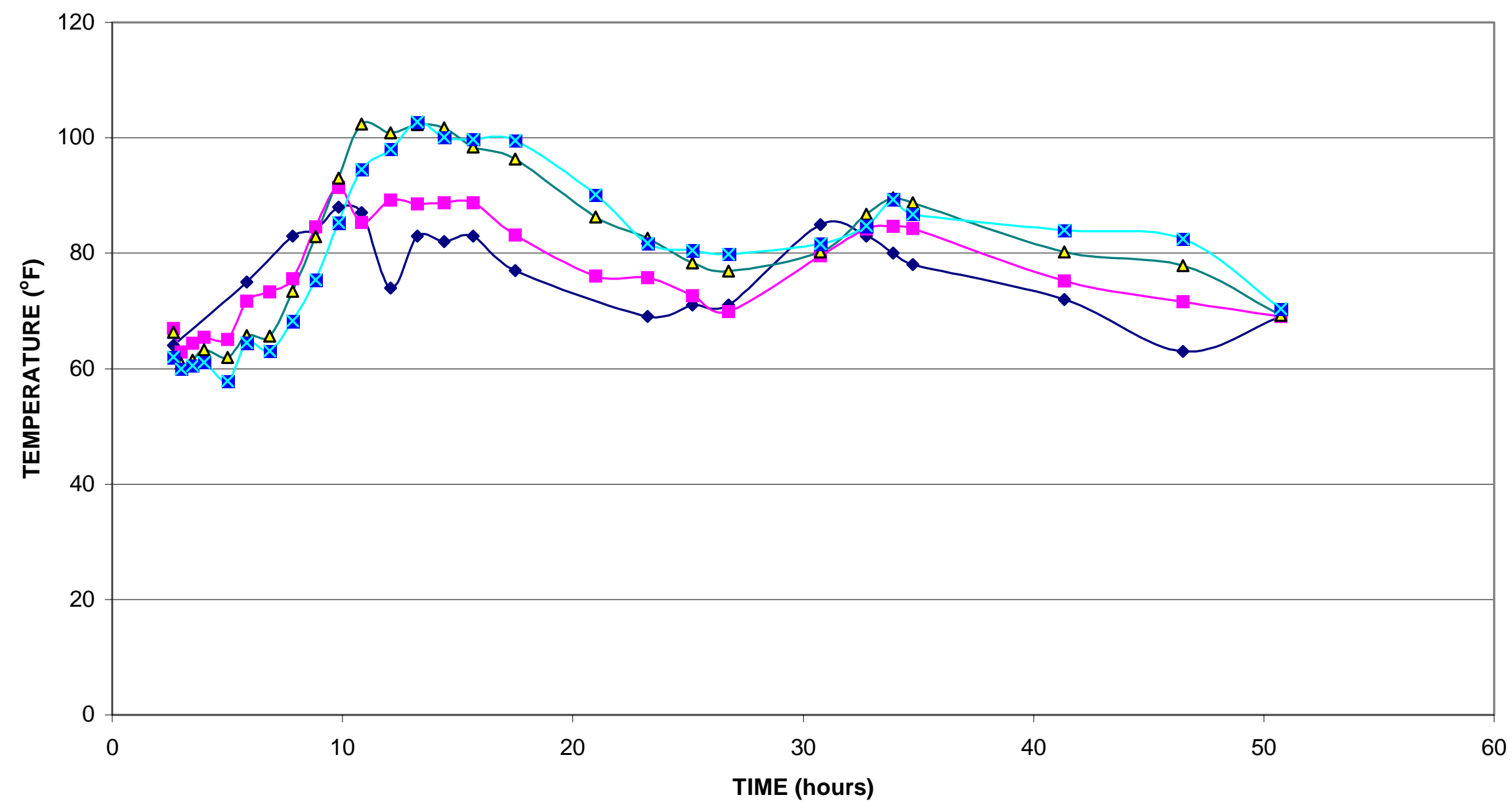

$\multimap$ Surface $\neg-1 \mathrm{~A} / \# 1 /$ top $\triangle-1 \mathrm{~B} / \# 2 /$ middle $₫-1 \mathrm{C} / \# 3 /$ bottom

Figure 7.1: Group \#1 Temperature Readings, I-80 Danville, PA 


\section{GROUP \#2 Thermocouple Readings (Location X=650 feet) I-80 Eastbound Lanes near Danville, PA \\ (16 October 1998 time $=0$ at $0800 \mathrm{hrs}$ )}

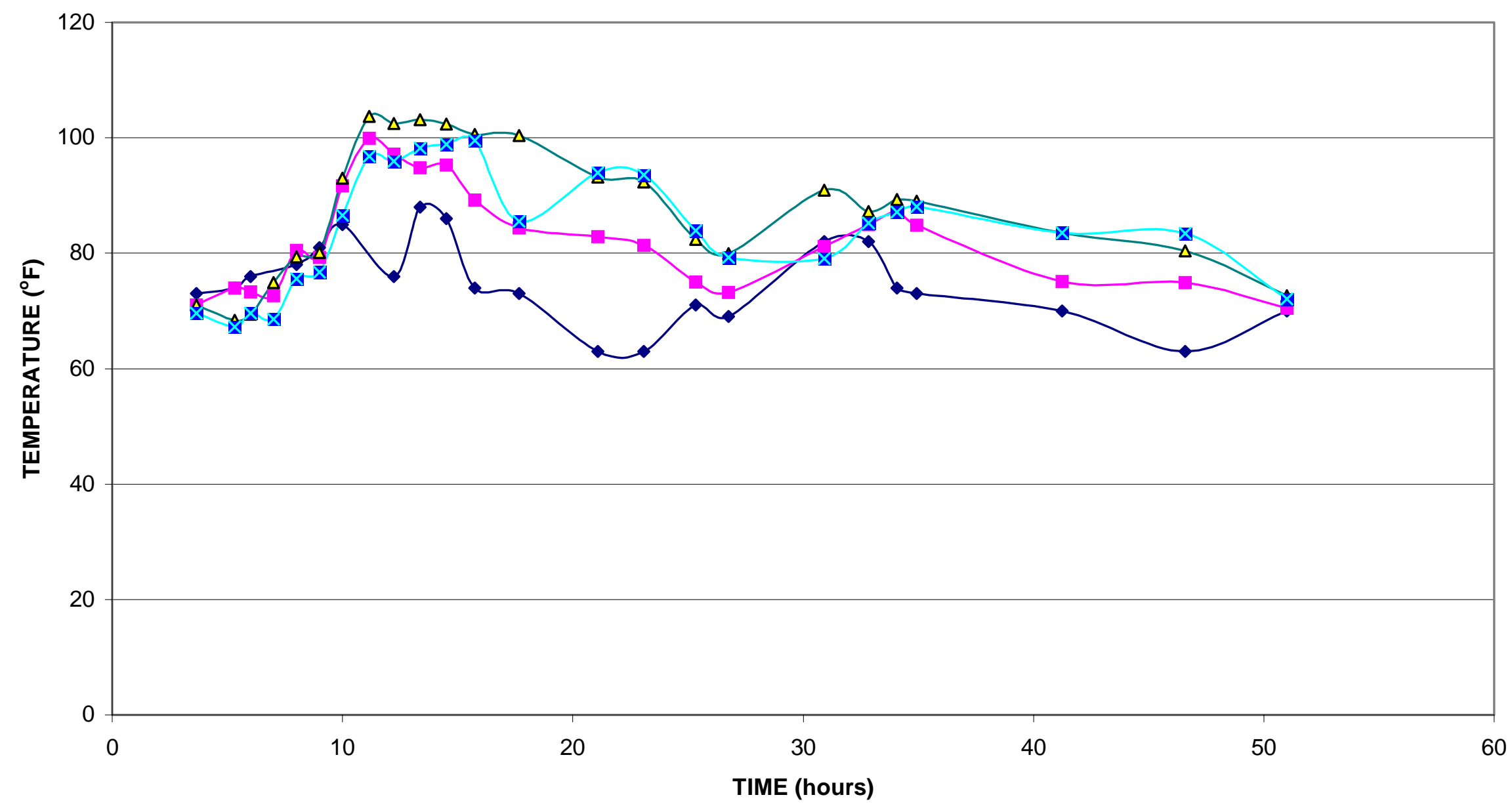

Surface $\rightarrow-2 \mathrm{~A} / \# 4 /$ top $\triangle-2 \mathrm{~B} / \# 5 /$ middle $\rightarrow-2 \mathrm{C} / \# 6 /$ bottom

Figure 7.2: Group \#2 Temperature Readings, I-80 Danville, PA 


\section{GROUP \#3 Thermocouple Readings (Location X=1250 feet) \\ I-80 Eastbound Lanes near Danville, PA \\ (16 October 1998 time $=0$ at $0800 \mathrm{hrs}$ )}

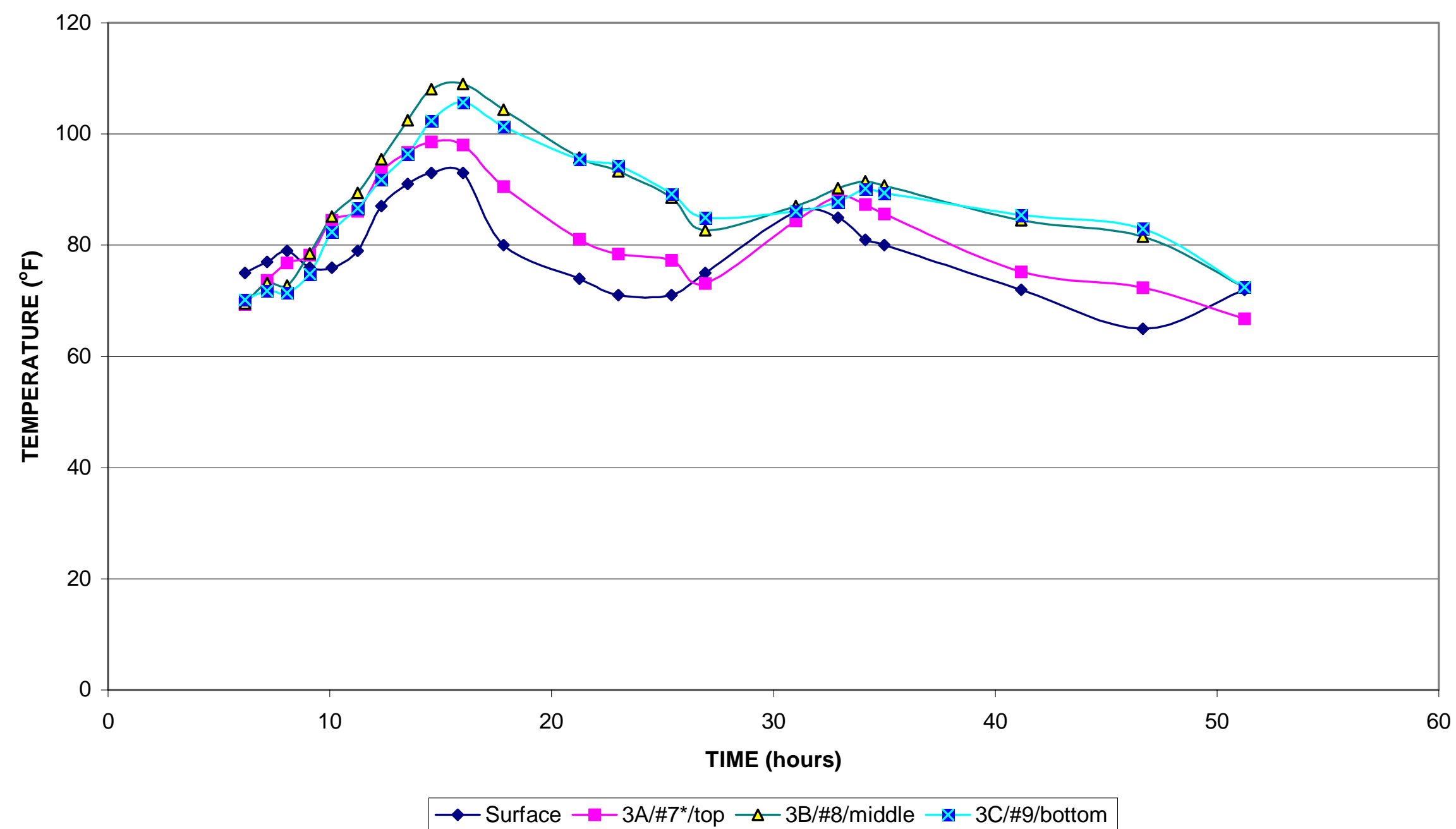

Figure 7.3: Group \#3 Temperature Readings, I-80 Danville, PA 


\section{GROUP \#4 Thermocouple Readings (Location X=1950 feet)}

I-80 Eastbound Lanes near Danville, PA

(16 October 1998 time $=0$ at 0800 hrs)

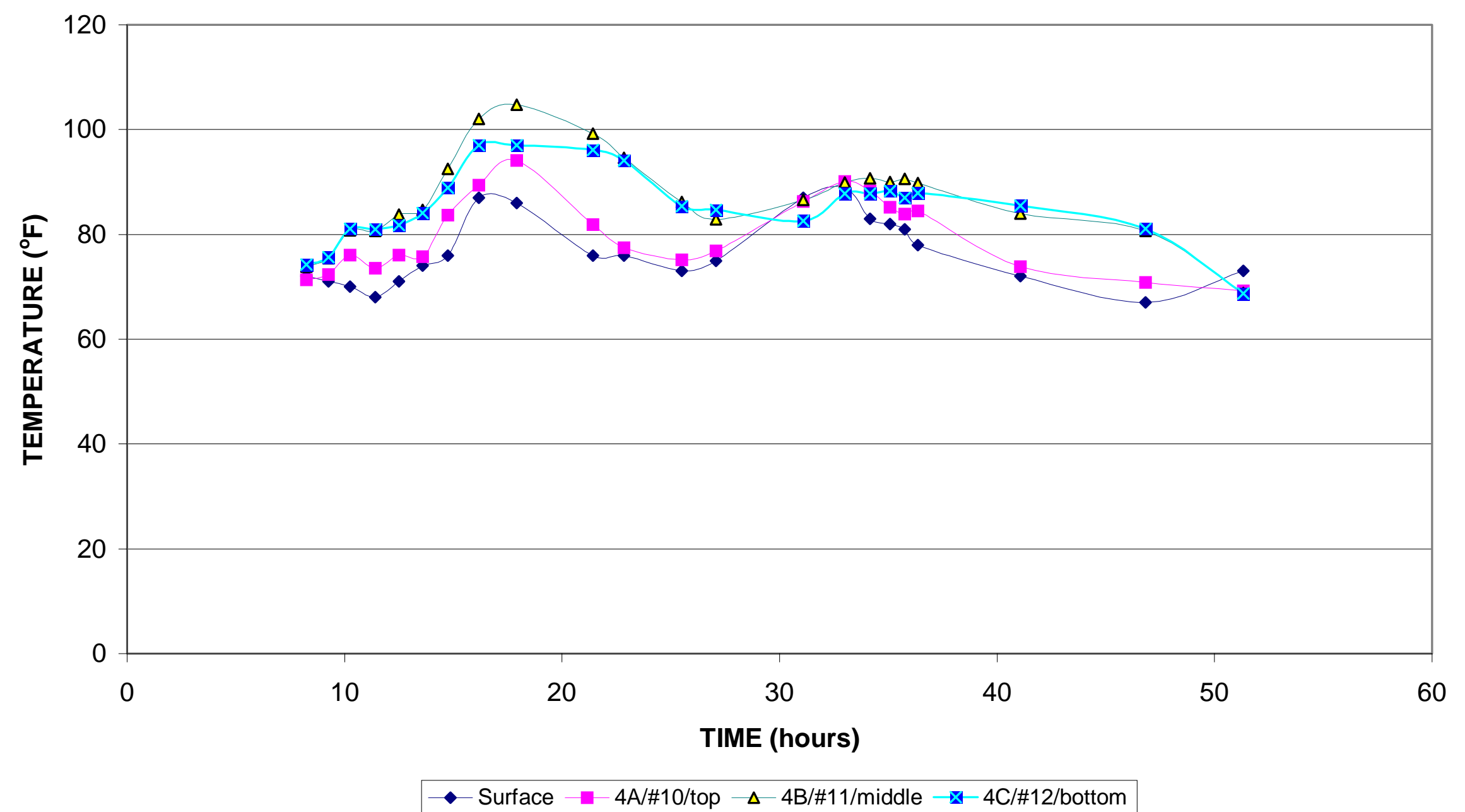

Figure 7.4: Group \#4 Temperature Readings, I-80 Danville, PA 


\section{GROUP \#5 Thermocouple Readings (Location X=2650 feet) \\ I-80 Eastbound Lanes near Danville, PA \\ (16 October 1998 time $=0$ at $0800 \mathrm{hrs}$ )}

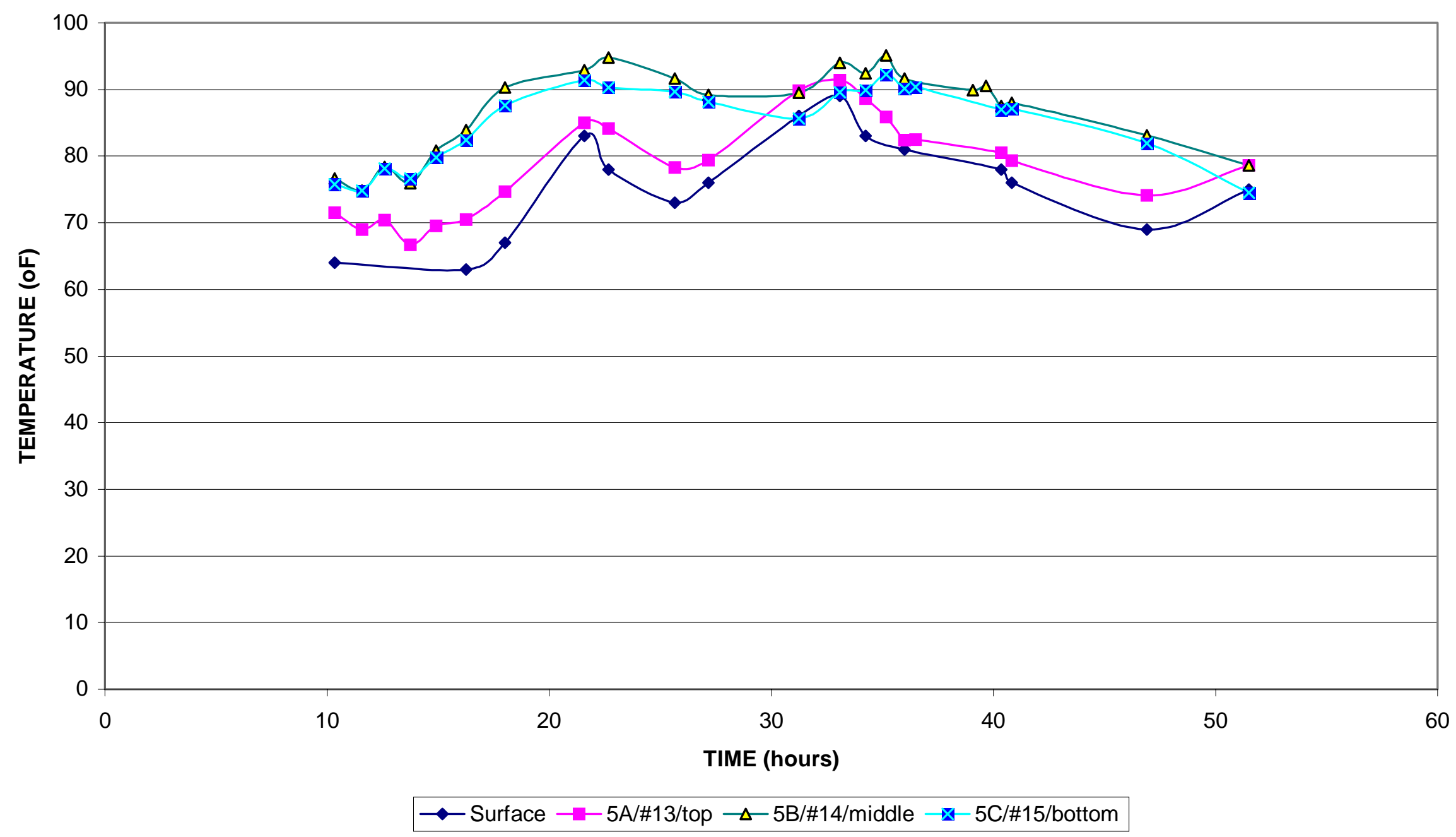

Figure 7.5: Group \#5 Temperature Readings, I-80 Danville, PA 


\section{GROUP \#6 Thermocouple Readings (Location X=2830 feet) \\ I-80 Eastbound Lanes near Danville, PA \\ (16 October 1998 time $=0$ at $0800 \mathrm{hrs}$ )}

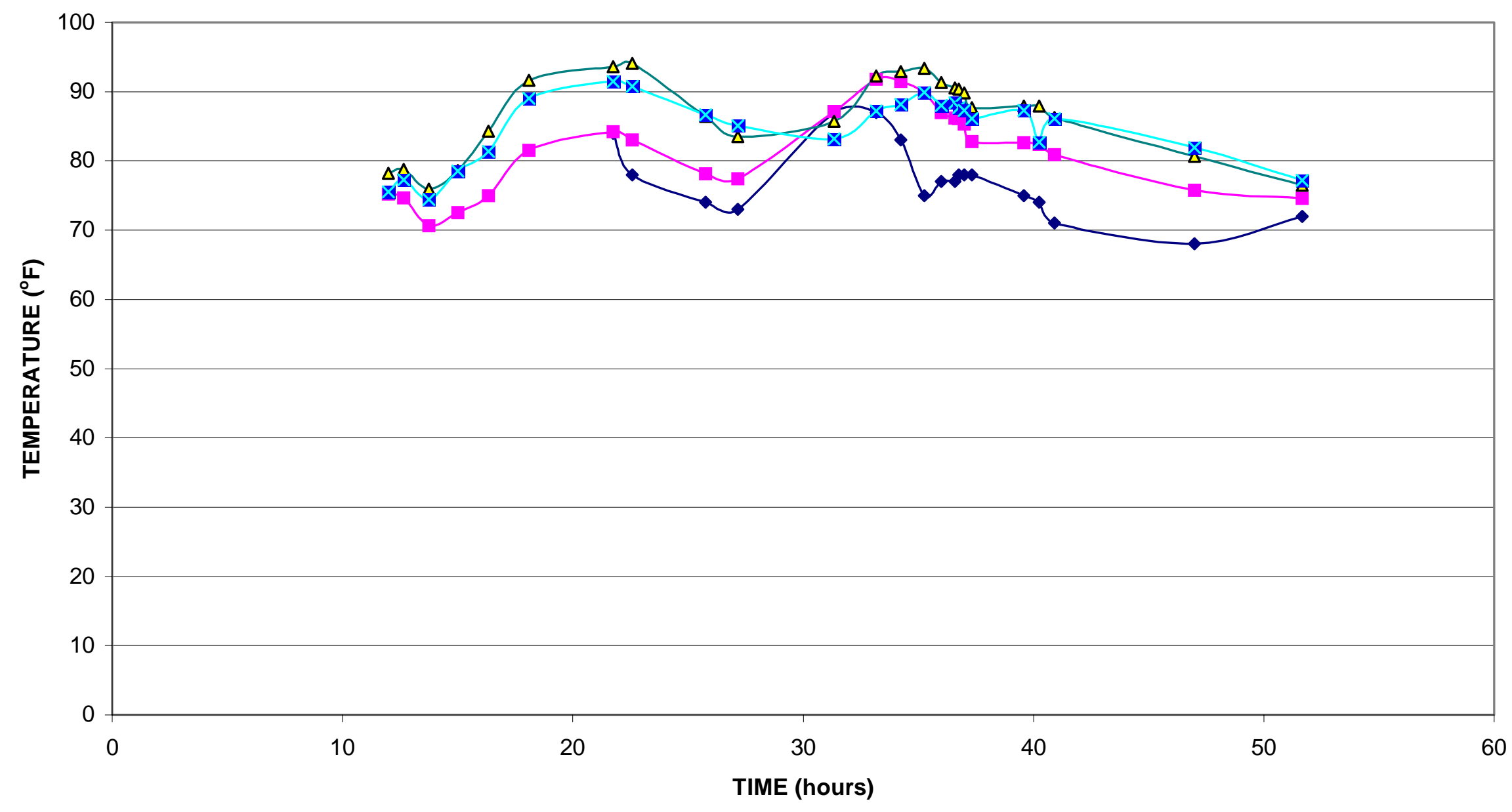

$\multimap$ Surface $\neg-6 \mathrm{~A} / \# 3 s /$ top $\triangle-6 \mathrm{~B} / \# 4 \mathrm{~s} /$ middle $₫-6 \mathrm{C} / \# 5 \mathrm{~s} /$ bottom

Figure 7.6: Group \#6 Temperature Readings, I-80 Danville, PA 
AMBIENT TEMPERATURES versus TIME

I-80 Danville Investigation (field data compared to climatic data)

(Time $=0$ at 0800 hrs 16 Oct 98)

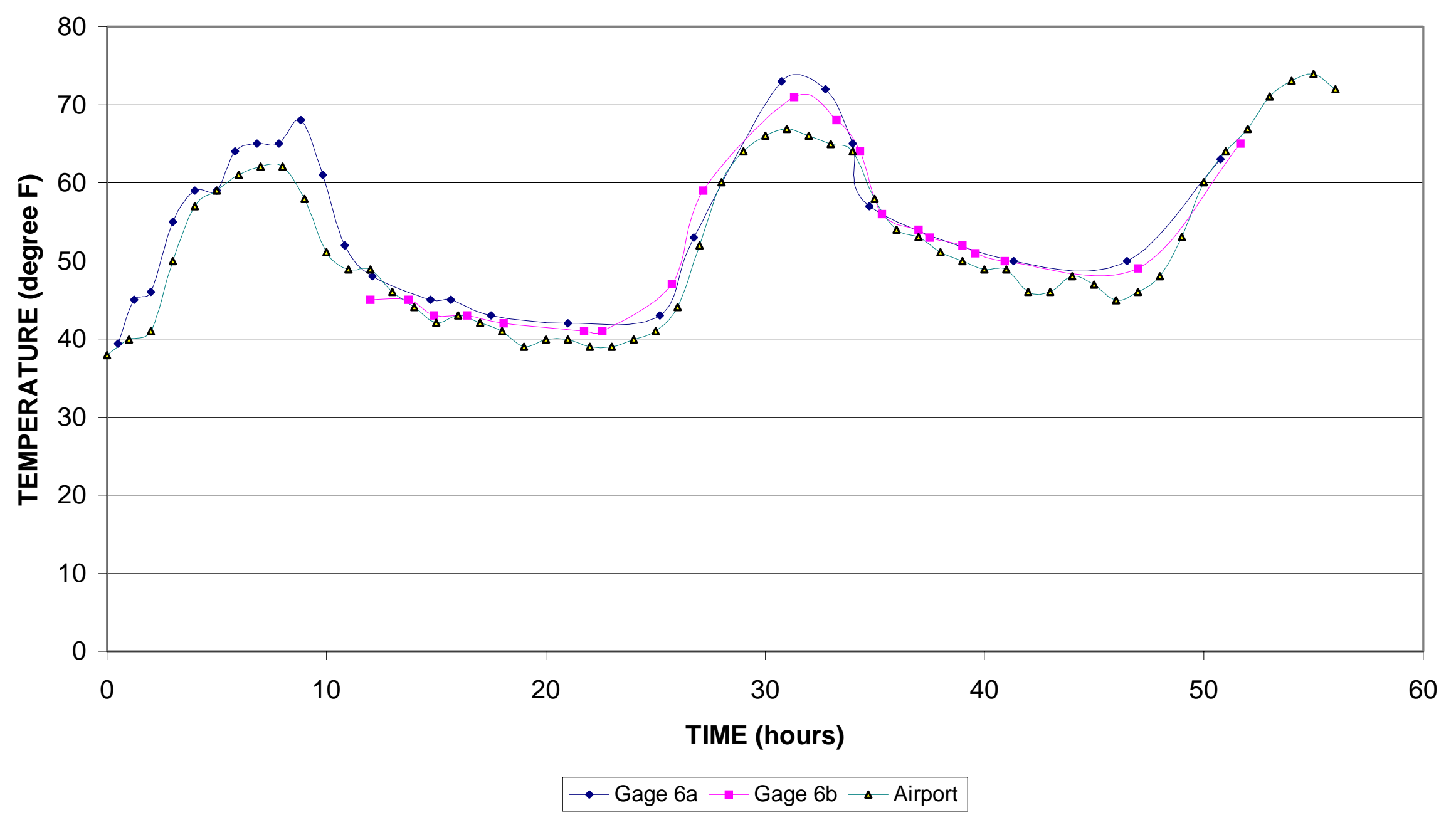

Figure 7.7: Field Thermocouples versus Local Airport Ambient Temperatures, I-80 Danville, PA 
ASHPHALT TREATED PERMIABLE BASE AND AMBIENT TEMPERATURES

DURING CONCRETE PLACEMENT

I-80 Danville Investigation 16 October 1998 (time $=0$ at $0800 \mathrm{hrs}$ )

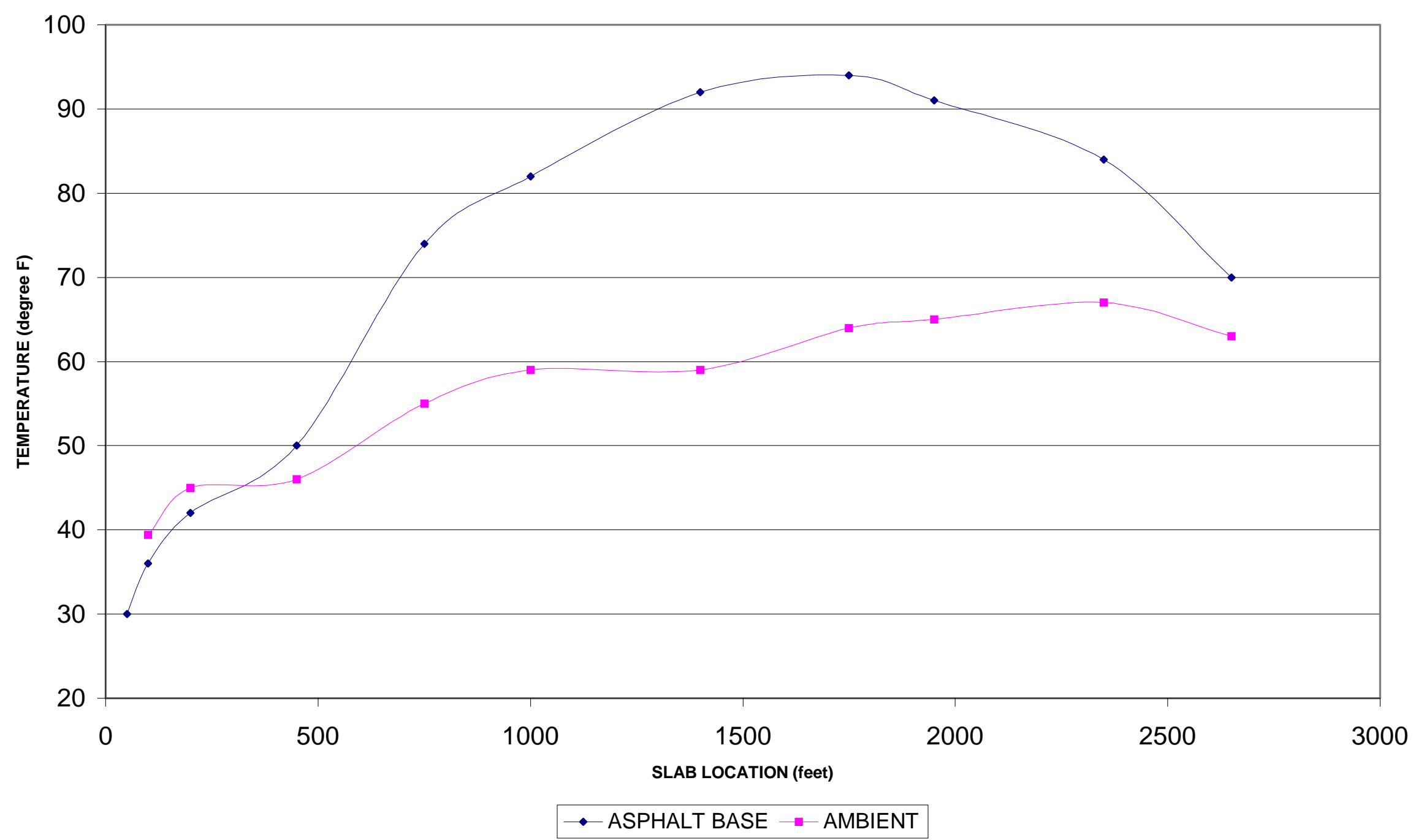

Figure 7.8: Asphalt Base and Corresponding Ambient Temperature Readings, I-80 Danville, PA 


\subsection{Crack Behavior, I-80 Danville}

\section{3a. 16 October 1998 slab section (Instrumented)}

As previously mentioned, there were two separate slab sections of I-80 near Danville, PA that were checked for transverse joint crack development during this investigation. The section of pavement instrumented and continuously monitored is discussed in this section. The crack formations were monitored on the outside lane edge only for reasons discussed in chapter 5.3a. Crack initiation by location was not recorded, but crack formation was visually seen to basically start at the earlier placed slab end and propagated toward the younger end. Actual crack width measurements were taken at the top and bottom of the joint crack, being 1-inch down from the base of the saw cut and 1inch up from the base course, respectively. The measurements were taken along the slab length and given an average time for reference, being 26 and 51.25 hours after initial concrete placement. The results can be seen in Figures 7.9 and 7.10. Little differences in the top and bottom measurements were observed at the times the measurements were taken. The times when measurements were taken were both daytime hours when temperature gradients in the slab were low. Observations of nighttime cracks revealed the tops in many cases to be reasonably wider than the bottoms when the temperature gradients in the slab were high. Unfortunately due to the reasons discussed in Section 7.1, these results were not recorded.

The transverse, joint crack width development over time, using the top measurements only, can be seen in Figure 7.11. From these graphs, it can be seen that the concrete slab did not crack over the entire length the first night; only $2 / 3$ to $3 / 4$ did. The larger joint cracks found after the first night were around 1 to $2 \mathrm{~mm}$ wide and spaced around every 
fourth to sixth joint, or 80 to 120 feet. Several very small joint cracks, less than $0.2 \mathrm{~mm}$, were found to have formed between some of the more vastly-spaced, larger joint cracks. Most of these smaller cracks were found not to increase in size much, if at all, in later checks. The growth of the larger joint cracks from the first night to the second night can be seen to have increased in size, up to around 3 to $5 \mathrm{~mm}$ in width. Also during the second night, intermediate joints cracked between some of the first night larger joint crack locations. These cracks were found to be much smaller in width.

The non-cracked section of slab from the first night, after joint number 101, became critical during the early evening hours of the second night. The second night's joint cracks were of similar size and spacing of the larger joints observed during the first night of cracking. The crack width formations the second night expanded much faster than those during the first night. The section that did not crack during the first night was observed to propagate in cracking sequence from the older concrete to the younger concrete end of the slab. The remaining slab length cracked quickly after joint number 101 and reached widths similar to those cracks that formed the first night.

The majority of early transverse joint crack formation was believed to be mostly complete after the second night of observation. The monitoring was ended after cracking had stopped for several hours and temperature gradients in the slab decreased when the sun came up and the ambient temperature rose, around eleven o'clock on the 18th.

The final crack formation observed at 51.25 hours after initial concrete placement was of similar spacing to that seen at the I-79 Marianna investigation at 43 hours after placement which was discussed in Chapter 6. The comparisons of all the investigated slabs will be further discussed in Chapter 9. 
Upon the completion of the instrumented and monitored slab, another section of I-80 pavement placed on October $12^{\text {th }} 1998$ was examined for joint crack width formation. The results from this are in the following section.

\section{3b. 12 October 1998 slab section (Non-instrumented)}

The second section of I-80 eastbound lanes, whose joint crack formations were recorded, but was not instrumented, was on a slab section placed on October $12^{\text {th }}, 1998$. This slab section was constructed in the same manner as the instrumented section, being slip-formed. The mix designs were identical, but the course depths were not. This section of pavement had a typical concrete thickness of 16 inches, an ATPBC ranging from 6 to 12 inches thick, and was again placed on rubblized concrete. The slab was 2535 feet long and the transverse joints cut on a 1:6 skew. The joints were saw-cut at 20foot spacing. The joints were numbered from 0 , at the start, to 127 , at the end of that day's construction. The last slab section was only 15 -feet long, totaling the 2535 feet slab. Concrete placement was known to have commenced at 0745 hours on the $12^{\text {th }}$. The joint crack measurements at the top and bottom of the slab were performed at around 147 hours after that time, between 915 a.m. and 1030 a.m. on the $18^{\text {th }}$. The results can be seen in Figure 7.12.

The joint crack formation was found to have similar spacing, being every $4^{\text {th }}$ to $6^{\text {th }}$ saw cut joint cracked. As expected, the crack widths observed were larger, since the slab was older and had cooled more during observation. The cracks ranged from 4 to $8 \mathrm{~mm}$, generally. It was seen that where smaller intermediate joint cracks had formed, the relatively larger nearby joint crack widths were only 3 to $5 \mathrm{~mm}$. The top and bottom 
measurements were quite similar because of the slab age and temperature stabilization, and because there was little temperature gradient. These results along with the other slab investigation results are further discussed in chapter 9. 


\section{Crack Width Development at 26 Hours}

I-80 Eastbound Lanes Danville, PA

(Time $=0$ at 8:00 AM, 16 Oct 98)

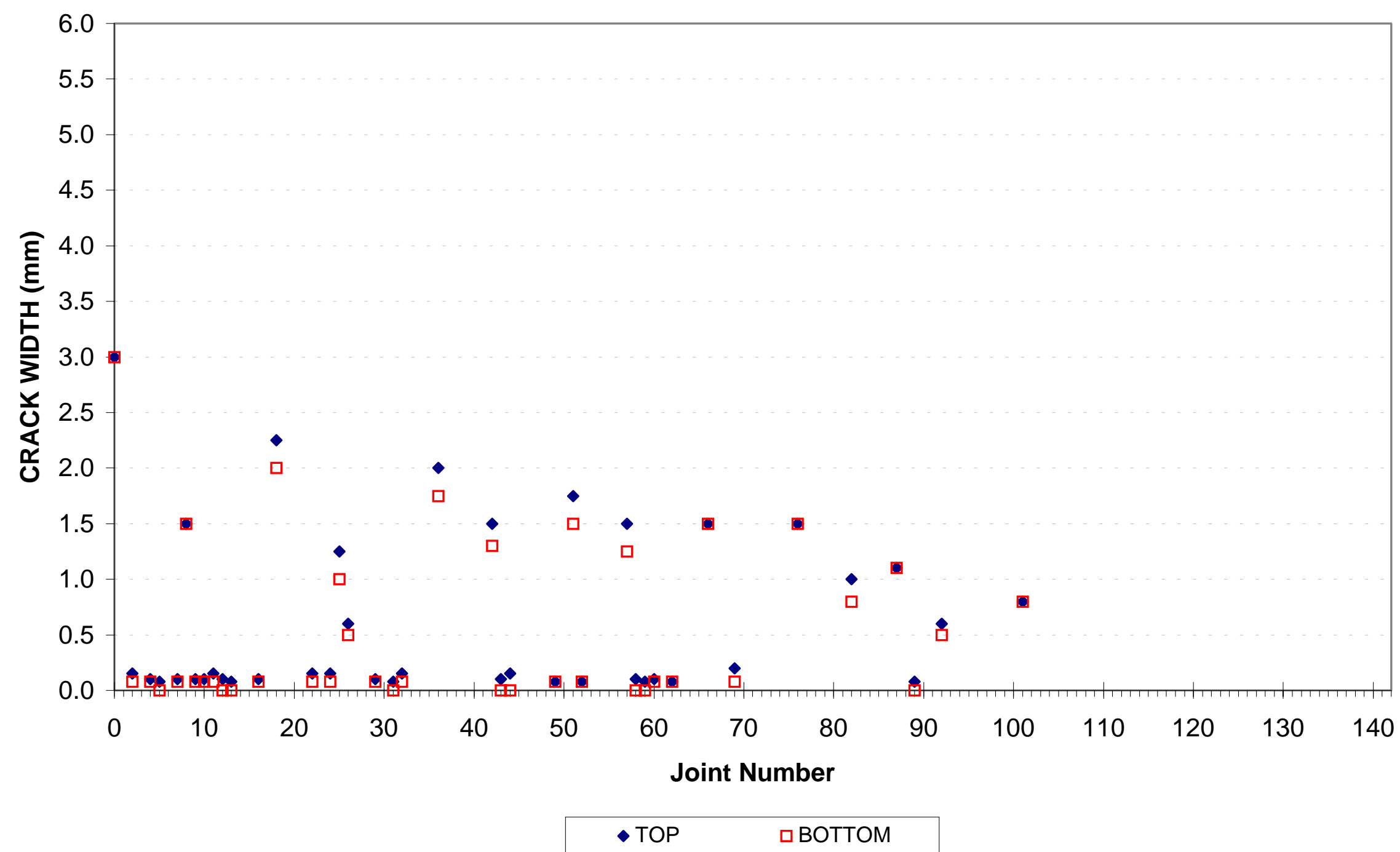


Crack Width Development at 51.25 Hours

I-80 Eastbound Lanes near Danville, PA

(Time $=0$ at 8:00 AM, 16 Oct 98)

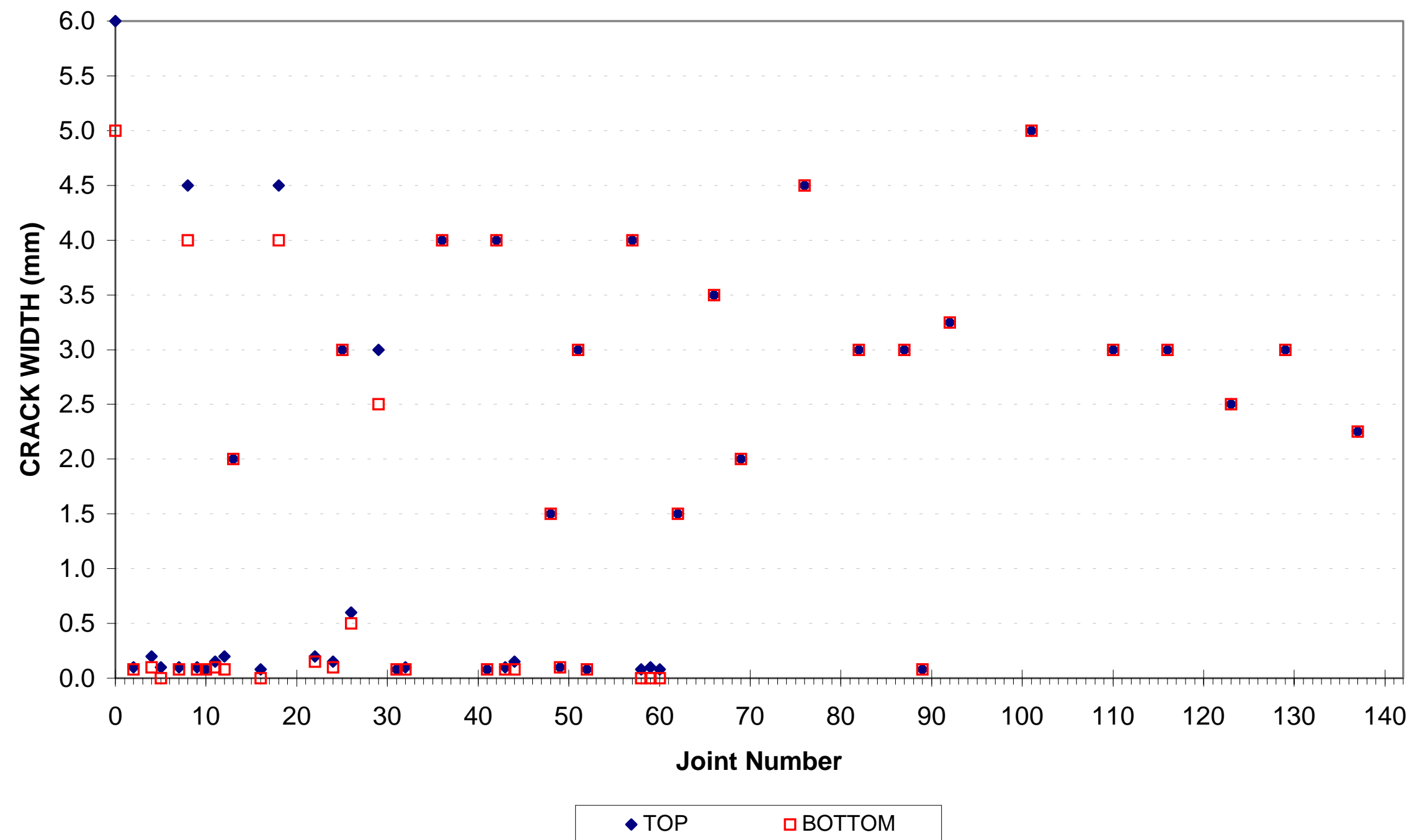




\section{Crack Width Development \\ I-80 Eastbound Lanes Danville, PA}

(Time $=0$ at 8:00 AM, 16 Oct 98)

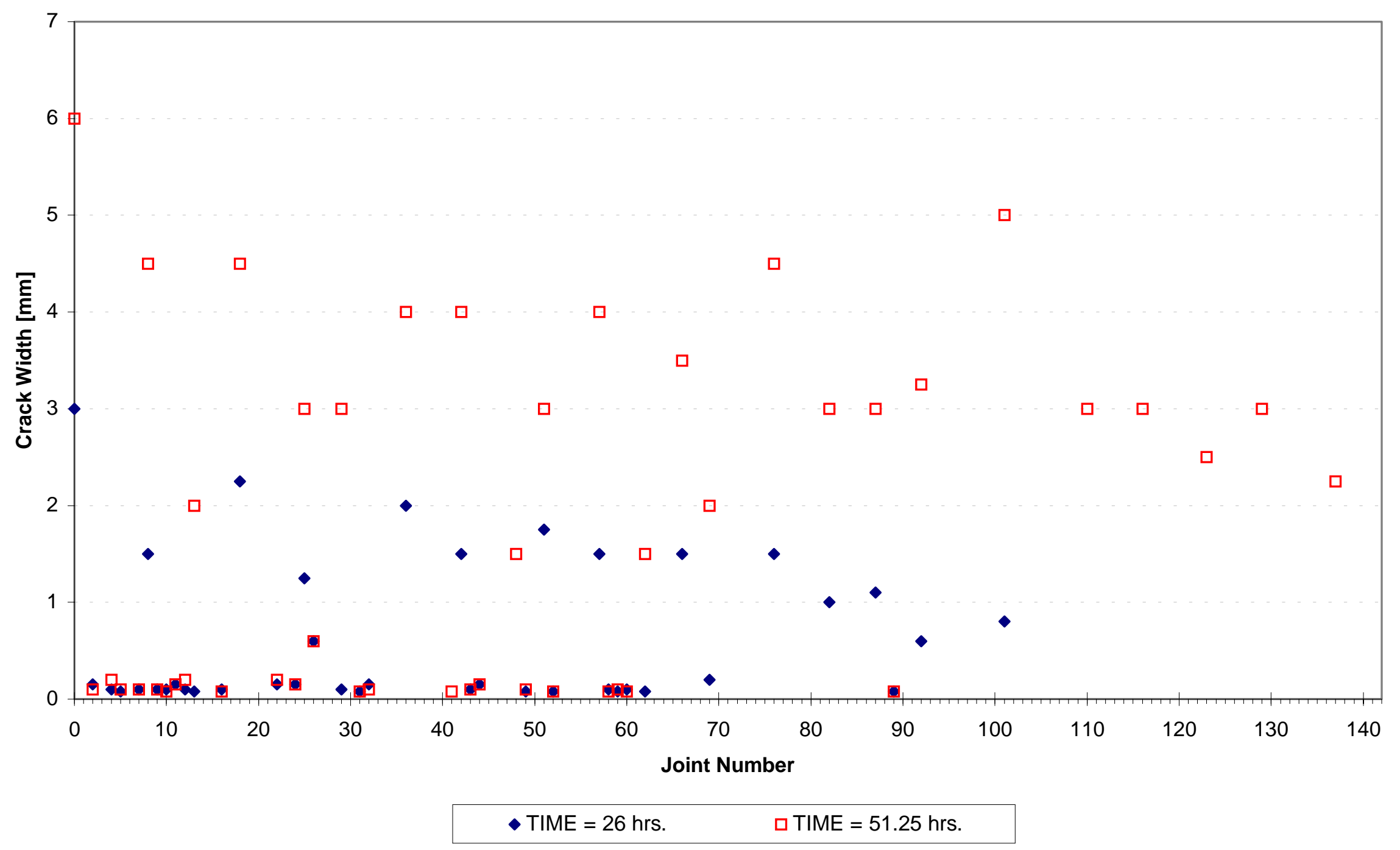

Figure 7.11: Crack Development at various times (Instrumented Slab Section), I-80 Danville, PA 
Crack Width Development at 147 hours

I-80 Eastbound Lanes near Danville, PA

(time $=0$ at 7:45 AM, 12 Oct 98)

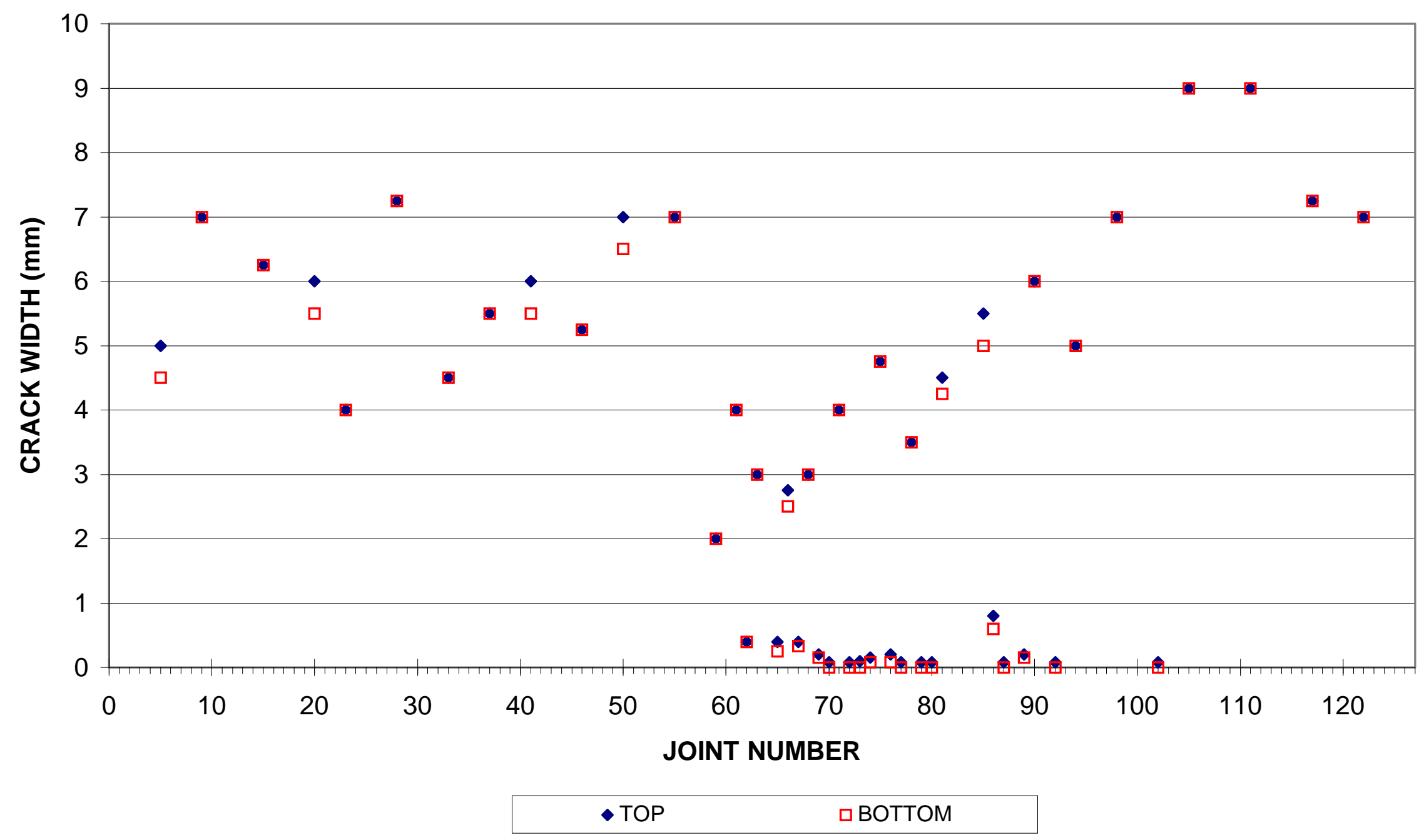

Figure 7.12: Crack Development of Non-instrumented Slab Section (at 147 hours), I-80 Danville, PA 


\subsection{Discussion, I-80 Danville}

The examination of the temperature and joint crack formation data obtained from the I-80 Danville investigation showed similar behavior to the I-79 Marianna investigation. The slab temperature trends by depth and location were nearly identical, although the actual values were different. The concrete temperature increased due to the hydration process as expected. The maximum temperature reached by each location was again between 10 to 12 hours of concrete age by location. Each location's temperature history profile varies due to the ambient temperature history the maturing concrete was exposed to. After the initial hydration process was completed, the ambient temperature affects on the concrete were much more pronounced.

Crack development in the I-80 slab section was found to occur during the nighttime hours only. It was seen that the first $2 / 3$, or so, of the slab cracked during the first night and cracking recommenced the second night. By looking at the different group temperature graphs, different cracking potentials could be expected. Crack formation was observed to occur when large temperature gradients due to the lower ambient temperature at night and where the core temperature in the slab sufficiently dropped. The combination of the temperature behavior's develop tensile stresses, which cause the crack formation. During the daytime, the concrete was seen to warm up due to higher ambient temperatures and solar radiation, which caused very low temperature gradients and retained or increased the slab core temperatures. Therefore during the daytime hours, the additive stresses developed were not greater than the available tensile strengths throughout the slab length, so no additional cracking was observed. 
The core temperature drop from the maximum varied along the slab length during the first night. The more mature concrete at the beginning of the slab was affected more by the ambient temperature drop than the less mature concrete at the end of the slab. The last third of the slab length did not crack the first night. This is mainly due to the fact that the ambient temperatures during the first night did not affect that sections core temperatures very much. The less mature concrete region was reaching a maximum temperature around the same time as the second-day daylight arrived. The increasing daytime ambient temperatures reduced the tensile stresses and reduced the cracking potential of the entire slab.

The concrete slab temperature profiles for each location were becoming similar as the second night's ambient temperature dropped. The entire slab was seen to have significant core temperature drop and temperature gradient, thus, making the entire slabs cracking potential higher. The remaining non-cracked section was expected to be experiencing full restraint stresses, while the section that cracked during the first night would be experiencing mainly frictional restraint stress. (See also chapter 10)

The final temperature checks performed, taken at 52 hours from initial concrete placement, showed that the entire slab was converging to similar temperature values for every depth and location, only slightly higher at the less mature end of the slab. The core temperature drop was significant, 20 to $30^{\circ} \mathrm{F}$, and the temperature gradients were very small, almost zero, at every location. The entire slab length had cracked and the initial crack formation was believed to be complete. It was expected that the joint cracks would only widen after that point, thus came the judgement to conclude the investigation. 
Further discussion of the early age concrete slab behaviors investigated can be seen in chapter 9. 


\section{Chapter 8: Corridor H Investigation near Elkins, WV October 12, 1999:}

\subsection{Introduction and Site Description}

The last, PCC highway pavement construction investigation performed was on a section of Corridor H near Elkins, WV (project number APD-0484 (145), X342-H-31.00 03). The concrete slab section investigated was placed on October 12, 1999. Concrete placement commenced at 0830 hours and concluded the day's placement at 1830 hours. The concrete was placed at approximately 11 inches in depth and 24 feet wide. The construction was slip-form non-reinforced rigid pavement as required. The construction design was different than the other investigations, but was placed in similar technique. Mix designs, base coarse materials, various course depths and concrete curing techniques can be seen in Chapter 3. The base course material was FDB, (free drain base), that of the design studied in Phase I. The cross-sectional design for the investigated pavement can be seen in Figure 5.4c. Two sections joint crack formations were obtained during this investigation; one from the instrumented investigated section placed on October $12^{\text {th }}$ and one from the next day's construction on October $13^{\text {th }}$. The WVDOT District 8 engineers, supervisors, and other personnel, as well as Hi-way Paving Inc. personnel were all very helpful and cooperative in every aspect of the work we performed. Their assistance and interest in the work we were performing was vital to the resulting data that we were able to collect. Mr. Gary Robson of the ACPA was also very helpful in making the monitoring a success.

The concrete slab construction started at a wooden framed bulkhead around location $80+878$ and ended at another wooden bulkhead around station $80+325$. The thermocouples, strain gages and joint crack measuring instrumentation equipment and 
techniques used during this investigation can be seen in Chapter 3.5. The concrete slab sections placed were cured with white curing compound as required by WVDOT specifications.

The pavement section monitored was designed in metric, but our analysis procedure to date is based on standard, English units. This is mainly because the previously monitored pavements were utilizing English units. Therefore, these conversions will cause some slight errors in some of the locations and other measurements documented. The stationing markings at the construction site were mainly approximate. The approximate starting location of concrete placement on the $12^{\text {th }}$ of October 1999 was station $80+878$, which is to be considered the zero location. The end of that day's pavement section ended around station $80+325$. This gives an approximate length of 553 meters placed, or 1814.3 feet. For our analysis, the slab placed must start at a zero location and end at a designated length in the English unit of feet. In this particular pavement section, one thousand eight hundred and fifteen feet (1815 ft) of pavement was continuously placed at an approximate rate of 181.5 feet per hour. The slab was supposed to be sectioned to transverse saw cut at every 4.5 meters, (14.76 feet). But, the joints were done at approximate 15 feet intervals instead. Therefore, one hundred and twenty (120) transverse saw cuts done closer to 15 feet instead of 4.5 meters apart forming one hundred and twenty-one (121) 15 feet sections totaling 1815 feet. This does not compare well with the field stationing showing 553 meters, but should be 544.5 meters by the number of sections cut. This error in field markings may be contributed to the lay out procedure coming from the centerline between the east and westbound lanes instead of the centerline of the concrete slab. But theoretically by using English units to measure 
where the joints should be cut at 15 feet, (4.572 meters), instead of 4.5 meters giving an 8.712 meters loss in metric conversion error in the slab specified and matches the 553.212 meter section the stationing shows. Therefore, the error is only that the joint locations were measured in the old English units, or 15 feet spacing instead of 4.5-meter spacing.

The base time frame, time equal to zero, used for the analysis was set at location zero at the onset of the concrete placement at 830 hours on October 12, 1999. This was performed for a few reasons. First, a time reference was required such that any documented events had a reference time from the beginning of concrete placement. Next, the concrete is at different maturity at different locations along the slab length and these concrete properties must be adjusted for each location, all of which must be based on the same time frame to be analyzed correctly. The equivalent time chart for the Corridor H investigation can be seen in Table 8.1.

The saw cutting began around 2100 hours on the $12^{\text {th }}$ of October $1999,12.5$ hours after concrete placement began and was completed around 0500 hours on the $13^{\text {th }}$, totaling 120 joints cut in 8 hours. The joints were cut perpendicular to the slab unlike the skewed cuts made in the Pennsylvania projects. They were 1/8-inch wide and cut to a depth of $\mathrm{h} / 4$ by design. The actual first cut depth was only 2 to 2.5 inch the first night, not to specifications. All transverse cuts were deepened to a depth of 4 inches during the afternoon of the second day. No unwanted intermediate cracking occurred due to the error.

The transverse saw cut locations were given a numbering designation starting with zero at the very beginning of the slab and ending at joint number 121 at the end of the 
slab section. The joint locations will further be designated by joint number only to ease in the analysis and explanations. (Example: For every joint number's location, simply take the joint number and multiply it by fifteen (15) feet to obtain the linear location on the slab)

The modified EM-5 strain gages utilized during the Corridor $\mathrm{H}$ investigation were to accomplish two tasks. First, the gages were tested for their compatibility in early age concrete slabs with internal stresses developing from the curing concrete and the external environmental exposure of the slab. Second, the Modulus of Elasticity tests to be conducted were designed to use the gages to assist in comparing the field sampled data and the laboratory test specimens data so that the early age values may be utilized. Five modified flanged EM-5 strain gages were purchased for the monitoring. Three were placed inside of the concrete slab and two were suspended in 6 inch by 12 -inch plastic concrete cylinder molds. The objective was to place a strain gage close to where the location of a transverse joint crack might occur. The prediction of the actual location of joint cracking is still very uncertain and could only be estimated from the behavior of previously observed concrete sections. Thus, three locations 150 feet apart, starting 153 feet from the zero location, were selected for the strain gages. The location of the placement of the strain gages numbering 1 through 3 were after joints 10, 20 and 30, respectively, (153 feet, 303 feet and 453 feet from the zero location, respectively). The location of the gages in the slab can be seen in Figure 8.1b. A crack did not occur at any of the number joints 10, 20 or 30, unfortunately. Strain Gage \#4 was suspended in one of the field specimen concrete cylinder molds as a dummy gage for the slab embedded gages. Further tests on that specimen, (7,14 and 28-day compression tests) were used to 
compare values obtained from another suspended concrete cylinder Gage \#5. Gage \#5 was suspended in a laboratory mix cylinder mold made for compression tests. (Results of the comparative compression tests can be seen in Chapter 4)

The gages placed in the slab had to be suspended and secured prior to the concrete slab placement. A suspension technique was quickly developed to allow free longitudinal movement with the gage in the slab, but not to allow the orientation, depth or transverse location of the gage to be disturbed during the concrete placement. The strain gages could not simply be placed in the slab after the concrete was placed because that would disturb a lot of concrete and the exact location and orientation could never be known precisely. The support technique developed utilized a 1/4 inch welded steel support chair, 4 stainless steel spiked bars 1 foot long with an anchor hole in each, 50 pound test mono-filament fishing line and plastic tie straps. The support systems were discussed in Chapter 3.5e. The four strain gages to be utilized in the field-testing were placed the night prior to the concrete slab placement. Three of the gages were suspended from the support system on the base course. Trenches or ditches, about $1 / 2$ to 1 inch deep and about eight feet long, were made in the base course to contain the gages cables and each covered with a $3 / 4$ inch plywood sheet to protect them from the construction equipment that had to track over those locations. Fresh concrete was shoveled from the concrete paving equipment and placed under and around the gage just prior to paving equipment arrival. That was done to minimize any impact that may occur from the concrete being placed by the auger machine. The vibrators in the paving equipment then pass over the gage location and assist in molding the concrete sufficiently around the gage. The cables were undamaged after the equipment tracked over them. The complete 
stability of the gages can not be known for certain but the best precautions were utilized to minimize any disturbances. 
Table 8.1

Converted Time Chart

Equivalent Time Chart for Interpretation and Analysis

Corridor H Elkins, WV October 12, 1999

( Time $=0$ at $0830 \mathrm{hrs}$ )

\begin{tabular}{|c|c|c|c|c|c|c|c|c|c|}
\hline Date & Hour & Mil Time & Act Time & AM/PM & Date & Hour & Mil Time & Act Time & AM/PM \\
\hline \multirow[t]{16}{*}{ 12-Oct-99 } & 0 & 830 & 830 & AM & |14-Oct-99 & 40 & 30 & 1230 & AM \\
\hline & 1 & 930 & 930 & & & 41 & 130 & 130 & \\
\hline & 2 & 1030 & 1030 & & & 42 & 230 & 230 & \\
\hline & 3 & 1130 & 1130 & & & 43 & 330 & 330 & \\
\hline & 4 & 1230 & 1230 & PM & & 44 & 430 & 430 & \\
\hline & 5 & 1330 & 130 & & & 45 & 530 & 530 & \\
\hline & 6 & 1430 & 230 & & & 46 & 630 & 630 & \\
\hline & 7 & 1530 & 330 & & & 47 & 730 & 730 & \\
\hline & 8 & 1630 & 430 & & & 48 & 830 & 830 & \\
\hline & 9 & 1730 & 530 & & & 49 & 930 & 930 & \\
\hline & 10 & 1830 & 630 & & & 50 & 1030 & 1030 & \\
\hline & 11 & 1930 & 730 & & & 51 & 1130 & 1130 & \\
\hline & 12 & 2030 & 830 & & & 52 & 1230 & 1230 & PM \\
\hline & 13 & 2130 & 930 & & & 53 & 1330 & 130 & \\
\hline & 14 & 2230 & 1030 & & & 54 & 1430 & 230 & \\
\hline & 15 & 2330 & 1130 & & & 55 & 1530 & 330 & \\
\hline \multirow[t]{24}{*}{ 13-Oct-99 } & 16 & 30 & 1230 & AM & & 56 & 1630 & 430 & \\
\hline & 17 & 130 & 130 & & & 57 & 1730 & 530 & \\
\hline & 18 & 230 & 230 & & & 58 & 1830 & 630 & \\
\hline & 19 & 330 & 330 & & & 59 & 1930 & 730 & \\
\hline & 20 & 430 & 430 & & & 60 & 2030 & 830 & \\
\hline & 21 & 530 & 530 & & & 61 & 2130 & 930 & \\
\hline & 22 & 630 & 630 & & & 62 & 2230 & 1030 & \\
\hline & 23 & 730 & 730 & & & 63 & 2330 & 1130 & \\
\hline & 24 & 830 & 830 & & 15-Oct-99 & 64 & 30 & 1230 & AM \\
\hline & 25 & 930 & 930 & & & 65 & 130 & 130 & \\
\hline & 26 & 1030 & 1030 & & & 66 & 230 & 230 & \\
\hline & 27 & 1130 & 1130 & & & 67 & 330 & 330 & \\
\hline & 28 & 1230 & 1230 & PM & & 68 & 430 & 430 & \\
\hline & 29 & 1330 & 130 & & & 69 & 530 & 530 & \\
\hline & 30 & 1430 & 230 & & & 70 & 630 & 630 & \\
\hline & 31 & 1530 & 330 & & & 71 & 730 & 730 & \\
\hline & 32 & 1630 & 430 & & & 72 & 830 & 830 & \\
\hline & 33 & 1730 & 530 & & & 73 & 930 & 930 & \\
\hline & 34 & 1830 & 630 & & & 74 & 1030 & 1030 & \\
\hline & 35 & 1930 & 730 & & & 75 & 1130 & 1130 & \\
\hline & 36 & 2030 & 830 & & & 76 & 1230 & 1230 & PM \\
\hline & 37 & 2130 & 930 & & & 77 & 1330 & 130 & \\
\hline & 38 & 2230 & 1030 & & & 78 & 1430 & 230 & \\
\hline & 39 & 2330 & 1130 & & & & & & \\
\hline
\end{tabular}



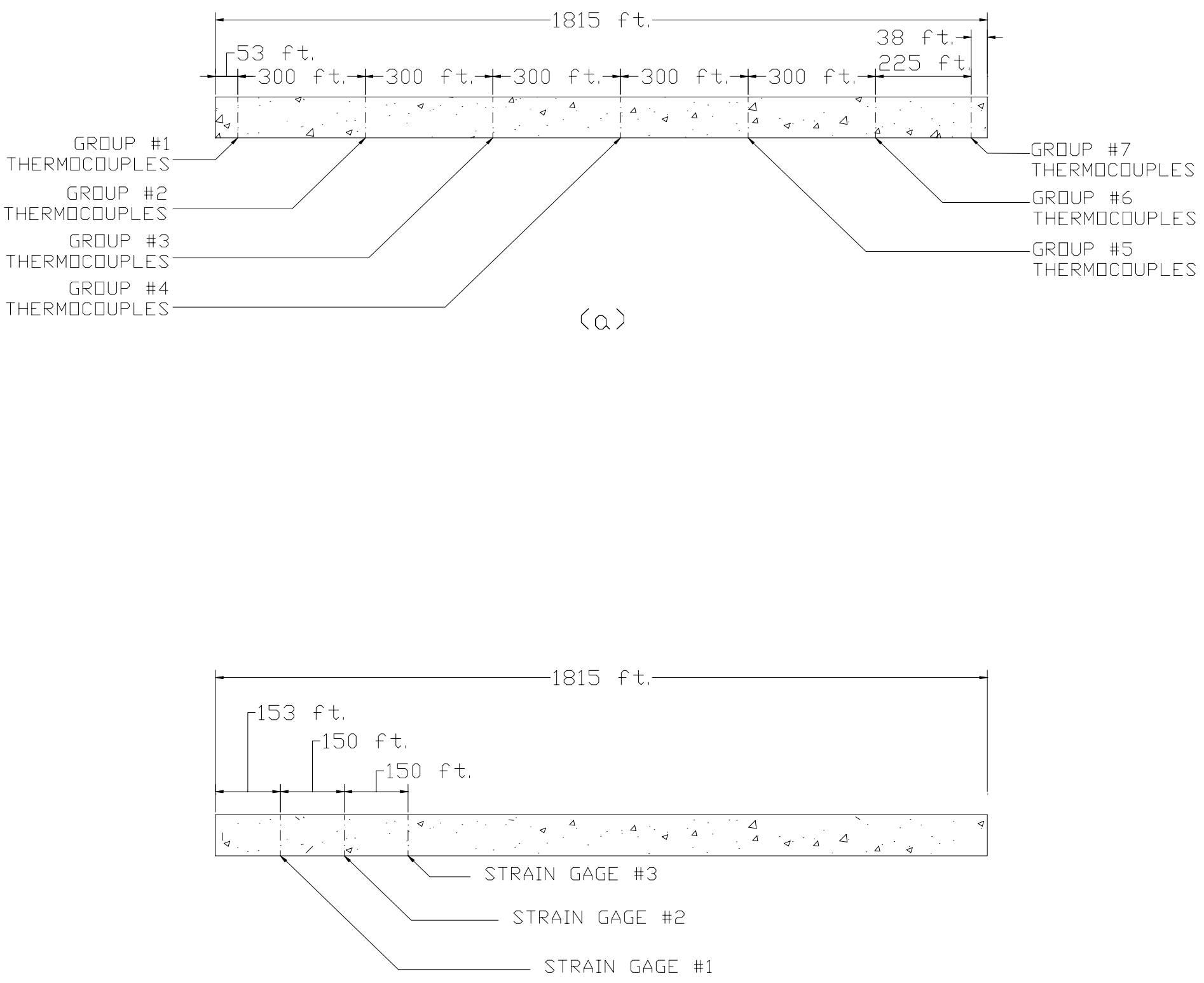

$\langle k\rangle$

Figure 8.1: Corridor H Instrumentation Locations: a) Thermocouple Groups, 


\subsection{Temperature Data, Corridor H Elkins}

The temperature data collected from the Corridor $\mathrm{H}$ investigation is the most thorough of the three investigated slab sections studied. Twenty-four type K thermocouples with six feet of wire were calibrated and labeled for use. The calibrations performed can be seen in Table 8.2. A new, back-up thermometer was obtained and both were tested during the calibrations. The thermocouples were to be utilized in various locations along the slab as well as give two ambient temperatures at two different locations, being the beginning and ending of the slab. Temperatures were to be collected at four different depths in the slab at different locations. These depths were predetermined for the 11-inch thick slab being the surface of the slab, two inches down, the center of the slab and one inch from the bottom of the slab. These were chosen because of the analysis procedure being tested and because of the concrete stability near the surface being too weak for our only insertion technique. The thermocouples were placed into the outside lane edge to a depth of 12-inches from the edge of the pavement. (See also Chapter 3)

A thermal radar unit (gun) was used to measure the slab surface temperature at the thermocouple group locations. Therefore, groups of three thermocouples were needed to collect the remaining depth temperature data at each location. The corresponding height's up from the base course were 1 inch, 5.5 inches, 9 inches and 11 inches, giving data for bottom, middle, top and surface locations, respectively. A thermocouple insertion technique was developed and discussed in Chapter 3.5b. The groups were to be placed at 300 feet intervals centered between each to the two consecutive saw cut locations, the center of the 15 feet slab sections. The first group had to be placed after the initial start of the concrete placement because of the equipment and construction method. Therefore 
the first group was placed at 52.5 feet from the zero location between joints 3 and 4 . The following groups 2 through 6 were spaced at 300 feet intervals between the respective joint locations. Group seven was placed at location 1777.5 feet from the zero location, which was 37.5 feet from the end of the slab and only 225 feet after group six. The seven thermocouple group locations are shown graphically in Figure 8.1a. Temperature data from each of the four depths at each group location were collected hourly during critical times and every other hour during non-critical times.

The temperature data collected from the seven group's based on the zero time scale can be seen in Figures 8.2 through 8.8. Examination of the group's slab temperature behaviors by depth was performed. From these seven graphs, it can be seen that the temperature behaviors at every location become more similar after 35 to 40 hours after initial concrete placement. For the first 35 to 40 hours, the slab temperature behavior varies from each location. This can be explained by the ambient temperature effects on the various ages of concrete at the seven different locations. The early age slab temperature profiles variations along the slab length directly effect the behavior of the total slab section. The maturity of the concrete combined with the exposed ambient temperature history dictates the resulting slab temperature profile at a given location during the early age.

Two thermocouples were used to collect the ambient temperatures during the slab investigation, one located at either end of the monitored slab section. The ambient temperature results based on the zero time scale can be seen in Figure 8.9. Each of the seven group thermocouple readings can be compared to the ambient temperature readings over time. The warm days and cooler night's ambient effects on the slab temperature 
profile behavior can be easily seen. Solar radiation and warmer temperatures during the daytime hours and cooler nighttime temperatures drastically effected the slab temperature profile histories.

From Phase I theory, the thought of placing concrete at various times of the day might effect the cracking behavior by allowing the concrete to mature longer could reduce the crack width. By evaluating the individual group temperature profile histories in terms of concrete age and comparing the ambient temperatures experienced to each history, the variable of time of concrete placement my be evaluated to an extent. The seven group temperature histories were plotted versus the concrete age at each group location. (See Figures 8.10 through 8.16) From these graphs, the ambient effects on various ages of concrete are evaluated. The group temperature behaviors vary by location up to around 30 hours on the time zero scale. This was after sufficient time that the initial heat of hydration processes throughout the slab length was finished. After that time, every group location temperature profile histories follow the ambient temperature behavior similarly. The initial temperature histories, or rate of heat of hydration, found during the first 24 hours of cure time for every group location was seen to have been coinciding with the experienced ambient history. These results show that there are lower maximum temperatures reached at the younger end of the slab. These are mainly due to the cooler nighttime ambient temperatures experienced during that end's heat of hydration process. Examining the cracking behavior along the slab length, (See Section 8.3 Crack behavior), differences in crack spacing and width were not seen to be effected, but only when cracking occurred. Therefore from the three investigations, changing the time of day of concrete placement will only effect when the concrete slab will crack, and not how. 
The maturity of the concrete varies along the slab length. The concrete at the beginning of the slab section was 10 hours more mature than the concrete placed at the end. During the heat of hydration process, the curing concrete reached a maximum temperature at each location at a concrete age of approximately 9 to 11.5 hours. The maximum core temperature's reached at each location (after the time for initial concrete set) was determined. This can be seen graphically in Figure 8.17 and 8.18. Figure 8.17 shows the maximum temperature reached and Figure 8.18 shows the times that the maximum temperatures, relative to the time the concrete was placed, were reached at each group location. The differences in the maximum core temperature reached by location can be attributed to the ambient temperatures experienced by the varying concrete maturity. The more matured end of the slab section reached a maximum heat of hydration temperature early in the evening hours of the first day. The maximum core temperatures attained in the more matured end were higher than those reached in the less matured end. This is attributed to the daytime temperatures observed during the early curing hours of the concrete in the more matured slab end. The less matured end of the slab section was being placed as the ambient temperatures began dropping in the early evening hours of the first day. This end was being placed at the same time frame that the beginning of the slab was already reaching maximum core temperatures due to the heat of hydration. The younger slab section did not reach a maximum heat of hydration until nearing the daytime hours of the second day and was exposed to cooler nighttime temperatures during early curing hours. The time for each location to reach maximum core temperature can be seen in Figure 8.19. The combination of the three Figures 8.17, 
8.18 and 8.19, shows the added ambient and solar radiation effect on the concrete by location and maturity.

Just prior to concrete slab overlay, the free drain base surface temperatures were recorded in terms of time and location. The base temperatures, along with the corresponding ambient temperatures, were plotted against time and location graphs. They can be seen in Figures 8.20 and 8.21. The base course temperatures were found to increase dramatically from 0800 hours to around 1300 to 1400 hours, being from around $40^{\circ} \mathrm{F}$ to over $100^{\circ} \mathrm{F}$ respectively. The ambient temperatures observed during the first day did not exceed $80^{\circ} \mathrm{F}$. Therefore, solar radiation greatly effected surface temperature due to the dark, blackish color of the FDB as was seen during the I-80 Danville investigation. The last three base temperature readings were inadvertently missed, but the solar radiation effect on the base surface temperature's can be easily seen without them. The increased base course temperature may effect the temperature and cracking behavior of the slab by location. The rate and value of temperature reached during the heat of hydration process by slab location, as well as other concrete material and behavioral properties, may be increased due to the higher temperatures the concrete is exposed to. If you compare the maximum core temperature reached by time and location figures (Figures 8.17 through 8.19) to the FDB temperature figures (Figures 8.20 and 8.21), and the corresponding group temperature graphs (Figures 8.2 through 8.8), the increased base course and ambient temperatures enhance the concrete slabs temperature behavior. To what extent the temperature's effect the overall slab behavior is not completely known at this time, but these factors may be useful at a later date and further analysis. 
It should be noted that the bottom thermocouple readings from Group \#2 location are not consistent with other bottom thermocouple behavior. These readings are much lower than expected. It is believed that the bottom thermocouple depth location, 1-inch up from the base course, may have been compromised during insertion, or the thermocouple tip was against an aggregate exposed to the base course. The attained readings show that the thermocouple was responding to temperature change, but the results are not justifiable and must be discarded from further analysis.

Further discussion on the slab temperature profile histories will follow in section 8.5 Discussion and Chapter 9. 


\section{Table 8.2}

THERMOCOUPLE CALIBRATIONS for Elkins, WV

Tested in a Sealed Cooler on 10 Oct 99

\begin{tabular}{|c|c|c|c|c|c|c|c|c|}
\hline \multirow{3}{*}{$\begin{array}{l}\text { Calibration } \\
\text { Designation } \\
\text { Gage \# }\end{array}$} & \multicolumn{8}{|c|}{$\begin{array}{l}\text { Temperatures (degree F) by test series } \\
\text { and Thermometer used }\end{array}$} \\
\hline & NEW & OLD & NEW & OLD & NEW & OLD & NEW & OLD \\
\hline & 1 & 1 & 2 & 2 & 3 & 3 & 4 & 4 \\
\hline $\bar{~} 1$ & 6 65.7 & $\bar{~} 66.8$ & "65.6 & 6767.0 & 6 65.4 & 666.8 & 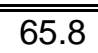 & $\bar{~} 67.1$ \\
\hline 2 & 64.7 & 66.1 & 65.1 & 66.7 & 65.2 & 66.6 & 65.6 & 67.1 \\
\hline 3 & 65.3 & 66.3 & 65.1 & 66.6 & 65.3 & 66.8 & 65.8 & 67.2 \\
\hline 4 & 65.9 & 66.8 & 65.7 & 67.1 & 65.0 & 66.5 & 65.8 & 67.2 \\
\hline 5 & 65.4 & 66.7 & 65.5 & 67.0 & 64.5 & 66.2 & 65.5 & 66.6 \\
\hline 6 & 65.3 & 66.8 & 65.6 & 67.1 & 64.7 & 66.3 & 65.0 & 66.9 \\
\hline 7 & 65.1 & 66.6 & 64.9 & 66.5 & 64.9 & 66.4 & 65.1 & 66.7 \\
\hline 8 & 65.4 & 66.7 & 65.3 & 66.8 & 64.9 & 66.4 & 64.9 & 66.6 \\
\hline 9 & 64.8 & 66.8 & 65.3 & 66.8 & 64.8 & 66.4 & 65.0 & 66.6 \\
\hline 10 & 65.5 & 66.3 & 65.4 & 66.8 & 64.6 & 66.3 & 65.2 & 66.7 \\
\hline 11 & 65.5 & 66.9 & 65.3 & 66.8 & 64.7 & 66.4 & 65.4 & 66.9 \\
\hline 12 & 65.4 & 66.9 & 64.9 & 66.5 & 64.8 & 66.5 & 65.4 & 66.8 \\
\hline 13 & 65.6 & 67.0 & 65.2 & 66.8 & 65.1 & 66.6 & 65.4 & 66.8 \\
\hline 14 & 65.5 & 66.9 & 65.1 & 66.8 & 65.2 & 66.6 & 65.4 & 66.8 \\
\hline 15 & 65.5 & 66.9 & 65.1 & 66.7 & 65.0 & 66.6 & 65.4 & 66.8 \\
\hline 16 & 65.5 & 67.0 & 65.5 & 67.0 & 65.1 & 66.7 & 65.4 & 66.8 \\
\hline 17 & 65.4 & 66.9 & 65.4 & 67.0 & 65.1 & 66.7 & 65.5 & 67.0 \\
\hline 18 & 65.2 & 66.7 & 64.6 & 66.5 & 65.2 & 66.6 & 65.4 & 66.9 \\
\hline 19 & 65.4 & 66.9 & 65.2 & 66.9 & 65.4 & 66.9 & 65.7 & 67.1 \\
\hline 20 & 65.3 & 66.9 & 65.5 & 67.1 & 65.1 & 66.8 & 65.7 & 67.0 \\
\hline 21 & 65.7 & 67.0 & 65.7 & 67.2 & 65.4 & 66.9 & 65.8 & 67.1 \\
\hline 22 & 65.6 & 67.0 & 65.5 & 67.2 & 65.6 & 66.9 & 65.8 & 67.1 \\
\hline 23 & 65.5 & 66.8 & 65.1 & 67.0 & 64.9 & 66.7 & 65.5 & 67.0 \\
\hline 24 & 65.4 & 66.9 & 65.5 & 67.3 & 65.4 & 66.9 & 65.8 & 67.1 \\
\hline
\end{tabular}

\begin{tabular}{|l|l|l|l|l|l|l|l|l|}
\hline Stand DEV & 0.262099 & 0.236367 & 0.275806 & 0.229682 & 0.285869 & 0.211576 & 0.278941 & 0.191816 \\
\hline
\end{tabular}

\begin{tabular}{|c|c|}
\hline Standard Deviations of new thermometer & Standard Deviations of old thermometer \\
\hline 0.262099 & 0.236367 \\
\hline 0.275806 & 0.229682 \\
\hline 0.285869 & 0.211576 \\
\hline 0.278941 & 0.191816 \\
\hline Avg.St.Dev. 0.275679 & 0.21736 \\
\hline
\end{tabular}


GROUP \#1 Thermocouple Readings (Location X=52.5 feet)

Corridor $\mathrm{H}$ Westbound Lanes near Elkins, WV

(October 12,1999 time $=0$ at 8:30 AM)

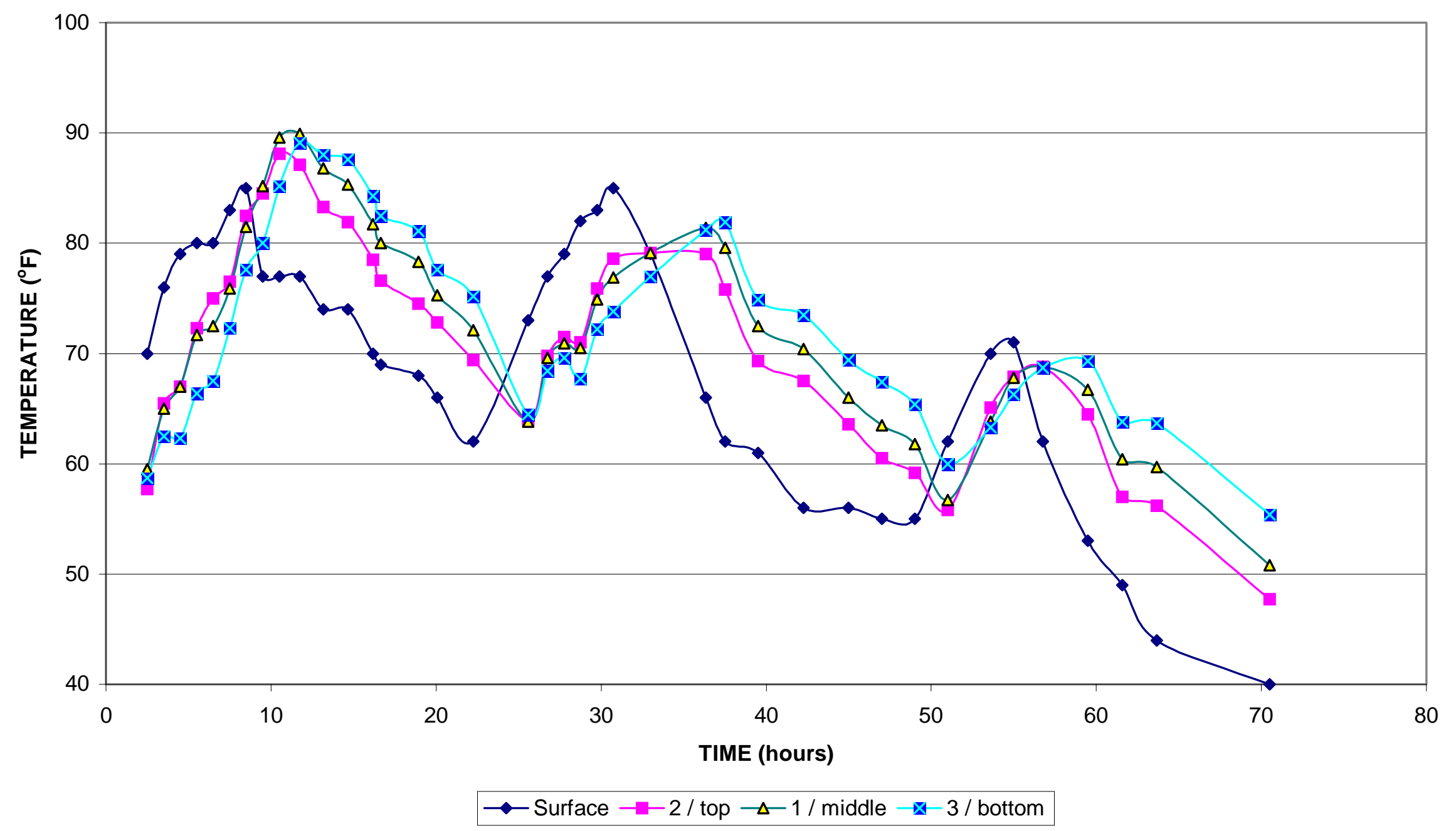

Figure 8.2: Group \#1 Temperature Readings, Corridor H Elkins, WV 


\section{GROUP \#2 Thermocouple Readings (Location X= 352.5 feet) \\ Corridor $\mathrm{H}$ Westbound Lanes near Elkins, WV \\ (October 12,1999 time $=0$ at 8:30 AM)}

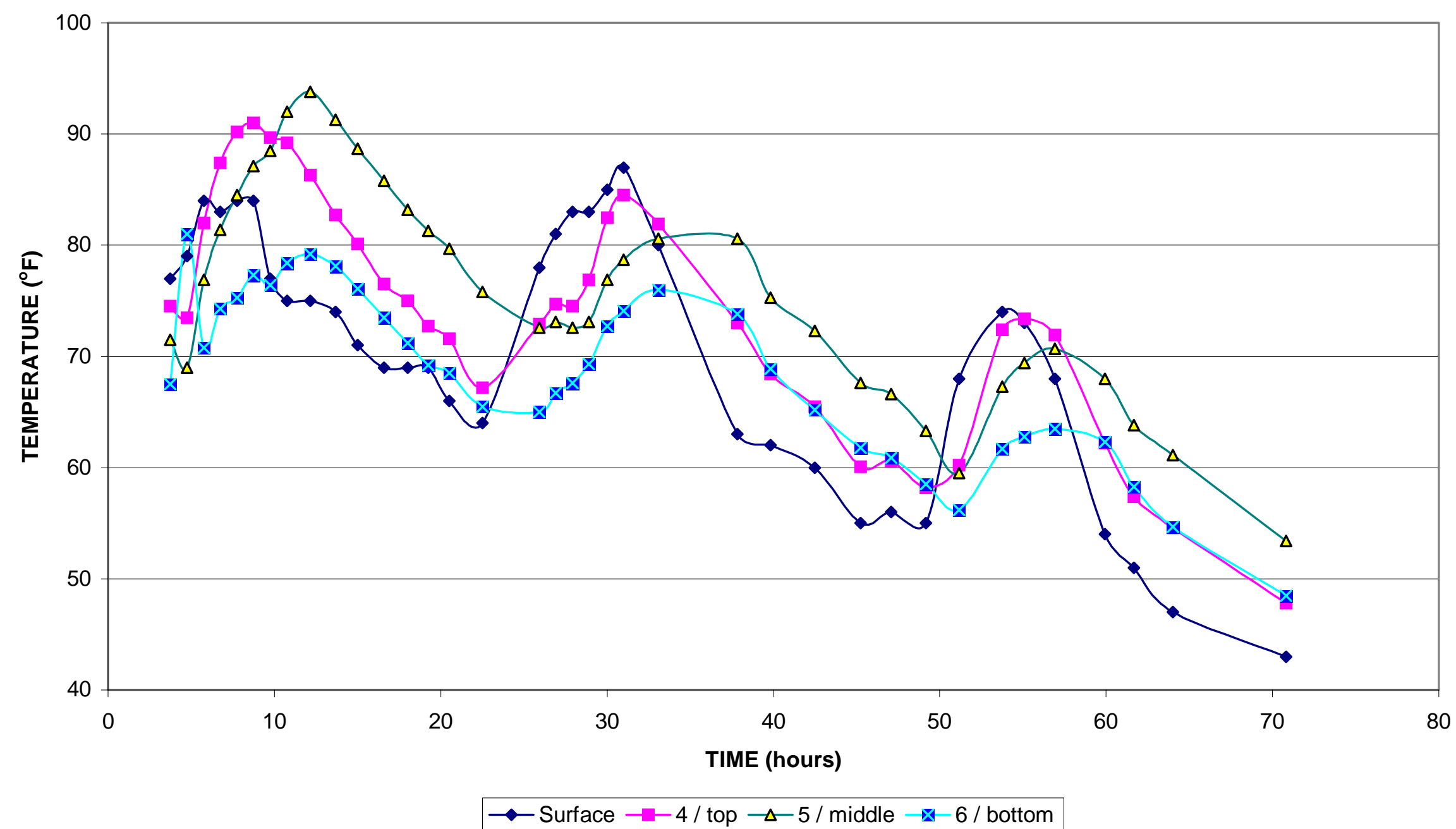

Figure 8.3: Group \#2 Temperature Readings, Corridor H Elkins, WV 


\section{GROUP \#3 Thermocouple Readings (Location X= 652.5 feet) \\ Corridor $\mathrm{H}$ Westbound Lanes near Elkins, WV \\ (October 12,1999 time $=0$ at 8:30 AM)}

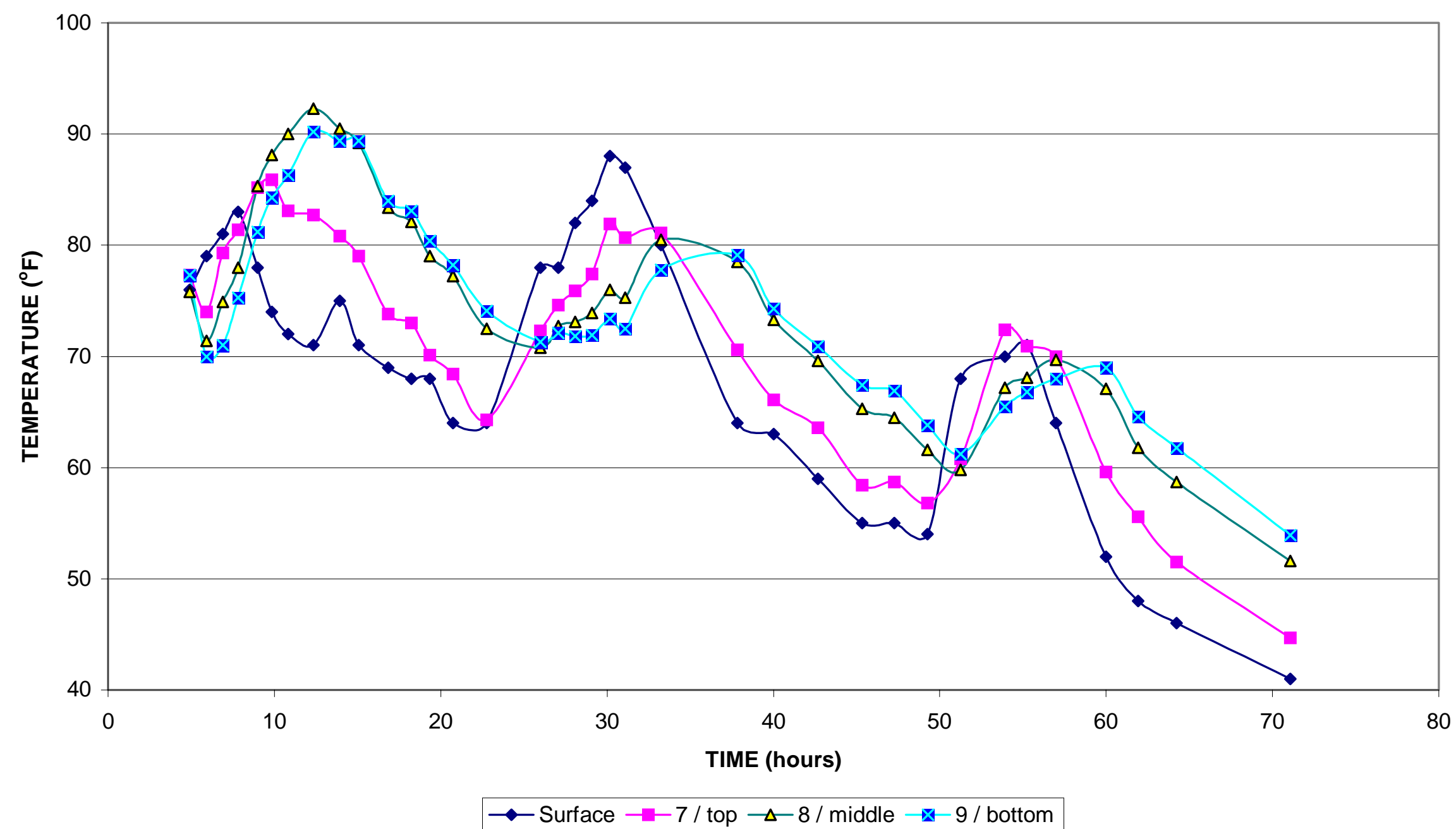

Figure 8.4: Group \#3 Temperature Readings, Corridor H Elkins, WV 


\section{GROUP \#4 Thermocouple Readings (Location X=952.5 feet) \\ Corridor $\mathrm{H}$ Westbound Lanes near Elkins, WV \\ (October 12,1999 time $=0$ at 8:30 AM)}

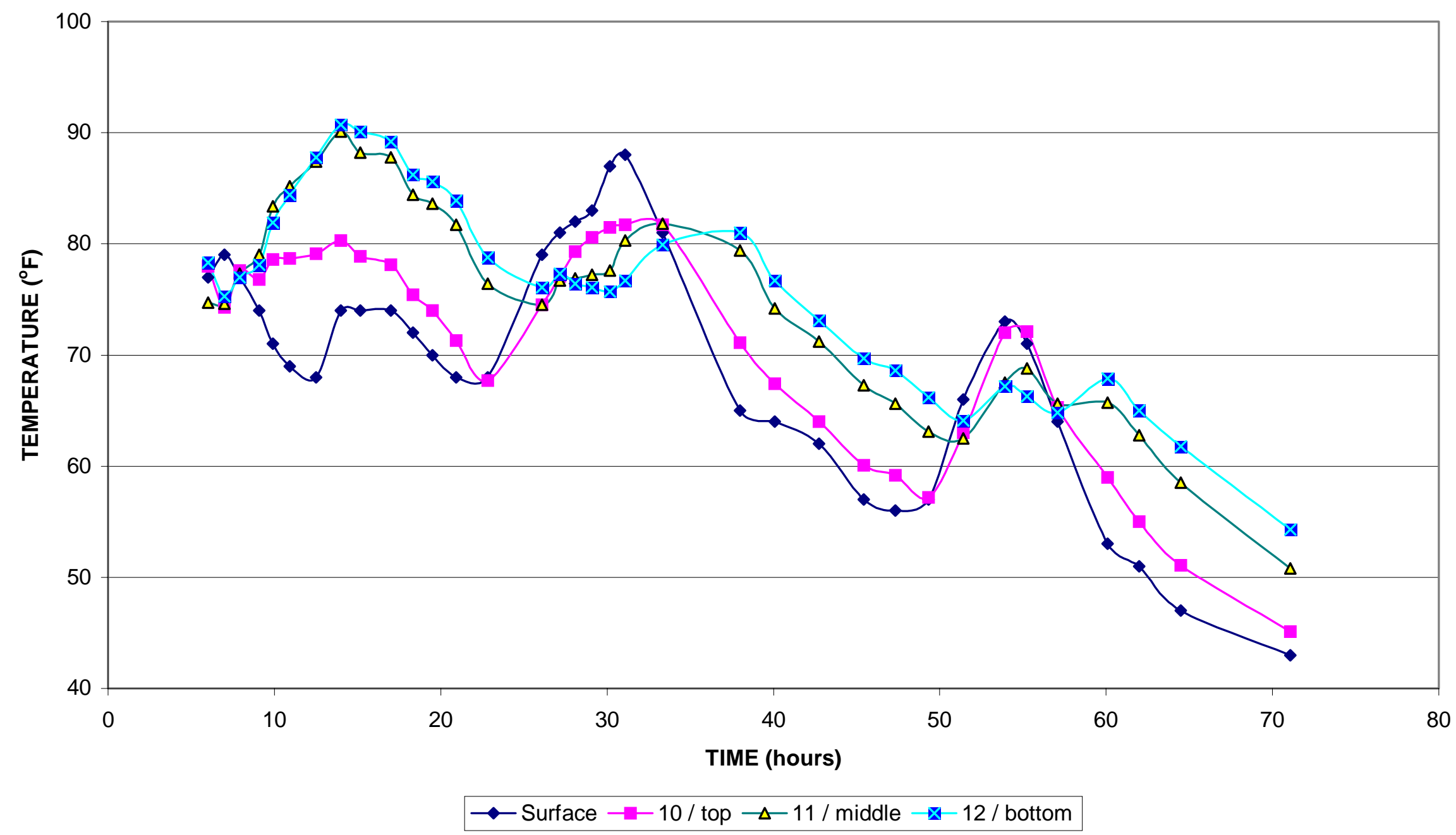

Figure 8.5: Group \#4 Temperature Readings, Corridor H Elkins, WV 


\section{GROUP \#5 Thermocouple Readings (Location X=1252.5 feet) \\ Corridor $\mathrm{H}$ Westbound Lanes near Elkins, WV \\ (October 12,1999 time $=0$ at 8:30 AM)}

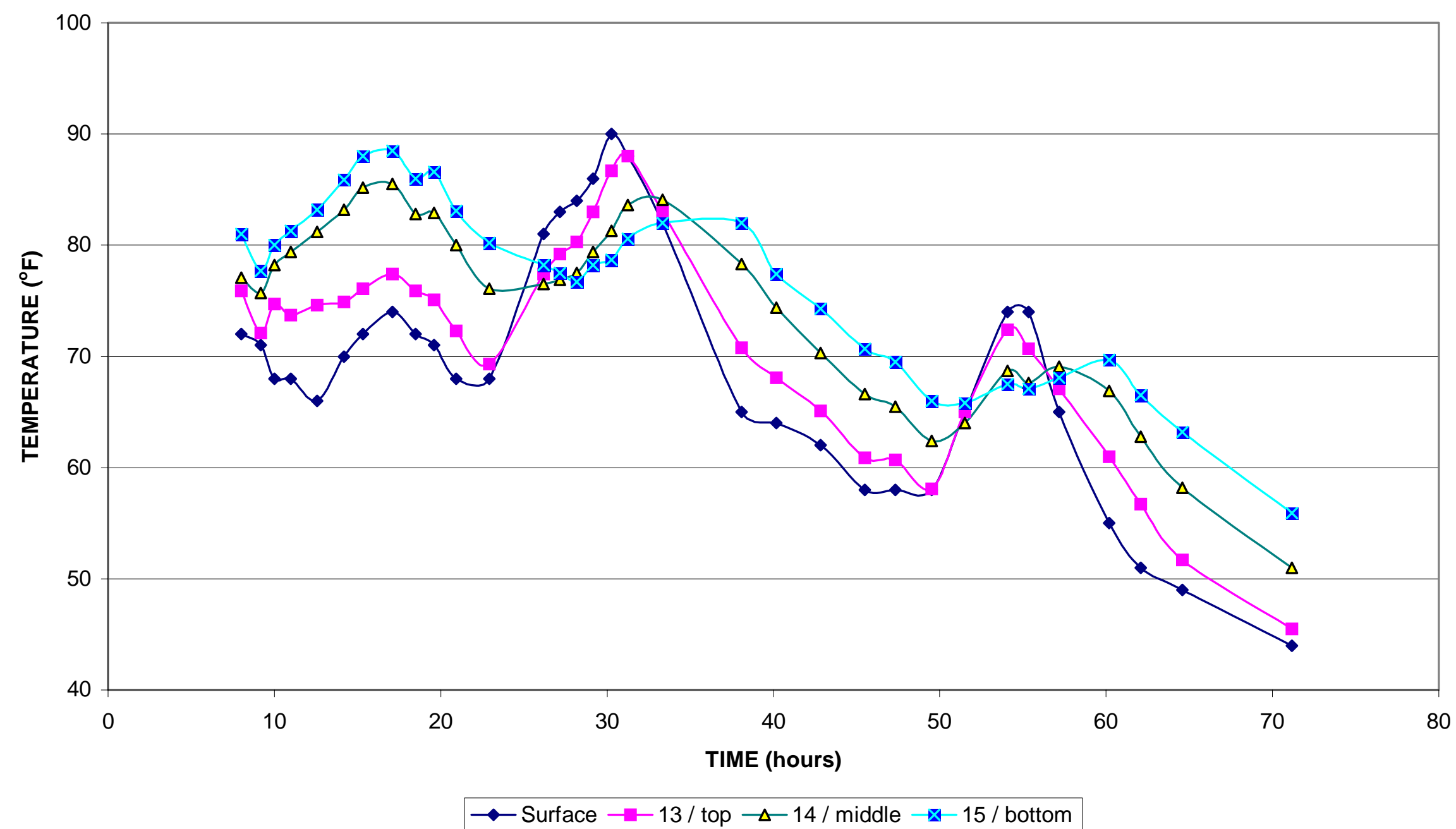

Figure 8.6: Group \#5 Temperature Readings, Corridor H Elkins, WV 


\section{GROUP \#6 Thermocouple Readings (Location X=1552.5 feet) \\ Corridor $\mathrm{H}$ Westbound Lanes near Elkins, WV \\ (October 12,1999 time $=0$ at 8:30 AM)}

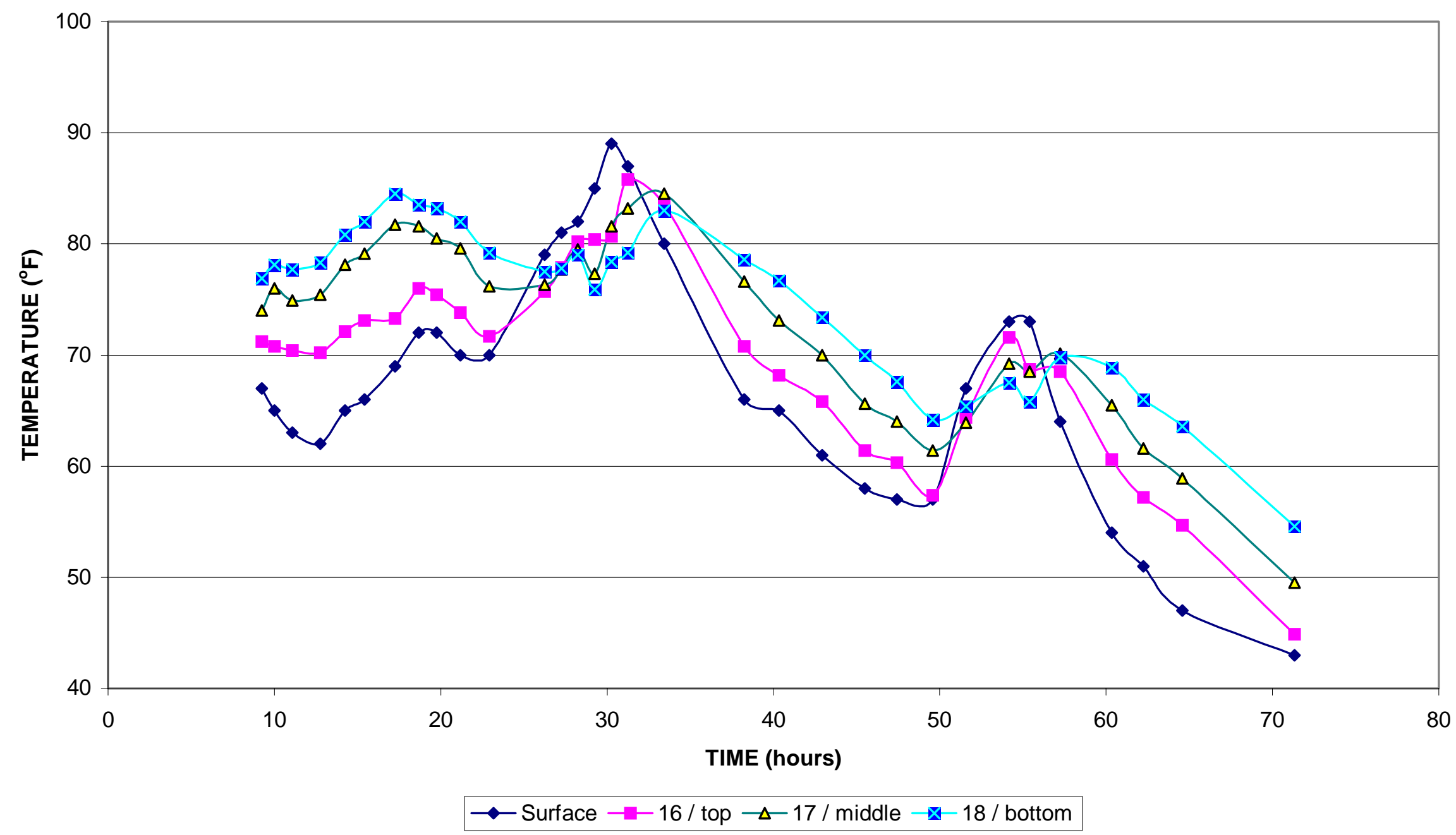

Figure 8.7: Group \#6 Temperature Readings, Corridor H Elkins, WV 


\section{GROUP \#7 Thermocouple Readings (Location X=1777.5 feet) \\ Corridor H Westbound Lanes near Elkins, WV \\ (October 12,1999 time $=0$ at 8:30 AM)}

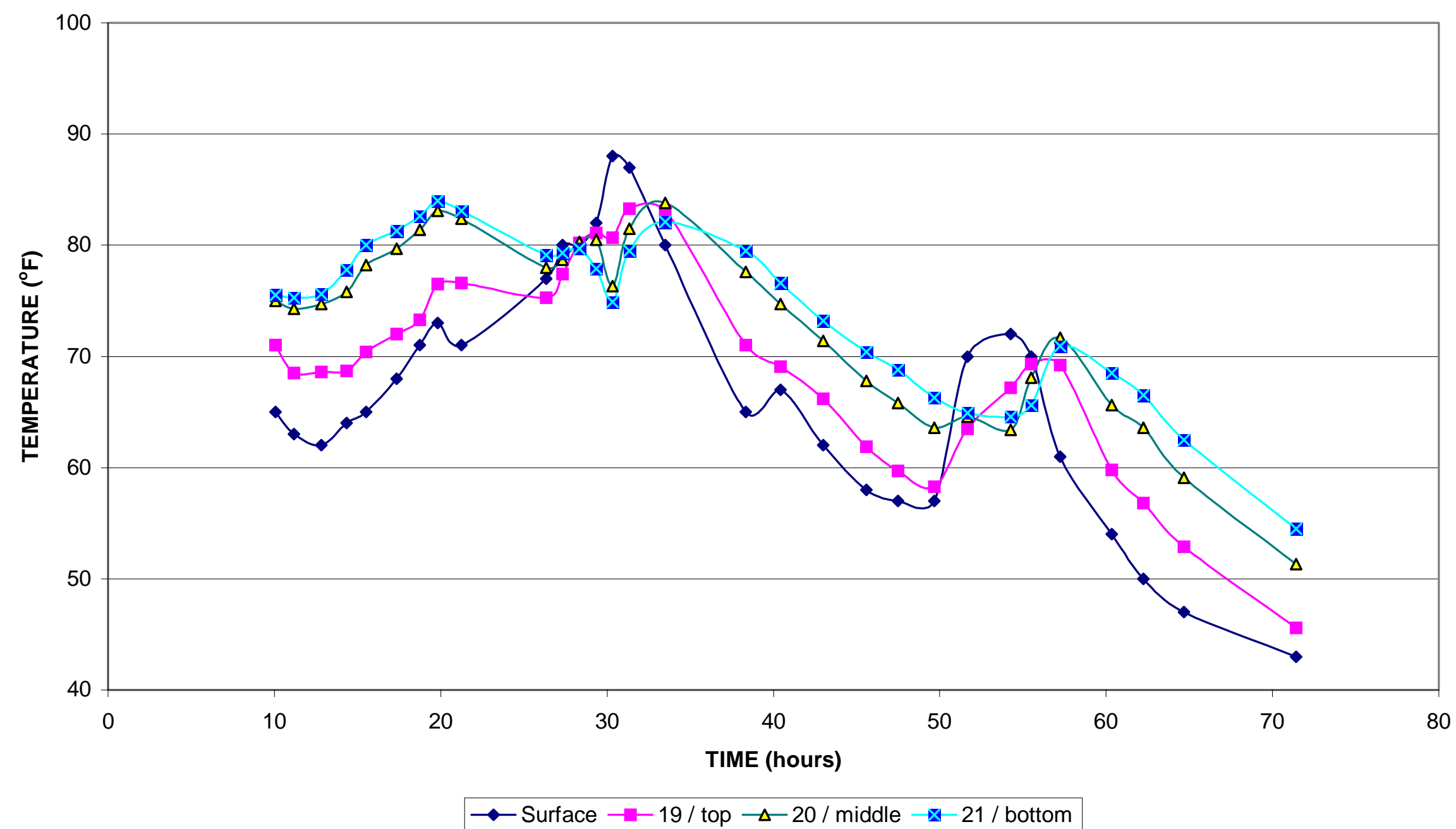

Figure 8.8: Group \#7 Temperature Readings, Corridor H Elkins, WV 


\section{AMBIENT THERMOCOUPLE TEMPERATURES \\ Corridor $\mathrm{H}$ near Elkins, WV \\ (TC \#1 at Location 45 feet, TC\#2 at Location 1780 feet) \\ (time $=0$ at 0830 hrs 12 October 1999)}

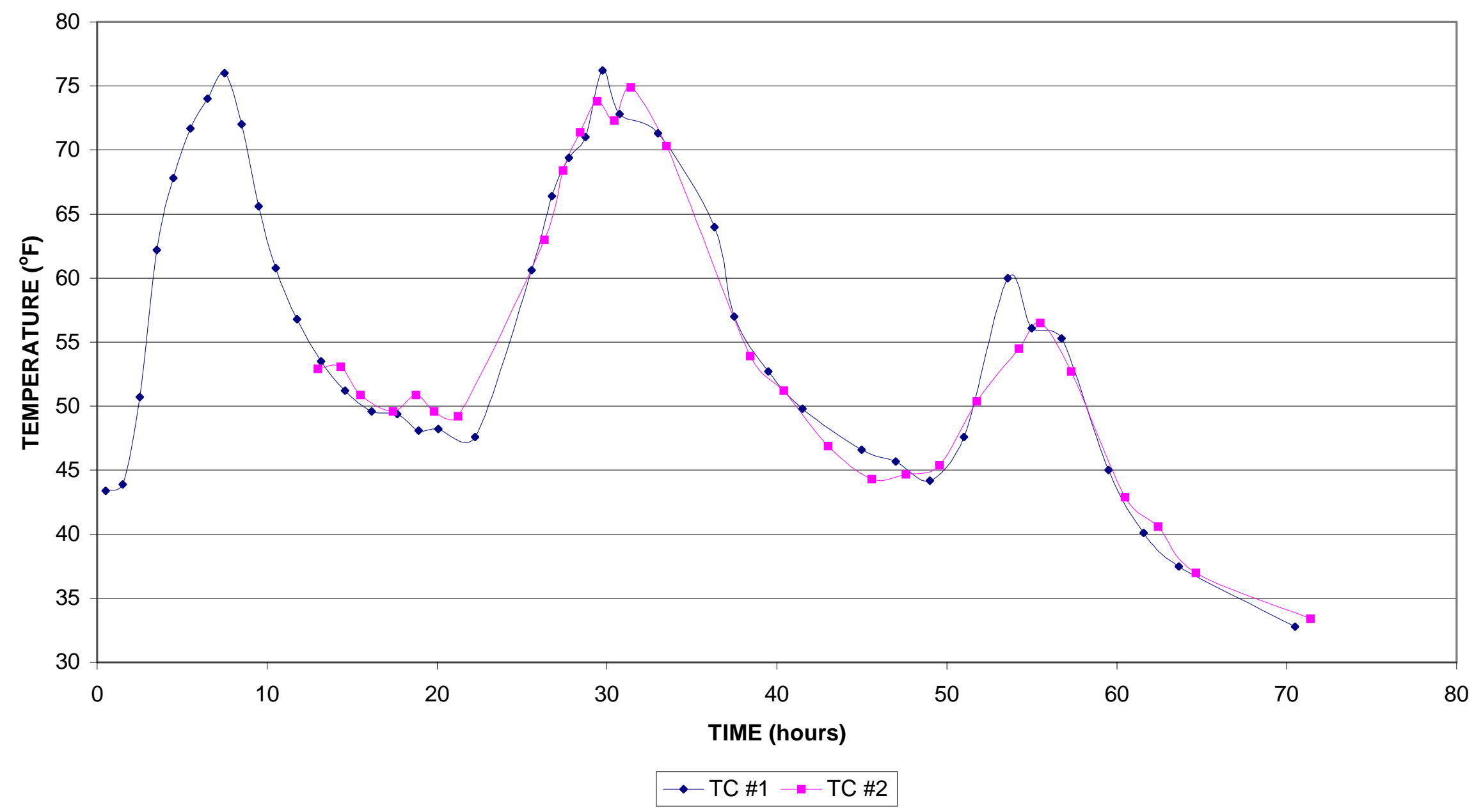




\section{Group \#1 Thermocouple Readings (Location X=52.5 feet)}

Corridor $\mathrm{H}$ Westbound Lanes near Elkins, WV

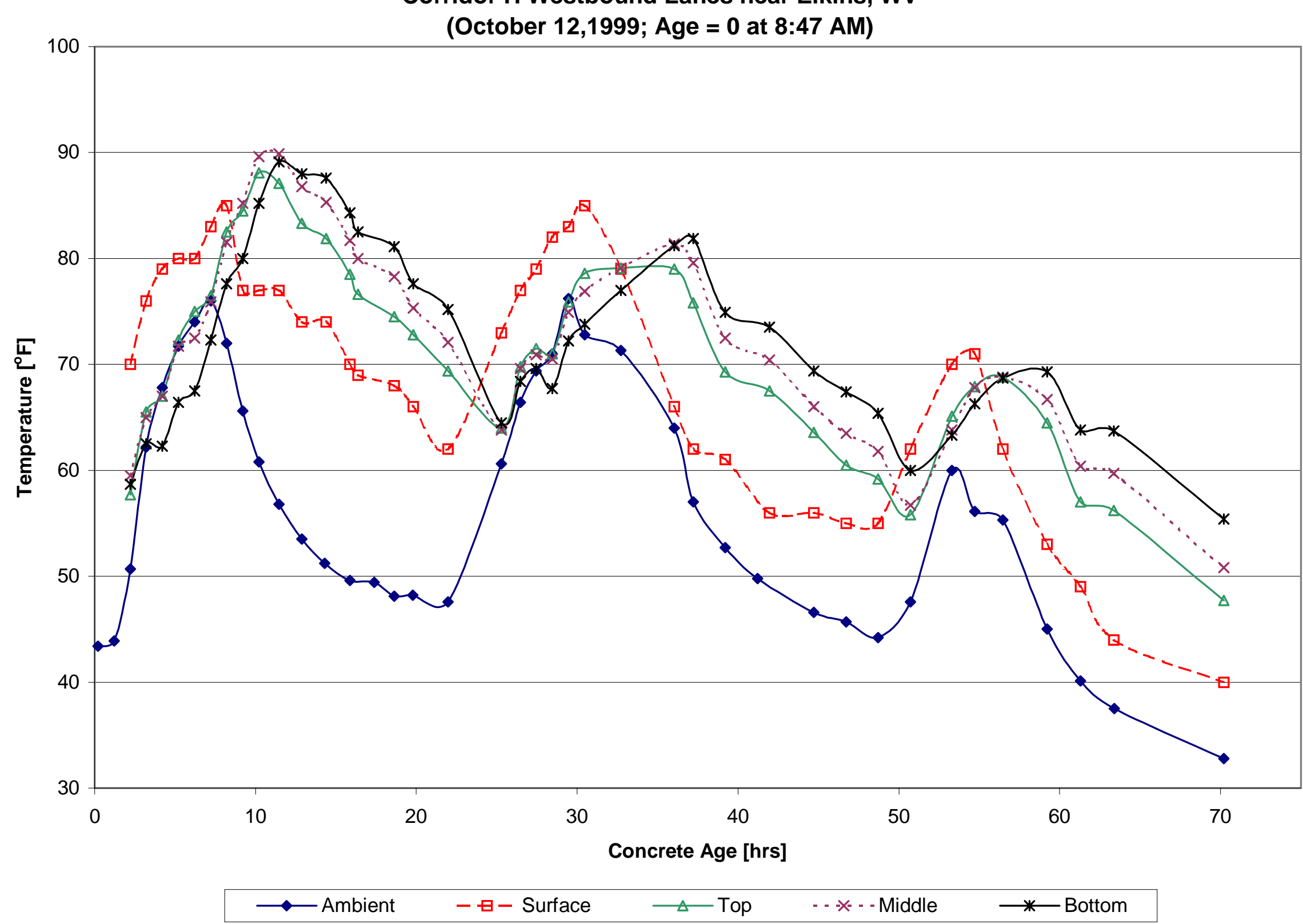

Figure 8.10: Group \#1 Temperature Behavior by Concrete Age, Corridor H 
Group \#2 Thermocouple Readings (Location X= 352.5 feet)

Corridor $\mathrm{H}$ Westbound Lanes near Elkins, WV

(October 12,1999; Age = 0 at 10:27 AM)

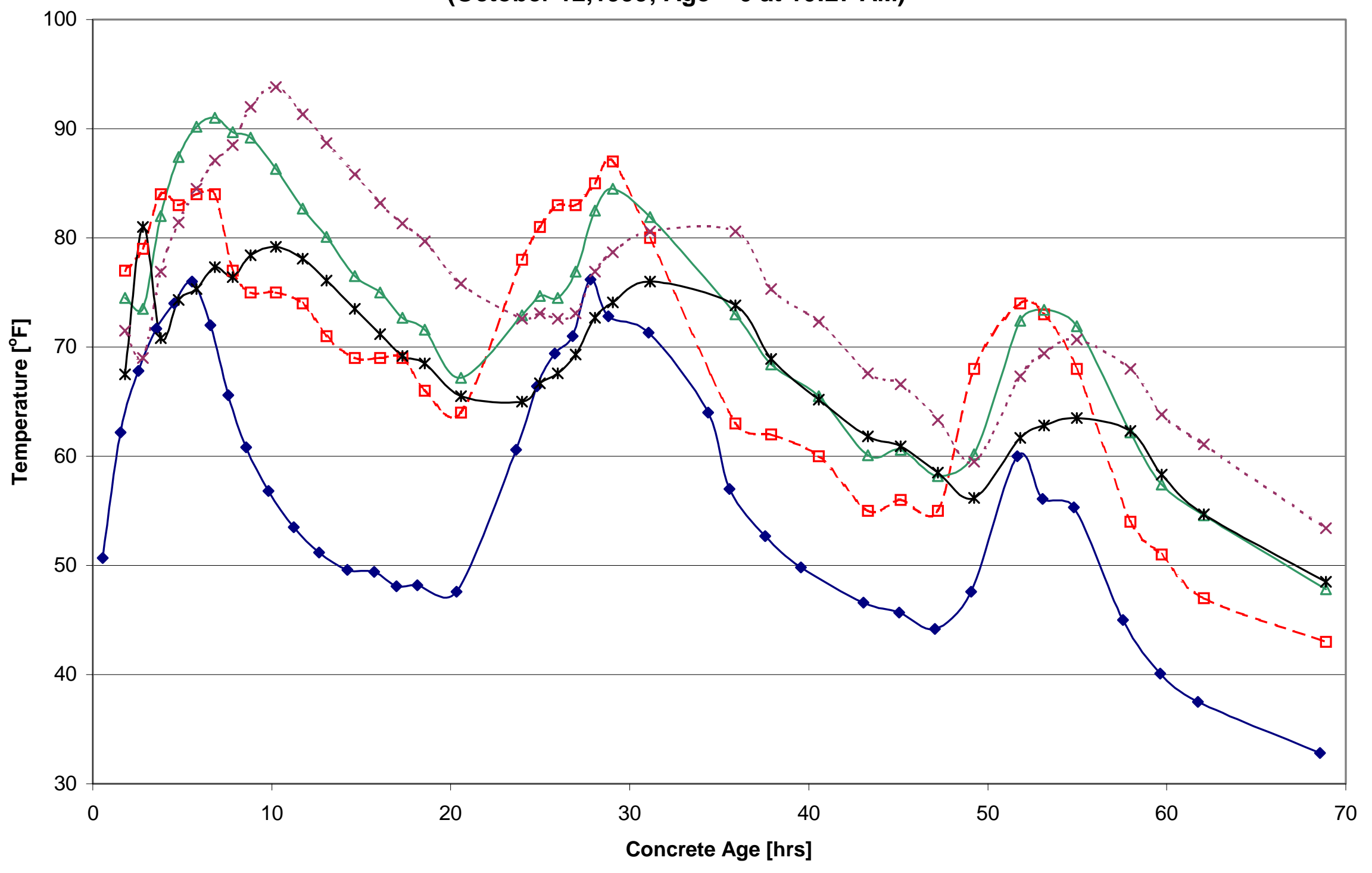

$\longrightarrow$ Ambient $\quad-\because-$ Surface $\quad \triangle$ Top $\quad--\star--$ Middle $\quad$ * Bottom

Figure 8.11: Group \#2 Temperature Behavior by Concrete Age, Corridor H 


\section{Group \#3 Thermocouple Readings (Location X= 652.5 feet)}

Corridor $\mathrm{H}$ Westbound Lanes near Elkins, WV

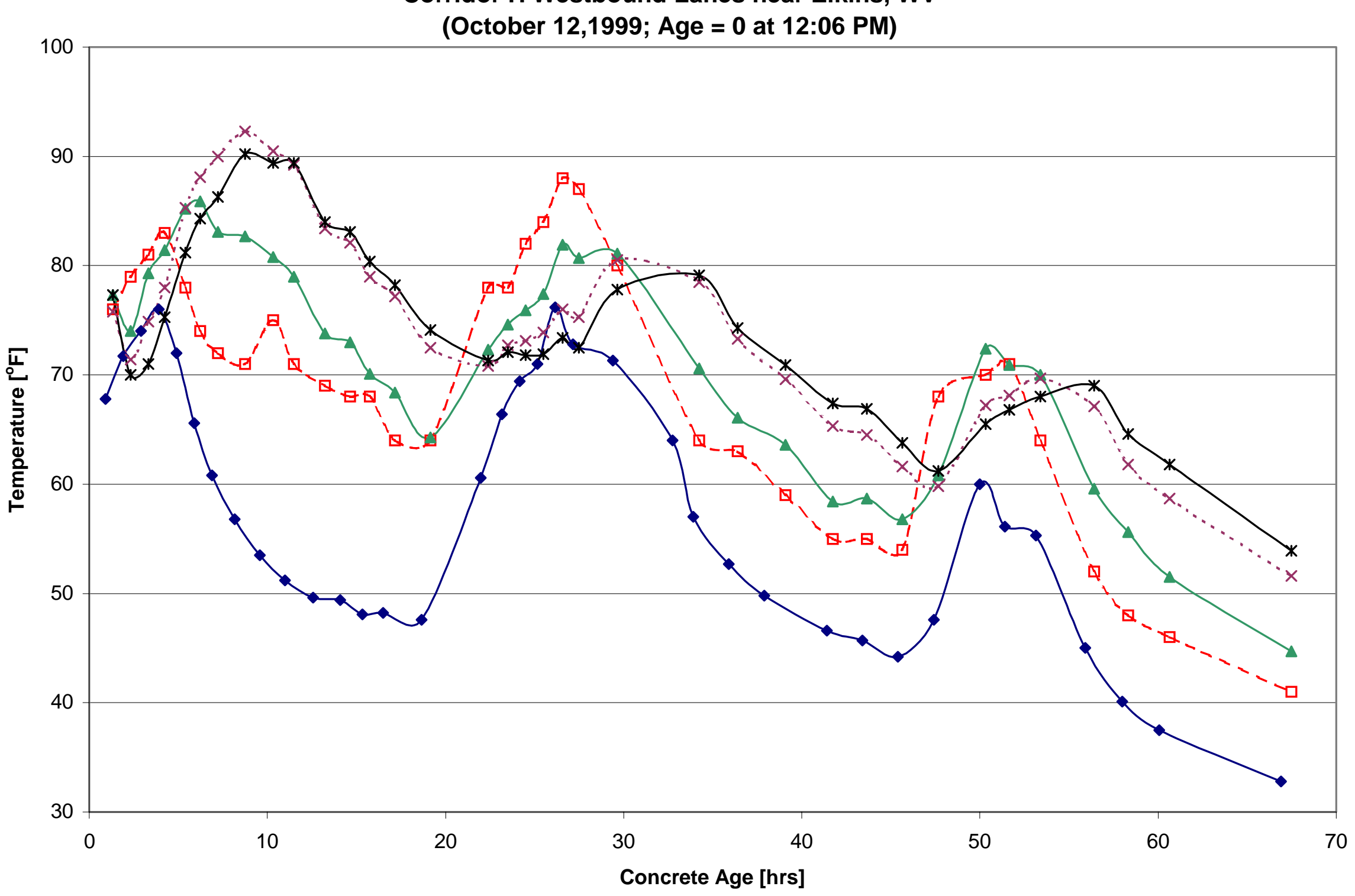

$\longrightarrow$ Ambient $\quad-\because-$ Surface $\longrightarrow$ Top $\quad-*--$ Middle $\rightarrow$ Bottom

Figure 8.12: Group \#3 Temperature Behavior by Concrete Age, Corridor H 


\section{Group \#4 Thermogage Readings (Location $X=952.5$ feet)}

Corridor $\mathrm{H}$ Westbound Lanes near Elkins, WV

(October 12,1999; Age = 0 at 1:45 PM)

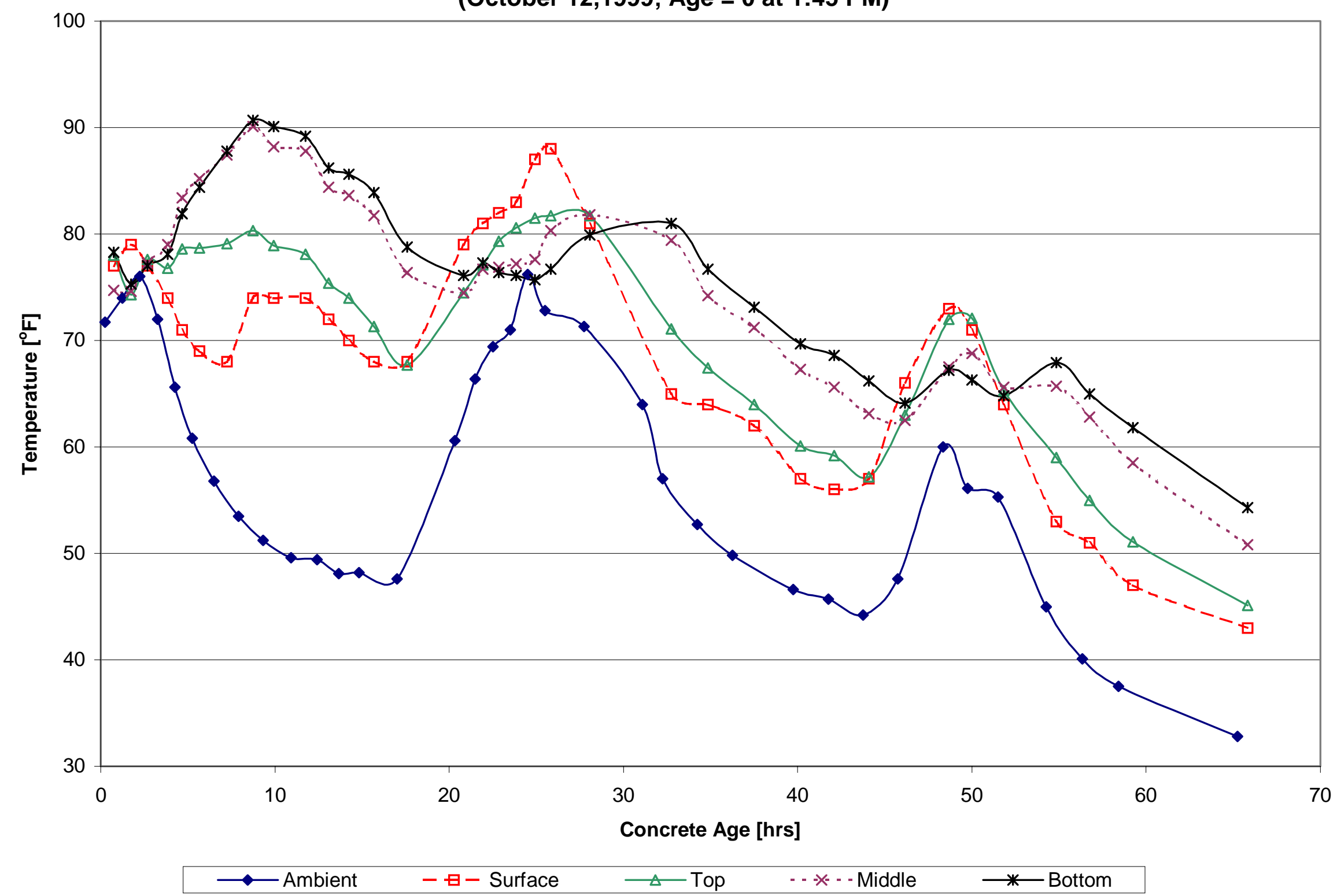

Figure 8.13: Group \#4 Temperature Behavior by Concrete Age, Corridor H 


\section{Group \#5 Thermocouple Readings (Location X=1252.5 feet)}

Corridor $\mathrm{H}$ Westbound Lanes near Elkins, WV

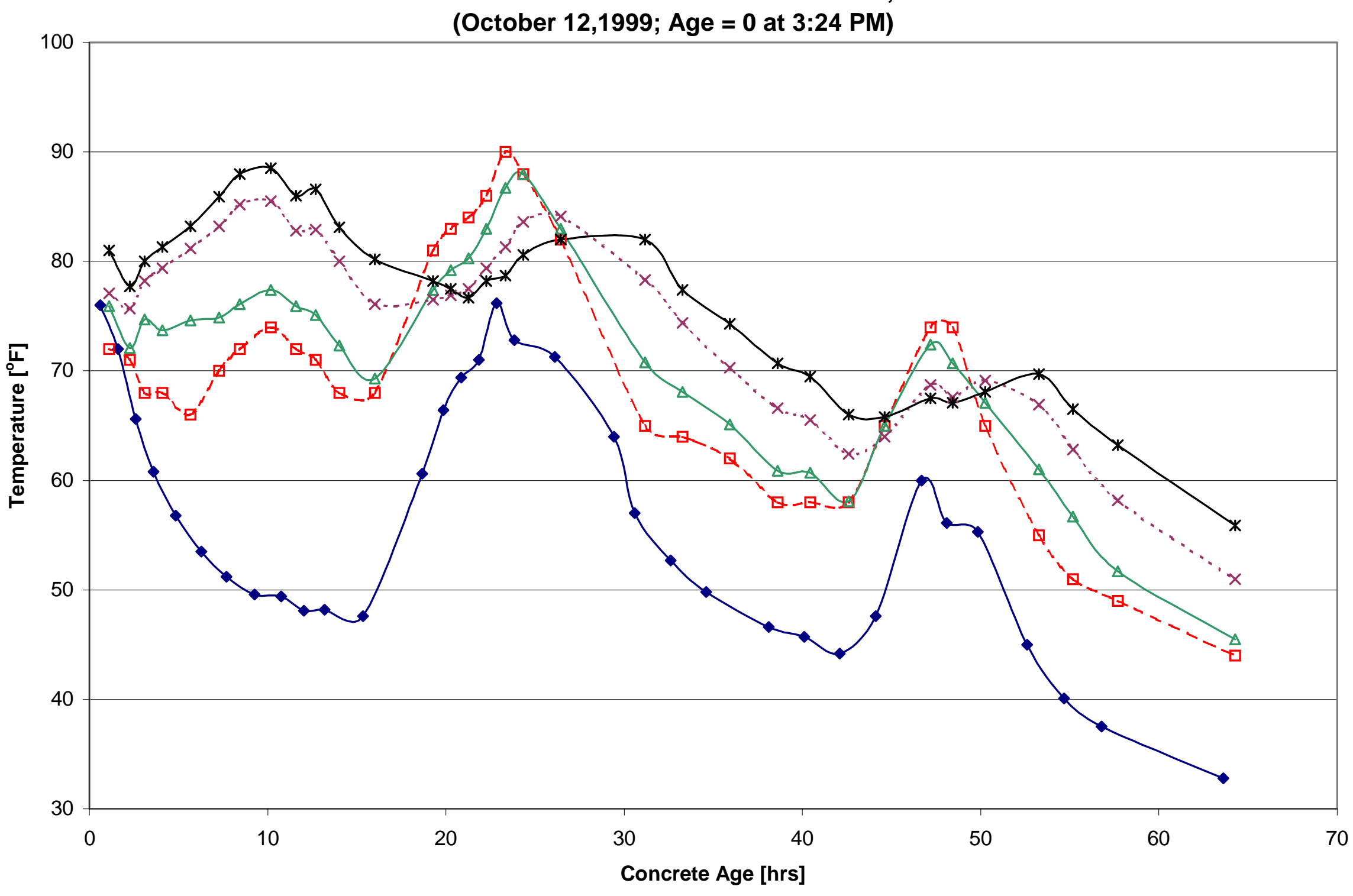
$\longrightarrow$ Ambient
$-\boxminus-$ Surface
$\triangle$ Top $\quad--x--$ Middle
* Bottom

Figure 8.14: Group \#5 Temperature Behavior by Concrete Age, Corridor H 


\section{Group \#6 Thermocouple Readings (Location X=1552.5 feet)}

Corridor $\mathrm{H}$ Westbound Lanes near Elkins, WV

(October 12,1999; Age = 0 at 5:03 PM)

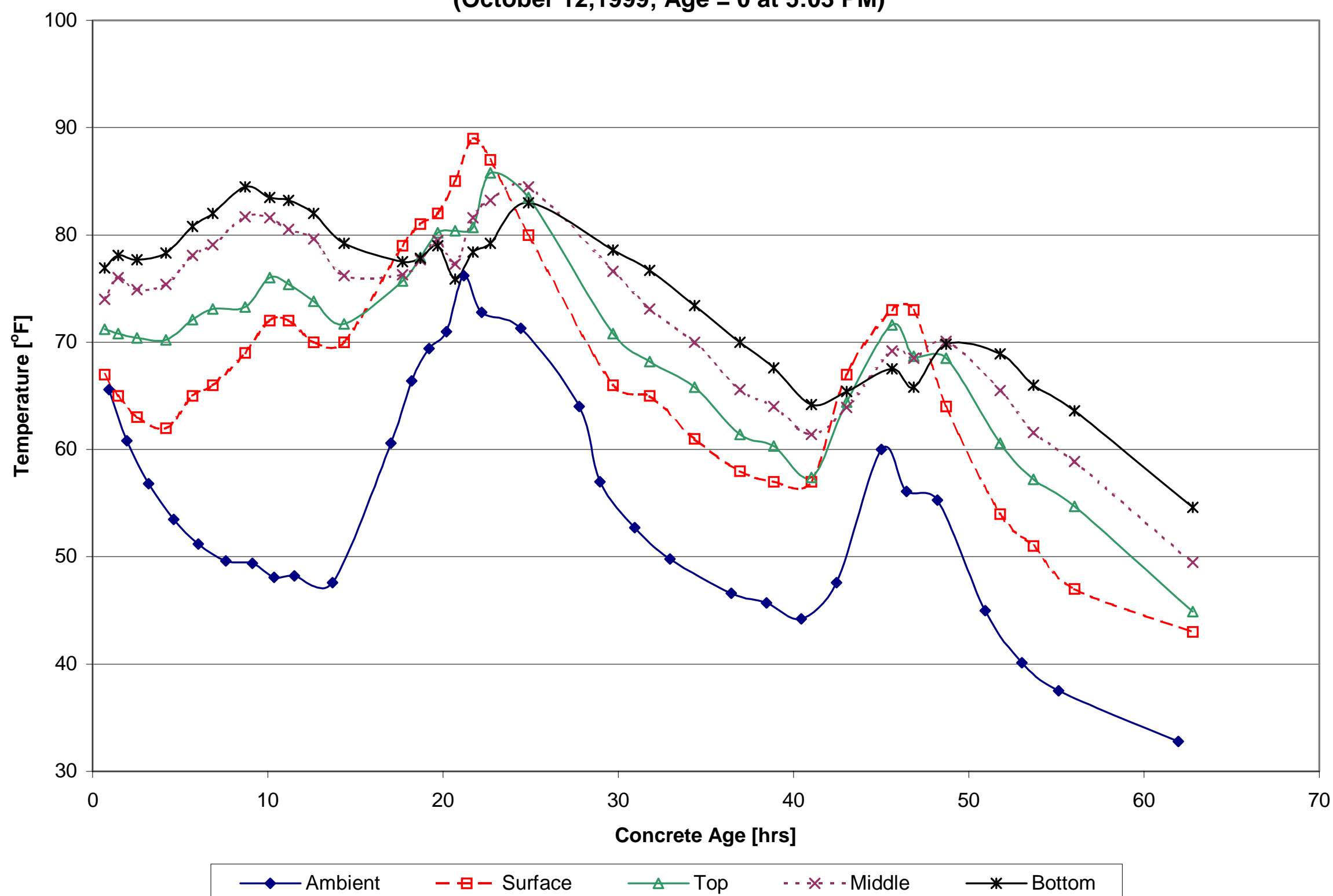

Figure 8.15: Group \#6 Temperature Behavior by Concrete Age, Corridor H 


\section{Group \#7 Thermocouple Readings (Location X=1777.5 feet) \\ Corridor $\mathrm{H}$ Westbound Lanes near Elkins, WV}

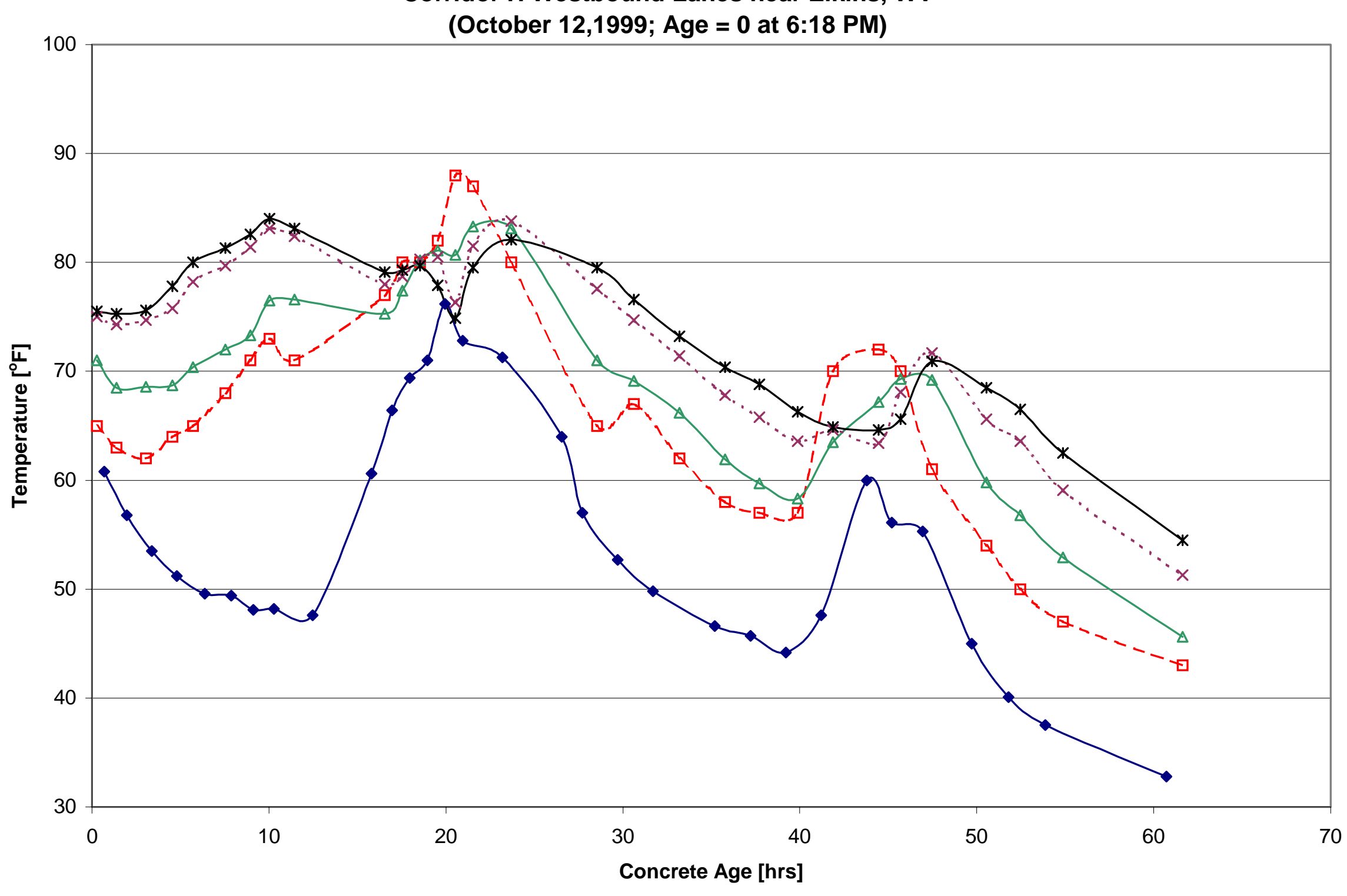

$\longrightarrow$ Ambient $\quad-\because-$ Surface $\quad \triangle$ Top $\quad-*-$ - Middle $\quad *$ Bottom

Figure 8.16: Group \#7 Temperature Behavior by Concrete Age, Corridor H 
Maximum Core Temperature reached by Location

Corridor H Elkins, WV 12 October 1999

(Time $=0$ at 0830 hours)

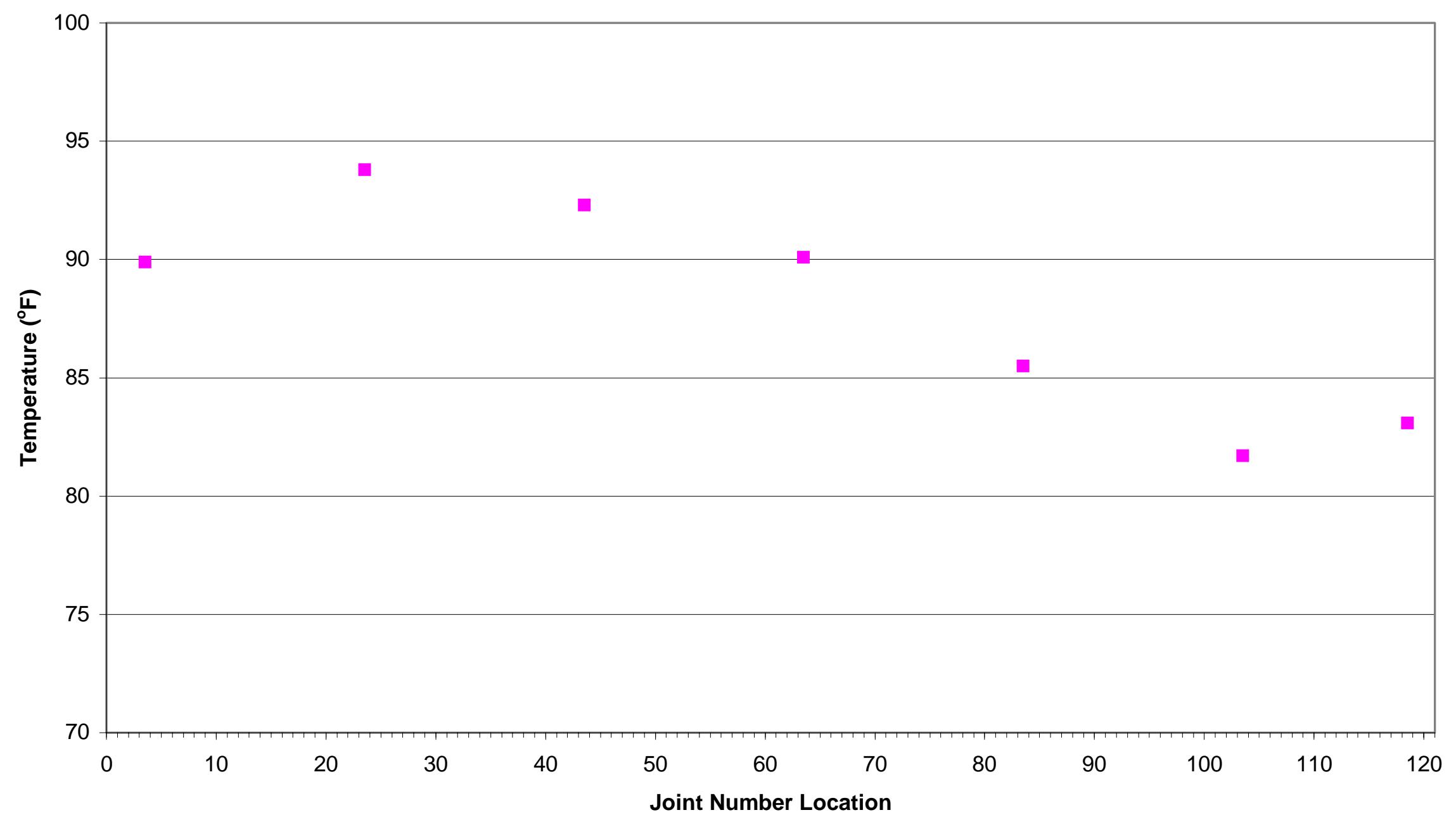

Figure 8.17: Maximum Core Temperatures by Location, Corridor $\mathrm{H}$ 
Times Max Core Temp Reached and Time Placed versus Joint Number

Based on Time Zero Scale

Corridor H (time=0 at 0830 hrs 12 October 1999)

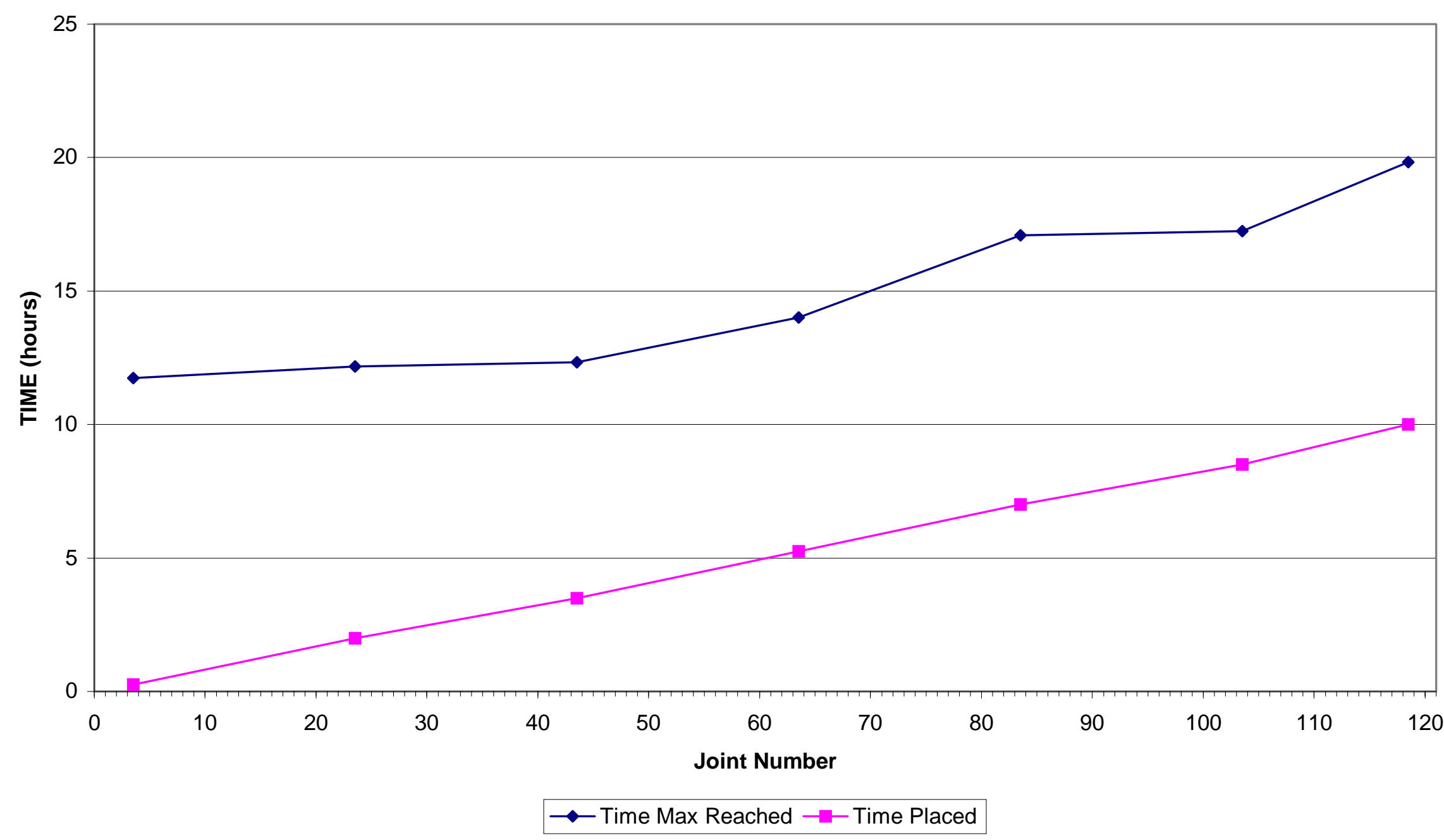

Figure 8.18: Time Concrete Placed and Time Maximum Core Temperature Reached, Corridor H 
Time to reach Maximum Temperature from Time Placed versus Joint Number Corridor $\mathrm{H}$ (time $=0$ at 0830 hrs 12 October 1999

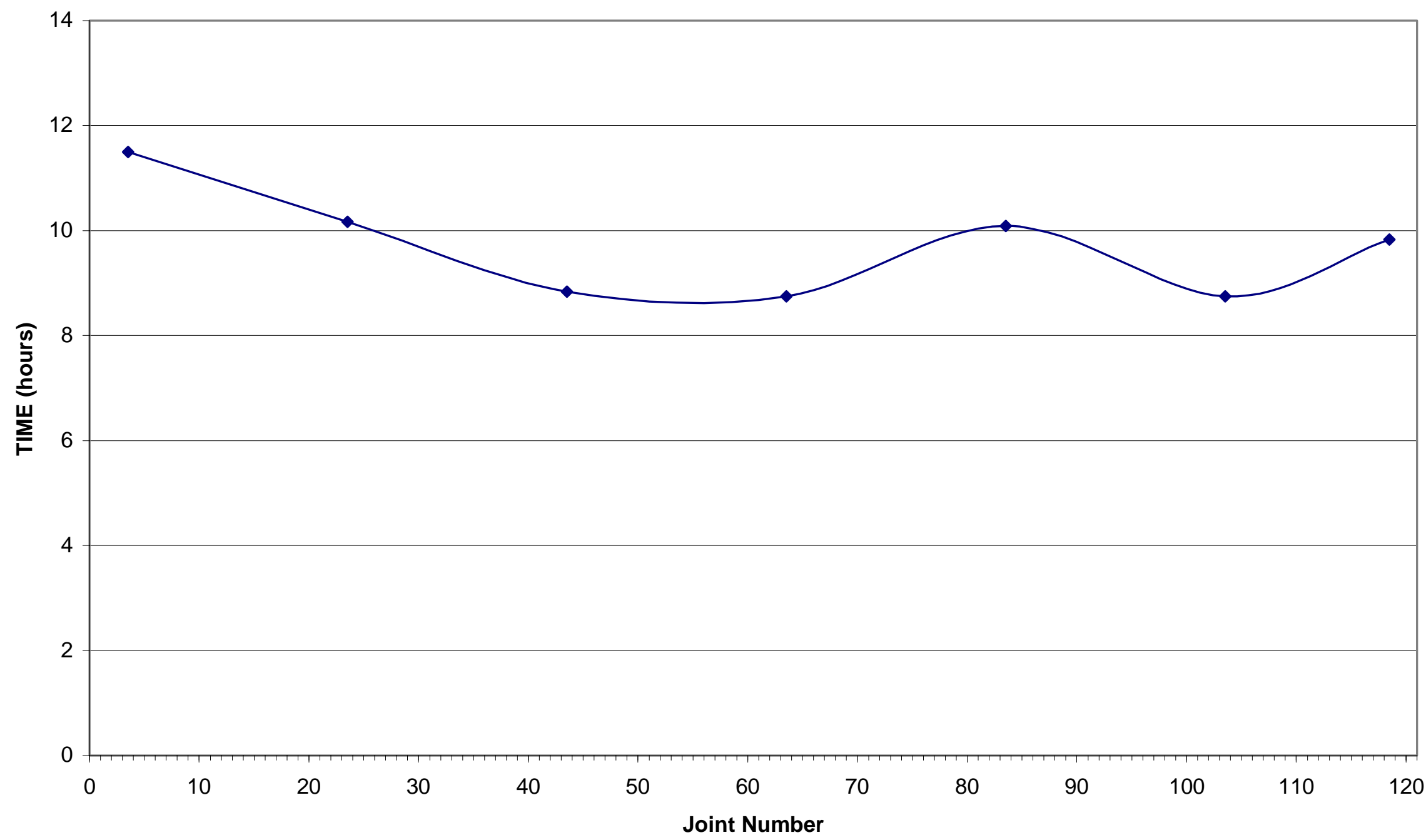

Figure 8.19: Total Time to Reach Maximum Core Temperature by Location, Corridor $\mathrm{H}$ 


\section{FDB Temps just prior to concrete overlay and corresponding Ambient temps \\ Corridor H Elkins WV}

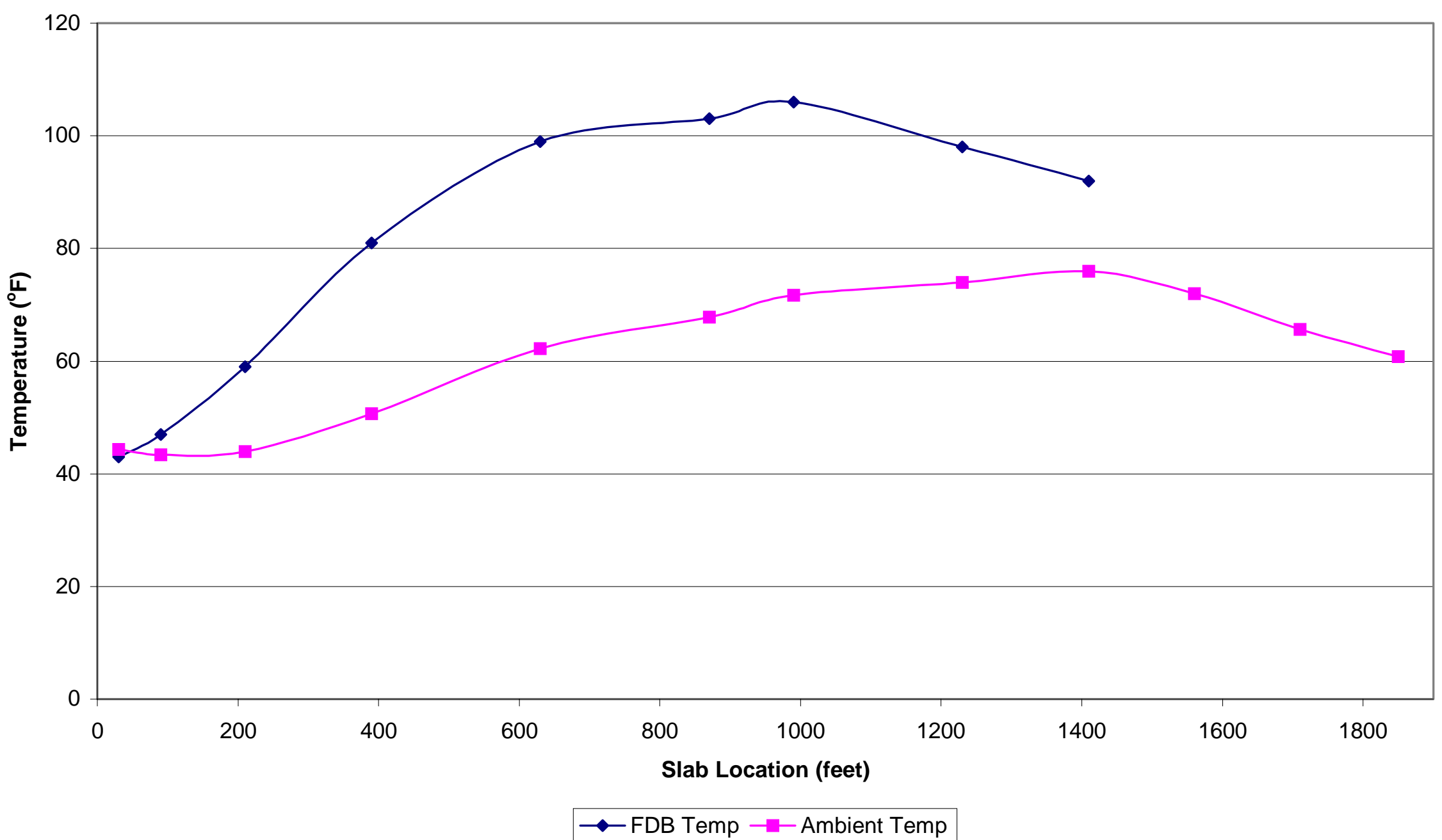

Figure 8.20: Base Course and Ambient Temperatures by Location prior to Concrete Overlay, Corridor $\mathrm{H}$ 
FDB and Ambient Temperature versus Time

Corridor $\mathrm{H}$ near Elkins WV (time $=0$ at 0830 hours)

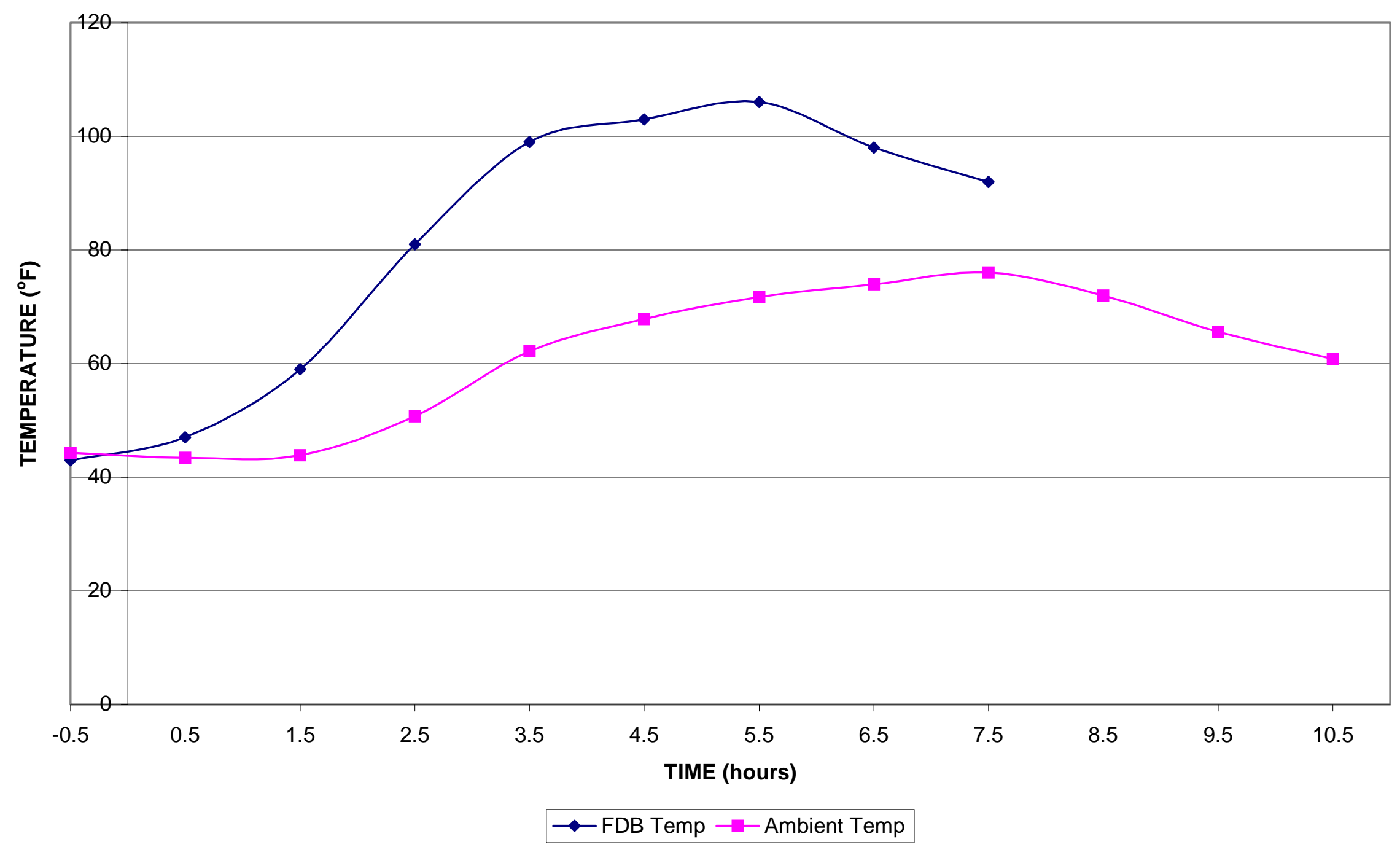

Figure 8.21: Base Course and Ambient Temperatures at Varying Times during Slab Construction, Corridor H 


\subsection{Cracking Behavior, Corridor H Elkins:}

\section{3a. 12 October 1999 slab section (Instrumented)}

The concrete slab placement began at 0830 hours and concluded at 1830 hours. Therefore, the concrete placed at the slab beginning was 10 hours more matured than the concrete placed at the end. This can be seen graphically in Figure 8.22. Concrete age by location has been found to be a controlling factor in the overall slab section behavior. The results obtained from the two 1998 investigations allowed joint crack locations and frequency to be estimated which assisted in the investigation of cracking sequence. The transverse joint-crack formation behavior for this slab section was closely monitored. During this investigation, the joint-crack formation sequence and width developments, along with detailed slab temperature profile history, were closely monitored. The transverse saw-joint design and joint numbering sequence, discussed in section 8.1, formed 121 slab sections, 15 -feet long. The joint number begins at zero at the start location and ends at joint 121 at another wooden bulkhead.

The results from the transverse joint-crack formations were plotted in three separate graphs, Figures 8.23, 8.24 and 8.25. The first, Figure 8.23, shows the joint-crack development at various times during the first 24-hours. The second, Figure 8.24, shows the cracking development ranging from 33-hours to 71-hours of monitoring. The third, Figure 8.25, shows developments from selected times during this investigation. The joint crack sequence was found to progress from the older end of the slab to the younger. After the first night of investigation, approximately the first half of the slab section had developed cracking, all of which were less than 2-mm in width. The initiation of cracking was found to occur during the cooler nighttime hours only and none during the 
warmer daytime hours. The crack width growth rates were found to be faster the second night than the first nights. This behavior may be attributed to that the concrete stress required to crack the more matured slab the second night had to be higher than the first.

The crack sequence the first night was found to be every $8^{\text {th }}$ to $12^{\text {th }}$ saw-cut joints or 120 to 180 -feet apart along the first half of slab section only. During the second-day daylight hours, crack widths were found to remain approximately the same width with no additional formation. The second night, as the slab cooled from the dropping ambient temperatures, crack formation propagated over the remaining length of slab. Also in the first half of slab region where cracks formed during the first night, the longer noncracked joint sections, 10 to 12 joints apart, showed smaller intermediate joint crack formations. By the end of the second night, it was believed that the majority of initial joint-crack formation development was complete and the slab was behaving more uniformly. The joint spacing by the $38^{\text {th }}$ hour, 1030 p.m. October $13^{\text {th }}$, was approximately every $6^{\text {th }}$ to $8^{\text {th }}$ joint or 90 to 120 -feet and the average crack width was between 2 to $3 \mathrm{~mm}$. The crack widths continued growing overnight as the slab cooled. The last joint crack measurements were taken at 71-hours, 730 a.m. October $14^{\text {th }}$. By that time, the crack widths had grown averaging from 4 to $7 \mathrm{~mm}$. Although, addition intermediate joint crack widths remained quite small, less than $0.5 \mathrm{~mm}$.

The adjoining concrete slab section constructed on October $13^{\text {th }}$ was also monitored for joint crack formation. This section was checked over the first 48 hours of concrete slab age. Results from that monitoring are found in Section 8.3b. Further discussion on the crack behavior, along with overall slab section behavior, can be seen in Section 8.5 and Chapter 9. 


\section{$\underline{\text { 8.3b. } 13 \text { October } 1999 \text { slab section (Non-instrumented) }}$}

The second day of highway construction continued from the end location from the first day. The construction of this section also began at 0830 hours, but on October $13^{\text {th }}$. The concrete construction lasted until 1530 hours on the $13^{\text {th }}, 7$ hours total. The slab section placed was 1530 -feet in length, with 102 saw-cut sections 15 -feet long. This slab section was not instrument with thermocouples but was checked for joint crack development at various times. The crack formations were recorded at three different times from the zero time of that section, (0830 hours October 13, 1999). They were plotted in Figure 8.26. The joint-crack formations from the second day slab section were very similar to the formations from the first day's construction. The crack spacing during the first night of slab cure was generally every 10 to 12 joints, or 150 to 180 feet. They were all less than $1 \mathrm{~mm}$ wide and only located in the beginning end of the slab section. At the beginning of the second evening, 37 hours, joint crack formation was seen to continue throughout the length of the slab. Crack widths were now along the range of 1.5 to $3 \mathrm{~mm}$ in width. Intermediate joint cracks also formed between the wider spaced joints. At the $48^{\text {th }}$ hour of concrete age, the joint crack formation was checked again. The frequency of the crack location ranged from every $6^{\text {th }}$ to $10^{\text {th }}$ saw-cut joint and was generally 3 to $5.5 \mathrm{~mm}$ wide. These results compare very well in frequency and width to those found from the instrumented slab section. The crack formations were not identical but very similar in behavior. 
Estimated concrete age and Approximate analysis age versus Joint Number Location Corridor H near Elkins, WV (Time $=0$ at 0830 hours 12 October 1999)

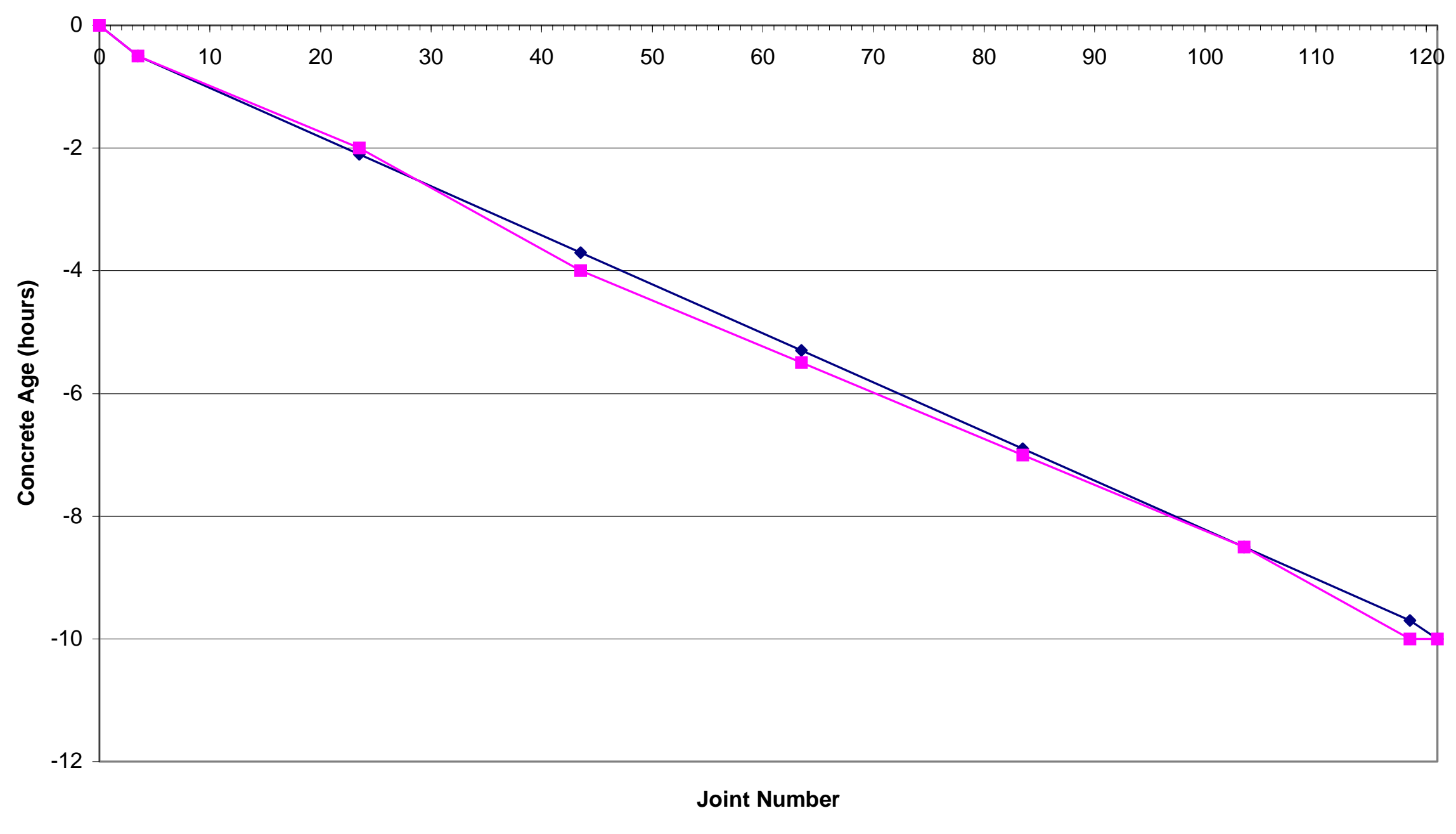

Estimated Concrete Age $\rightarrow$-Approximate Analysis Age

Figure 8.22: Concrete Age by Location, Corridor $\mathrm{H}$ 
Crack Width Development (first 24 hours)

Corridor H Westbound Lanes near Elkins, WV

(time $=0$ at 8:30 AM, October 12, 1999)

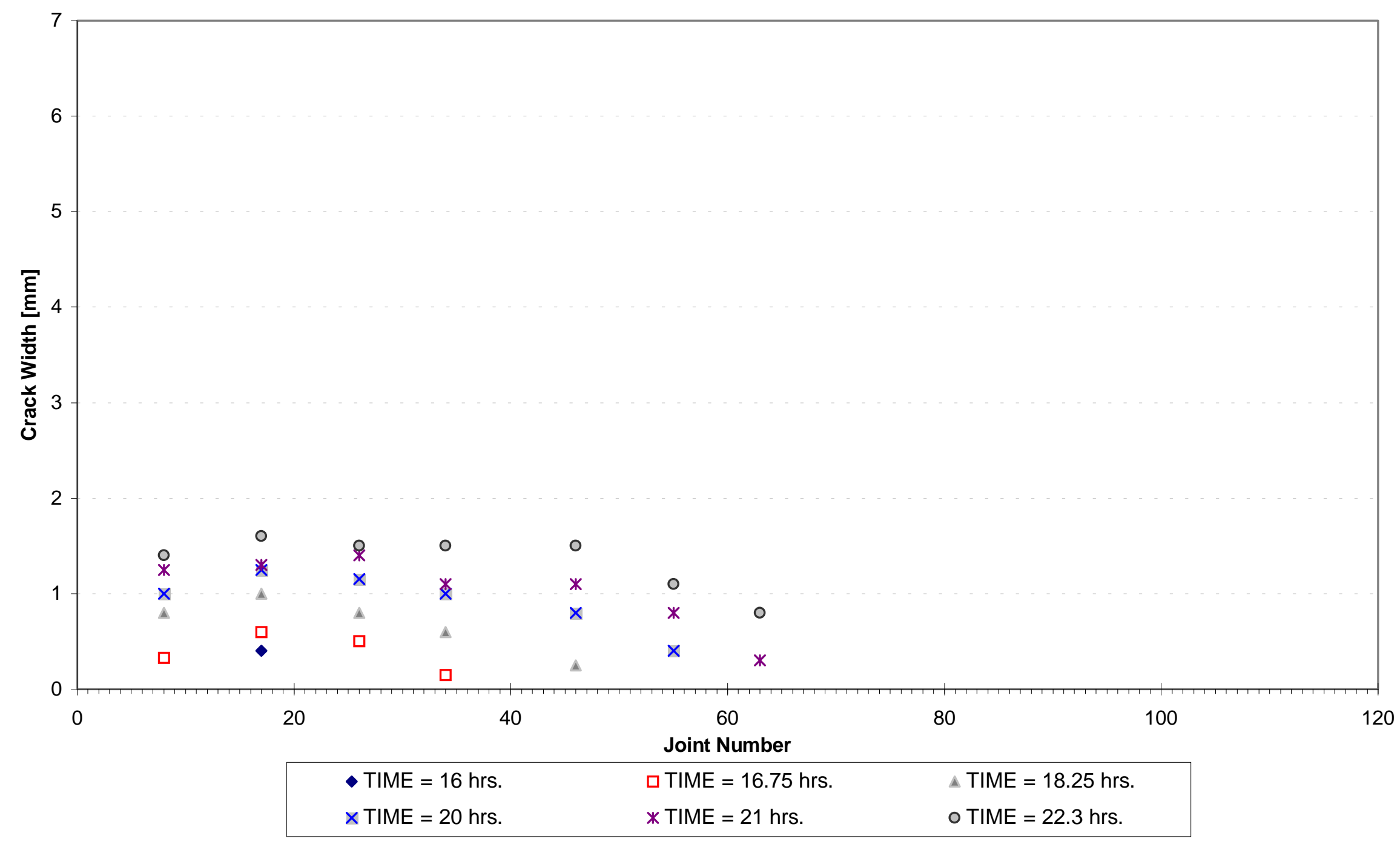

Figure 8.23: Crack Development up to 24 hours, Corridor H 
Crack Width Development (after 24 hours)

Corridor $\mathrm{H}$ Westbound Lanes near Elkins, WV

(time $=0$ at 8:30 AM, October 12, 1999)

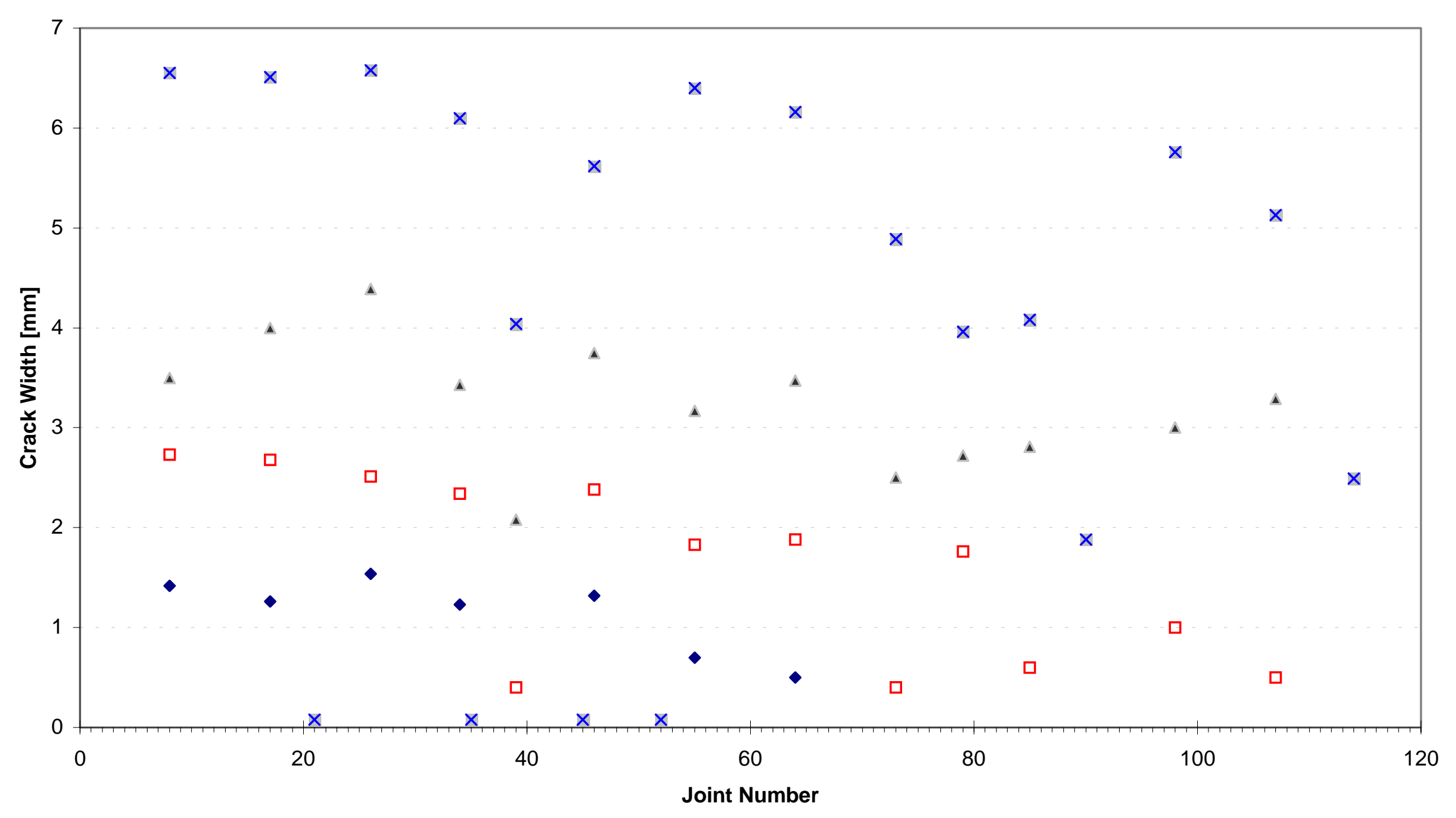

- TIME = 33 hrs.

$\square$ TIME = 38 hrs.

$\triangle \mathrm{TIME}=51.3 \mathrm{hrs}$

$\times$ TIME $=71 \mathrm{hrs}$

Figure 8.24: Crack Development after 24 hours, Corridor H 
Crack Widths for Each Joint at Selected Times

Corridor $\mathrm{H}$ Westbound Lanes near Elkins, WV

(TIME=0 at 8:30 AM, Oct. 12, 1999)

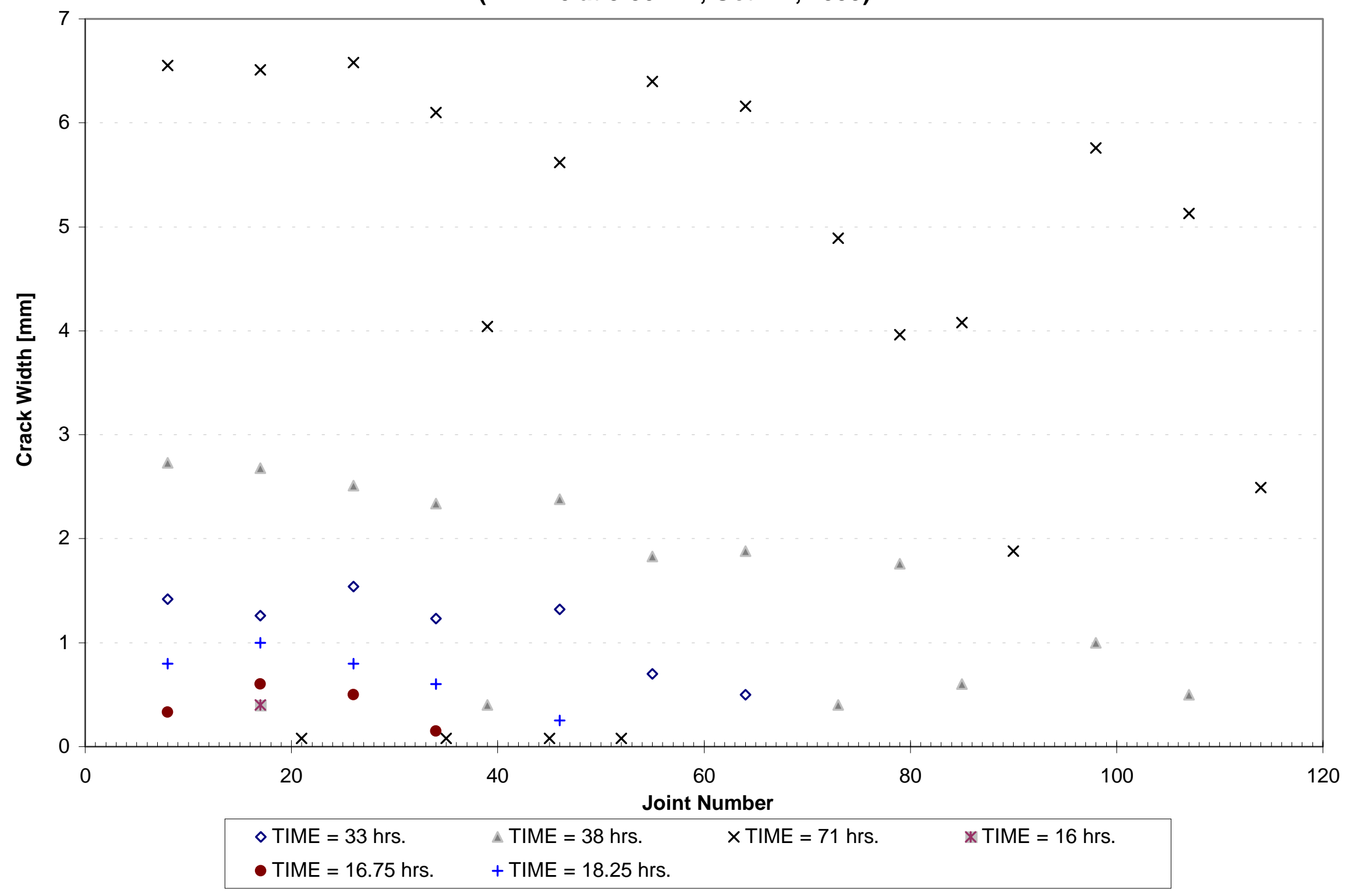

Figure 8.25: Crack Development at Select Times, Corridor H 
2nd Slab Section Joint Crack Development (over 48 hour period)

Corridor H near Elkins, WV (time=0 at 0830 hours 13 October 1999)

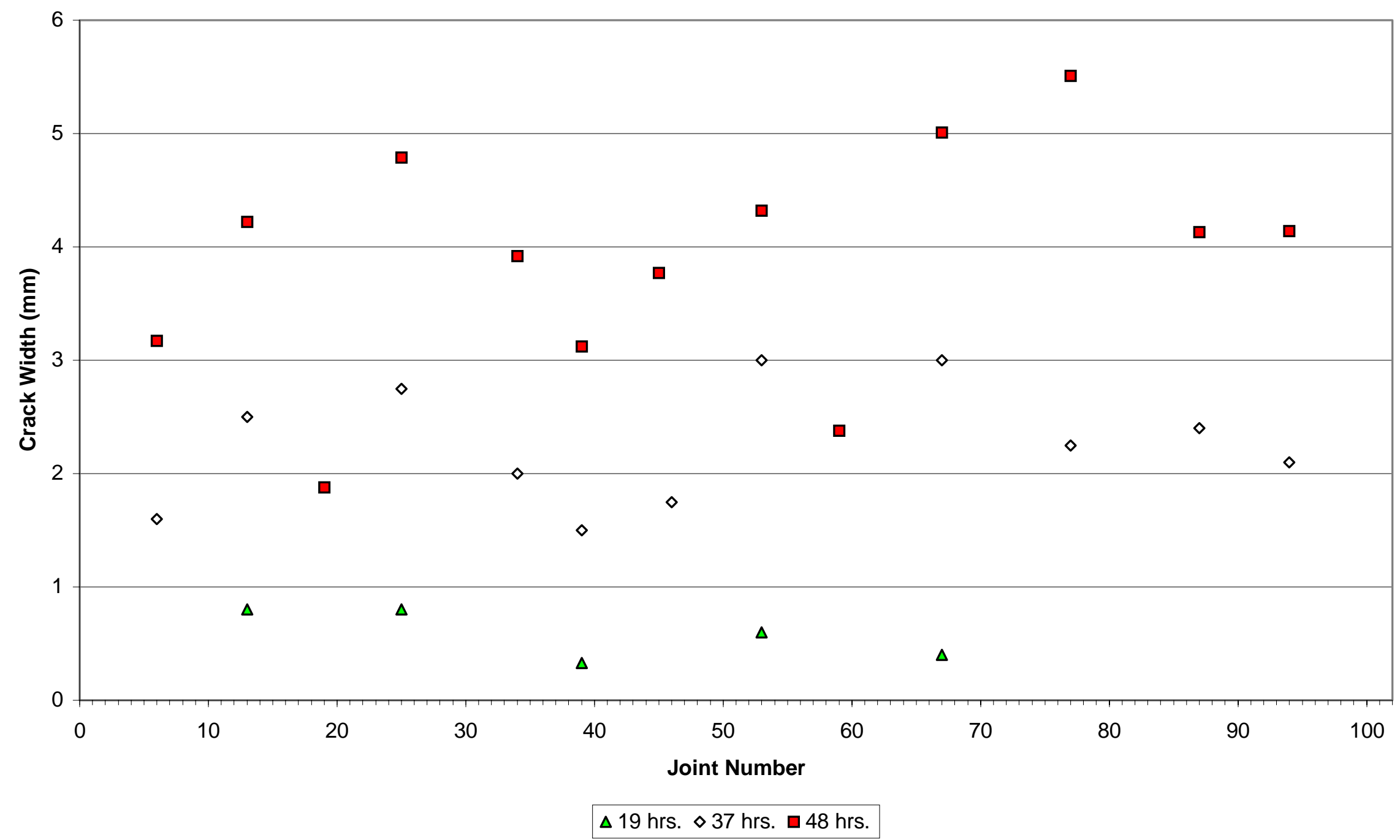

Figure 8.26: $2^{\text {nd }}$ Section Crack Development at varying times up to 48 hours, Corridor $\mathrm{H}$ 


\subsection{Strain Gage Data, Corridor H Elkins}

Five modified EM-5 strain gages were obtained for the Corridor $\mathrm{H}$ concrete slab section investigation and subsequent laboratory compression tests. The slab section location of each gage was discussed in Section 8.1, being Gage\#1 at 153 feet, Gage\#2 at 303 feet and Gage\#3 at 453 feet from the zero location. This was three feet after each of the proposed saw-cut joint locations, joints 10, 20 and 30, respectively. The gages were suspended at mid-slab depth, 5.5 inches, and three feet in from the outside lane edge. They were oriented to measure longitudinal concrete slab strains. This was done so that theoretical determined strain values could be compared to mechanically measured strain values. Gages \#4 and \#5 were suspended in plastic concrete cylinder molds, one filled with field mixed concrete and the other with laboratory mixed concrete. Gage\#4 was used for a field analysis dummy gage as well as a laboratory testing comparison. (See Chapter $3.5 \mathrm{f}$ and Chapter 4)

The data collected from the embedded slab strain gages by the MB-6T readout unit can be seen in Tables 8.3, 8.4 and 8.5. The data reduction technique described in Chapter $3.5 \mathrm{~d}$ utilizes both the thermal coefficients of the gage and the concrete to determine strain values. The thermal coefficients of the EM-5 gages obtained from the manufacturer were $11.5 \mu \mathrm{m} / \mathrm{m} /{ }^{\circ} \mathrm{C}$, for each. The thermal coefficient for concrete at various early ages currently can be assumed. The assumed value of the concrete's thermal coefficient may be obtained from laboratory testing or the examination of the dummy-gage's concrete cylinder temperature behavior. Phase I literature review, Roctests' instruction manuals and other resources provided estimated ranges of values for the thermal coefficient of 
concrete, ranging from 7 to $20 \mu \mathrm{m} / \mathrm{m} /{ }^{\circ} \mathrm{C}, 3.89$ to $11.1 \mu \mathrm{in} / \mathrm{in} /{ }^{\circ} \mathrm{F}$. Determining the value of thermal expansion is critical for data reduction as well as the theoretical analysis.

For analysis, a time and base temperature for which the concrete can be assumed set must be established. This should be ample time for which the gages may deform integrally with the concrete surrounding them. The maximum concrete temperature reached during initial heat of hydration occurs at an age of 10 to 12 hours. Crack formation and subsequent slab deformations did not occur until 16 hours or so. Therefore, little to no strain values should have been read at any of the gage locations prior to 16 hours. Detectable strain measurements may be seen by the embedded gages when coinciding transverse joints cracked and widened, or when the region of slab end movement exceeded the distance between the closest joint-crack and the gage. The actual crack width developments were obtained, see Section 8.3. Utilizing this information, an approximate thermal coefficient may allow for the coinciding achieved coefficient of friction to be determined.

Coefficient of thermal expansion and contraction tests were performed on the I-80 Danville, PA concrete mix design in the laboratory at a concrete age of 28 to 30 days. The determined thermal coefficient was found to be approximately $4.2 \mu$ strain $/{ }^{\circ} \mathrm{F}$, or 7.56 $\mu$ strain $/{ }^{\circ} \mathrm{C}$. (See Chapter 4.5) The value obtained is less than the value determined during Phase I review, being around $6 \mu$ strain $/{ }^{\circ} \mathrm{F}, 10.8 \mu$ strain $/{ }^{\circ} \mathrm{C}$. Therefore, it was desirable to check for the thermal coefficient of the Corridor H, Elkins concrete mix design also.

Early age concrete compatibility with current strain gage technologies is limited to the concrete strength surrounding the gage or the bond strength of the gage to the concrete 
specimen. Concrete strength development during maturity may provide for a source of error in strain gage data reported due to localized concrete, or cement paste, failure around the strain gage. Thermal changes are seen in early-age concrete starting after the initial mixing of materials. The heat of hydration process of the cement paste raised the concrete temperature and is then effected by the surrounding ambient temperature behavior. A non-loaded, concrete cylinder with an embedded modified EM-5 gage was made from the field mixed concrete at the Corridor H, Elkins pavement investigation. The temperature and strain fluctuations were monitored over the course of the investigation. The time, for which the concrete was believed to have developed adequate strength to control the strain gage deformity completely, needed chosen. The time was selected to be the time when the maximum concrete temperature during heat of hydration was reached, around 10 to 12 hours. The EM-5 strain gages data was recorded due to changes in strain from any selected point. The actual point in concrete maturity when the concrete completely controls the gage deformity may or may not be accurately known, but must be assumed to allow for data reduction and interpretation. These values were determined by the data reduction method described in Chapter 3.5d. The influence of the thermal behavior of the EM-5 gage was removed from the measured strains. The cylinder was free to expand and contract with restraint only from the plastic cylinder mold, if any. Therefore, the observed real strains recorded are mainly due to the thermal strains of the concrete, neglecting shrinkage. The real strains were divided by the differential temperature change and revealed approximate values for the thermal coefficient of the concrete mix. (See Table 8.6) The resulting thermal coefficient found from Field Cylinder \#1 and embedded modified EM-5 strain gage (Gage \#4) can be seen 
in Figures 8.27 and 8.28, being in the respective terms of Fahrenheit or Centigrade. They were averaged approximated to be $4.67 \mu$ strain $/{ }^{\circ} \mathrm{F}$, or $8.39 \mu$ strain $/{ }^{\circ} \mathrm{C}$. To check this method of calculation, various values of the thermal coefficient were used to calculate the total strain observed. The total strain is determined by the removal of both thermal effects of the strain gage and the concrete. The remaining strain values would be due to hydration strains or shrinkage, both of which are very difficult to determine. The total strains by varying thermal coefficients of concrete versus time for concrete cylinder Specimen \#1 and Strain Gage \#4 can be seen in Figure 8.29. Due to the means in which the thermal coefficient was determined, the total strain observed should remain near zero. These results neglect shrinkage and other effective strains, but for early age concrete these strains may be considered negligible because moisture loss was restricted by the plastic cylinder mold and cap. The total strain by varying thermal coefficient's shows that the estimated value of $8.39 \mu$ strain $/{ }^{\circ} \mathrm{C}$ gives near zero values for the total strain for the cylinder, as expected. Assuming that the thermal coefficient $\left(4.67 \mu\right.$ strain $/{ }^{\circ} \mathrm{F}$, or 8.39 $\mu$ strain $/{ }^{\circ} \mathrm{C}$ ) was correct, the real strain and total strain values over time for the other three embedded gages could be determined. The real strain results for the four embedded gages can be seen in Figures 8.30. The total strain by varying thermal coefficient of concrete results for each slab embedded gage can be seen in Figures 8.31 through 8.33. Different results may come from the evaluation of the data recorded depending on what time one assumes total compatibility.

The thermal coefficient and resulting real strain versus time by strain gage will need evaluated also in the theoretical analysis. Use of the determined thermal coefficient in stress development calculations will affect the stress values seen because only thermal 
stresses are considered in the analysis. Further study on the accuracy of the thermal coefficient value obtained may need performed to reduce chances of error from other estimated or assumed values in further analysis.

Additional discussion on the importance and affect of the variation of the concrete thermal coefficient is elaborated on in Chapter 10 and Chapter 11. 
Table 8.3

GAGE \#1 Modified EM-5 Strain gage field data

Corridor H Westbound Lanes near Elkins, WV

Gage location in slab: Location $L=153 \mathrm{ft}$

Gage placed $3 \mathrm{ft}$ in slab from outside edge of mainline pavement

Orientation: longitudinal and parallel with slab, at mid-depth (5.5 in)

Prior to Placement:

$\mathrm{N}=1363.88$

$14.6 \mathrm{C}$

$L=2183.8$

$58.3 \mathrm{~F}$

\begin{tabular}{|l|r|l|l|l|l|l|}
\hline Date & TIME & HOUR & N & L & C & F \\
\hline 11 -Oct-99 & 1800 & & 1363.88 & 2183.8 & 14.6 & 58.3 \\
\hline
\end{tabular}

\begin{tabular}{|r|r|r|r|r|r|r|}
\hline 12-Oct & 930 & 1 & 1697.16 & 1411.2 & 14.6 & 58.3 \\
\hline & 1110 & 2.667 & 1304.25 & 2387.8 & 20.4 & 68.7 \\
\hline & 1210 & 3.667 & 1337.44 & 2271.1 & 20.8 & 69.4 \\
\hline & 1310 & 4.667 & 1345.48 & 2243.9 & 22.2 & 72.0 \\
\hline & 1410 & 5.667 & 1349.96 & 2229.1 & 24.1 & 75.4 \\
\hline & 1510 & 6.667 & 1355.31 & 2211.6 & 26.3 & 79.3 \\
\hline & 1610 & 7.667 & 1361.75 & 2190.6 & 28.6 & 83.5 \\
\hline & 1710 & 8.667 & 1369.21 & 2167.0 & 30.8 & 87.4 \\
\hline & 1810 & 9.667 & 1377.04 & 2142.3 & 33.5 & 92.3 \\
\hline & 1905 & 10.583 & 1381.95 & 2127.2 & 35.4 & 95.7 \\
\hline & 2030 & 12 & 1382.01 & 2127.1 & 35.4 & 95.7 \\
\hline & 2200 & 13.5 & 1379.07 & 2136.2 & 34.6 & 94.3 \\
\hline & 2315 & 14.75 & 1374.59 & 2150.1 & 33.1 & 92.3 \\
\hline $13-O c t$ & 45 & 16.25 & 1371.30 & 2160.4 & 32.0 & 89.6 \\
\hline & 220 & 17.833 & 1370.61 & 2162.5 & 30.4 & 86.7 \\
\hline & 330 & 19 & 1368.73 & 2168.4 & 29.3 & 84.7 \\
\hline & 445 & 20.25 & 1367.29 & 2173.0 & 28.2 & 82.8 \\
\hline & 645 & 22.25 & 1364.75 & 2181.2 & 26.7 & 80.1 \\
\hline & 1015 & 25.75 & 1363.24 & 2185.8 & 25.2 & 77.4 \\
\hline & 1120 & 26.833 & 1364.93 & 2180.4 & 25.6 & 78.1 \\
\hline & 1220 & 27.833 & 1366.34 & 2176.1 & 25.9 & 78.6 \\
\hline & 1320 & 28.833 & 1367.88 & 2171.1 & 26.7 & 80.1 \\
\hline & 1420 & 29.833 & 1369.88 & 2164.8 & 27.4 & 81.3 \\
\hline & 1520 & 30.833 & 1371.92 & 2158.4 & 28.2 & 82.8 \\
\hline & 1735 & 33.083 & 1373.58 & 2153.2 & 28.6 & 83.5 \\
\hline & 2200 & 37.5 & 1368.43 & 2169.5 & 26.3 & 79.3 \\
\hline & 0 & 39.5 & 1364.44 & 2182.1 & 24.1 & 75.4 \\
\hline & 245 & 42.25 & 1362.12 & 2189.5 & 22.2 & 72.0 \\
\hline & 1410 & 53.667 & 1356.94 & 2206.4 & 19.7 & 67.5 \\
\hline & 1530 & 55 & 1359.65 & 2197.5 & 20.8 & 69.4 \\
\hline & 1720 & 56.833 & 1361.48 & 2191.6 & 21.5 & 70.7 \\
\hline & 2020 & 59.833 & 1357.60 & 2204.2 & 19.7 & 67.5 \\
\hline & 2235 & 62.083 & 1353.69 & 2216.9 & 17.8 & 64.0 \\
\hline & 30 & 64 & 1351.03 & 2225.6 & 16.4 & 61.5 \\
\hline & 710 & 70.667 & 1343.58 & 2250.5 & 12.5 & 54.5 \\
\hline
\end{tabular}


Table 8.4

GAGE \#2 Modified EM-5 Strain gage field data Corridor H Westbound Lanes near Elkins, WV

Gage location in slab: Location $L=303 \mathrm{ft}$

Gage placed $3 \mathrm{ft}$ in slab from outside edge of mainline pavement

Orientation: longitudinal and parallel with slab, at mid-depth (5.5 in)
$\mathrm{N}=1413.04$
$13.2 \mathrm{C}$
$\mathrm{L}=2034.2$
$55.8 \mathrm{~F}$

\begin{tabular}{|r|r|r|r|r|r|r|}
\hline Date & \multicolumn{1}{|l|}{ TIME } & HOUR & N & L & C & F \\
\hline 11-Oct-99 & 1900 & & 1350.47 & 2229.3 & 10.8 & 50.7 \\
\hline 12-Oct & 1010 & 1.667 & 1359.31 & 2198.7 & 14.6 & 58.3 \\
\hline & 1040 & 2.167 & 1383.90 & 2121.3 & 19.7 & 67.5 \\
\hline & 1110 & 2.667 & 1380.26 & 2132.4 & 20.4 & 68.0 \\
\hline & 1210 & 3.667 & 1384.24 & 2120.1 & 20.8 & 69.4 \\
\hline & 1310 & 4.667 & 1386.89 & 2112.0 & 22.2 & 72.0 \\
\hline & 1410 & 5.667 & 1390.62 & 2100.6 & 23.7 & 74.7 \\
\hline & 1510 & 6.667 & 1397.38 & 2080.5 & 25.6 & 78.1 \\
\hline & 1610 & 7.667 & 1405.52 & 2056.3 & 27.8 & 82.0 \\
\hline & 1710 & 8.667 & 1414.32 & 2030.8 & 29.7 & 85.5 \\
\hline & 1810 & 9.667 & 1422.90 & 2006.3 & 32.0 & 89.6 \\
\hline & 1910 & 10.667 & 1428.96 & 1989.5 & 33.5 & 92.3 \\
\hline & 2035 & 12.083 & 1432.94 & 1978.5 & 34.6 & 94.3 \\
\hline & 2205 & 13.583 & 1429.56 & 1987.9 & 33.9 & 93.0 \\
\hline & 2325 & 14.917 & 1424.22 & 2002.8 & 32.7 & 90.9 \\
\hline $13-O c t$ & 100 & 16.5 & 1422.63 & 2007.3 & 31.2 & 88.2 \\
\hline & 230 & 18 & 1420.07 & 2014.5 & 30.1 & 86.2 \\
\hline & 335 & 19.083 & 1418.23 & 2019.7 & 29.3 & 84.7 \\
\hline & 500 & 21.5 & 1416.30 & 2025.0 & 28.2 & 82.0 \\
\hline & 655 & 22.417 & 1413.74 & 2032.5 & 26.7 & 80.1 \\
\hline & 1020 & 25.833 & 1411.96 & 2037.7 & 25.9 & 78.6 \\
\hline & 1125 & 26.917 & 1414.72 & 2029.7 & 26.7 & 80.1 \\
\hline & 1225 & 27.917 & 1416.85 & 2023.7 & 27.1 & 80.8 \\
\hline & 1325 & 28.917 & 1419.16 & 2017.1 & 28.2 & 82.8 \\
\hline & 1425 & 29.917 & 1422.04 & 2008.9 & 28.9 & 84.0 \\
\hline & 1525 & 30.917 & 1425.03 & 2000.5 & 29.7 & 85.5 \\
\hline & 1735 & 33.083 & 1427.41 & 1993.9 & 30.4 & 86.7 \\
\hline & 2210 & 37.667 & 1419.30 & 2016.6 & 27.1 & 80.8 \\
\hline & 15 & 39.75 & 1413.88 & 2032.2 & 24.8 & 76.6 \\
\hline & 300 & 42.5 & 1410.24 & 2042.7 & 22.6 & 72.7 \\
\hline & 1415 & 53.75 & 1405.79 & 2055.6 & 21.1 & 70.0 \\
\hline & 1535 & 55.0833 & 1410.36 & 2042.3 & 22.6 & 72.7 \\
\hline & 1725 & 56.917 & 1412.98 & 2034.7 & 23.0 & 73.4 \\
\hline & 2025 & 59.917 & 1406.86 & 2052.6 & 20.4 & 68.7 \\
\hline & 2230 & 62 & 1401.57 & 2068.1 & 18.6 & 65.5 \\
\hline & 40.75 & 1388.72 & 2106.4 & 12.8 & 55.0 \\
\hline
\end{tabular}


Table 8.5

GAGE \#3 Modified EM-5 Strain gage field data

Corridor H Westbound Lanes near Elkins, WV

Gage location in slab: Location $L=453 \mathrm{ft}$

Gage placed $3 \mathrm{ft}$ in slab from outside edge of mainline pavement

Orientation: longitudinal and parallel with slab, at mid-depth (5.5 in)

Prior to Placement:

$\mathrm{N}=1409.37 \quad 9 \mathrm{C}$

$\mathrm{L}=2045.4 \quad 48.2 \mathrm{~F}$

\begin{tabular}{|l|r|l|l|l|l|l|}
\hline Date & TIME & HOUR & N & L & C & F \\
\hline 11-Oct-99 & 2000 & & 1377.49 & 2140.9 & 9.4 & 48.9 \\
\hline
\end{tabular}

\begin{tabular}{|r|r|r|r|r|r|r|}
\hline 12-Oct & 1110 & 2.667 & 1359.13 & 2199.1 & 23.7 & 74.7 \\
\hline & 1115 & 2.75 & 1369.59 & 2165.6 & 21.9 & 71.4 \\
\hline & 1220 & 3.833 & 1464.50 & 1894.2 & 21.9 & 71.4 \\
\hline & 1320 & 4.833 & 1457.76 & 1911.7 & 22.6 & 72.7 \\
\hline & 1420 & 5.833 & 1457.59 & 1912.2 & 23.7 & 74.7 \\
\hline & 1520 & 6.833 & 1461.82 & 1901.0 & 24.8 & 76.6 \\
\hline & 1620 & 7.833 & 1469.62 & 1881.0 & 26.7 & 80.1 \\
\hline & 1725 & 8.917 & 1480.24 & 1854.0 & 28.9 & 84.0 \\
\hline & 1820 & 9.833 & 1487.55 & 1835.9 & 30.4 & 86.7 \\
\hline & 1920 & 10.833 & 1495.79 & 1815.6 & 32.3 & 90.1 \\
\hline & 2045 & 12.25 & 1505.96 & 1791.3 & 35.0 & 95.0 \\
\hline & 2220 & 13.833 & 1504.08 & 1795.8 & 35.0 & 95.0 \\
\hline & 2325 & 14.917 & 1499.23 & 1807.4 & 33.9 & 93.0 \\
\hline $13-O c t$ & 115 & 16.75 & 1494.55 & 1818.7 & 32.7 & 90.9 \\
\hline & 240 & 18.167 & 1492.84 & 1822.9 & 31.2 & 88.2 \\
\hline & 345 & 19.25 & 1490.65 & 1828.1 & 30.4 & 86.7 \\
\hline & 505 & 20.583 & 1488.28 & 1834.1 & 29.3 & 84.7 \\
\hline & 710 & 22.667 & 1485.13 & 1841.9 & 27.8 & 82.0 \\
\hline & 1025 & 25.917 & 1481.22 & 1851.6 & 26.7 & 80.1 \\
\hline & 1130 & 27 & 1483.09 & 1847.1 & 27.1 & 80.8 \\
\hline & 1230 & 28 & 1484.54 & 1843.2 & 27.4 & 81.3 \\
\hline & 1330 & 29 & 1486.68 & 1838.0 & 28.2 & 82.8 \\
\hline & 1435 & 30.083 & 1489.22 & 1831.7 & 28.9 & 84.0 \\
\hline & 1530 & 31 & 1491.91 & 1825.0 & 29.7 & 85.5 \\
\hline & 1740 & 33.167 & 1496.23 & 1814.7 & 30.4 & 86.7 \\
\hline & 2220 & 37.833 & 1490.36 & 1828.9 & 27.8 & 82.6 \\
\hline & 25 & 39.917 & 1484.68 & 1843.0 & 25.6 & 78.1 \\
\hline & 305 & 42.583 & 1481.35 & 1851.2 & 23.7 & 74.7 \\
\hline & 1420 & 53.833 & 1472.89 & 1872.5 & 21.1 & 70.0 \\
\hline & 1540 & 55.167 & 1477.19 & 1861.8 & 22.2 & 72.0 \\
\hline & 1730 & 57 & 1480.72 & 1852.8 & 23.0 & 73.4 \\
\hline & 2030 & 60 & 1476.82 & 1862.7 & 21.1 & 70.0 \\
\hline & 2240 & 62.167 & 1472.09 & 1874.6 & 19.3 & 66.4 \\
\hline & 420 & 64.167 & 1468.60 & 1883.5 & 17.8 & 64.0 \\
\hline & 70.917 & 1458.70 & 1909.3 & 13.6 & 56.5 \\
\hline
\end{tabular}


Table 8.6

Thermal Coefficient of Concrete calculations

EM-5 Strain Gage \#4 ("Dummy-Gage"), Field Concrete Cylinder Embedded

Corridor H near Elkins, WV; Actual Slab Concrete Sample

(time $=0$ at 0830 hours) 12 October 1999

Calculated $\alpha_{\mathrm{C}}\left(\mathrm{mm} / \mathrm{mm} /{ }^{\circ} \mathrm{C}\right.$ or in $\left./ \mathrm{in} /{ }^{\circ} \mathrm{F}\right)$

\begin{tabular}{|c|c|c|c|c|c|}
\hline HOUR & $\begin{array}{c}\text { Real Strain } \\
\text { (by Centigrade) } \\
\varepsilon_{\mathrm{r} .} \mathrm{C}\end{array}$ & \begin{tabular}{|c|} 
Thermal \\
Coefficient \\
$\varepsilon_{\mathrm{r}} \mathrm{C} / \Delta \mathrm{TC}$
\end{tabular} & HOUR & $\begin{array}{c}\text { Real Strain } \\
\text { (by Fahrenheit) } \\
\varepsilon_{\mathrm{r}} \mathrm{F}\end{array}$ & $\begin{array}{c}\text { Thermal } \\
\text { Coefficient } \\
\varepsilon_{r} . \mathrm{F} / \Delta \mathrm{TF}\end{array}$ \\
\hline 9.583 & -32 & 10.000 & 9.583 & -32.262 & 5.562 \\
\hline 10.583 & -85.2 & 8.192 & 10.583 & -85.093 & 4.550 \\
\hline 12 & -142.9 & 7.683 & 12 & -143.065 & 4.271 \\
\hline 13.5 & -178.95 & 7.551 & 13.5 & -179.253 & 4.198 \\
\hline 14.833 & -204.55 & 7.604 & 14.833 & -204.476 & 4.225 \\
\hline 16 & -220.2 & 7.699 & 16 & -220.385 & 4.279 \\
\hline 17.917 & -230.9 & 7.697 & 17.917 & -230.96 & 4.277 \\
\hline 19.083 & -235.15 & 7.660 & 19.083 & -235.467 & 4.258 \\
\hline 20.25 & -240.2 & 7.650 & 20.25 & -240.135 & 4.250 \\
\hline 22.25 & -245.15 & 7.637 & 22.25 & -245.342 & 4.245 \\
\hline 25.75 & -168.25 & 7.545 & 25.75 & -168.678 & 4.196 \\
\hline 26.833 & -147.8 & 7.946 & 26.833 & -147.965 & 4.417 \\
\hline 27.833 & -134 & 8.171 & 27.833 & -133.905 & 4.539 \\
\hline 28.833 & -118.7 & 8.359 & 28.833 & -118.984 & 4.648 \\
\hline 29.833 & -105.85 & 9.204 & 29.833 & -105.873 & 5.115 \\
\hline 30.833 & -96.1 & 9.610 & 30.833 & -96.12 & 5.340 \\
\hline 33 & -122.6 & 9.431 & 33 & -122.626 & 5.240 \\
\hline 39.5 & -238.15 & 8.415 & 39.5 & -238.59 & 4.678 \\
\hline 42.25 & -253.6 & 8.342 & 42.25 & -253.533 & 4.635 \\
\hline 45.083 & -269.15 & 8.282 & 45.083 & -269.215 & 4.602 \\
\hline 53.667 & -189.8 & 8.953 & 53.667 & -190.098 & 4.976 \\
\hline 55 & -175.6 & 9.242 & 55 & -175.638 & 5.136 \\
\hline 56.833 & -191.95 & 9.550 & 56.833 & -192.118 & 5.307 \\
\hline 59.833 & -264.6 & 8.820 & 59.833 & -264.66 & 4.901 \\
\hline 62.083 & -300.05 & 8.597 & 62.083 & -299.992 & 4.777 \\
\hline 64 & -315.75 & 8.511 & 64 & -315.952 & 4.730 \\
\hline 70.583 & -335.3 & 8.218 & 70.583 & -335.765 & 4.568 \\
\hline
\end{tabular}

\begin{tabular}{|ll|ll}
\hline Average $\alpha_{C}\left(\mu \mathrm{mm} / \mathrm{mm} /{ }^{\circ} \mathrm{C}\right)=$ & 8.391 & Average $\alpha_{C}\left(\mu \mathrm{in} / \mathrm{in} /{ }^{\circ} \mathrm{F}\right)=$ & 4.664
\end{tabular} 
Coefficient of Thermal Contraction versus Time

EM-5 Gage\#4 Results Corridor H near Elkins, WV

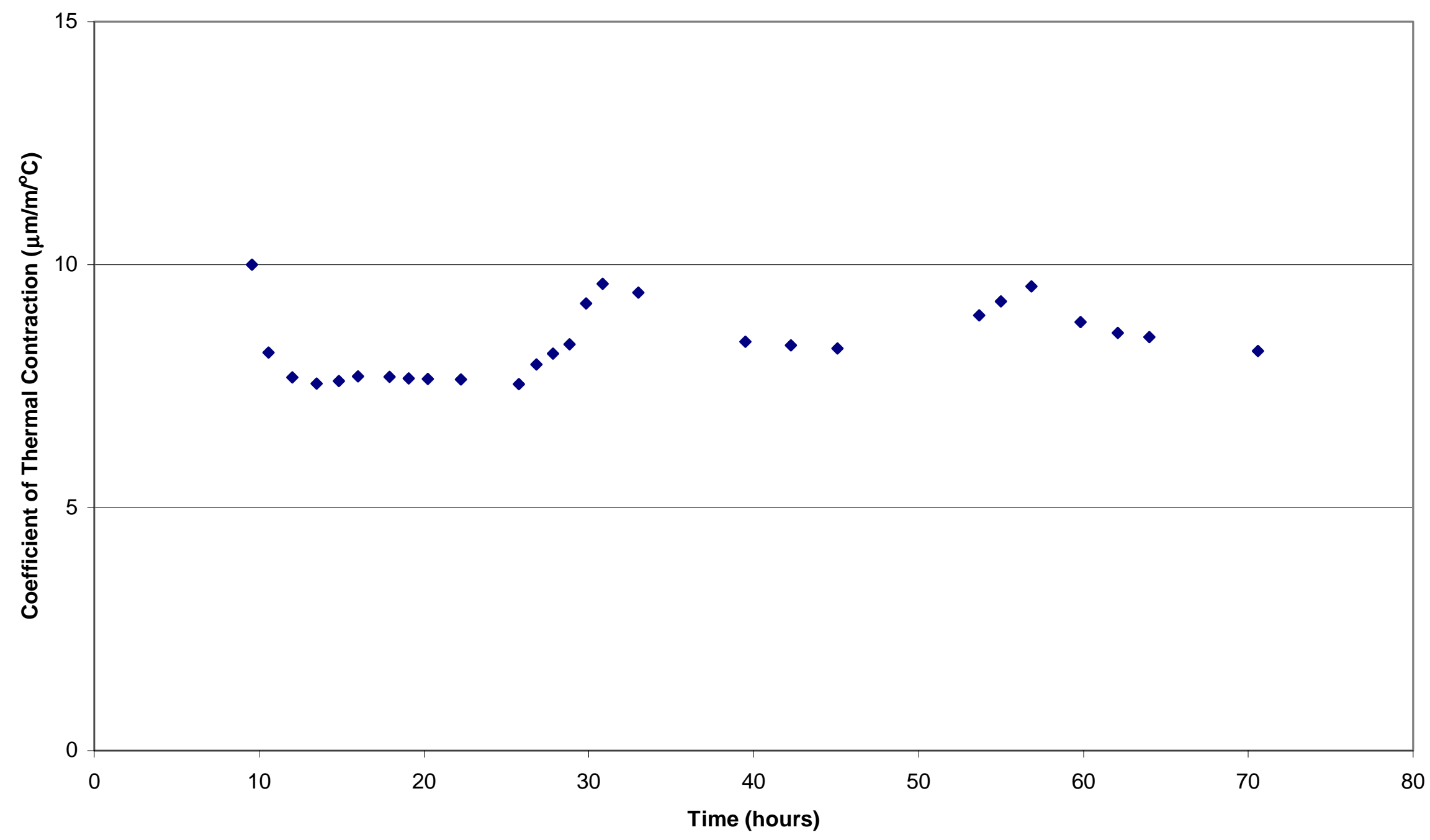

Figure 8.27: Calculated Thermal Coefficients of Concrete Results \#1, (Strain Gage \#4 Data), Corridor H 


\section{Coefficient of Thermal Contraction versus Time \\ EM-5 Gage\#4 Corridor H near Elkins, WV}

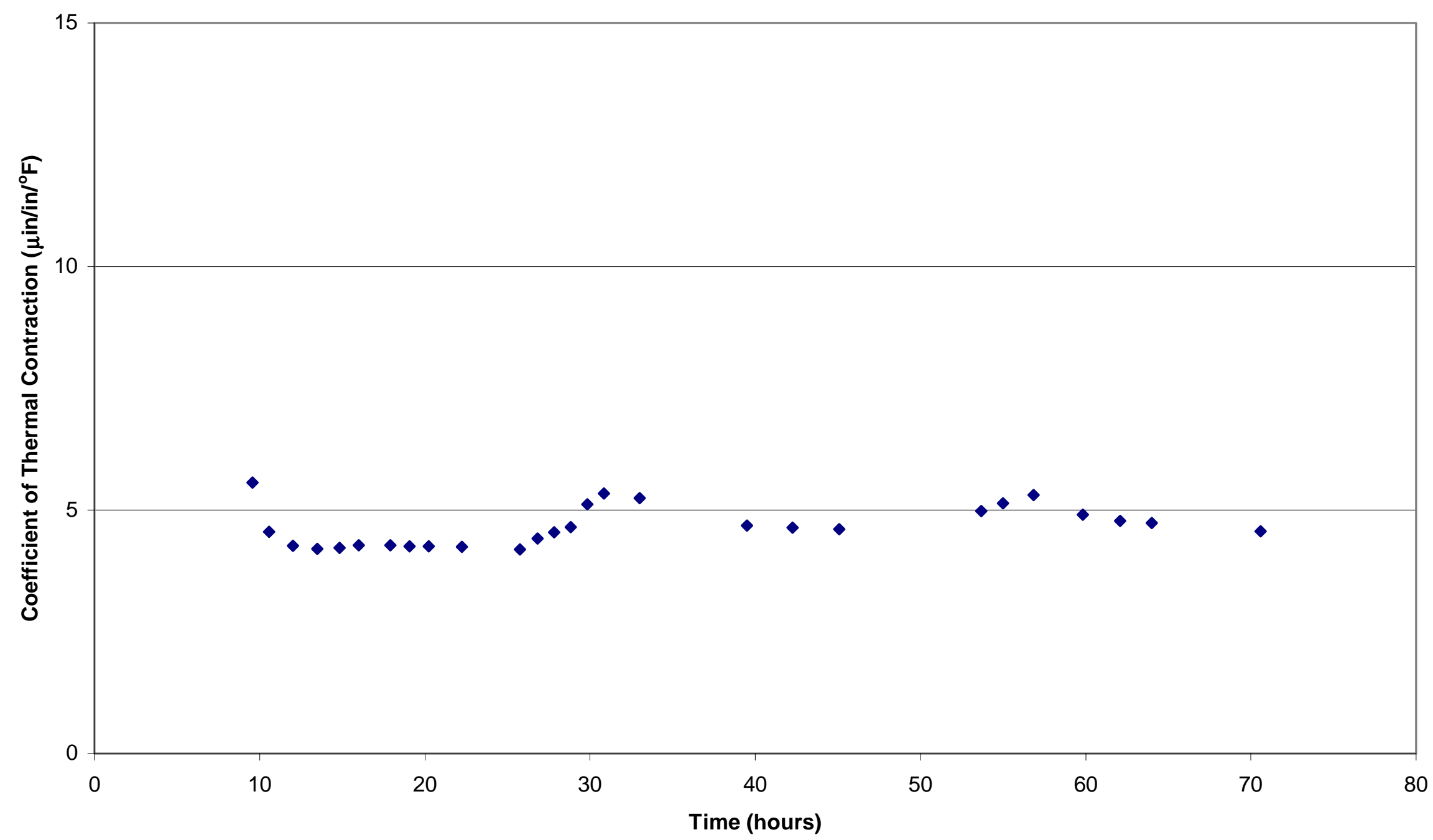


EM-5 Gage\#4 Total Strain versus Time by varying $\alpha_{C}$

(Cylinder Gage) Corridor H near Elkins, WV

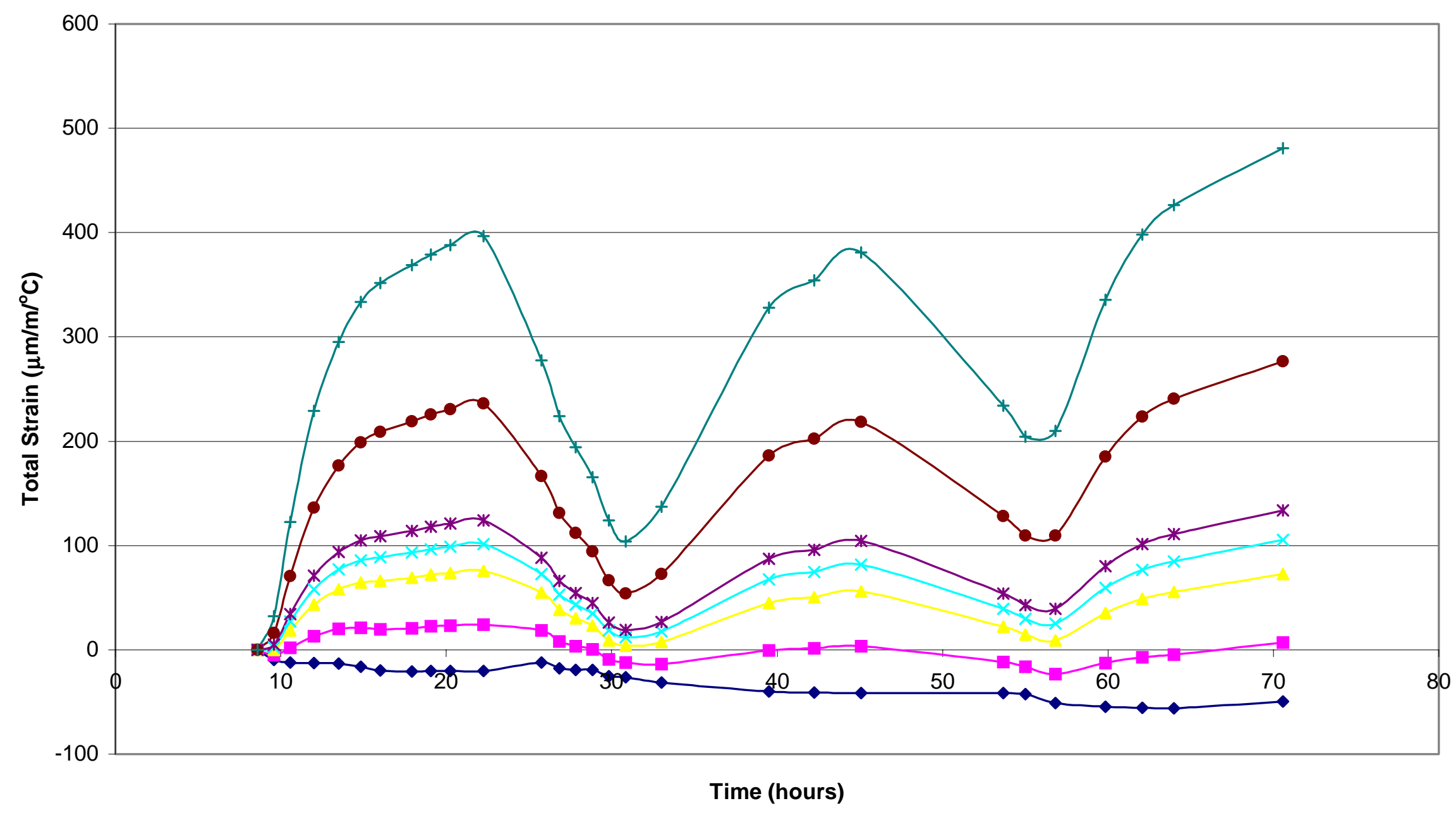

$\multimap \mathrm{nb}=7 \multimap \mathrm{nb}=8.39 \multimap \mathrm{nb}=10 \multimap \mathrm{nb}=10.8 \multimap \mathrm{nb}=11.5 \multimap \mathrm{nb}=15 \multimap \mathrm{nb}=20$

Figure 8.29: Total Strain by Time, (Strain Gage \#4), Corridor H 
Real Strain versus Time (Modified EM-5 gage results)

Corridor H near Elkins, WV (time-0 at 0830 hrs 12 October 1999)

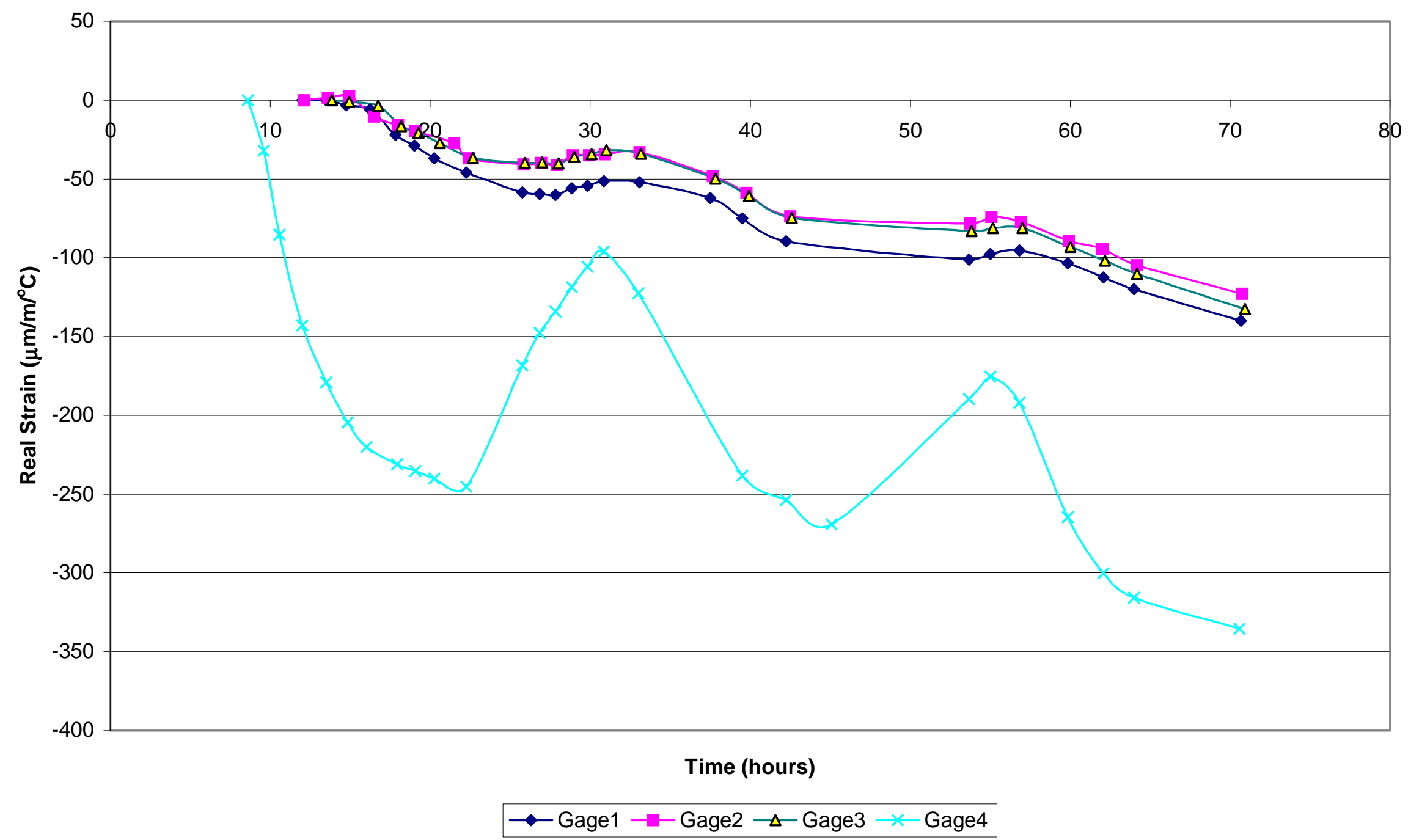

Figure 8.30: Real Strain versus Time for all Field Strain Gages, Corridor H 
(EM-5 Gage\#1) Total Strain versus Time by varying $\alpha_{C}$ Corridor H location 153 feet from zero

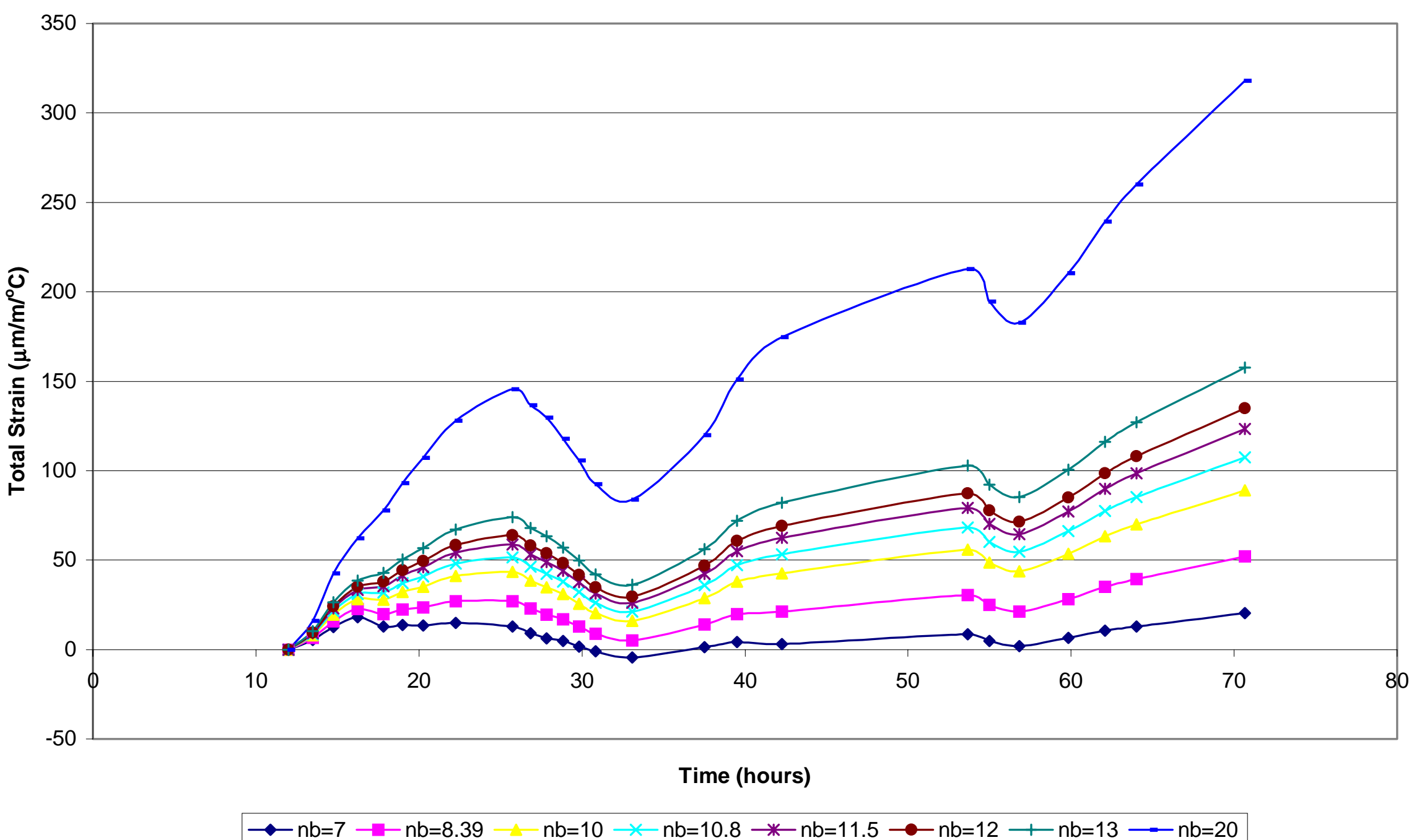

Figure 8.31: Gage \#1 Total Strain by varying Thermal Coefficient of Concrete versus Time, Corridor H 
(EM-5 Gage\#2) Total Strain versus Time by varying $\alpha_{C}$ Corridor H location $\mathbf{3 0 3}$ feet from zero

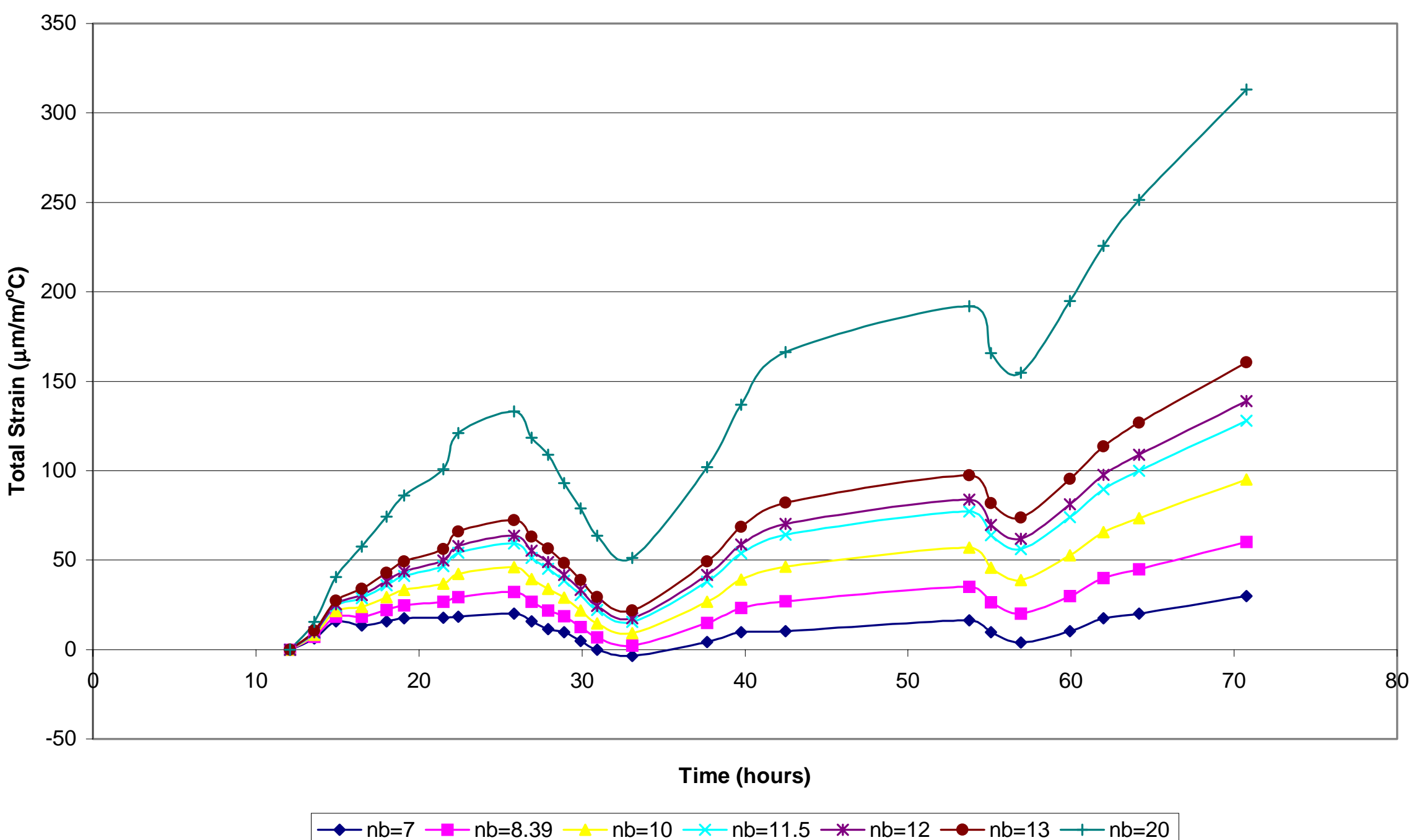

Figure 8.32: Gage \#2 Total Strain by varying Thermal Coefficient of Concrete versus Time, Corridor H 
(EM-5 Gage\#3) Total Strain versus Time by varying $\alpha_{C}$ Corridor H location $\mathbf{4 5 3}$ feet from zero

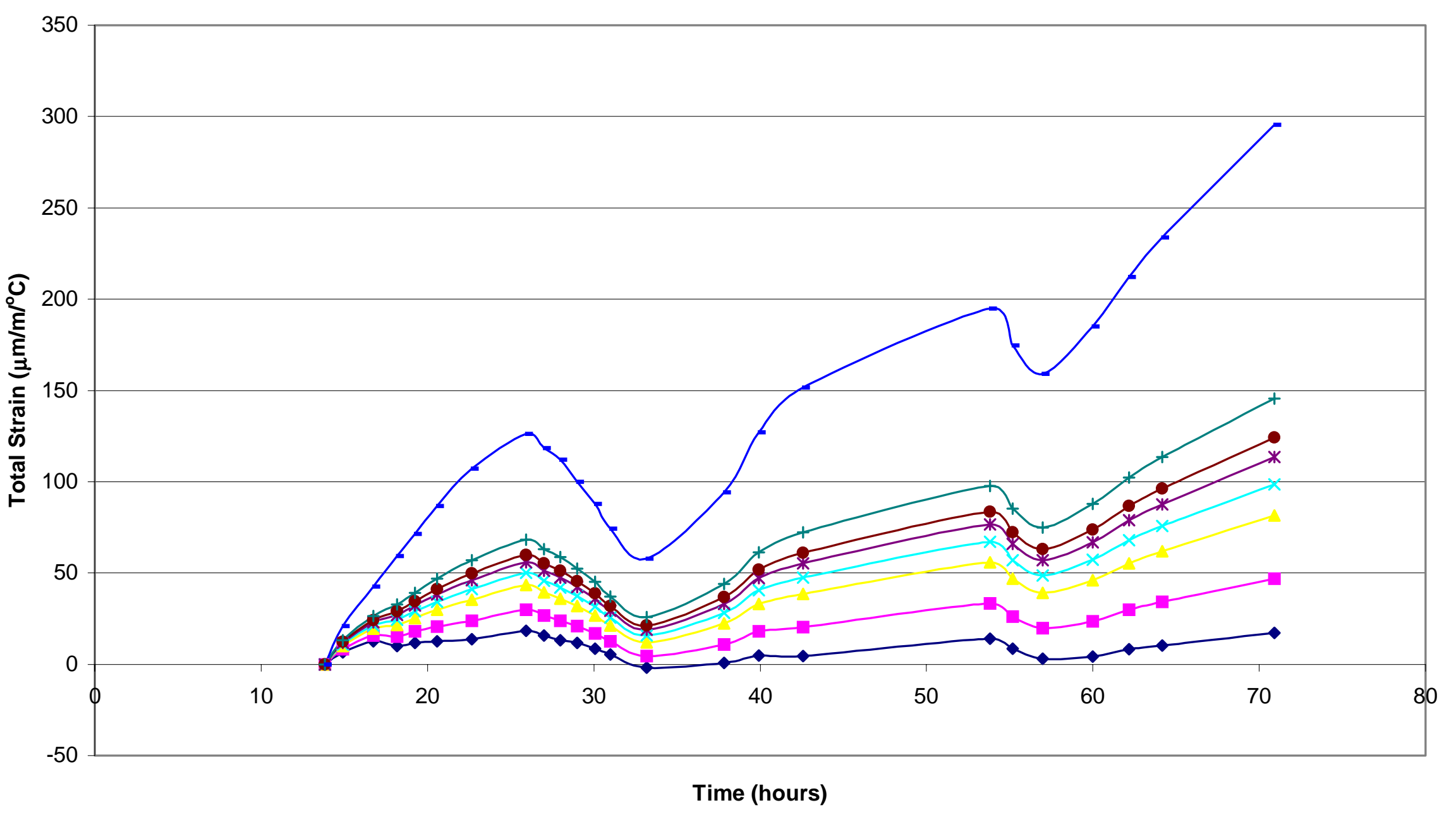

Figure 8.33: Gage \#3 Total Strain by varying Thermal Coefficient of Concrete versus Time, Corridor H 


\subsection{Discussion, Corridor H Elkins}

The section of Corridor H near Elkins, WV was monitored closely enough such that the detailed joint crack development and temperature profile histories were obtained simultaneously. The description of the slab section behavior, thus far, has been limited mainly to the actual field data obtained. Temperature profile histories and joint crack development history were described with simple analysis comparison. The propagating behaviors from the beginning of the slab section to the end of the slab justified time and location dependent analysis. Because of the decreasing maturity of concrete along the slab length, the prediction of earlier, higher stress development in more mature concrete regions was elementary.

The ambient temperature histories that the varying maturity of concrete by region were exposed to, controlled the slab temperature behaviors. During the heat of hydration process of the concrete along the slab length, the ambient temperature behavior either amplifies or reduces the concrete set temperatures. The amount of time required to reach maximum temperature in concrete of various ages was found to be unaffected, remaining around 10 to 12 hours. (See Figure 8.19)

The core temperature drops from maximums at each location, $\Delta \mathrm{T}_{1}$, and the temperature gradients from bottom to surface, $\Delta \mathrm{T}_{2}$, along the slab length, are the results required. By examining the group temperature readings graphs, Figures 8.2 through 8.8 , the resulting $\Delta \mathrm{T}_{1}$ and $\Delta \mathrm{T}_{2}$ can be visualized. From Phase I analysis equations, these two variables are responsible for the majority of stress development in maturing concrete slab sections. The cooler nighttime temperatures cause a larger temperature gradient, $\Delta \mathrm{T}_{2}$, at every slab location than the gradients experienced during the daytime hours. Also, the 
maximum core temperature drop at each location, $\Delta \mathrm{T}_{1}$, can be easily traced. During the first 24-hours, the younger end of the slab had much less of a core temperature drop than the older slab end, being $10^{\circ} \mathrm{F}$ and $25^{\circ} \mathrm{F}$ respectively. The greater drop in core slab temperature from the concrete set temperature at the more matured end of the slab section depicts definitely higher axial stress development in that region. Continuing the observations that the maturity levels and temperature behaviors propagate from the older end of the slab to the younger end, the joint crack propagating by location behavior data obtained from the investigation was understandable.

The temperature profiles observed become similar after around 30 to 40 hours (time zero scale). The entire concrete slab length was reasonably young in material property and strength during that time frame. A more uniform behavior resulted between the smaller subsections throughout the slab length after all initial joint crack formations. The developing stresses become mainly frictional and curling at that time. The overall concrete slab behavior was virtually identical to the other investigated slab sections with only slight variations in magnitudes of measurements. The behavior was propagating from the mature concrete slab end with joint crack formation and slab temperature profile behavior. The ambient temperature affect was again critical in the overall slab behavior. Ambient temperature fluctuation controlled the slab temperature profiles and subsequent stress developments along the slab length.

To thoroughly understand the slab behavior, some theoretical stress analysis for comparison to the observed behavior is needed. Actual slab temperature profile behavior will be utilized to calculate stress development and compared to available tensile strengths. Exceeded strength reveals cracking is probable in those regions at a given 
time. Crack development by time and location should be attainable within reason after total theoretical analysis.

Further discussion on the investigated PCC pavements, early age temperature and cracking behavior can be found in Chapter 9. Modified theoretical stress analysis of the Corridor $\mathrm{H}$ concrete slab section investigated and comparison to actual cracking behavior observed can be seen in Chapter 10 and further discussed in Chapter 11. 


\section{CHAPTER 9: COMPARISONS OF PROJECT OBSERVATIONS:}

\subsection{PCC Pavement Slab Behavior Similarities}

\section{1a. Introduction}

The PCC pavement sections investigated during Phase II were monitored for slab temperature profile histories, ambient temperature histories, transverse joint crack development and overall behaviors. The continuous investigations of the three PCC pavement sections contained similarities in the various monitored behaviors. Similarity in weather conditions and ambient exposure histories during the different investigations allow for better comparison. Early autumn weather conditions experience warm days and cool nights, which is ideal for study of temperature change effects and stress developments. Alternating seasonal environmental conditions would minimize comparative reasoning of varying concrete slab designs. The various slab designs with similar early age environmental conditions permit comparison of behaviors that would otherwise not be possible. The different pavement designs investigated were discussed in Chapter 3 and 5. The results from each investigation were discussed in their respective chapters. The I-79 Marianna, PA investigation was discussed in Chapter 6, the I-80 Danville, PA investigation in Chapter 7 and the Corridor $\mathrm{H}$ investigation near Elkins, WV in Chapter 8. To ease in explanation and comparison, references made throughout this chapter will be described as I-79, I-80 and Corridor H sections. The following sections will discuss the collected temperature and crack data and other behavioral similarities. Discrete theoretical analysis can be seen in Chapter 10. 


\section{1b. Temperature behavior}

The temperature data collected from each of the investigations consisted of ambient temperature histories, varying concrete slab temperature histories by depth and location and base course surface temperatures just before concrete slab overlay. The theoretical stress analysis proposed is dependent on the slab temperature histories by depth, location and concrete material properties. The concrete slab temperature behaviors were shown in the respective chapters of each investigation. Each investigation showed similar slab temperature behavior and each consistently followed the ambient temperature history experienced. The slab temperature behavior by location was either amplified or reduced in magnitude due to the variation in concrete maturity during the initial heat of hydration process, typically within the first 12 to 15 hours of concrete age. Concrete age by location for each investigation showed temperature behavior differences along the slab length directly attributed to the ambient temperatures experienced.

The ambient temperatures experienced at each investigation can be seen in Figure 6.16, Figure 7.7 and Figure 8.9. Overlaying these ambient histories can be seen in Figure 9.1. As seen in this figure, the ambient temperature histories of the I-80 and Corridor $\mathrm{H}$ investigations were very similar in behavior and value. Although, the I-79 investigation experienced less temperature magnitude fluctuation, the behavior did follow the warm day and cooler nighttime temperature history. The concrete slab temperatures reflected the ambient temperature history. The heat of hydration process of the concrete by slab location was either enhanced or restricted by the ambient temperatures experienced.

Concrete pavement construction commenced in early morning hours and ended in early evening hours for each of the investigated slab sections. The concrete placed at the 
beginning of each site was around 9 to 12 hours more matured than the concrete placed at the end of each slab section studied. This concrete age by slab location drastically effects the overall behavior. The heat of hydration process along the slab length is affected by the ambient temperature. By inspecting the ambient temperature histories of each site, the first 24 hours of temperature history varies to nearly $40^{\circ} \mathrm{F}$ in magnitude at two of the site investigations. It can be seen that concrete placed at the zero hour would experience much higher ambient temperatures than concrete place at around 10 hours. The propagating maturity of concrete and temperature behavior along the slab length was observed.

After the initial heat of hydration process, the concrete was observed to more consistently mimic the ambient temperature behavior at every site investigation. Groups of temperature measurement at varying depths along each slab were taken at varying intervals. The groups were labeled in increasing value from the beginning to ending of slab construction. The group temperatures were measured at four depths at each location, being surface, top, middle and bottom. (See Chapter 3.5b) The results of all group temperature histories for each site were described in the respective site chapters. The temperature histories for each site were found to behave similarly by slab location. This behavior may be slightly inconspicuous. By examining only the core (or middle), temperature histories of each group, temperature behavior along slab length can be seen similar for each project and comparable to the ambient temperatures observed. This can be seen in Figures 9.2, 9.3 and 9.4. These three temperature trend figures by slab locations directly show the variation in concrete maturity from each slab beginning to ending. The heat of hydration process and ambient temperature experience is readily 
seen during the first 25 to 30 hours at each site. After the initial heat of hydration process is complete along the total slab length, each sites core temperature behavior is seen to mimic and converge toward the ambient temperature behavior. This concrete temperature behavior observed is typical of maturing concrete. The similarity in concrete temperature behavior by depth and location for each site is mainly because of the similarity in ambient temperature history each site had. Variation in the ambient temperature history would undoubtedly change the slab temperature behavior and subsequent cracking behavior.

The cyclic ambient temperature behavior for the projects allowed for the best evaluation of the thermal stress development analysis. The cycling temperature fluctuation along the slab lengths would theoretically produce cycling stress development also. This behavior would be justifiable if the critical cracking behavior was also known by when, where and how wide of development. Thus, the joint crack development histories for each site were also obtained and discussed in the respective site chapters.

The next section discusses the similarities in the joint crack developments of the three investigated sites slab sections and the additional cracked sections observed. The combination of total behavior can be seen in Section 9.3. 


\section{1c. Joint crack development}

The transverse saw-cut joint crack developments were recorded for each of the investigated sites. Other additional slab sections, which were not instrumented with thermocouples, were also checked for crack developments. The results from each investigation were discussed in their respective site chapters. The joint crack development to date was thought to be non-uniform and sporadic in nature. The results from this investigation show that a pattern does exist and is somewhat uniform. The joint cracks were observed to form initially at the most matured end of the concrete slab section and propagate towards the less matured end for every section observed. The spacing of the joint cracks was different for each site but the sequenced behavior was identical.

The similarity in cracking behavior may be attributed the similarity of ambient temperature behavior for the sites, causing similar slab temperature profile behavior, and the variation in concrete maturity along the slab length. Smaller, secondary intermediate joint cracks were found to develop between larger spaced initial joint cracks. This remained consistent for every site investigation.

The site-specific joint crack frequencies also contributed to the crack widths observed. The greater the crack frequency the smaller the average crack width. The reduction in length, neglecting shrinkage, is theoretically due to the drop in temperature of the set slab, the concrete thermal coefficient, the modulus of the concrete and the resistance provided from the base course friction. Detailed analysis and estimation of joint crack frequency and width can be seen in Chapter 10. For now, the discussion of joint crack frequency and size will be accounted only by temperature drop. 
Early age concrete is closer to liquid form when first mixed. During the cement paste hydration process, the mixture becomes harder and develops somewhat solid material properties. The time when the concrete reaches a more solid state is assumed during this study to be the time when the concrete reaches a maximum temperature during the hydration process. This assumption is known not to be precise but must be made for theoretical analysis and explanation at this time. The time when the concrete sets, reaches maximum hydration temperature, along the entire slab pavement length is a function of the concrete age. The set temperature is approximately 10 to 12 hours of concrete age. The drop in temperature from set temperature decreases along the entire pavement length due to the ambient temperature behavior. Therefore, the amount of length reduction and tensile stress would both be higher at the most matured end of the slab sections. This behavior was visualized in the joint crack formation propagating from the more matured concrete slab end at all investigated sites.

The transverse joint cracks that developed, after the first night of placement, progressed over the first one-half to two-thirds of the total slab length only. This was observed at each site investigation. The remaining section length of each site with noncracked transverse saw-cut joints did not continue cracking until the evening or nighttime hours of the second night. This behavior could be attributed to the ambient temperature behavior seen during daytime and nighttime hours. Reduced rate slab temperature drops were experienced during the second day of the less matured concrete slab ends. The second nights dropping ambient temperatures were then observed to effect the less matured slab end, and crack development continued. Cracking progressed throughout the entire pavement lengths, which was seen at every site. 
Actual joint crack initiations were observed to begin cracking at the base of the sawcuts and progressed down the slab depth. The distinction of where the crack initiated is representative of where the highest stresses are located over the slab depth. The crack formations were seen to occur during the nights when the slab surfaces were cooler than the slab bottoms, showing differential slab depth deformation, or curling behavior. The cooler surfaces produce deformations between the saw-cuts. At the saw-cut bases, deformation is restricted and thus produces additive tensile stresses at those depths. These tensile stresses added to the overall-length reduction stresses, due to the average middle depth temperature drop, cause the joint-crack formations. The curling behavior between the saw-cuts can be visualized as a wishbone effect. The top of the saw-cut opens and the bottom can not. The predetermination of joint cracking locations by weakening of the slab cross-section using saw-cuts is the wanted. Stress concentration at the saw-cuts was the desired result. Thus, the top to bottom propagating effect was seen.

The rate of crack propagation was seen to be slower during the first nights crack formation than the second night's formation. The rate of crack formation is due to the maturity of the concrete and total tensile stresses. The concrete tensile strength increases with time. The tensile stress to exceed the strength and then cause cracking also increases with time. Once crack initiation begins, the higher tensile stresses more quickly open the crack as the slab sections shift location of maximum stress away from the crack. This is typical crack formation behavior.

The transverse joint-cracks were observed to change in appearance. During cooler nighttime hours, the joint-cracks were found to be opened wider at the tops than at the bottoms, up to one-half millimeter wider in some cases. In documenting the behavior, 
crack measurements were recorded at top and bottom locations. Consistency in measurements was achieved by taking top measurements around one inch below the base of the saw-cuts and the bottom measurements around one inch up from the base course surface, or one-inch from the bottom of the slab. The differences in crack width by depth were found to be more prevalent and pronounced during nighttime hours. The behavior is believed to be attributed to when the ambient temperatures were lower, the slab surface temperature was lower than the slab base temperature causing curling stresses, or differential temperature deformations over slab depth. The joint-crack opening behavior and measurement locations can be seen in Figure 9.5a. The daytime and nighttime jointcrack appearance can be seen in Figure $9.5 \mathrm{~b}$ and c. This differential behavior was observed at every site investigation.

The average joint-crack widths and crack spacing were determined from each investigated site. The I-79 joint-cracks were found to be approximately $1.5 \mathrm{~mm}$ wide and averaged every $3^{\text {rd }}$ to $5^{\text {th }}$ saw-cut by 43 hours of age. Another previously placed section of I-79 was also observed to have similar crack frequency, every $3^{\text {rd }}$ to $5^{\text {th }}$ joint, but had increased in average width up to over $4 \mathrm{~mm}$ at an age of around 120 hours. The thermocouple instrumented I-80 slab section joint-cracks averaged about 3 to $5 \mathrm{~mm}$ wide and spaced every $4^{\text {th }}$ to $6^{\text {th }}$ joint by an age of 56 hours. The non-instrumented slab section observed was found to have similar frequency of cracking but had widths ranging from 6 to $9 \mathrm{~mm}$ at an age of 147 hours. The continuously investigated slab section of Corridor $\mathrm{H}$ also produced similar behaviors. The average crack spacing was around every $6^{\text {th }}$ to $8^{\text {th }}$ saw-cut joint and had widened to 5 to $7 \mathrm{~mm}$ at an age of 72 hours. The slab section of Corridor $\mathrm{H}$ placed the day after the instrument section was also checked for joint-crack 
development. The spacing and widths at $48^{\text {th }}$ hour age were again similar to the adjoining slab sections, being every $6^{\text {th }}$ to $8^{\text {th }}$ joint and very similar in magnitude around 3 to $4 \mathrm{~mm}$. Evaluating all of the slab sections crack developments, all have exceeded the $1 / 8^{\text {th }}$ inch, or 3.175-mm allowable crack width specified in WVDOT specifications.

By observing the data as described above, the I-79 slab design would appear to have the best results in crack frequency and overall average crack widths compared to the allowable width. In actuality, the I-79 joint-crack frequencies and spacing should be evaluated considering all behavioral aspects and not only with the joint-crack development observed. The crack formation and crack widths are dependent on slab temperature profile history, concrete material property development and slab to base course interaction. Calculations showing the average total strains for each site investigation can be seen in Table 9.1 .

The true concrete thermal coefficient could be calculated by determining the total restricted frictional strain and adding that to the measured average total strain for each project and dividing by the corresponding average temperature drop. The actual concrete thermal coefficient for each project would result being on the order of around 4 to 6 $\mu$ strain $/{ }^{\circ} \mathrm{F}$. The magnitude of slab to base interaction for each site will be different but the total restricted strains would be similar because of the way they are determined. The above, determined values are based on assumed and estimated behavior and should not be utilized in evaluation at this point.

The joint-crack frequency and spacing is determined by the total frictional restraint causing tensile concrete stress. By decreasing the friction between the slab and the base the crack frequency will also decrease. (Goldbeck, 1991) Thus in retrospect by 
increasing the friction, the frequency will also increase producing smaller average crack widths. Ideally, every saw-cut joint should crack and be of similar width. But by increasing the friction, the long-term stress development may cause unwanted intermediate cracking causing slab failure.

Theoretical analysis of the early age behavior should be performed first to find justifiable analytical equations that could model the early age behavior. Once performed, possible changes in concrete mix design, pavement design or other recommendations could be made and analyzed. Then, the long-term effects of any changes recommended could also be checked. 
Ambient Temperature Histories by Investigation versus Time Time $=0$ at pavement construction initiation

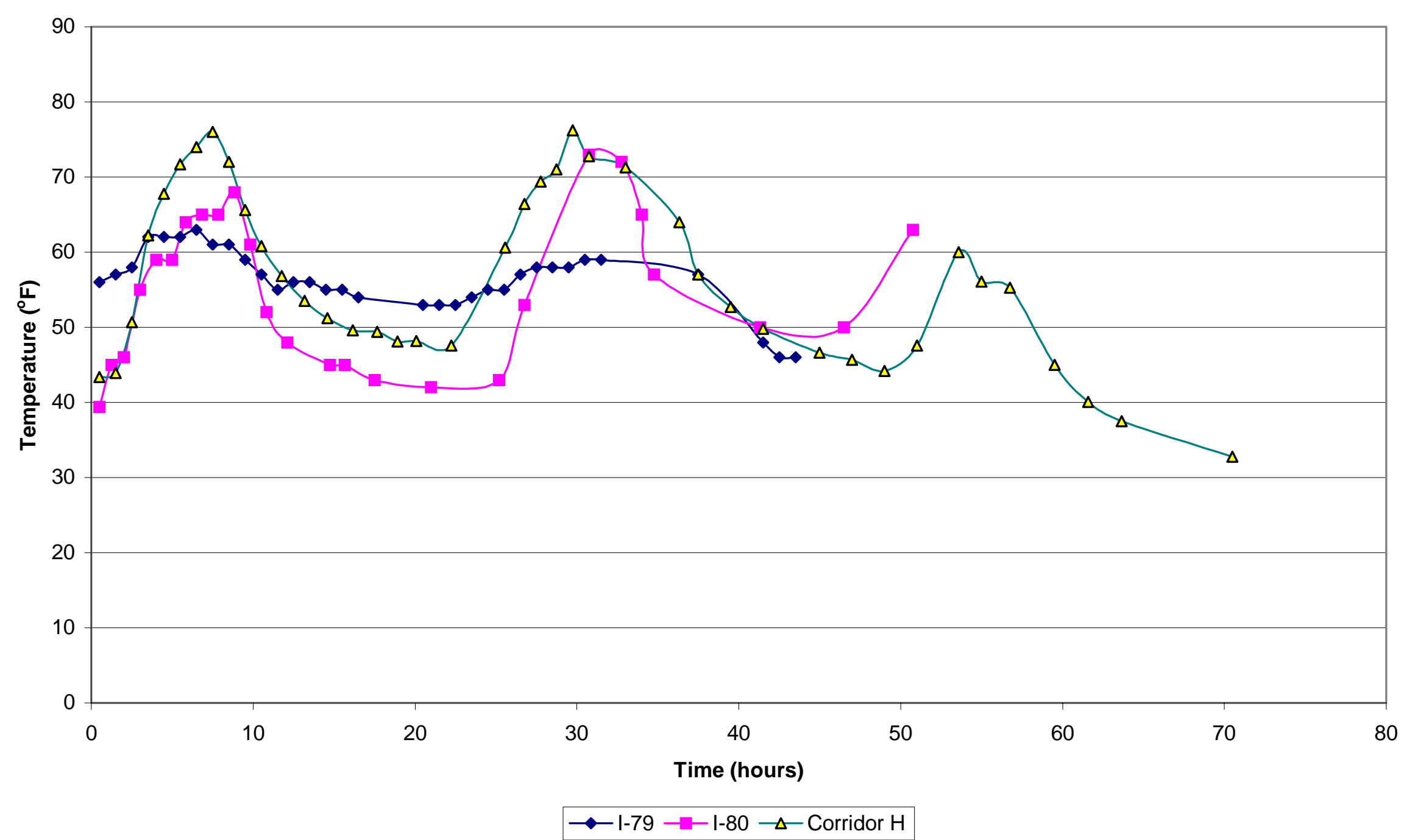

Figure 9.1: Ambient Temperature Histories by Site Investigation 


\section{Core Temperatures vs. Time at Monitored Locations}

I-79 Southbound Lanes near Marianna, PA

October 9-11, 1998; Time=0 at 7:30 AM

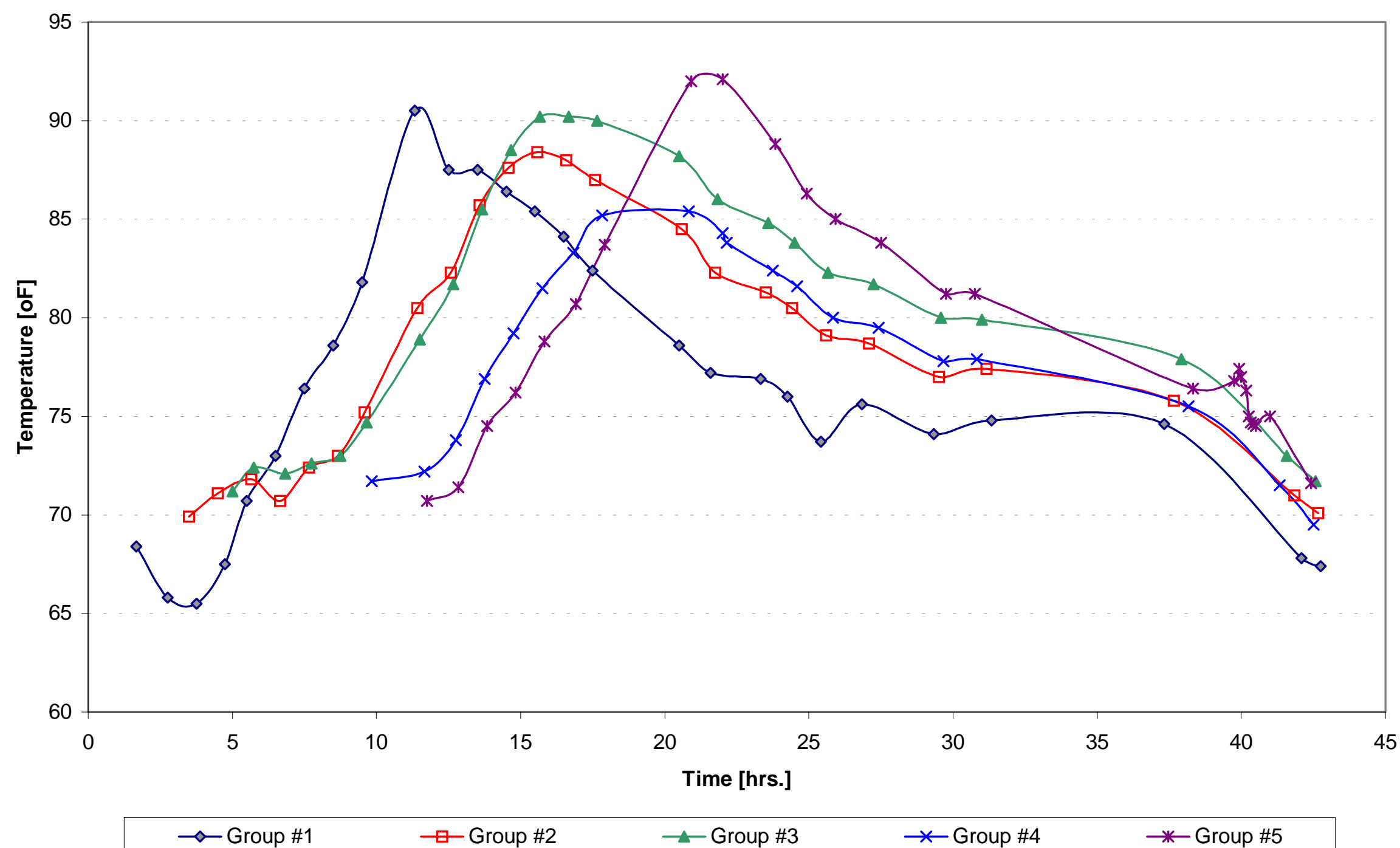

Figure 9.2: Group Core Temperature Histories, I-79 Marianna, PA 


\section{Core Temperatures vs. Time at Monitored Locations \\ I-80 Eastbound Lanes near Danville, PA \\ October 16-18, 1998; Time=0 at 8:00 AM}

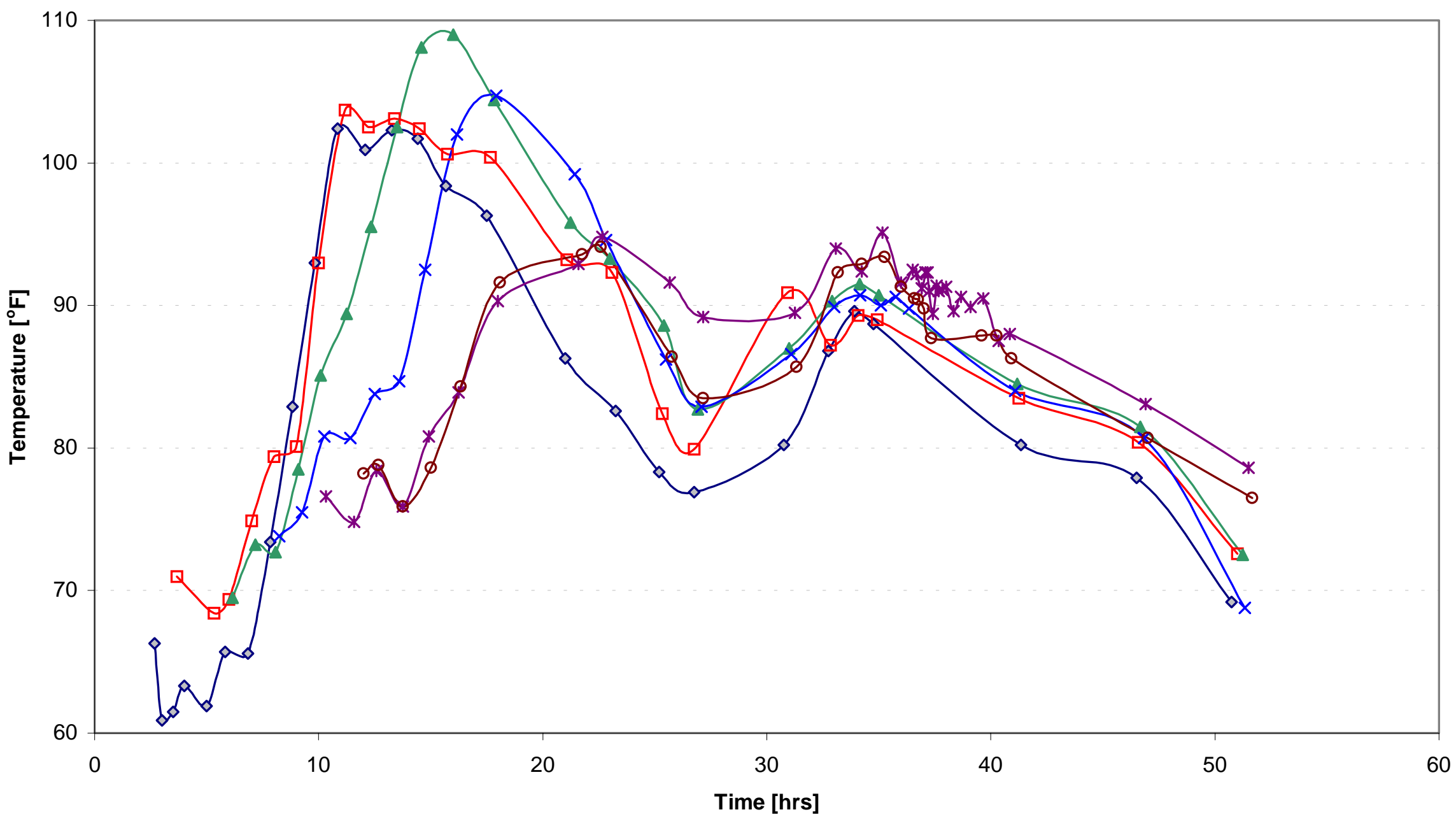

$\multimap$ Group \#1 $\quad \square$ Group \#2

$\neg-$ Group \#3

* Group \#4

* Group \#5

- Group \#6

Figure 9.3: Group Core Temperature Histories, I-80 Danville, PA 
Core Temperatures vs. Time at Monitored Locations

Corridor H Westbound Lanes near Elkins, WV

October 12-15,1999; Time $=0$ at 8:30 AM

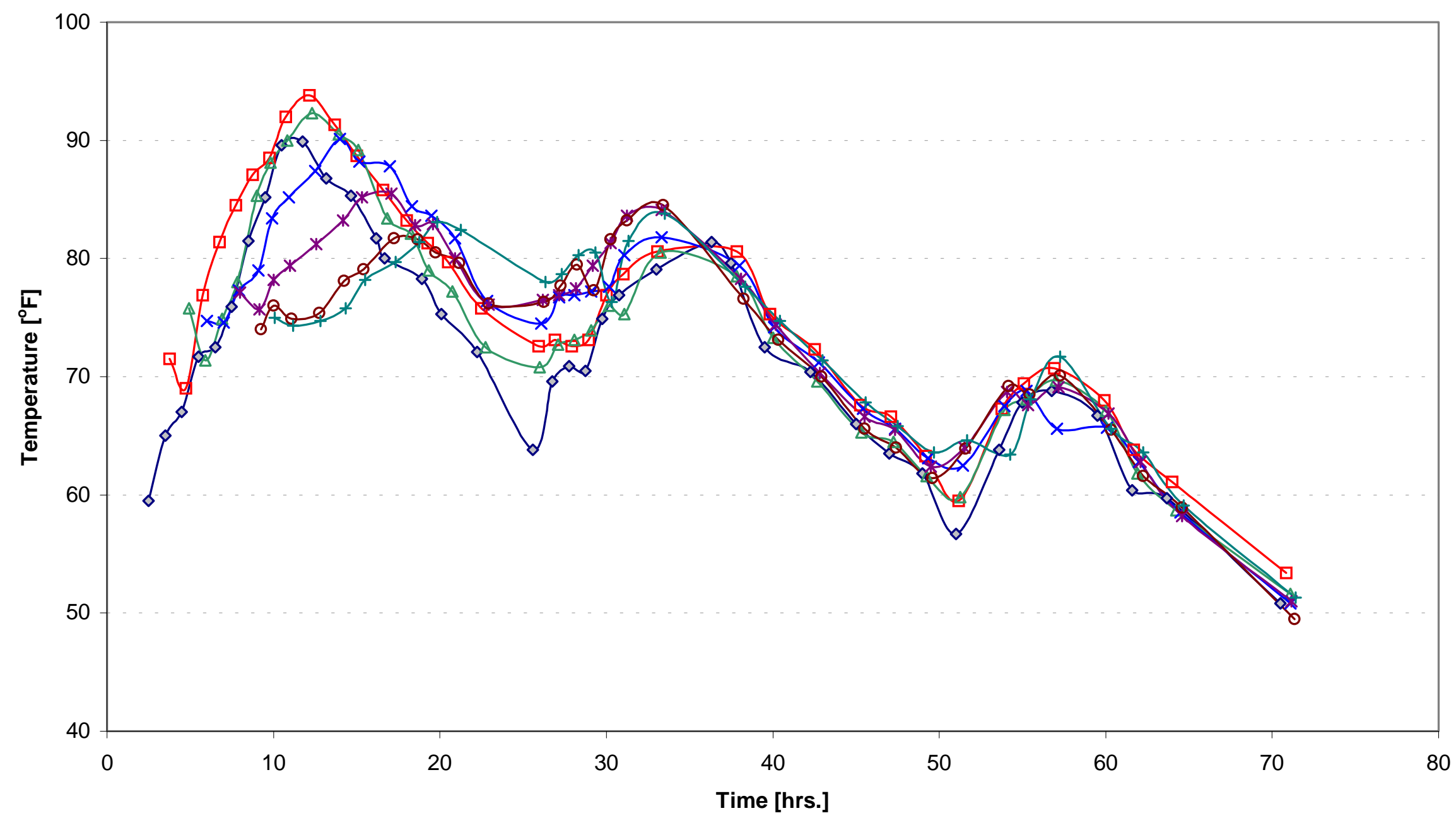

$\curvearrowright$ Group \#1

$\square-$ Group \#2

$\triangle$ Group \#3

$\rightarrow$ Group \#4

* Group \#5

๑ Group \#6

- Group \#7

Figure 9.4: Group Core Temperature Histories, Corridor H Elkins, WV 


\section{DAY TIME AND NIGHT TIME CRACK VISUAL}
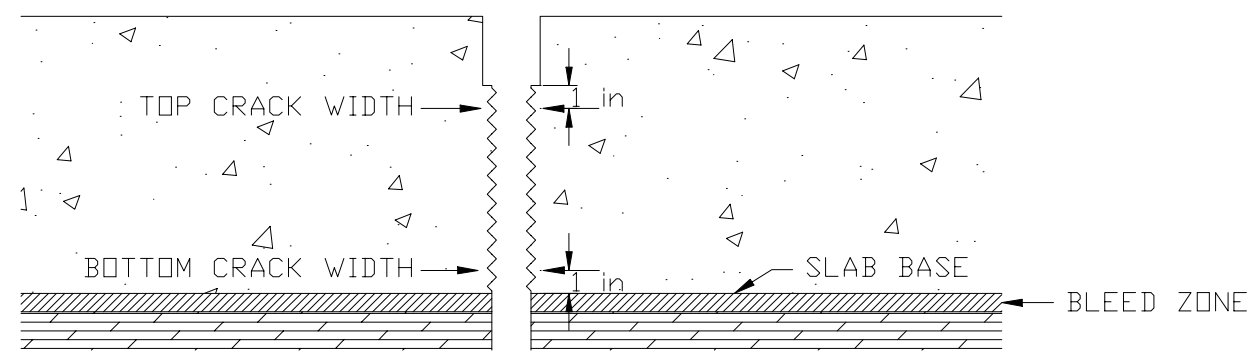

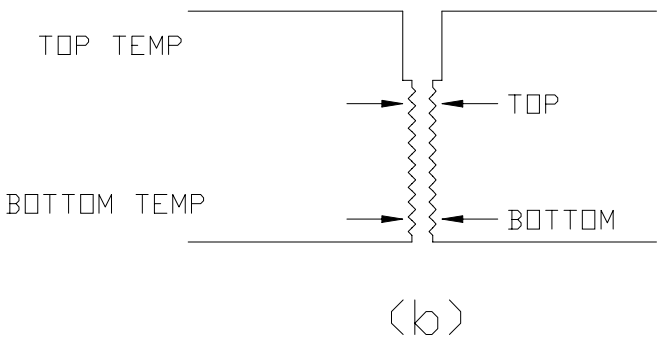

DAY TIME

$$
\begin{aligned}
\text { TOP } & \cong \text { ВОTTOM } \\
\text { TOP ТЕMP } & \cong \text { ВОТTOM ТЕMР }
\end{aligned}
$$

No Visible Curling Stress Deformation

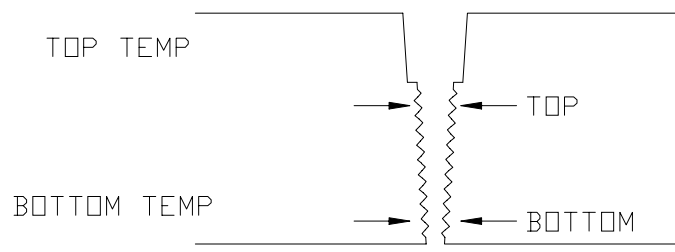

NIGHT TIME

TOP $>$ BOTTOM
TOP TEMP $<$ BOTTOM TEMP
Visible Curling Stress Deformation

Figure 9.5: Joint-crack Details: a) Measurement depth locations,

b) Daytime appearance and c) Nighttime appearance. 
Table 9.1

Estimated Total Strain by Site Investigation

\begin{tabular}{|c|c|c|c|c|c|c|c|}
\hline Site & $\begin{array}{c}\text { Total Slab } \\
\text { (feet) }\end{array}$ & $\begin{array}{l}\text { Length } \\
(\mathrm{mm})\end{array}$ & $\begin{array}{l}\text { Sum Total } \\
\text { measured } \\
\text { crack widths } \\
(\mathrm{mm})\end{array}$ & $\begin{array}{c}\text { Total \# of } \\
\text { Cracks } \\
\text { Greater } \\
\text { than } 0.5 \mathrm{~mm}\end{array}$ & $\begin{array}{l}\text { Average } \\
\text { Crack } \\
\text { Spacing } \\
\text { (feet) }\end{array}$ & $\begin{array}{l}\text { Average } \\
\text { Crack } \\
\text { Width } \\
(\mathrm{mm})\end{array}$ & $\begin{array}{c}\text { Actual } \\
\text { Averaged } \\
\text { top and bottom } \\
\text { Measured Strain } \\
\text { ( } \mu \text { strain) }\end{array}$ \\
\hline I-79(43 hrs) & 2570 & 783336 & 28.37 & 32 & 80.3 & 0.88 & 36.217 \\
\hline I-80(56 hrs) & 2840 & 865632 & 80.3 & 23 & 123.5 & 3.49 & 92.765 \\
\hline Corr. H (72 hrs) & 1815 & 553212 & 71.97 & 15 & 121 & 4.8 & 130.095 \\
\hline
\end{tabular}

\begin{tabular}{|lccc|}
\hline Actual Site Investigation Data & & & \\
\hline \hline & & & \\
Actual Sum $(41.5 \mathrm{hrs})=(\mathrm{mm})$ & 34.41 & 22.33 & 28.37 \\
& & & \\
Actual Sum $(56 \mathrm{hrs})=(\mathrm{mm})$ & 82.09 & 78.51 & 80.3 \\
& & & \\
Actual Sum $(72 \mathrm{hrs})=(\mathrm{mm})$ & 76.47 & 67.47 & 71.97 \\
\hline
\end{tabular}




\subsection{Slab to Base Course Interaction}

The frictional behavior between concrete slabs and the base courses has been believed to be one of the main contributing factors in the joint-crack formations of slip-formed concrete highway pavements. Different organizations have performed modified coefficient of friction tests on concrete sections and base course materials, which include Hiperpav, Inc., the University of Texas, Austin and West Virginia University. The results showed large bond strength development between the concrete and bases at young concrete ages, less than 24 hours. Reported coefficients of friction ranged from 1.5 to nearly 5. These values were of question during Phase II investigation. Frictional coefficients of these ranges would require shearing failures in the weakest material and not necessarily be the friction between the materials. Phase I research showed an area of "bleed-zone" formed when the concrete was placed on the permeable bases. Concrete was seen to infiltrate the base surface, down around one-inch. The push-off tests performed revealed what was then believed to be the coefficient of friction. This has been since determined to be more like the value of bond strength. The tests do show that high bond strength values between the concrete and base course is achieved by the same time initial tensile stress development is occurring in the slab sections.

New time and location dependent analysis developed during Phase II research provides distinct propagation behavior in strength and stress development. This in turn dictates propagating joint-crack development. The propagation behavior was seen at every site investigation to always begin with the most matured concrete slab end and progress toward the least matured concrete end. Re-evaluation of the Phase I stress development equations showed that maximum stress locations were not obtained and that 
areas between regions of slab end movement had equal values of maximum tensile stress. The equations used were found to be theoretically correct except that the slab temperature behavior and stress development was considered constant over the slab length.

Modification of the evaluation technique was performed to include time and location dependant behaviors. (See Chapter 10)

In performing these modifications, the evaluation technique revealed decreasing tensile stress and strength development over the slab length. The location of maximum tensile stress was seen to be at the location of the region of slab end movement. This location was due to the full axial restraint stress divided by the density of the concrete and the coefficient of friction between the slab and the base. This stress evaluation showed that the value of the coefficient of friction was the main factor dictating the maximum tensile stress location and subsequent crack formation location.

During the site investigations, the joint-crack formations and slab behaviors were recorded. It was seen at every site that the joint-crack propagated through the concrete slabs and also through the base courses. The base courses cracked in similar widths as the slab themselves. The base course failures can be attributed to the high bond strengths between the concrete and the base at early ages, as also seen during laboratory tests. The slab to base course interaction becomes not a frictional behavior but a composite behavior. The frictional resistance would thus come from what lies beneath the permeable base courses. Each site investigation had different sub-base designs. The I-79 lean base course was placed on a six to eight-inch PA class 2A aggregate sub-base course placed on existing sub-base material. The I-80 asphalt treated permeable base course was placed directly on the existing rubblized highway concrete. The Corridor $\mathrm{H}$ free-drain 
base course was placed on separation/filter fabric on a soil sub-base. (See also Figure 5.8a, b and c) Each of these base courses to sub-base interactions would be different, producing different crack formation spacing behaviors. This was justified from the site observation and the crack formations documented.

The base course failures were observed to form in different ways. Some propagated in the same transverse direction clear to the edge of the base course. Others were seen to fail directly along side the concrete slab edge and some were seen to fail at angles away from the joint-crack locations. The base course failure is a function of the base course material with applied tensile stress from a complete bonded surface source. The base courses are not designed for tensile strength and the failures are believed to extend completely through the base courses. Therefore, the base course to sub-base frictional behaviors should be utilized for the theoretical analyses instead of the concrete slab to permeable base courses. An example of the frictional forces acting against concrete slab section deformations can be seen in Figure 9.6. The composite-slab section, made up of the concrete slab and the stabilized base course, reacts jointly over the sub-bases. The frictional forces between the base and the sub-base constitute the frictional coefficient needed for future analysis. 


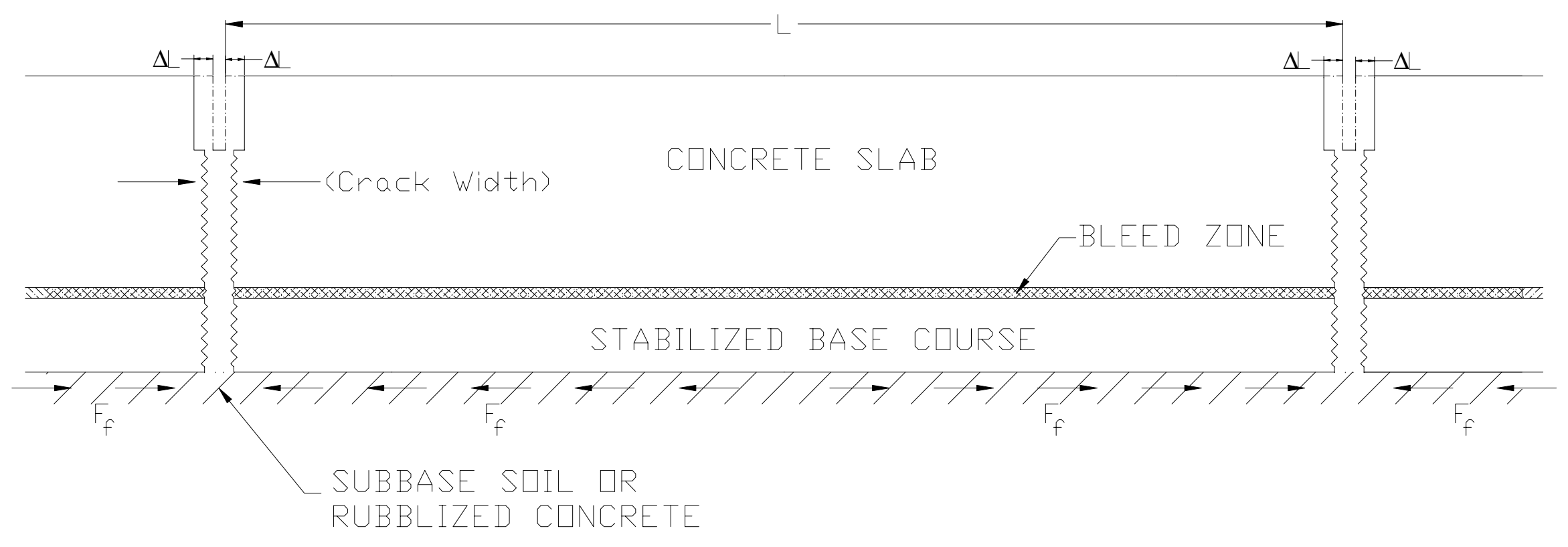

Figure 9.6: Slab Section and Frictional Interaction Detail 


\subsection{Generalized Observations of Concrete Slab Behavior}

The concrete pavement studies performed were instrumental in the further understanding and determination of the overall slab behaviors. The overall slab section behaviors were controlled by the initial concrete hydration process by location and observed ambient temperature histories. The ambient temperature histories dictated the resulting slab temperature profiles and subsequent stress development. The concrete slab temperature behaviors were similar in hydration effect and ambient temperature dependent. Thus understandably, the resulting joint-crack behaviors were also found to be similar.

Ambient temperature fluctuation during daytime and nighttime hours is typical. The magnitude of fluctuation is generally variable during seasonal change. The investigations performed were done in early autumn revealing similar climatic conditions. Although variation of seasonal conditions would change the slab temperature profile history and stress development in a slab section, the factors contributing to the stress developments do not change. Modification of ambient conditions, slab temperature profile histories, stress development and overall initial joint-crack formation is possible. The initial jointcrack development of any slab section would follow the slab temperature profiles and resulting stress developments. Variation in joint-crack locations would be dependent on the slab strength, developed tensile stress and the region of slab end movement.

The region of slab end movement is defined to be the location where the maximum tensile stress, or full restraint stress, is found. This value is dependent upon the full restraint stress divided by the density of the concrete and coefficient of friction. (See also Chapter 10) The stress developments and concrete densities should be similar for the 
three site investigations because of the similar ambient and slab temperature behaviors. The variable in the joint-crack formations between the projects was seen to be the initial crack spacing. The frictional coefficient is the dictating variable in these sites. Because of the concrete slab to base course interactions discussed in Section 9.2, the frictional coefficients that should be utilized in analysis should be that between the stabilized base courses and the sub-bases. The failures of the stabilized base courses at the joint-crack locations were observed. The I-79 and I-80 investigations stabilized base courses were on course aggregate and rubblized concrete, respectively. The Corridor H stabilized base course was placed on separation/filter fabric. The resulting frictional coefficients obtained at each site would be seen to decrease in respective order also. An increase of the frictional coefficients decreases concrete slab end movement and subsequent jointcrack spacing. Observed initial joint-crack spacing for each project was different and increasing in distance by site: I-79, I-80 and Corridor H. This estimation may be reasonably accepted because free course aggregate would have greater frictional characteristics than would separation/filter fabric. The boundary conditions for each site would reveal different achieved frictional coefficients for each. Increase in the achieved frictional coefficient may not be a viable solution due to long-term slab stress behaviors.

The observed daytime and nighttime joint-crack shapes, seen in Figure 9.5a, b and c, showed the existence of the differential temperature behavior, or curling behavior. The contribution of the curling effect was re-evaluated because of these deformation observations.

The joint-crack formations and slab temperature behaviors found during these investigations were propagating by slab location and concrete age. The hydration process 
propagated from the most matured concrete end, or the starting slab end. Subsequent stress development began at the matured end and decreased along slab length. Therefore, the concrete slab failures were also observed to propagate along the slab length from the most matured end. The region of slab end movement obtained depicted the initial jointcrack locations. If the non-cracked concrete slab subsections were sufficiently long, intermediate smaller joint-cracks could form. These behaviors were seen at each site investigation. The I-79 and I-80 investigations were not as detailed in documentation of crack sequencing but was visually observed to behave in the same propagating manner. The propagating behavior would be typical with slip-form continuous paving construction. The concrete slab's analysis initially would have a starting point and then could be assumed infinitely long. The starting point end would be able to move freely to the length were frictional resistance prohibits movement, or the region of slab end movement. Where the movement is completely restricted is the location of highest stress, because the maturity level and stress level decreases along the infinite slab length. Thus dictating the initial joint-crack locations. Between consecutive joint-cracks, the subsections perform independently. Some minimal stress transfer may be experienced by the bond strength between the transverse steel dowel bars and the connecting slabs. Additional intermediate saw-cut joint cracking should be seen smaller because the achieved length of slab end movement would be much less in the slab subsections than the initial infinite slab movements. The initial slab movements, or initial joint-crack widths, are determined by the stress that originally moved the slab end. When consecutive initial joint-cracks form, the maximum stresses shift toward the mid-points 
between the consecutive cracks. The total stress reduction seen would be dependent on the frictional resistance and the slab subsection length.

The propagating stress development behavior could be instrumental in the development of a solution to the undesirable joint-crack movement behavior. The formation of similar size consistently spaced joint-cracks is achievable. Further theoretical analysis and comparison to actual behavior must be performed to establish basis for any correctional solution. The modified theoretically analysis will be discussed and in Chapter 10. 


\section{CHAPTER 10: MODIFICATION OF THEORETICAL STRESS ANALYSIS:}

\section{$\underline{10.1 \text { Introduction }}$}

The propagating cracking behavior was monitored closer during the Corridor $\mathrm{H}$ investigation than the other investigations. The temperature behaviors were monitored for a longer period of time and at greater frequency. The Corridor $\mathrm{H}$ investigation was also instrumented with embedded strain gages. Therefore, theoretical analysis was performed on the Corridor H slab section only. The basic concepts of the analysis will be transferable in describing the other investigated slab sections, since the ambient and slab temperatures behaved similarly. Several aspects of the inadequacy of the previous analysis of early-age concrete pavement were described throughout this report. The most influential was the inability of the analysis to evaluate time and location dependent behaviors found during site investigations. The modification of the theory required that complete re-evaluation be performed. Each step of the analysis was examined to see if modification was required to comply with the variable behaviors. The basic theory of stress and strength development of the slabs was re-evaluated for correctness also.

The time and location dependent modifications drastically complicated the analysis of a given slab section. The initial theory showed that material property development and temperature fluctuation behavior during early-age maturing of concrete controlled the strength and stress development of the slab sections. A modified analysis process was developed to utilize addition location dependent behavior. The initial Phase I analysis method utilized a simple spreadsheet-format to reduce and manipulate data and equations. The data collected from the first two continuous site investigations showed that joint cracking occurred in sequencing and reduced during specific critical time 
frames. This required that sufficiently small time and location intervals be used in evaluation. From initial spreadsheet analysis attempts, sufficient interval's for the modified analysis to produce reliable results was not achievable in the spreadsheet format. The modified analysis proved to be repetitive in nature, thus being adaptable to computer program looping analysis.

A modified analysis method was developed from the combined knowledge of a Fortran program development and the three continuous site investigations. The additional information determined from the site investigations allowed for more discrete analysis to be undertaken. Also, the time and location dependent concepts' determined for the Fortran programming were instrumental in the development of new discrete analysis techniques.

The modified analysis has a time equal to zero scale designated for each slab analysis, being the time initial slab concrete placement began. The modified analysis method utilizes defined regions of the slab being investigated to assume specific concrete material properties at varying concrete age by region and simultaneously consider individual regional temperature behaviors. The regional analysis assumes that within a given slab length the material and behavior properties are sufficiently consistent. Concrete age by location is estimated by the actual construction. Thermocouple groups were placed incrementally along the slab, and the slab temperature profiles were obtained during each site investigation. The collected temperature data along the slab lengths was not in a consistent time scale for each location. Interpolation of the temperature data was still required to obtain same time scales for each data set for analysis. Once performed, the stress and strength developments could be calculated using the modified analysis 
equations at each region. When the available concrete tensile strengths were exceeded by the developed tensile stresses, the specific region was considered susceptible to cracking. The calculated region of slab end movements would reveal the approximate length to the maximum full restraint stress location, or estimated joint-crack location.

More thorough descriptions of the modified analysis and equations follow in Section 10.2. Actual modified theoretical analysis was performed utilizing the Corridor $\mathrm{H}$ near Elkins, WV contingent data and can be seen in Section 10.3 and 10.4. 


\subsection{Modified Discrete Regional Analysis}

The theoretical analysis developed during Phase I was modified upon during Phase II. A new step-by-step procedure is presented describing the theoretical stress, strength and joint-crack development of a given pavement section. The variables used in the analysis will be project specific and must account for concrete mix and pavement design variations. The analysis must be performed at specific times to evaluate the variable maturity and behavior of each slab region. At a given time, the slab strength and developed tensile stress by region may be determined. The analysis must also be performed in progressive times because joint-crack development could effect full restraint or frictional behavior at varying times.

Initial analysis should begin after the initial maximum core temperature has been reached during the heat of hydration process (approximately 10 to 15 hours). Incremental times should then be continued throughout the stress analysis to obtain reliable results.

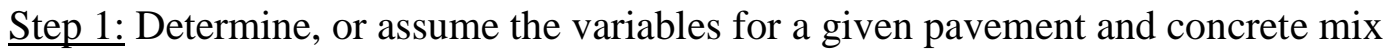
design.

Assumed Non-Concrete Age Dependent Variables:

$$
\begin{aligned}
& \mathrm{h}=\text { slab thickness (inches) } \\
& \mathrm{d}=\text { depth of saw-cut (inches) } \\
& \mathrm{s}=\text { transverse dowel bar spacing, center-to-center (inches) } \\
& \mu=\text { coefficient of friction } \\
& \mathrm{w}=\text { density of concrete }\left(\mathrm{lb} / \mathrm{in}^{3}\right) \\
& \alpha=\text { thermal coefficient of concrete }\left(\mu \mathrm{in} / \mathrm{in} /{ }^{\circ} \mathrm{F}\right)
\end{aligned}
$$


Assumed Concrete Age Dependent Variables:

$$
\begin{aligned}
& \sigma_{\mathrm{st}}=\text { split tensile strength of concrete (psi) } \\
& \sigma_{\mathrm{DB}}=\text { resistive dowel bar stress (psi) } \\
& \mathrm{E}=\text { modulus of elasticity of concrete (psi) }
\end{aligned}
$$

Step 2: Establish time and age equal to zero scale.

This may be assumed the time and location when initial concrete placement began. The concrete age by region varies by the rate the slab was placed. Analysis times are based on the time zero scale. Concrete age by region is corrected during future array development.

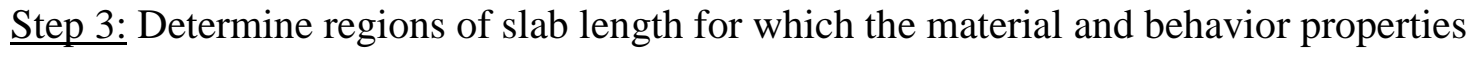
may be considered constant over the length.

The maximum length chosen for a region should range between 300 and 600 feet. Thermocouple group locations for actual and theoretical analysis behavior comparison should be representative of the individual regions. Group temperatures need to consist of varying depth readings, not less than surface, middle and bottom depth locations, at various times.

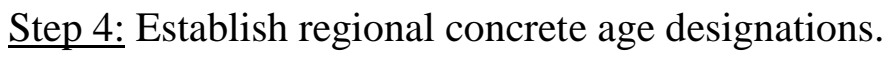

This may be approximated by rate of concrete placement. Each region will then assume individual concrete and behavioral properties by age at any given time for the analysis. 
Step 5: Construct time and region arrays for concrete age dependent variables.

These variables are designated in Step 1 , being $\sigma_{\mathrm{st}}, \sigma_{\mathrm{DB}}$ and E. One-half hour time intervals should be made and adjusted by region to accommodate for variable regional concrete age.

Step 6: Determine $\Delta \mathrm{T}_{1}$ and $\Delta \mathrm{T}_{2}$ for each region at various times.

Ideally, interpolate regional temperatures for half-an-hour increments first.

$\Delta \mathrm{T}_{1}=$ Change in uniform temperature of concrete $\left({ }^{\circ} \mathrm{F}\right)$

$=($ Maximum core temperature $)-($ Current core temperature $)$

$\Delta \mathrm{T}_{2}=$ The difference in the change of temperatures from the maximum surface and core temperatures to the current surface and core temperatures. $=[($ Maximum surface temp $)-($ current surface temp $)]-\Delta T_{1}$

The method of determining $\Delta \mathrm{T}_{2}$ was modified during Phase II after re-evaluation of the fundamental concrete-slab thermal behavior and determination of developing stresses. Phase I described $\Delta \mathrm{T}_{2}$ as the difference in the temperature from the bottom to the top of a slab causing curling stress development. Phase I definition of stress development assumed that the maximum temperature reached by depth was constant. This assumption caused error in the determination of stress when observations revealed that the maximum temperatures by depth varied. By changing the assumption and individualizing the thermal stress behaviors, the contribution of the core thermal shrinkage in the curling stress equation could be removed, which corrected the definition. A new assumption, which utilizes observations that the core and bottom temperature behaviors are similar, 
was accepted for ease in the calculations of the $\Delta \mathrm{T}_{2}$ values. (The curling stress calculation was also modified due to the redefinition of $\Delta \mathrm{T}_{2}$, see Step 9.)

Step 7: Determine free slab length, L(t), (feet).

This is either the initial total slab length, or distance between consecutive saw-cut joint cracks. A region may consist of variable slab lengths. The maximum free slab length in a given region should be evaluated because it will develop subsequent cracking first. Subsequent analysis, after initial joint-crack formation, is typically frictional and not full restraint analysis.

Step 8: Calculate the region of slab end movement, $\mathrm{x}$ (feet).

$$
\mathrm{x}=\mathrm{E} \alpha \Delta \mathrm{T}_{1} / 12 \mathrm{w} \mu(\text { feet })
$$

If $\mathrm{L}(\mathrm{t}) / 2>\mathrm{x}$, go to Step 10 .

If $\mathrm{L}(\mathrm{t}) / 2<\mathrm{x}$, go to Step 12 .

Each region will have different lengths of slab end movements. Prior to initial jointcrack formation, only either end of the slab actually experiences the movement. Therefore, the region of slab end movement designates the location of the maximum full restraint stress. During initial joint-crack formations between the slab end movements along the total slab length, the age and location dependent properties control the value of movement and decrease in value from the most matured slab end. Subsequent frictional restraint stress should reach a maximum near mid-slab length being analyzed. 
Step 9: Calculate restraint-curling stress, $\sigma_{\mathrm{C}}(\mathrm{psi})$, for each region.

A modified method of determining $\Delta \mathrm{T}_{2}$ was developed that only considered the additive curling tensile stresses. The value of the temperature differential, $\Delta \mathrm{T}_{2}$, is affected by the slab saw-cuts. After saw-cutting, consecutive joints permit free thermal deformation at the slab surface. To compensate for that stress relief, a saw-cut depth factor, DF, was approximated. (If $d=h / 3$, then $D F=3$, if $d=h / 4$, then $D F=2$.)

$$
\sigma_{\mathrm{C}}=\left(\mathrm{E} \alpha \Delta \mathrm{T}_{2}\right)[\text { Prior to slab saw-cuts }]
$$

or

$$
\sigma_{\mathrm{C}}=\left(\mathrm{E} \alpha\left(\Delta \mathrm{T}_{2} / \mathrm{DF}\right)\right)[\text { After slab saw-cuts }]
$$

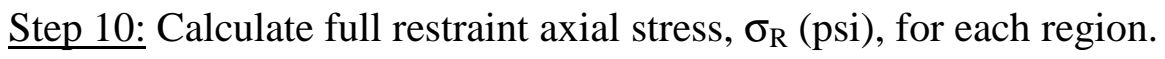

$$
\sigma_{\mathrm{R}}=\mathrm{E} \alpha \Delta \mathrm{T}_{1}(\mathrm{psi})
$$

Step 11: Calculate the total tensile stress developed, $\sigma_{\mathrm{T}}(\mathrm{psi})$, by region. [Before saw-cut]

$$
\begin{aligned}
& \sigma_{\mathrm{T}}=\sigma_{\mathrm{R}}+\sigma_{\mathrm{C}}(\mathrm{psi}) \\
& \sigma_{\mathrm{C}}=(\text { See Step 9) }
\end{aligned}
$$

Go to Step 14.

Step 12: Calculate the frictional axial restraint stress, $\sigma_{\mathrm{f}}(\mathrm{psi})$.

$$
\sigma_{\mathrm{f}}=\mathrm{L}(\mathrm{t}) \mathrm{w} \mu / 2(\mathrm{psi})
$$

This was modified during Phase II theoretical development. Phase I determination utilized $x$, region of slab end movement instead of $L(t)$, the length of given subsection 
being analyzed. If $L(t) / 2$ is equal to $x$, then full restraint axial stress exists and not frictional axial restraint stress.

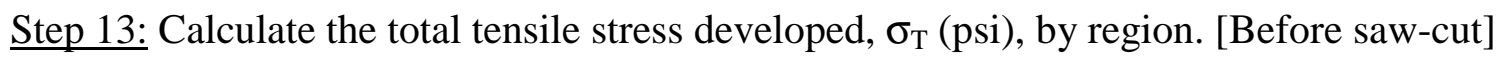

$$
\begin{aligned}
& \sigma_{\mathrm{T}}=\sigma_{\mathrm{f}}+\sigma_{\mathrm{C}}(\mathrm{psi}) \\
& \sigma_{\mathrm{C}}=(\text { See Step 9) }
\end{aligned}
$$

Go to Step 14.

Step 14: Calculate the total reduced sectional tensile stress, $\sigma_{\text {red }}(\mathrm{psi})$, after saw cutting.

The reduced cross-section stress correction factor was assumed to be approximately equal to $[\mathrm{h} /(\mathrm{h}-\mathrm{d})]$, (or 1.5 in the example trial \#1). The stress correction factor was estimated for the stress increase at the saw-cut locations.

$$
\sigma_{\text {red }}=[\mathrm{h} /(\mathrm{h}-\mathrm{d})]^{*} \sigma_{\mathrm{T}}(\mathrm{psi})
$$

Step 15: Determine the total tensile strength of the slab, $\sigma_{\mathrm{RST}}$ (psi), by region.

$$
\sigma_{\mathrm{RST}}=\sigma_{\mathrm{st}}+\sigma_{\mathrm{DB}}(\mathrm{psi})
$$

Step 16: Check to see if any region has developed greater tensile stress than available strength.

$$
\sigma_{\mathrm{RST}}-\sigma_{\mathrm{red}}=\text { (If negative in a region, crack development occurs.) }
$$

If a region shows initial joint crack formation, check the value of the region of slab end movement, $\mathrm{x}$ (feet). This value of movement should be consistent to the approximate location of maximum stress, thus being the spacing of consecutive joint-cracks in the 
region. If this is a previously crack region, additional crack formation should be around mid-length of the subsection being analyzed.

Step 17: Re-establish slab lengths for regional analysis, L(t).

If no regions have cracked, $\mathrm{L}(\mathrm{t})=$ Original total slab length .

If a region has cracked subtract that regional length from the original, or new slab length, and assume remaining length valid for remaining non-cracked regions.

Regions that have cracked will assume $\mathrm{L}(\mathrm{t})=\mathrm{x}$ at the time of crack formation.

Each cracked slab region must be analyzed assuming all subsections developed after initial joint-crack formation are of equal length and have the same material and behavior properties across the region. If additional subsequent cracking occurs in any region's subsections, the length for analysis should be divided by two, and re-analyzed. The remaining non-cracked slab length will consider full restraint analysis until $x>L(t) / 2$.

Go to Step 7.

The stated numerical procedure was based on English units, but could be converted to metric analysis. Caution should be taken to ensure that all unit conversions and unit multipliers are considered. The analysis, in the current description, predicts approximate times that regions of a concrete slab become critical with thermal tensile stresses. Actual specific, joint-crack development modeling will probably not occur, but similar spacing and timing of crack development by region may. Use of the analysis procedure can be seen in Sections 10.3, 10.4, Appendix C and D. 


\section{$\underline{\text { 10.3 Material and Behavioral Properties for Modified Regional Analysis }}$}

The material and behavioral properties needed to perform the theoretical analysis were listed and defined in Step 1 and Step 6 of Section 10.2. Every property for the analysis is project specific. Specific concrete mix design material and behavior properties are critical to the early-age behavioral analysis. The pavement cross-section designs are critical in determining or estimating the frictional restraint being imposed on the concrete slab. The actual slab temperature profiles must also be obtained and be representative of the individual slab regions, enabling more accurate tensile stress developments to be calculated.

Phase I laboratory tests and literature review determined or approximated property developments by concrete age for a specific concrete mix design. Concrete mix designs evaluated during Phase II were found to vary between slab constructions and required their own material and behavioral property characteristics to be known. In addition to determining each of the observed concrete mix designs behaviors, re-evaluation of Phase I approximations and test results were also performed. The most critical properties were re-determined for individual analysis purposes, which were identified and discussed in Chapters 2, 3 and 4 . The concrete material behavioral properties requiring age dependency that needed determined were the modulus of elasticity, E (psi), the split tensile strength of the concrete, $\sigma_{\mathrm{st}}(\mathrm{psi})$, the resistive dowel bar stress, $\sigma_{\mathrm{DB}}(\mathrm{psi})$, and the actual regional temperature profile histories. The other material and behavioral properties required were the thermal coefficient of the concrete, $\alpha\left(\mu \mathrm{in} / \mathrm{in} /{ }^{\circ} \mathrm{F}\right)$, the

concrete density, $\mathrm{w}\left(\mathrm{lb} / \mathrm{in}^{3}\right)$, the coefficient of friction between the base course and subbase, $\mu$, and the slab cross-section design specific variables: $\mathrm{h}, \mathrm{d}$ and $\mathrm{s}$. The early-age 
determinations of some of these variables are questionable in accuracy and reliability at best, but needed determined or estimated for the analysis. Future property determination techniques may prove or disprove the accuracy and reliability of approximations made during this study, but for now the current approximations must be utilized for the theoretical analysis being attempted.

The theoretical analysis performed for this report was based on the material, behavioral and design properties from the Corridor H, (near Elkins, WV), PCC highway pavement slab section investigation. As stated in Chapter 9, the modified analysis was intensive and time consuming in the current format. Therefore, only one numerical analysis was performed during this study. The properties, which were believed to remain constant over the duration of the proposed analysis time frame, utilized during theoretical analysis are as follows.

- $\mathrm{h}=11$ inches

- $\mathrm{d}=3.5$ inches, or approximately $\mathrm{h} / 3$

- $\mathrm{s}=12$ inches

- $\mu=0.6$ (approximated from friction between asphalt aggregates or between the stabilized aggregate and separation/filter fabric)

- $\mathrm{w}=0.08303 \mathrm{lb} / \mathrm{in}^{3}$

- $\alpha=4.67 \mu \mathrm{in} / \mathrm{in} /{ }^{\circ} \mathrm{F}$

The remaining properties required in the theoretical analysis are age and/or region dependent properties. The time equal to zero scale established for the Corridor $\mathrm{H}$ analysis was based on the actual construction and can be seen in Figure 8.1. The concrete material and resistive strength properties requiring age dependency are $\mathrm{E}(\mathrm{psi}), \sigma_{\mathrm{st}}(\mathrm{psi})$ 
and $\sigma_{\mathrm{DB}}(\mathrm{psi})$. The values listed were determined from actual testing or approximation, which were all discussed in prior chapters. The various regionally defined ages determine when each region was considered concrete age equal to zero. For the theoretical analysis of the Corridor $\mathrm{H}$ slab section, the defined concrete age by slab region can be seen in Figure 10.1, 10.2 and Table 10.1. The thermocouple group numbers were made identical to the defined regional numbers. For the analysis, half-anhour to one hour increments were required. To obtain these intermediate values, linear interpolations were performed between determined values. The time-incremented, regionally independent, defined property value tables for $\mathrm{E}, \sigma_{\mathrm{st}}$ and $\sigma_{\mathrm{DB}}$, constructed for the theoretical analysis, can be seen in Appendix C. These properties were listed in tabular format describing each property's development over time and were constructed to the time equal zero scale for defined region numbers. The linear interpolation approximates intermediate values for the purposes of this analysis were considered sufficient.

The temperature history profiles, obtained from the Corridor $\mathrm{H}$ slab investigation, were discussed in detail in Section 8.2. The actual temperature histories by depth at varying times were not utilized directly in the analysis, but the time equal to zero interpolated incremental temperature values by depth were manipulated to obtain thermal variation stress developments. As described in Section 10.2, the determination of $\Delta \mathrm{T}_{1}$ and $\Delta T_{2}$ values, specific for each region at varying given times, were required for the analysis. Ideally, each thermocouple's data would be interpolated to specified increments based on the time equal to zero scale. For this study, specific time's based on the time equal zero scale were determined for evaluation in the theoretical analysis. The chosen 
times were based on knowledge obtained from the actual slab behavior. The most critical time frames, when joint cracking was seen, were analyzed at closer time increments than non-critical time frames. Each time for analysis needed equivalent interpolated temperature values for every group number. Once the depth temperatures were in equivalent time equal to zero scale in every region, the analysis values of $\Delta \mathrm{T}_{1}$ and $\Delta \mathrm{T}_{2}$ were determined. The determined values for given times and regions are shown in Tables 10.2 and 10.3. These can also be seen graphically in Figures 10.3 and 10.4. The $\Delta \mathrm{T}_{1}$ values, (the changes in core temperature from maximum value to current values), are utilized to determine full, or frictional, axial restraint stresses. The $\Delta \mathrm{T}_{2}$ values, (the differences between core and surface changes of respective maximum to current temperatures), are used to determine the differential, or curling, stresses. From Figures 10.3 and 10.4 , the thermal stress development by region over time can be visualized. In Figure 10.3, the value of $\Delta \mathrm{T}_{1}$ fluctuates over time but also generally increases in value for every location. The continuous slab-cooling behavior follows the ambient temperature history when fluctuating. Observing the actual slab core temperatures as time increases, the concrete was simply stabilizing to the environment. In Figure 10.4, the values of $\Delta \mathrm{T}_{2}$ are also seen to fluctuate. This was attributed to the increased solar radiation during daytime hours and cooler nighttime ambient temperature behavior. During the daytime hours, the slab surface was heated by the sunlight. That behavior made the surface warmer than the core. Differential, or curling, stresses are considered additive in tensile development only when $\Delta \mathrm{T}_{2}$ values are positive. The negative values show a surface thermal relaxation differential behavior from the core shrinkage thermal behavior. For this study, the surface relaxation behavior was neglected; therefore only positive $\Delta \mathrm{T}_{2}$ 
values were utilized for analysis and the negative $\Delta T_{2}$ values were recorded as zero values because of the reduction of tensile stress behavior (assuming no concrete compression failure exists).

The material and behavioral properties utilized for the Corridor $\mathrm{H}$ theoretical analysis were time and region established. The age dependencies and value approximations have dramatic affects on the theoretical results obtained. Caution has been taken in the determination or approximations of all values utilized. Future tests and/or literature review could result in more accurate value approximations. Utilization of the previously stated properties in the theoretical analysis of the Corridor $\mathrm{H}$ concrete slab section are contained in Section 10.4 and Appendix D, and are compared to the actual behaviors in Section 10.5. 


\section{Estimated concrete age and Approximate analysis age versus Joint Number Location Corridor H near Elkins, WV (Time $=0$ at 0830 hours 12 October 1999)}

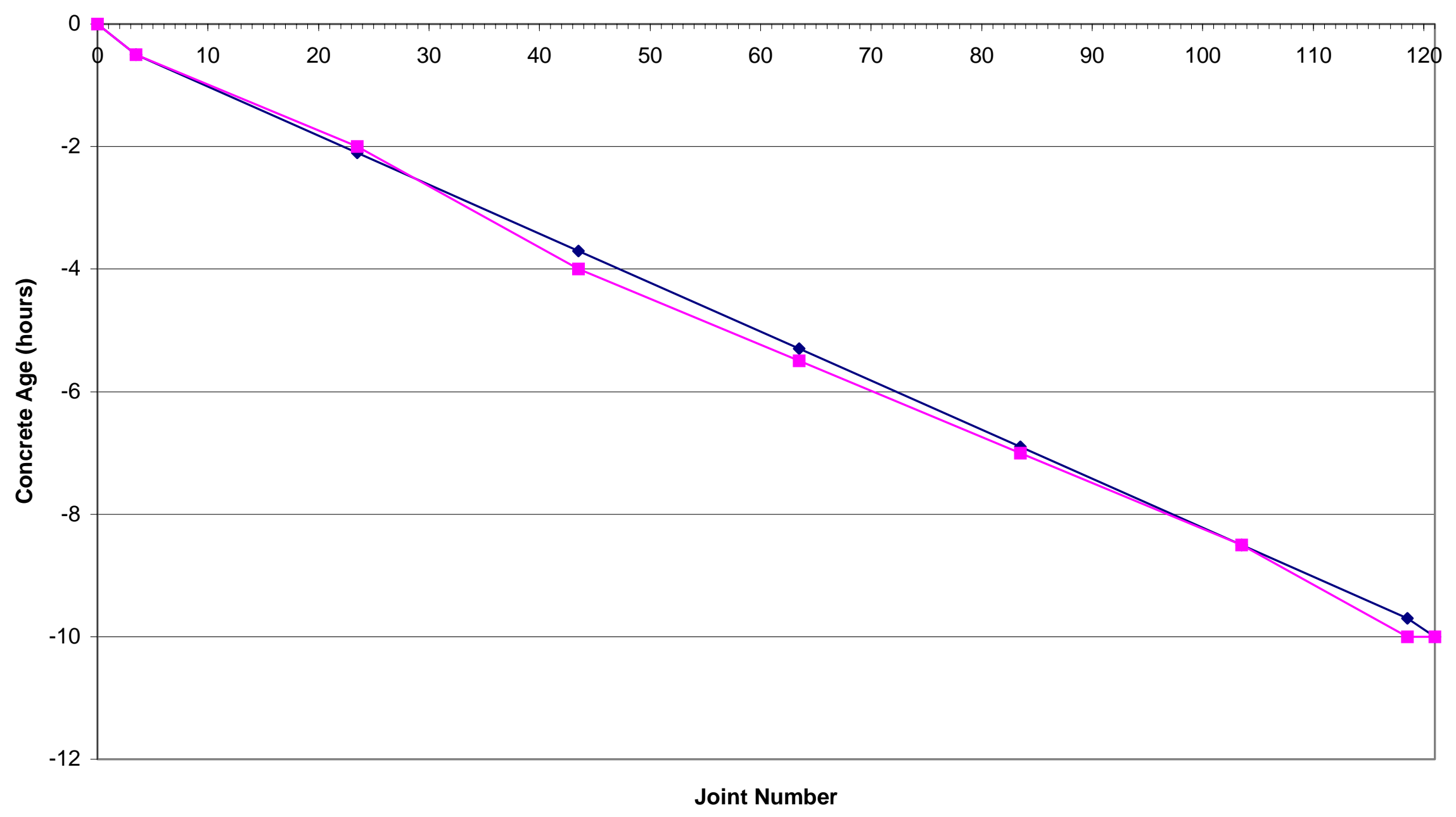

Estimated Concrete Age $\rightarrow$-Approximate Analysis Age 
Modified Analysis Delta T1 versus Time by Location Corridor H Elkins, WV time=o 0830 hrs 12 October 1999

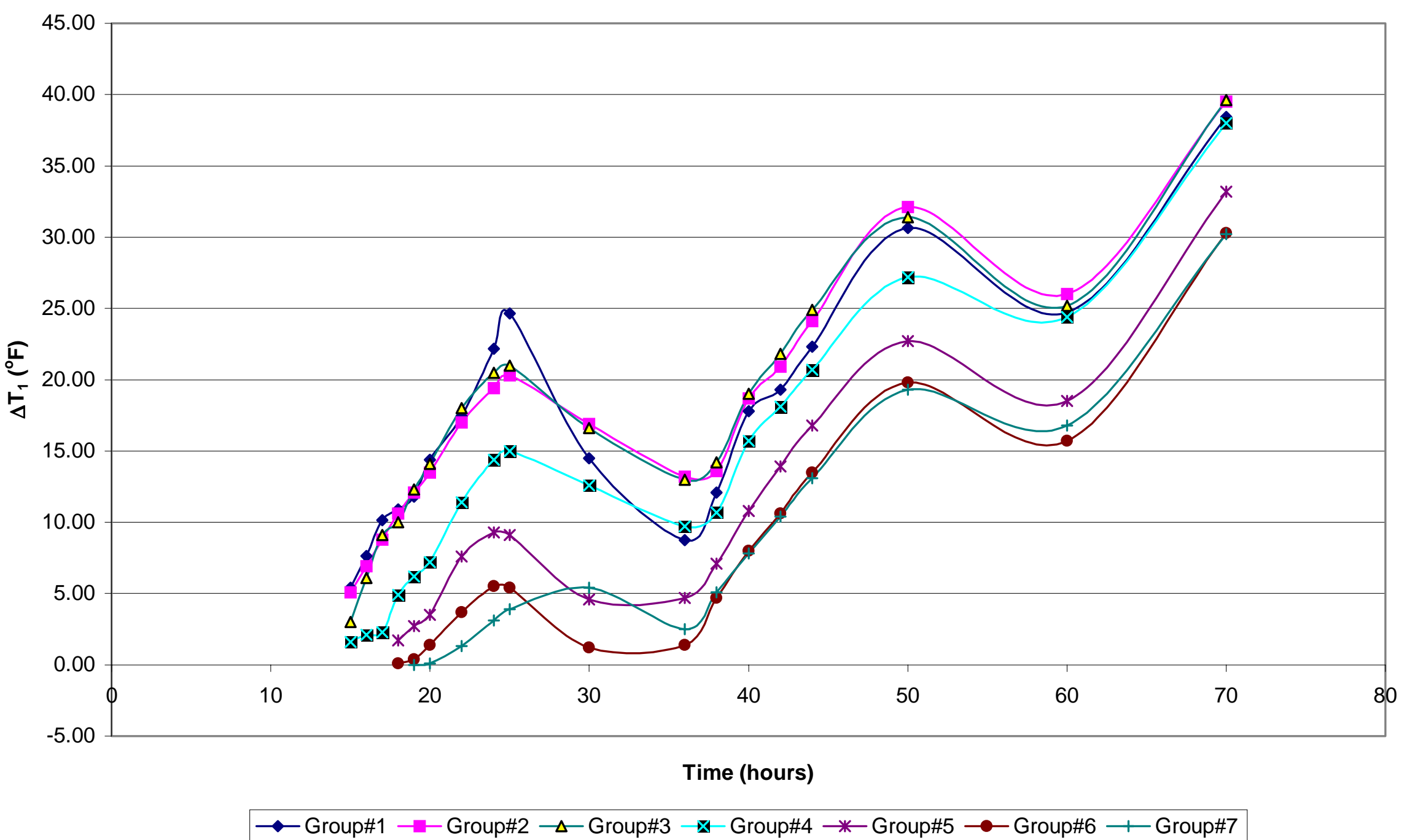

Figure 10.2: Modified Analysis Delta T1 Values by Group versus Time, Corridor H 


\section{Modified Delta T2 versus Time by location Saw-cut Depth Factor of 2}

Corridor H Elkins, WV time=0 at 0830 hrs 12 October 1999

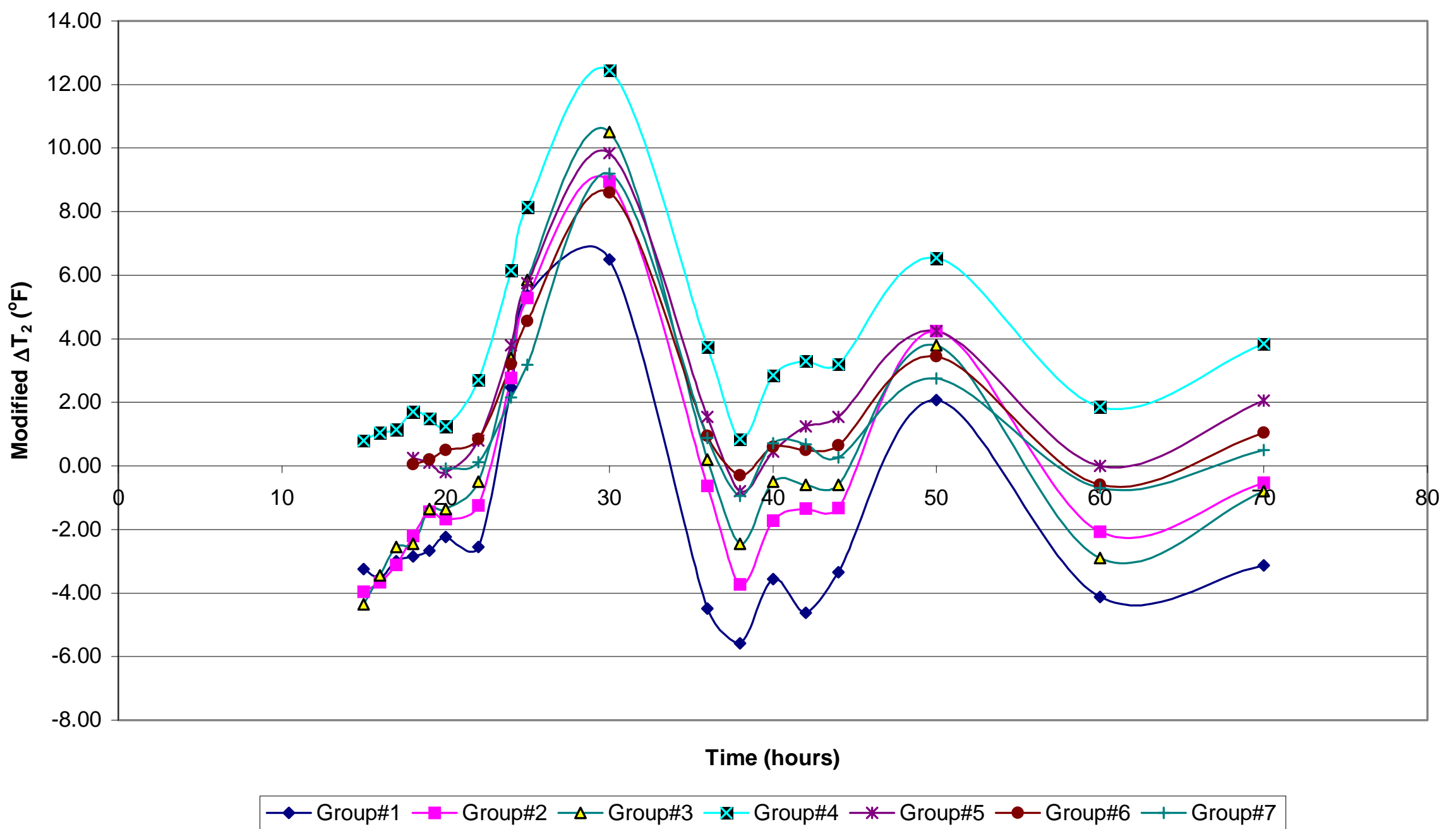


Table 10.1

Concrete Age by Slab Region

Corridor $\mathrm{H}$ near Elkins, WV

Time $=0$ at 0830 hrs 12 October 1999

$\mathrm{L}_{\text {total }}=1815$ feet

\begin{tabular}{|c|c|c|c|c|c|}
\hline Region & $\begin{array}{l}\text { Represented } \\
\text { Slab Lengths }\end{array}$ & $\begin{array}{l}\text { Temp } \\
\text { Group\# }\end{array}$ & $\begin{array}{l}\text { Thermocc } \\
\text { Group Lo }\end{array}$ & $\begin{array}{l}\text { e } \\
\text { ons }\end{array}$ & $\begin{array}{l}\text { Concrete } \\
\text { Age (hours) }\end{array}$ \\
\hline 1 & 0 to 200 feet & 1 & 52.5 & 3.5 & 0 \\
\hline 2 & 201 to 500 feet & 2 & 352.5 & 23.5 & -2 \\
\hline 3 & 501 to 800 feet & 3 & 652.5 & 43.5 & -4 \\
\hline 4 & 801 to 1100 feet & 4 & 952.5 & 63.5 & -5.5 \\
\hline 5 & 1101 to 1400 feet & 5 & 1252.5 & 83.5 & -7 \\
\hline 6 & 1401 to 1700 feet & 6 & 1552.5 & 103.5 & -8.5 \\
\hline 7 & 1701 to 1815 feet & 7 & 1777.5 & 118.5 & -10 \\
\hline
\end{tabular}

$\underline{\text { Table } \mathbf{1 0 . 2}}$

$\Delta \mathrm{T}_{1}$ by Region, or Group Number versus Time

Corridor $\mathrm{H}$ near Elkins, WV

time $=0$ at $0830 \mathrm{hrs} 12$ October 1999

$\Delta \mathrm{T}_{1}=\Delta \mathrm{T}_{\text {core }}$

TIME

[HRS]

$\Delta \mathrm{T}_{1}\left({ }^{\circ} \mathrm{F}\right)$

\begin{tabular}{|c|c|c|c|c|c|c|c|}
\hline & Group\#1 & Group\#2 & Group\#3 & Group\#4 & Group\#5 & Group\#6 & Group\#7 \\
\hline \hline 15 & 5.39 & 5.10 & 3.00 & 1.60 & & & \\
\hline 16 & 7.63 & 6.90 & 6.10 & 2.10 & & & \\
\hline 17 & 10.15 & 8.80 & 9.10 & 2.30 & & & \\
\hline 18 & 10.91 & 10.60 & 10.00 & 4.90 & 1.70 & 0.10 & \\
\hline 19 & 11.81 & 12.10 & 12.30 & 6.20 & 2.70 & 0.40 & 0.00 \\
\hline 20 & 14.39 & 13.50 & 14.10 & 7.20 & 3.50 & 1.40 & 0.10 \\
\hline 22 & 17.43 & 17.00 & 18.00 & 11.40 & 7.60 & 3.70 & 1.30 \\
\hline 24 & 22.16 & 19.40 & 20.50 & 14.40 & 9.30 & 5.50 & 3.10 \\
\hline 25 & 24.65 & 20.30 & 21.00 & 15.00 & 9.10 & 5.40 & 3.90 \\
\hline 30 & 14.50 & 16.90 & 16.60 & 12.60 & 4.60 & 1.20 & 5.40 \\
\hline 36 & 8.73 & 13.20 & 13.00 & 9.70 & 4.70 & 1.40 & 2.50 \\
\hline 38 & 12.08 & 13.60 & 14.20 & 10.70 & 7.10 & 4.70 & 5.10 \\
\hline 40 & 17.78 & 18.70 & 19.00 & 15.70 & 10.80 & 8.00 & 7.80 \\
\hline 42 & 19.31 & 20.90 & 21.80 & 18.10 & 13.90 & 10.60 & 10.40 \\
\hline 44 & 22.30 & 24.10 & 24.90 & 20.70 & 16.80 & 13.50 & 13.10 \\
\hline 50 & 30.65 & 32.10 & 31.40 & 27.20 & 22.70 & 19.80 & 19.30 \\
\hline 60 & 24.71 & 26.00 & 25.20 & 24.40 & 18.50 & 15.70 & 16.80 \\
\hline 70 & 38.45 & 39.50 & 39.60 & 38.00 & 33.20 & 30.30 & 30.20 \\
\hline
\end{tabular}


$\underline{\text { Table } 10.3}$

$\Delta T_{2}$ by Region, or Group Number versus Time

Corridor $\mathrm{H}$ near Elkins, WV

time $=0$ at $0830 \mathrm{hrs} 12$ October 1999

$\Delta \mathrm{T}_{2}=\left(\Delta \mathrm{T}_{\text {surface }}-\Delta \mathrm{T}_{\text {core }}\right) /$ saw-cut depth factor

Depth Factor $=$ If $d=h / 4, D F=2$ and if $d=h / 3, D F=3$

TIME

[hours] $\quad \Delta \mathrm{T}_{2}=\left(\Delta \mathrm{T}_{\text {core }}-\Delta \mathrm{T}_{\text {surface }}\right) / 2\left({ }^{\circ} \mathrm{F}\right)$

\begin{tabular}{|c|c|c|c|c|c|c|c|}
\hline & Group\#1 & Group\#2 & Group\#3 & Group\#4 & Group\#5 & Group\#6 & Group\#7 \\
\hline \hline 15 & 3.24 & 3.95 & 4.35 & -0.80 & 0.00 & 0.00 & 0.00 \\
\hline 16 & 3.52 & 3.67 & 3.45 & -1.05 & 0.00 & 0.00 & 0.00 \\
\hline 17 & 3.00 & 3.12 & 2.55 & -1.15 & 0.00 & 0.00 & 0.00 \\
\hline 18 & 2.84 & 2.20 & 2.45 & -1.70 & -0.25 & -0.05 & 0.00 \\
\hline 19 & 2.66 & 1.44 & 1.35 & -1.50 & -0.10 & -0.20 & 0.00 \\
\hline 20 & 2.24 & 1.67 & 1.35 & -1.25 & 0.20 & -0.50 & 0.08 \\
\hline 22 & 2.55 & 1.24 & 0.50 & -2.70 & -0.80 & -0.85 & -0.12 \\
\hline 24 & -2.47 & -2.78 & -3.40 & -6.15 & -3.80 & -3.20 & -2.16 \\
\hline 25 & -5.36 & -5.29 & -5.85 & -8.15 & -5.75 & -4.55 & -3.19 \\
\hline 30 & -6.50 & -8.95 & -10.50 & -12.45 & -9.85 & -8.60 & -9.20 \\
\hline 36 & 4.49 & 0.62 & -0.20 & -3.75 & -1.55 & -0.95 & -0.87 \\
\hline 38 & 5.59 & 3.72 & 2.45 & -0.85 & 0.80 & 0.30 & 0.95 \\
\hline 40 & 3.56 & 1.72 & 0.50 & -2.85 & -0.45 & -0.60 & -0.71 \\
\hline 42 & 4.62 & 1.34 & 0.60 & -3.30 & -1.25 & -0.50 & -0.68 \\
\hline 44 & 3.35 & 1.33 & 0.60 & -3.20 & -1.55 & -0.65 & -0.27 \\
\hline 50 & -2.08 & -4.25 & -3.80 & -6.55 & -4.25 & -3.45 & -2.75 \\
\hline 60 & 4.12 & 2.07 & 2.90 & -1.85 & 0.00 & 0.60 & 0.70 \\
\hline 70 & 3.13 & 0.53 & 0.80 & -3.85 & -2.05 & -1.05 & -0.50 \\
\hline
\end{tabular}




\subsection{Corridor H Theoretical Analysis Results}

The modified theoretical stress and joint-crack formation analysis developed during

Phase II was performed with the data obtained from the Corridor $\mathrm{H}$ slab section investigation. The details of the analysis process were shown in Section 10.2. The analysis, in current format, utilizes spreadsheet manipulations to obtain strength and tensile stress developments. The current format requires individualized input of data for any given time of interest and for every property and region. The theoretical analysis was performed for specific, pre-selected times. The times selected were based on the actual slab behavior and were adjusted as required to obtain all the theoretical regional failure results. Two example tables from the theoretical analysis can be seen in Tables 10.4 and 10.5 .

In those tables, the developing tensile strengths of the slab are compared to the developing tensile stresses by slab region for the specifically stated times, based on the time equal to zero scale already established for the Corridor $\mathrm{H}$ section. (See Table 8.1 Converted Time Chart) Regional behavior variations in strength and stress development can be seen in the tables. The last row in the analysis tables contain the difference values of the available strength, $\sigma_{\mathrm{RST}}(\mathrm{psi})$, and the developed, reduced section tensile stresses, $\sigma_{\text {red }}(\mathrm{psi})$, for each defined region. Tensile failure was concluded if the Difference value was negative. If negative, the available strength was exceeded and the region would experience tensile failure. The determination of the location of failure(s), or crack spacing, was established as the length of the region of slab end movement, $x$ (feet), of the region at the time of failure. The region of slab end movement was shown in feet and by number of joints in the tables. The nearest integer joint number at the time of failure was 
considered the approximate initial, primary joint-crack spacing of the region. The process required that when a region experienced failure, then that total regional length was subtracted from the total length, and the analysis continued. The new lengths of the regional subsections were considered equal to the joint-crack spacing at the time of failure. The remaining non-cracked slab section and the cracked subsections were then evaluated individually. The length of slab section being analyzed dictates the type of tensile stresses that develop. The process of the analysis required each regional failure time to be determined as accurately as possible to ensure that the slab lengths were analyzed correctly. This was performed by trial and error and also knowing the actual temperature behaviors to predict the most critical times.

The modified theoretical analysis results for the slab tensile strengths and developed tensile stresses for the times analyzed in Example Trial \#1 were summarized in Table 10.6. At times when any of the seven slab regions experienced tensile failure, the Difference rows in Table 10.6 were bold-faced. The primary transverse joint-crack formation was established after all regions experienced failure. The strength and stress developments for the time of failure for any region were summarized in Table 10.7. The crack formation sequence mimics the location of maximum tensile stress at varying times along the total slab length, as expected. The initial, primary joint-crack formations by region determined from the failure behaviors were assembled in Table 10.8. The jointcrack formation required two nights for total slab length propagation. The first four regions experienced joint-crack formation the first night, while regions 5 through 7 remained non-cracked until the second night. The time when each region experienced tensile failure was found to propagate from the most mature concrete slab end to the least 
mature end. The crack formations were seen to occur during nighttime hours when ambient and slab temperatures dropped and differential core to surface temperatures existed. Other influential behavior did exist, but those were attributed to one main source, the concrete maturity.

The concrete age by location variable was found to be the most influential factor, other than thermal behavior, in the strength and stress development across the total slab length. The concrete age by location influenced the slab temperature behaviors and estimated material property values by region during the varying heat of hydration processes time frames over the slab length. Thus, the tensile stress developments also followed the concrete maturity variations by region. The concrete maturity propagation behavior was found to drastically effect the early-age slab behavior and was the main contributing factor in the initial, primary transverse joint-crack formation of the slab section.

The estimation of joint-crack width was not performed at this time. But from estimated strain calculations performed in Table 9.1, theoretically the regional visible strains, or crack widths, may be approximated. The crack widths would be dependent upon the thermal shrinkage, hydration shrinkage and base course interaction restriction, as well as other sources. The actual crack widths recorded during the site investigation may be of future use in manipulation of theoretical analysis input data by the comparison of achieved visible strain values. The restricted strains may be comparable to the slab and base course interaction, or deformation restraints.

The coefficient of friction, $\mu$, utilized during the theoretical analysis was determined in a similar manner during this study. Coefficient of friction tests between concrete and 
free-drain base course material were performed during Phase I. The results at varying concrete age were not believed accurate as frictional coefficients, but may be bonding strength factors. The slab to base course interaction and failure behavior was seen during field investigations to propagate completely through the base course. Therefore, the early-age bond between the slab and the base was greater than the strength of the base course itself, as was shown at early-ages from the Phase I test results. The composite behavior of the thermally shrinking concrete slab and the bonded base course should be utilized. The theoretical analysis performed assumed that the frictional coefficient, $\mu$, could be assumed as an achievable constant value between the base course and sub-base, (or in the Corridor $\mathrm{H}$ case, separation/filter fabric). This value has not been laboratory tested for to date, thus requiring an approximated value for this analysis. By examining the strength and stress development tables, the first failure occurred in region number 1 at around 17 hours. The first initial failure from the site investigation was documented as joint number 8 , around 16.5 hours. By assuming the 8 -joint value for the region of slab end movement, the achieved frictional coefficient could be back-calculated and was determined to be approximately 0.6 . The value was believed reasonable compared to frictional coefficients of other known materials. Further investigation on the composite interaction between the slab, base course and sub-base should be performed.

The material property developments, the temperature behaviors and the base interaction behavior regulate the development of the joint-cracks. The spacing and width of cracks mainly revolves around the thermal and friction coefficients. The thermal and frictional coefficients become critical in solution determination. Long term affects from 
the possible manipulation must also be taken into consideration when proposing a solution.

The theoretical analysis produced a behavioral theory. The results revealed primary and secondary crack behavioral existence. During Example Trial \#1, the regional jointcrack formation was approximated as primary cracking only. The formation of secondary joint cracks was not seen with the utilized variables. The slab/base interaction behavior is believed to be the controlling variable determining secondary joint-crack formation. The free-slab lengths, between consecutive cracks, determined showed development of tensile stresses approaching allowable values, but were not enough to form secondary failures. The secondary joint-crack formations, if established by theoretical evaluation, may produce better slab/base interaction developments. Further investigation of the composite behavior and theoretical manipulation is required.

Additional discussion on the theoretical analysis results and comparison of the documented actual Corridor H slab section behaviors can be seen in Section 10.5. 
Table 10.4: Example Table 1 of Stress Analysis

Corridor $\mathrm{H}$ near Elkins, WV Theoretical Analysis

Time $=0$ at 0830 hours 12 October 1999

Stress Analysis for Time $=24$ Hours

Full Restraint Axial Stress Analysis and Curling Stress ONLY

REGION NUMBER

\begin{tabular}{llllllll}
1 & 2 & 3 & 4 & 5 & 6 & 7 \\
\hline \hline
\end{tabular}

Full Restraint Axial Stress, $\sigma_{\mathrm{R}}$

\begin{tabular}{|l|r|r|r|r|r|r|r|}
\hline \hline $\mathrm{E}$ & 2 & 1.9 & 1.8 & 1.68 & 1.56 & 1.44 & 1.35 \\
\hline$\alpha$ & 4.67 & 4.67 & 4.67 & 4.67 & 4.67 & 4.67 & 4.67 \\
\hline$\Delta \mathrm{T}_{1}$ & 22.16 & 19.4 & 20.5 & 14.4 & 9.3 & 5.5 & 3.1 \\
\hline \hline$\sigma_{\mathrm{R}}$ & 206.9744 & 172.1362 & 172.323 & 112.9766 & 67.75236 & 36.9864 & 19.54395 \\
\hline \hline
\end{tabular}

Region of slab end movement, $\mathrm{x}$

\begin{tabular}{|l|r|r|r|r|r|r|r|}
\hline$\sigma_{\mathrm{R}}$ & 206.9744 & 172.1362 & 172.323 & 112.9766 & 67.75236 & 36.9864 & 19.54395 \\
\hline $\mathrm{W}$ & 0.08303 & 0.08303 & 0.08303 & 0.08303 & 0.08303 & 0.08303 & 0.08303 \\
\hline$\mu$ & 0.6 & 0.6 & 0.6 & 0.6 & 0.6 & 0.6 & 0.6 \\
\hline $\mathrm{x}$ (feet) & 346.2176 & 287.9418 & 288.2542 & 188.9823 & 113.3331 & 61.8692 & 32.69225 \\
\hline \hline Joint \# & 23.08117 & 19.19612 & 19.21695 & 12.59882 & 7.555542 & 4.124614 & 2.179483
\end{tabular}

\begin{tabular}{|l|r|r|r|r|r|r|r|}
\hline $\mathrm{L}(\mathrm{t})$ feet & 120 & 120 & 105 & 1015 & 1015 & 1015 & 1015 \\
\hline
\end{tabular}

\begin{tabular}{|l|r|r|r|r|r|r|r|}
\hline $\mathrm{L} / 2-\mathrm{x}$ & -286.218 & -227.942 & -235.754 & 318.5177 & 394.1669 & 445.6308 & 474.8078 \\
\hline
\end{tabular}

If positive, full restraint analysis. If negative, frictional analysis.

Frictional Axial Restraint Stress, $\sigma_{f}$

\begin{tabular}{|l|r|r|r|r|r|r|r|}
\hline \hline $\mathrm{L}(\mathrm{t})$ inches & 1440 & 1440 & 1260 & & & & \\
\hline $\mathrm{W} \mu$ & 0.049818 & 0.049818 & 0.049818 & 0.049818 & 0.049818 & 0.049818 & 0.049818 \\
\hline$\sigma_{\mathrm{f}}$ & 35.86896 & 35.86896 & 31.38534 & 0 & 0 & 0 & 0 \\
\hline \hline
\end{tabular}

Curling Stress, $\sigma_{\mathrm{C}}$

\begin{tabular}{|l|r|r|r|r|r|r|r|}
\hline \hline $\mathrm{E}$ & 2 & 1.9 & 1.8 & 1.68 & 1.56 & 1.44 & 1.35 \\
\hline$\alpha$ & 4.67 & 4.67 & 4.67 & 4.67 & 4.67 & 4.67 & 4.67 \\
\hline$\Delta \mathrm{T}_{2}$ & 0 & 0 & 0 & 0 & 0 & 0 & 0 \\
\hline \hline$\sigma_{\mathrm{C}}$ & 0 & 0 & 0 & 0 & 0 & 0 & 0 \\
\hline \hline
\end{tabular}

\begin{tabular}{|l|r|r|r|r|r|r|r|}
\hline$\sigma_{T}$ & 35.86896 & 35.86896 & 31.38534 & 112.9766 & 67.75236 & 36.9864 & 19.54395 \\
\hline \hline$\sigma_{\text {red }}$ & 53.80344 & 53.80344 & 47.07801 & 169.465 & 101.6285 & 55.4796 & 29.31593 \\
\hline \hline
\end{tabular}

\begin{tabular}{|l|r|r|r|r|r|r|r|}
\hline$\sigma_{\mathrm{St}}$ & 151 & 143 & 135 & 127.5 & 120 & 112.5 & 103 \\
\hline$\sigma_{\mathrm{DB}}$ & 21.15 & 20.05 & 18.46 & 16.9 & 15.35 & 13.79 & 12.23 \\
\hline \hline$\sigma_{\mathrm{RST}}$ & 172.15 & 163.05 & 153.46 & 144.4 & 135.35 & 126.29 & 115.23 \\
\hline \hline
\end{tabular}

\begin{tabular}{|l|l|l|l|l|l|l|l|}
\hline$\sigma_{\mathrm{RST}}-\sigma_{\text {red }}$ & 118.3466 & 109.2466 & 106.382 & -25.065 & 33.72146 & 70.8104 & 85.91408 \\
\hline \hline
\end{tabular}

(If negative, section may crack) 
Table 10.5: Example Table 2 of Stress Analysis

Corridor $\mathrm{H}$ near Elkins, WV Theoretical Analysis

Time $=0$ at 0830 hours 12 October 1999

Stress Analysis for Time $=\mathbf{4 4}$ Hours

Full Restraint Axial Stress Analysis and Curling Stress ONLY

REGION NUMBER

\begin{tabular}{llllllll}
1 & 2 & 3 & 4 & 5 & 6 & 7 \\
\hline \hline
\end{tabular}

Full Restraint Axial Stress, $\sigma_{\mathrm{R}}$

\begin{tabular}{|l|r|r|r|r|r|r|r|}
\hline \hline $\mathrm{E}$ & 2.49 & 2.47 & 2.45 & 2.42 & 2.39 & 2.36 & 2.33 \\
\hline$\alpha$ & 4.67 & 4.67 & 4.67 & 4.67 & 4.67 & 4.67 & 4.67 \\
\hline$\Delta \mathrm{T}_{1}$ & 22.3 & 24.1 & 24.9 & 20.7 & 16.8 & 13.5 & 13.1 \\
\hline \hline$\sigma_{\mathrm{R}}$ & 259.3111 & 277.9911 & 284.8934 & 233.939 & 187.5098 & 148.7862 & 142.5424 \\
\hline \hline
\end{tabular}

Region of slab end movement, $\mathrm{x}$

\begin{tabular}{|l|r|r|r|r|r|r|r|}
\hline$\sigma_{\mathrm{R}}$ & 259.3111 & 277.9911 & 284.8934 & 233.939 & 187.5098 & 148.7862 & 142.5424 \\
\hline $\mathrm{W}$ & 0.08303 & 0.08303 & 0.08303 & 0.08303 & 0.08303 & 0.08303 & 0.08303 \\
\hline$\mu$ & 0.6 & 0.6 & 0.6 & 0.6 & 0.6 & 0.6 & 0.6 \\
\hline $\mathrm{x}($ feet $)$ & 433.7641 & 465.0111 & 476.5569 & 391.3227 & 313.6581 & 248.8829 & 238.4386 \\
\hline \hline Joint \# & 28.9176 & 31.00074 & 31.77046 & 26.08818 & 20.91054 & 16.5922 & 15.89591
\end{tabular}

\begin{tabular}{|l|r|r|r|r|r|r|r|}
\hline $\mathrm{L}(\mathrm{t})$ feet & 120 & 120 & 105 & 105 & 255 & 570 & 570 \\
\hline
\end{tabular}

\begin{tabular}{|l|l|l|l|l|l|l|l|}
\hline $\mathrm{L} / 2-\mathrm{x}$ & -373.764 & -405.011 & -424.057 & -338.823 & -186.158 & 36.11707 & 46.5614 \\
\hline
\end{tabular} If positive, full restraint analysis. If negative, frictional analysis.

Frictional Axial Restraint Stress, $\sigma_{f}$

\begin{tabular}{|l|r|r|r|r|r|r|r|}
\hline \hline $\mathrm{L}(\mathrm{t})$ inches & 1440 & 1440 & 1260 & 1440 & 3060 & & \\
\hline $\mathrm{W} \mu$ & 0.049818 & 0.049818 & 0.049818 & 0.049818 & 0.049818 & 0.049818 & 0.049818 \\
\hline$\sigma_{\mathrm{f}}$ & 35.86896 & 35.86896 & 31.38534 & 35.86896 & 76.22154 & 0 & 0 \\
\hline \hline
\end{tabular}

Curling Stress, $\sigma_{\mathrm{C}}$

\begin{tabular}{|l|r|r|r|r|r|r|r|}
\hline \hline $\mathrm{E}$ & 2.49 & 2.47 & 2.45 & 2.42 & 2.39 & 2.36 & 2.33 \\
\hline$\alpha$ & 4.67 & 4.67 & 4.67 & 4.67 & 4.67 & 4.67 & 4.67 \\
\hline$\Delta \mathrm{T}_{2}$ & 3.35 & 1.33 & 0.6 & 0 & 0 & 0 & 0 \\
\hline \hline$\sigma_{\mathrm{C}}$ & 19.4774 & 7.670709 & 3.43245 & 0 & 0 & 0 & 0 \\
\hline \hline
\end{tabular}

\begin{tabular}{|l|r|r|r|r|r|r|r|}
\hline$\sigma_{T}$ & 55.34636 & 43.53967 & 34.81779 & 35.86896 & 76.22154 & 148.7862 & 142.5424 \\
\hline \hline$\sigma_{\text {red }}$ & 83.01954 & 65.3095 & 52.22669 & 53.80344 & 114.3323 & 223.1793 & 213.8136 \\
\hline \hline
\end{tabular}

\begin{tabular}{|l|r|r|r|r|r|r|r|}
\hline$\sigma_{\mathrm{St}}$ & 203 & 199 & 195 & 191.25 & 187.5 & 183.75 & 180 \\
\hline$\sigma_{\mathrm{DB}}$ & 23.39 & 23.33 & 23.26 & 23.21 & 23.16 & 23.11 & 23.07 \\
\hline \hline$\sigma_{\mathrm{RST}}$ & 226.39 & 222.33 & 218.26 & 214.46 & 210.66 & 206.86 & 203.07 \\
\hline \hline
\end{tabular}

\begin{tabular}{|l|l|l|l|l|l|l|l|}
\hline$\sigma_{\mathrm{RST}}{ }^{-} \sigma_{\text {red }}$ & 143.3705 & 157.0205 & 166.0333 & 160.6566 & 96.32769 & -16.3193 & -10.7436 \\
\hline \hline
\end{tabular}

(If negative, section may crack) 


\section{Table 10.6}

Modified Theoretical Analysis Results: Trial \#1

Corridor H Elkins, WV time $=0$ at 0830 hours 12 October 1999

Concrete Resistive Strengths and Developed Tensile Stresses by Region

A negative Difference Value means that Region should fail in tension.

\begin{tabular}{|c|c|c|c|c|c|c|c|c|}
\hline \multirow{2}{*}{\multicolumn{2}{|c|}{$\begin{array}{l}\text { Time } \\
\text { (hours) }\end{array}$}} & \multicolumn{7}{|l|}{ Region } \\
\hline & & 1 & 2 & 3 & 4 & 5 & 6 & 7 \\
\hline \multirow[t]{3}{*}{15} & 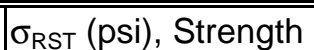 & 123.27 & 107.19 & 82 & 0 & 0 & $\overline{0}$ & 0 \\
\hline & $\sigma_{\text {red }}(p s i)$, Stress & 84.63 & 82.41 & 61.78 & 0 & 0 & 0 & 0 \\
\hline & Difference & 38.64 & 24.78 & 20.22 & 0 & 0 & 0 & 0 \\
\hline
\end{tabular}

\begin{tabular}{|c|l|c|c|c|c|c|c|c|}
\hline 16 & $\sigma_{\text {RST }}(\mathrm{psi})$, Strength & 129.31 & 115.23 & 99.15 & 78.5 & 0 & 0 & 0 \\
\cline { 2 - 9 }$\sigma_{\text {red }}(\mathrm{psi})$, Stress & 115.6 & 99.96 & 83.62 & 17.36 & 0 & 0 & 0 \\
\cline { 2 - 9 } & Difference & 13.71 & 15.27 & 15.53 & 61.14 & 0 & 0 & 0 \\
\hline
\end{tabular}

\begin{tabular}{|c|l|c|c|c|c|c|c|c|}
\hline 17 & $\sigma_{\text {RST }}$ (psi), Strength & 135.35 & 123.27 & 107.19 & 85.5 & 75 & 0 & 0 \\
\cline { 2 - 9 } & $\sigma_{\text {red }}$ (psi), Stress & 143.7 & 116.9 & 106.1 & 19.8 & 0 & 0 & 0 \\
\cline { 2 - 9 } & Difference & $\mathbf{- 8 . 3 5}$ & $\mathbf{6 . 3 7}$ & $\mathbf{1 . 0 9}$ & $\mathbf{6 5 . 7}$ & $\mathbf{7 5}$ & $\mathbf{0}$ & $\mathbf{0}$ \\
\hline
\end{tabular}

\begin{tabular}{|c|l|c|c|c|c|c|c|c|}
\hline 18 & $\sigma_{\mathrm{RST}}(\mathrm{psi})$, Strength & 141.38 & 129.31 & 115.23 & 103.17 & 82 & 0 & 0 \\
\cline { 2 - 9 } & $\sigma_{\text {red }}(\mathrm{psi})$, Stress & 86.43 & 132.7 & 117.74 & 43.94 & 14.29 & 0 & 0 \\
\cline { 2 - 9 } & Difference & $\mathbf{5 4 . 9 5}$ & $\mathbf{- 3 . 3 9}$ & $\mathbf{- 2 . 5 1}$ & $\mathbf{5 9 . 2 3}$ & $\mathbf{6 7 . 7 1}$ & $\mathbf{0}$ & $\mathbf{0}$ \\
\hline
\end{tabular}

\begin{tabular}{|c|l|c|c|c|c|c|c|c|}
\hline 19 & $\sigma_{\text {RST }}(\mathrm{psi})$, Strength & 147.42 & 135.35 & 123.27 & 111.21 & 99.15 & 78.5 & 0 \\
\cline { 2 - 9 } & $\sigma_{\text {red }}(\mathrm{psi})$, Stress & 85.85 & 69.54 & 60.32 & 57.76 & 23.64 & 3.31 & 0 \\
\cline { 2 - 9 } & Difference & 61.57 & 65.81 & 62.95 & 53.45 & 75.51 & 75.19 & 0 \\
\cline { 2 - 9 }
\end{tabular}

\begin{tabular}{|c|l|c|c|c|c|c|c|c|}
\hline 20 & $\sigma_{\text {RST }}(\mathrm{psi})$, Strength & 153.46 & 141.38 & 129.31 & 119.25 & 107.19 & 85.5 & 75 \\
\cline { 2 - 9 } & $\sigma_{\text {red }}(\mathrm{psi})$, Stress & 82.05 & 72.99 & 61.07 & 69.6 & 33.69 & 12.06 & 1.45 \\
\cline { 2 - 9 } & Difference & 71.41 & 68.39 & 68.24 & 49.65 & 73.5 & 73.44 & 73.55 \\
\hline
\end{tabular}

\begin{tabular}{|c|l|c|c|c|c|c|c|c|}
\hline 22 & $\sigma_{\text {RST }}(p s i)$, Strength & 163.05 & 153.46 & 141.38 & 132.33 & 123.27 & 111.21 & 99.15 \\
\cline { 2 - 9 } & $\sigma_{\text {red }}(\mathrm{psi})$, Stress & 87.74 & 69.44 & 52.82 & 121.38 & 74.53 & 34.47 & 11.38 \\
\cline { 2 - 9 } & Difference & 75.31 & 84.02 & 88.56 & 10.95 & 48.74 & 76.74 & 87.77 \\
\hline
\end{tabular}




\section{Table 10.6 (continued)}

Modified Theoretical Analysis Results: Trial \#1(Continued)

Corridor H Elkins, WV time $=0$ at 0830 hours 12 October 1999

Concrete Resistive Strengths and Developed Tensile Stresses by Region

A negative Difference Value means that Region should fail in tension.

\begin{tabular}{|c|l|c|c|c|c|c|c|c|}
\hline 24 & $\sigma_{\text {RST }}(\mathrm{psi})$, Strength & 172.15 & 163.05 & 153.46 & 144.4 & 135.35 & 126.29 & 115.23 \\
\cline { 2 - 9 } & $\sigma_{\text {red }}(\mathrm{psi})$, Stress & 53.8 & 53.8 & 47.08 & 169.47 & 101.63 & 55.48 & 29.32 \\
\cline { 2 - 9 } & Difference & $\mathbf{1 1 8 . 3 5}$ & $\mathbf{1 0 9 . 2 5}$ & $\mathbf{1 0 6 . 3 8}$ & $\mathbf{- 2 5 . 0 7}$ & $\mathbf{3 3 . 7 2}$ & $\mathbf{7 0 . 8 1}$ & $\mathbf{8 5 . 9 1}$ \\
\hline
\end{tabular}

\begin{tabular}{|c|l|c|c|c|c|c|c|c|}
\hline 25 & $\sigma_{\text {RST }}(\mathrm{psi})$, Strength & 176.7 & 167.6 & 158.5 & 150.44 & 141.38 & 132.33 & 123.27 \\
\cline { 2 - 9 } & $\sigma_{\text {red }}(\mathrm{psi})$, Stress & 53.8 & 53.8 & 47.08 & 87.43 & 104.54 & 57.5 & 38.25 \\
\cline { 2 - 9 } & Difference & 122.9 & 113.8 & 111.42 & 63.01 & 36.84 & 74.83 & 85.02 \\
\hline
\end{tabular}

\begin{tabular}{c|l|c|c|c|c|c|c|c|}
\hline 30 & $\sigma_{\text {RST }}(p s i)$, Strength & 192.63 & 186.26 & 179.89 & 174.43 & 167.6 & 160.78 & 153.46 \\
\cline { 2 - 9 } & $\sigma_{\text {red }}(p s i)$, Stress & 53.8 & 53.8 & 47.08 & 47.08 & 62.83 & 15.8 & 68.09 \\
\cline { 2 - 9 } & Difference & 138.83 & 132.46 & 132.81 & 127.35 & 104.77 & 144.98 & 85.37 \\
\hline
\end{tabular}

\begin{tabular}{c|l|c|c|c|c|c|c|c|}
\hline 36 & $\sigma_{\text {RST }}(\mathrm{psi})$, Strength & 208.13 & 203.07 & 198 & 193.97 & 189.44 & 184.67 & 179.89 \\
\cline { 2 - 9 } & $\sigma_{\text {red }}(\mathrm{psi})$, Stress & 128.35 & 63.92 & 47.08 & 47.08 & 72.76 & 21.09 & 36.6 \\
\cline { 2 - 9 } & Difference & 79.78 & 139.15 & 150.92 & 146.89 & 116.68 & 163.58 & 143.29 \\
\cline { 2 - 8 }
\end{tabular}

\begin{tabular}{|c|l|c|c|c|c|c|c|c|}
\hline 38 & $\sigma_{\text {RST }}(p s i)$, Strength & 213.2 & 208.13 & 203.07 & 199.25 & 195.22 & 190.94 & 186.17 \\
\cline { 2 - 9 } & $\sigma_{\text {red }}(\mathrm{psi})$, Stress & 148.17 & 115.56 & 87.07 & 47.08 & 125.62 & 78.11 & 91.97 \\
\cline { 2 - 9 } & Difference & 65.03 & 92.57 & 116 & 152.17 & 69.6 & 112.83 & 94.2 \\
\hline
\end{tabular}

\begin{tabular}{c|l|c|c|c|c|c|c|c|}
\hline 40 & $\sigma_{\text {RST }}(\mathrm{psi})$, Strength & 218.26 & 218.2 & 208.13 & 204.58 & 200.53 & 196.66 & 192.63 \\
\cline { 2 - 9 } & $\sigma_{\text {red }}(\mathrm{psi})$, Stress & 114.9 & 82.84 & 55.38 & 47.08 & 174.6 & 128.41 & 123.25 \\
\cline { 2 - 9 } & Difference & 103.36 & 135.36 & 152.75 & 157.5 & 25.93 & 68.25 & 69.38 \\
\hline
\end{tabular}

\begin{tabular}{c|l|c|c|c|c|c|c|c|}
\hline 42 & $\sigma_{\text {RST }}(\mathrm{psi})$, Strength & 222.33 & 218.26 & 213.2 & 209.4 & 205.6 & 201.8 & 198 \\
\cline { 2 - 9 } & $\sigma_{\text {red }}(\mathrm{psi})$, Stress & 133.74 & 76.8 & 57.21 & 47.08 & 228.82 & 172.27 & 166.83 \\
\cline { 2 - 9 } & Difference & $\mathbf{8 8 . 5 9}$ & $\mathbf{1 4 1 . 4 6}$ & $\mathbf{1 5 5 . 9 9}$ & $\mathbf{1 6 2 . 3 2}$ & $\mathbf{- 2 3 . 2 2}$ & $\mathbf{2 9 . 5 3}$ & $\mathbf{3 1 . 1 7}$ \\
\hline
\end{tabular}

\begin{tabular}{|l|l|c|c|c|c|c|c|c|}
44 & $\sigma_{\text {RST }}(\mathrm{psi})$, Strength & 226.39 & 222.33 & 218.26 & 214.46 & 210.66 & 206.86 & 203.07 \\
\cline { 2 - 9 } & $\sigma_{\text {red }}(\mathrm{psi})$, Stress & 83.02 & 65.31 & 52.23 & 53.8 & 114.33 & 223.18 & 213.81 \\
\cline { 2 - 9 } & Difference & $\mathbf{1 4 3 . 3 7}$ & $\mathbf{1 5 7 . 0 2}$ & $\mathbf{1 6 6 . 0 3}$ & $\mathbf{1 6 0 . 6 6}$ & $\mathbf{9 6 . 3 3}$ & $\mathbf{- 1 6 . 3 2}$ & $\mathbf{- 1 0 . 7 4}$ \\
\hline
\end{tabular}




\section{Table 10.6 (continued)}

Modified Theoretical Analysis Results: Trial \#1(Continued)

Corridor H Elkins, WV time $=0$ at 0830 hours 12 October 1999

Concrete Resistive Strengths and Developed Tensile Stresses by Region

A negative Difference Value means that Region should fail in tension.

\begin{tabular}{|c|l|c|c|c|c|c|c|c|}
\hline $44 a$ & $\sigma_{\text {RST }}(p s i)$, Strength & 226.39 & 222.33 & 218.26 & 214.46 & 210.66 & 206.86 & 203.07 \\
\cline { 2 - 9 } & $\sigma_{\text {red }}(p s i)$, Stress & 83.02 & 65.31 & 52.23 & 53.8 & 114.33 & 114.33 & 141.23 \\
\cline { 2 - 9 } & Difference & 143.37 & 157.02 & 166.03 & 160.66 & 96.33 & 92.53 & 61.84 \\
\hline
\end{tabular}

\begin{tabular}{c|l|c|c|c|c|c|c|c|}
\hline 50 & $\sigma_{\text {RST }}(\mathrm{psi})$, Strength & 239 & 234.52 & 230.46 & 227.41 & 224.36 & 221.31 & 218.26 \\
\cline { 2 - 9 } & $\sigma_{\text {red }}(\mathrm{psi})$, Stress & 53.8 & 53.8 & 47.08 & 47.08 & 114.33 & 114.33 & 141.23 \\
\cline { 2 - 9 } & Difference & 185.2 & 180.72 & 183.38 & 180.33 & 110.03 & 106.98 & 77.03 \\
\hline
\end{tabular}

\begin{tabular}{|c|l|c|c|c|c|c|c|c|}
\hline 60 & $\sigma_{\text {RST }}(\mathrm{psi})$, Strength & 264 & 259 & 254 & 250.25 & 246.5 & 242.75 & 239 \\
\cline { 2 - 9 } & $\sigma_{\text {red }}(\mathrm{psi})$, Stress & 53.8 & 53.8 & 47.08 & 47.08 & 114.33 & 114.33 & 141.23 \\
\hline Difference & 210.2 & 205.2 & 206.92 & 203.17 & 132.17 & 128.42 & 97.77 \\
\hline
\end{tabular}

\begin{tabular}{|c|l|c|c|c|c|c|c|c|}
\hline 70 & $\sigma_{\text {RST }}(\mathrm{psi})$, Strength & 285 & 280.8 & 276.6 & 273.45 & 270.3 & 267.15 & 264 \\
\cline { 2 - 9 } & $\sigma_{\text {red }}(\mathrm{psi})$, Stress & 112.78 & 63.75 & 62.1 & 47.08 & 114.33 & 114.33 & 141.23 \\
\cline { 2 - 9 } & Difference & 172.22 & 217.05 & 214.5 & 226.37 & 155.97 & 152.82 & 122.77 \\
\cline { 2 - 8 }
\end{tabular}




\section{Table 10.7}

Modified Theoretical Analysis Results: Trial \#1

Corridor H Elkins, WV time $=0$ at 0830 hours 12 October 1999

Concrete Resistive Strengths and Developed Tensile Stresses by Region

A negative Difference Value means that Region should fail in tension.

Time

Region

\begin{tabular}{l|l|c|c|c|c|c|c|c|}
\multicolumn{2}{c}{} & \multicolumn{1}{c}{1} & 2 & 3 & 4 & 5 & 6 & 7 \\
\hline \hline \multirow{3}{*}{17} & $\sigma_{\text {RST }}$ (psi), Strength & 135.35 & 123.27 & 107.19 & 85.5 & 75 & 0 & 0 \\
\cline { 2 - 9 } & $\sigma_{\text {red }}$ (psi), Stress & 143.7 & 116.9 & 106.1 & 19.8 & 0 & 0 & 0 \\
\cline { 2 - 9 } & Difference & -8.35 & 6.37 & 1.09 & 65.7 & 75 & 0 & 0 \\
\cline { 2 - 9 }
\end{tabular}

18

\begin{tabular}{|l|c|c|c|c|c|c|c|}
\hline$\sigma_{\text {RST }}(p s i)$, Strength & 141.38 & 129.31 & 115.23 & 103.17 & 82 & 0 & 0 \\
\hline$\sigma_{\text {red }}(p s i)$, Stress & 86.43 & 132.7 & 117.74 & 43.94 & 14.29 & 0 & 0 \\
\hline Difference & 54.95 & -3.39 & -2.51 & 59.23 & 67.71 & 0 & 0 \\
\hline
\end{tabular}

24

\begin{tabular}{|l|c|c|c|c|c|c|c|}
\hline$\sigma_{\text {RST }}(p s i)$, Strength & 172.15 & 163.05 & 153.46 & 144.4 & 135.35 & 126.29 & 115.23 \\
\hline$\sigma_{\text {red }}(p s i)$, Stress & 53.8 & 53.8 & 47.08 & 169.47 & 101.63 & 55.48 & 29.32 \\
\hline Difference & 118.35 & 109.25 & 106.38 & -25.07 & 33.72 & 70.81 & 85.91 \\
\hline
\end{tabular}

42

\begin{tabular}{|l|c|c|c|c|c|c|c|}
\hline$\sigma_{\mathrm{RST}}(\mathrm{psi})$, Strength & 222.33 & 218.26 & 213.2 & 209.4 & 205.6 & 201.8 & 198 \\
\hline$\sigma_{\text {red }}(p s i)$, Stress & 133.74 & 76.8 & 57.21 & 47.08 & 228.82 & 172.27 & 166.83 \\
\hline Difference & 88.59 & 141.46 & 155.99 & 162.32 & -23.22 & 29.53 & 31.17 \\
\hline
\end{tabular}

44

\begin{tabular}{|l|c|c|c|c|c|c|c|}
\hline$\sigma_{\text {RST }}(p s i)$, Strength & 226.39 & 222.33 & 218.26 & 214.46 & 210.66 & 206.86 & 203.07 \\
\hline$\sigma_{\text {red }}(p s i)$, Stress & 83.02 & 65.31 & 52.23 & 53.8 & 114.33 & 223.18 & 213.81 \\
\hline Difference & 143.37 & 157.02 & 166.03 & 160.66 & 96.33 & -16.32 & -10.74 \\
\hline
\end{tabular}

$44 a$

\begin{tabular}{|l|c|c|c|c|c|c|c|}
\hline$\sigma_{\mathrm{RST}}(\mathrm{psi})$, Strength & 226.39 & 222.33 & 218.26 & 214.46 & 210.66 & 206.86 & 203.07 \\
\hline$\sigma_{\text {red }}(\mathrm{psi})$, Stress & 83.02 & 65.31 & 52.23 & 53.8 & 114.33 & 114.33 & 141.23 \\
\hline Difference & 143.37 & 157.02 & 166.03 & 160.66 & 96.33 & 92.53 & 61.84 \\
\hline
\end{tabular}




\section{Table 10.8}

Modified Theoretical Analysis Results: Example Trial \#1

Corridor H Elkins, WV time $=0$ at 0830 hours 12 October 1999

Initial Transverse Saw-cut Joint-crack Formation Spacing

Approximate Transverse Crack Spacing by Number of Joints

Time (hrs) Region

\begin{tabular}{|c|c|c|c|c|c|c|c|}
\hline & 1 & 2 & 3 & 4 & 5 & 6 & 7 \\
\hline \hline 17 hours & 8 & & & & & & \\
\hline 18 hours & & 8 & 7 & & & & \\
\hline 24 hours & & & & 12 & & & \\
\hline 42 hours & & & & & 17 & & \\
\hline 44 hours & & & & & & 17 & 16 \\
\hline
\end{tabular}

Note:

Regional Crack Spacing approximately equal to the region of slab end movement $x$ (feet), at time of initial failure. 


\subsection{Analysis Comparison to Investigation Observations and Discussion}

The analysis from Example Trial \#1 resulted in the approximated primary transverse joint-crack development for a theoretical slab section experiencing identical, regional thermal behaviors, and estimated material and interactive behaviors as the actual Corridor H slab section constructed on 12 October 1999. The concrete material and thermal behaviors obtained from the site investigation were used to theoretically model the crack development. The theoretical analysis revealed a primary joint-crack formation similar to that of the actual field observations.

The actual joint-crack development at various times can be seen in Figures 8.23, 8.24 and 8.25. The crack development was thoroughly described in Section 8.3. Primary joint-crack formations were observed during the first two nights after slab placement. Crack progression the first night propagated to around half the total slab length and spaced around every $8^{\text {th }}$ to $10^{\text {th }}$ saw-cut. The second night, the crack progression eclipsed the entire slab length. The initial, primary crack spacing the second night was observed to be longer than the first nights. The second and third night, the longer subsections (being 10 non-cracked joints or greater) experienced secondary subsection mid-slab jointcrack formations. The secondary cracks were observed to be much smaller than the primary cracks.

The theoretical analysis results were shown and discussed in Section 10.4. Nearly identically, primary joint-crack formations were obtained. The joint-crack development the first night was found to progress through Region \#4, just over half the total slab length. The primary joint-crack development progressed throughout the remaining noncracked slab length the second night, the same as with the actual slab behavior. The 
primary crack spacing the second night was around every $16^{\text {th }}$ joint or so. This behavior was consistent with the actual behavior but did not develop secondary, frictional cracking as expected. The inability of the theoretical analysis to predict secondary joint-crack formations needed evaluated.

The stress development tables were examined for secondary subsection stress levels. The frictional stress developments combined with the differential thermal, or curling stress developments were found to be much lower than needed to cause secondary failures. These two stress developments are the only ones considered during the earlyage analysis. The tensile stress development equations were thought to be corrected during Phase II re-evaluations. Considering the analysis to be correct in theory, the error of the analysis not predicting secondary joint-crack formations is believed contingent on the variables being utilized. The variables $\mathrm{E}, \alpha$ and $\mu$ could be the source of the error. The development of the modulus of elasticity, E (psi) was determined from early-age compression tests performed during Phase II. The thermal coefficient of the concrete, $\alpha$ $\left(\mu \mathrm{in} / \mathrm{in} /{ }^{\circ} \mathrm{F}\right)$ was also determined from Phase II test results. The utilized values were obtained from the embedded vibrating wire strain gage data. Both of the values, $\mathrm{E}$ and $\alpha$, are approximations, but are considered reliable during this study. The achieved coefficient of friction, or the slab/base course interaction, was not determined by laboratory tests. The Phase I frictional values were determined to be incorrect due to misinterpretation of the collected data, which resulted in very large, erroneous values. The error was detected during the later part of the Phase II theoretical analyses. The achieved coefficient of friction, $\mu$, was estimated utilizing the theoretical stress development, initial joint-crack formation spacing (120 feet) and the theoretical region of 
slab end movement at the time of tensile failure. The coefficient was assumed to remain constant throughout the analysis time frame. This assumption was based on that the actual frictional behavior was between the base course and sub-base, which was freedrain base on separation/filter fabric over compacted graded soil sub-base. The base course was assumed to deflect integrally with the slab and the movement resisted by the sub-base friction only. In actuality, the slab and base course must function as a composite structure, sliding over the sub-base. The base course behavior and contribution to frictional resistance needs evaluated more closely. The slab/base interaction may not only produce frictional resistance but also composite inducing additional slab tensile forces. The composite interaction may not remain constant over time or location and needs further evaluation.

The exact theoretical modeling of any concrete slab sections' joint-crack formation would not be realistic, considering all of the variables encountered during early-age concrete behavior and slab construction methods. Though, estimating the overall slab behavior can be performed within reason. Investigation of the early-age theoretical stress and joint-crack development equations enable theoretical manipulation of the adjustable variables to determine possible solutions to the cracking problem. Further discussion on possible solutions can be found in Chapter 11 Discussion, Conclusions and Recommendations. 


\section{CHAPTER 11: DISCUSSION, CONCLUSIONS AND RECOMMENDATIONS:}

\section{$\underline{\text { 11.1 Discussion }}$}

The non-uniform, transverse saw-cut joint-crack development and extensive slab movement behavior cause unwanted and premature joint failures. During Phase I, the inconsistent joint-crack widths were believed to form at early-ages and a theoretical analysis method was developed. Re-evaluation of the stress development equations, the laboratory testing procedures, data reduction and results, were closely examined during

Phase II. The recommendation made in the last paragraph of Appendix A.1 of the Phase I report to closely consider temperature behavior variations along the slab length was instrumental in the Phase II re-evaluations. Phase I analysis was believed inadequate because the estimated joint-crack locations occurred at mid-slab lengths and contained constant material behavior, which did not coincide with actual slab behavior. In the following, Phase II observations and modifications are discussed in respect to the different aspects that the behavior verification and analysis validation involved. These are the field investigation results, the re-evaluation of Phase I theoretical analysis and the Phase II modification to the theoretical analysis.

Several improvements to the Phase I behavior theory and reliability were made during Phase II investigation. The Phase II modified theoretical analysis was developed from the Phase I concepts and improved upon as required by addition test results and behavioral observations. The modified analysis discussed and performed in Chapter 10 resulted in a better theoretical representation of the actual slab behavior. During the modified analysis, important characteristics and variables were observed to influence joint-crack developments. The reliability of the analysis results was found contingent 
upon the accuracy of the variable approximations, by rate of development and value, and the precision of the slab temperature profile histories. Variation of the property developments and temperature behavior could drastically effect the analysis results.

The non-uniform joint-crack developments are a result of the primary joint-crack formations. The concrete pavement slabs were found to develop primary and secondary crack developments within the first 72 hours after placement. Crack formation was controlled by slab thermal behavior, early-age concrete property development and frictional resistance to slab movement. The primary joint-crack development, slab subsection formations and extensive slab end movements produce the larger joint-crack widths being observed by the field engineers.

The primary joint cracks form at locations of the slab end movement during thermal contraction of the young slab. The slab end movement for a short slab section would be seen from both directions. But for the newly constructed slabs, the length could be considered semi-infinite because one ends movement is non-influential of the other. Therefore, movement is seen to propagate from the most mature slab end. As the jointcracks develop and the total non-cracked slab length shortens, the influence of the end movements together may be seen. This was observed to typically occur during the second night of slab maturity, when crack formations approached the end location of the initial, continuously placed slab section. The slab end movements are controlled by the thermal contraction during early stress development. Sequential crack formations from the primary joints opening, produce a shifting behavior in the stress profiles. The shifting behavior and slab failures produce the slab subsections. The secondary joint-cracks would develop in these subsections. The secondary cracks would be found smaller in 
width than the primary cracks and should be located near the mid-span of the subsections. The difference in crack widths developed was due to the stress transfer being reduced by half after the secondary crack formations. The available slab length affected by tensile stress developed in the subsections was considerably lower, producing smaller secondary crack widths.

The crack widths should vary in size along the slab lengths because of the independent thermal and material property behaviors. The joint-cracks and tensile stress failures were found to develop at varying concrete maturity levels. From that behavior, the maximum stress location at the time of failure would be different for varying slab regions producing variably located and sized joint-cracks.

The influence of plastic shrinkage should be considered minimal because low moisture losses are observed when curing compound coating is used at early-ages. Also, long-term drying shrinkage would enhance the non-uniform widths, but would not be of any additional contribution to the early-age stress development.

The joint-crack movements were found to have quite individualized behavior. The stress developments, crack locations and widths, and slab subsection movement behavior are controlled by many time and location dependent variables. These are the concrete slab temperature profiles, material properties, slab and base course interaction and frictional development and the reduced cross-sectional strengths at the joint saw-cuts. Each variable must be taken into consideration for the estimation of crack development. Identical joint-crack formations of separately constructed slabs would probably not occur because of the many variables influencing the total slab behavior. However, as a result of 
this study, slab behaviors can be predicted with some certainty in the determination of stress development and joint-crack formation.

The non-uniform transverse joint-cracking behavior should be corrected. Unwanted and premature joint failures are inevitable with these crack developments. Various longterm behavioral problems occur due to the primary cracking developments. Pumping, spalling and several other pavement behaviors are enhanced upon by the fluctuating large joint movements. The premature roadway deterioration dramatically increases the operational, maintenance and personnel costs of the concrete highway pavement systems. 


\section{$\underline{\text { 11.2 Conclusions }}$}

The field investigations performed during this study produced critical information for the understanding of newly constructed pavement behavior. There were four key results:

- The necessity for time and location dependent analysis was verified due to the thermal behavior differences and concrete maturity levels found along the slab lengths. The concrete age variation by location forced variable concrete maturity and thermal behaviors to be accounted for in the analysis.

- The transverse saw-cut joint-crack developments were observed to follow propagation sequencing from the earliest placed most mature slab ends. Primary and secondary crack formations were observed. The primary crack formations were the initial cracks that formed along the slab length, which revealed subsection formation. Secondary cracks developed between consecutive primary cracks within the independent subsections. The secondary cracks were seen to open less than the primary cracks.

- At all three continuous site investigations, the base courses failed integrally with the concrete slabs, producing somewhat composite-like behaviors. The achieved frictional behavior would not be as described in Phase I and required re-evaluation.

- The ambient temperature has dramatic effect on the slab temperature profile at earlyages. The ambient conditions either amplified or reduced the hydration processes of the varying concrete maturity by location. After the initial concrete hydration was complete, the slab temperature behaviors mimicked and converged toward the ambient temperatures. 
Various aspects of the modifications and corrections of the previous Phase I study were discussed throughout this report and summarized as:

- The theoretical analysis was modified to include time and location dependent behavior.

- Early-age concrete properties were better approximated because of additional test results and field observations.

- Differential thermal or curling stress equation and the frictional stress development equations were corrected.

- Vibrating wire strain gages were utilized because thermal correction of added gage strain readings were adjustable. The low relative stiffness of the strain gage allows for young concrete deformations to be detected. 


\section{$\underline{11.3 \text { Recommendations }}$}

Consideration should be given to control the primary joint-crack initial spacing. The primary joint-cracks and initial length of slab end movements cause the unwanted excessive joint movements. An increase in the crack frequency would decrease the average crack width and subsequent joint movements. Caution should be taken in the development of methods to evaluate the long-term effects.

Detailed examination of the early-age behavior of the slabs allowed for possible theoretical stress developments to be determined. Possible corrections, which could decrease the primary crack spacing, were identified. To date two possibilities of correction have been evaluated.

1. Decrease the cross-section at the saw-cut locations.

2. Adjust material, behavioral or interactive properties.

The decrease of the cross-section at saw-cut locations would drastically increase the reduced section total stresses compared to the tensile strength developments of the concrete. The reduction must be performed before the maximum heat of hydration is reached and cooling thermal stresses begin developing. Sufficient reduction of crosssections could be estimated from the theoretical modeling of stress development. Earlyage tensile stress development with the knowledge of the contribution of the resistance to movement could show a recommended reduced cross-sectional amount.

Another primary joint-crack development correction possibility would be to adjust the material, behavioral and/or interactive properties of slab designs which are involved with the failure stress locations. Other than the temperature fluctuations, the controlling factors for these failure locations are the concrete mix designs developments of modulus 
of elasticity, $\mathrm{E}$, and thermal coefficient, $\alpha$, and the coefficient of friction, $\mu$. Early-age determinations of $\mathrm{E}$ and $\alpha$ of concrete should be tested. Adjusting of these two variables enough to assist in the reduction of crack frequency could compromise the concrete integrity for strength. The determinations of these values at early-age are mix design dependent, which would require further development testing.

Adjusting the coefficient of friction could be performed with design modifications. The concrete slab to base course interaction was found to be a composite-like structure behavior due to the large bond strength values obtained at ages prior to initial crack development. During this study, a frictional coefficient between the base and the subbase was estimated and assumed constant due to the base failures observed. Currently the estimate neglects the composite behavior of the base course and the slab. Additional resistance to movement could be contributed to the cooling concrete slab by the compression behavior of the set base course. Further evaluation of this behavior could produce a viable solution to the primary crack development.

Further study should also be conducted on the composite-like behavior encountered during the site investigations. Additional base course resistive stresses should be better understood. The knowledge could lead to combinations of corrections of not only the excessive joint movements but also other unwanted concrete highway behavioral problems stemming from the slab to base course interaction as well.

Finally, the determination of the maximum transverse saw-cut spacing is typically a long-term consideration. The initial set spacing of shear devices for slab expansion/contraction and for load transfer, dictate the design criteria. The continuation 
of this study, by examining the long-term effects of the early-age primary joint-crack development is needed. 


\section{References}

1. Al Rawi, R.S. and G.F. Kheder. "Control of Cracking Due to Volume Change in

Base Restrained Concrete Members." ACI Structural Journal. July-August 1990: $397-405$.

2. American Concrete Pavement Association. "Subgrades and Subbases for Concrete Pavements." Concrete Paving Technology. ACPA, 1995.

3. Ballardini, P. "Prediction of Hydration Stresses in Mass Concrete." Creep and Shrinkage of Concrete. Ed. Z.P. Bazant and I. Carol. London: E \& FN Spon, 1994. 265-270.

4. Channel, Brian C., $\underline{\text { Study of the Joint Movements of 15-ft Rigid Concrete }}$ Highway Pavements, A Thesis, West Virginia University, 1998.

5. Chapman, Ralph A., and Surrendra P. Shah. "Early Age Bond Strength in Reinforced Concrete.” ACI Materials Journal. Nov.-Dec. 1987: 501-510.

6. Chui, J.J. and W.H. Dilger. "Temperature, Stress, and Cracking Due to Hydration Heat." Creep and Shrinkage of Concrete. Ed. Z.P. Bazant and I. Carol. London: E \& FN Spon, 1994. 271-276.

7. Cribben, Joe, PennDOT, Personnel Communication, 1998.

8. Dilly, Ronald L., Beizai, V., and Woodward L. Vogt. "Integration of Time Temperature Curing Histories with PC Spreadsheet Software.” ACI Materials Journal. Sept.-Oct. 1988: 375-388. 
9. Fleischer, W., and R. Springenschmid. "Measures to Avoid Temperature Cracks in Concrete for a Bridge Deck." Creep and Shrinkage of Concrete. Ed. Z.P. Bazant and I. Carol. London: E \& FN Spon, 1994. 401-408.

10. Frum, Paul, West Virginia University, Personnel Communications, 1998-1999.

11. Goldbeck, A.T. "Friction Tests of Concrete on Various Sub-bases." Roads. 1985.

12. King, Dan, PennDOT, Personnel Communication, 1998-1999.

13. Lindeburg, Micheal R., PE. "Civil Engineering Reference Manual for the PE Exam, sixth ed., Professional Publications, Inc., Belmont, CA, 1998. Sections 11 and 14 .

14. Long, Micheal J., Stabilized Permiable Bases, Construction Report, Research Project \#91-99, PennDOT Bureau of Maintenance and Operations, Engineering District 3-0, August, 1994.

15. Mazars, J. and J.P. Bournazel. "Global Modeling for Creep, Shrinkage, and Damage Processes of Maturing Concrete.” Creep and Shrinkage of Concrete. Ed. Z.P. Bazant and I. Carol. London: E \& FN Spon, 1994. 277-282.

16. Menezes, N.C., and J.K. Trinh. "Influence of Water Content on the TimeDependent Properties of Concrete." Creep and Shrinkage of Concrete. Ed. Z.P. Bazant and I. Carol. London: E \& FN Spon, 1994. 277-282.

17. Nagy, Agnes. "Determination of Elastic Modulus of Young Concrete with Nondestructive Method." Journal of Materials in Civil Engineering. Vol. 9, No. 1. Feb., 1997. 15-20.

18. Neville, A. M. Properties of Concrete. Halsted Press, 1973. 
19. Odell, Harry, PennDOT Project Supervisor, Personnel Communication, 1998.

20. Okamoto, P.A., Nussbaum, P.J., et. al. Guidelines for Timing Contraction Joint

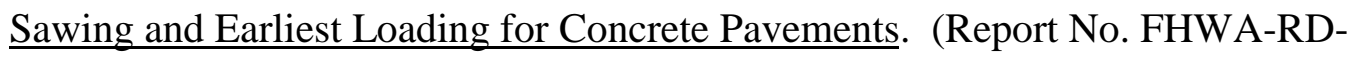
91-079). (Vol. 1). Skokie: Federal Highways Administration, 1994.

21. Okamoto, P.A., Nussbaum, P.J., et. al. Guidelines for Timing Contraction Joint

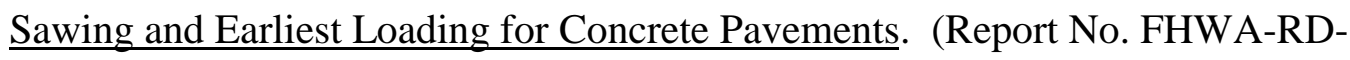
91-079). (Vol. 2). Skokie: Federal Highways Administration, 1994.

22. Powers, Treval C. The Properties of Fresh Concrete. John Wiley and Sons, 1968.

23. Rasmussen, Robert, Ph.D., Transtec Consultants, Austin, Texas, Personnel Communication, 1998-1999.

24. Robson, G., Freeman G., ACPA, Personal Communication, 1998-1999.

25. Roctest, Inc., Technical assistance and personnel communication, 1998-1999.

26. Schoppel, K., Plannerer, M., and R. Springenschmid. "Determination of Restraint Stresses and Material Properties During Hydration of Concrete With the Temperature Stress Testing Machine.” Thermal Cracking in Concrete at Early Ages. Ed. R. Springenschmid. London: E \& FN Spon, 1994. 153-160.

27. Schoppel, K., and R. Springenshmid. "The Effects of Thermal Deformation, Chemical Shrinkage, and Swelling on Restrained Stresses in Concrete at Early Ages.” Thermal Cracking in Concrete at Early Ages. Ed. R. Springenschmid. London: E \& FN Spon, 1994. 213-220.

28. Serway, Raymond A., "Physics for Scientists and Engineers", $3^{\text {rd }}$ ed., Saunders Golden Sunburst Series, updated printing, 1992. 113-114. 
29. Springenshmid, R., Breitenbucher, R., and M. Mangold. "Development of the Cracking Frame and the Temperature-Stress Testing Machine.” Thermal Cracking in Concrete at Early Ages. Ed. R. Springenschmid. London: E \& FN Spon, 1994. 137-144.

30. Suzuki, K., Ohno, Y., and T. Nakagawa. "Test Method for Cracking of Concrete Due To Drying Shrinkage.” Creep and Shrinkage of Concrete. Ed. Z.P. Bazant and I. Carol. London: E \& FN Spon, 1994. 63-70.

31. Thielen, G., and W. Hintzen. "Investigation of Concrete Behavior Under Restraint With a Temperature-Stress Test Machine.” Thermal Cracking in Concrete at Early Ages. Ed. R. Springenschmid. London: E \& FN Spon, 1994. $145-152$.

32. United States Department of Transportation and Federal Highways Administration. Technical Advisory: Concrete Pavement Joints. Nov. 1990.

33. West Virginia Department of Transportation. Division of Highways. "SI Metric Standard Specifications, Roads and Bridges”, 1994. (Blue Book)

34. Wylie, Bill, PennDOT Project Engineer, Personnel Communication, 1998.

35. Yang, Shungsheng, and Jiakui Chen. "Bond Slip and Crack Width Calculations of Tension Members.” ACI Structural Journal. July-Aug. 1988: 414-422.

36. Young, J. Francis. Concrete. Prentice-Hall, 1983. 


\section{$\underline{\text { Appendix A }}$}

\section{Examples of Compression Tests Stress-Strain Relationships}




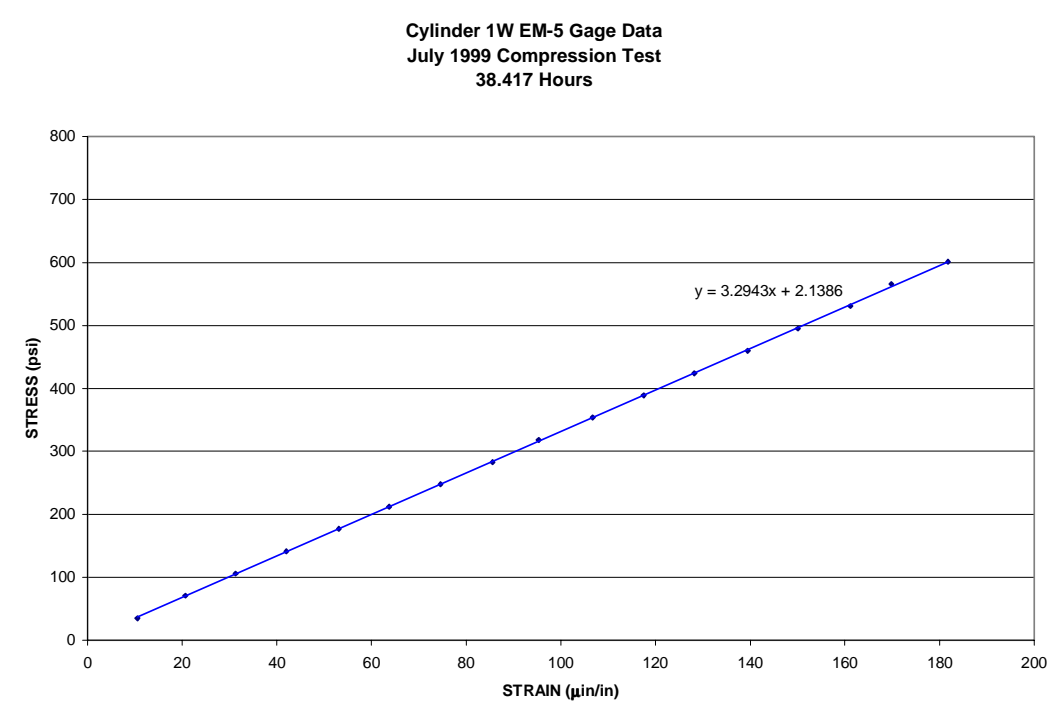

Cylinder 1W EM-5 Gage Data

July 1999 Compression Test

51.5 Hours

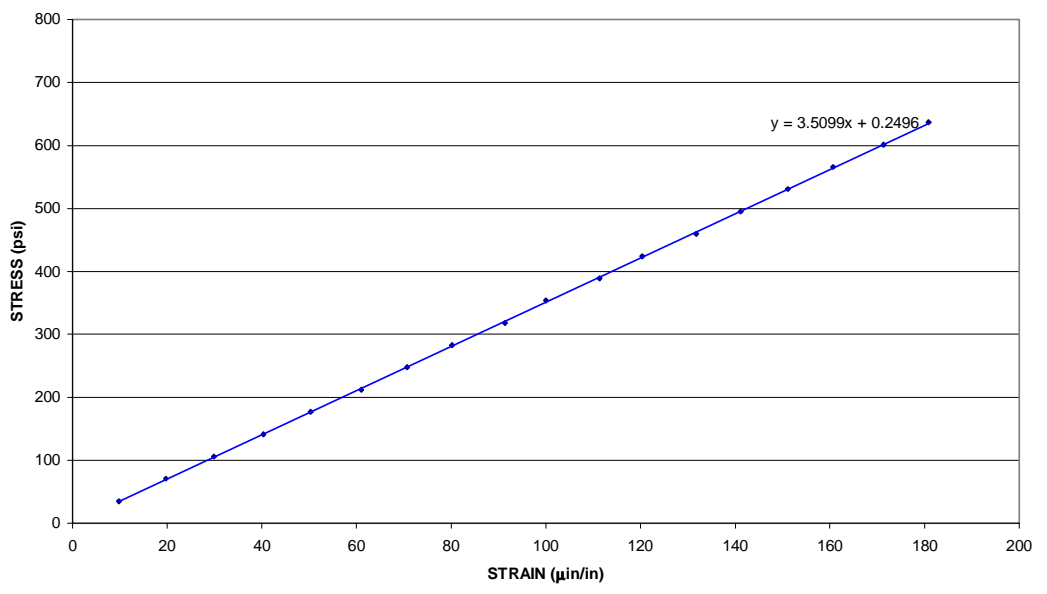

Cylinder 1W EM-5 Gage Data

July 1999 Compression Test

73 Hours

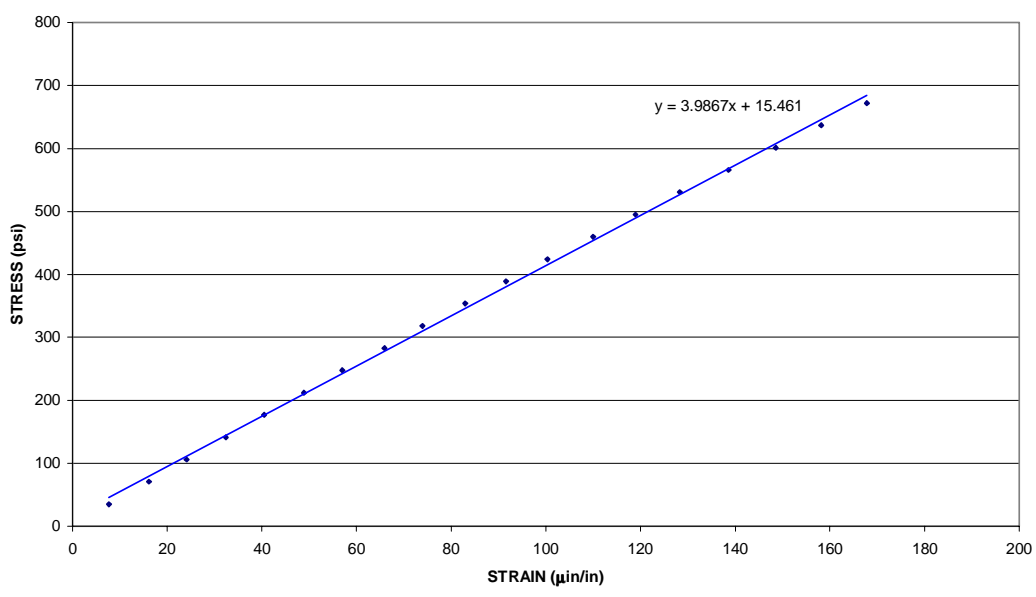

Figure A1: July 1999 early-age EM-5 Gage tests 
Cylinder 1W Dial Gage Data

July 1999 Compression Test

51.5 Hours

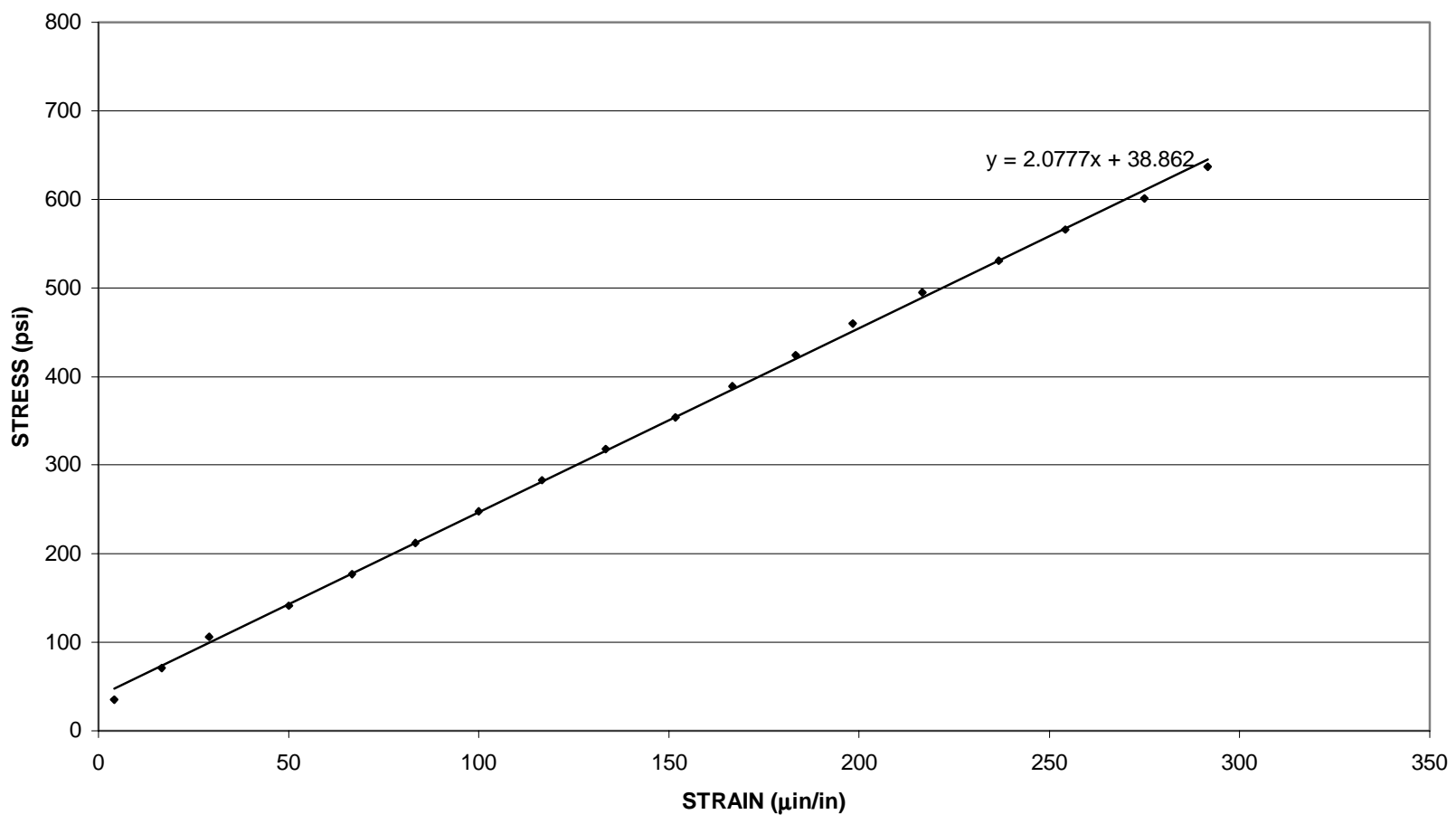

Cylinder 1W Dial Gage Data

July 1999 Compression Test

73 Hours

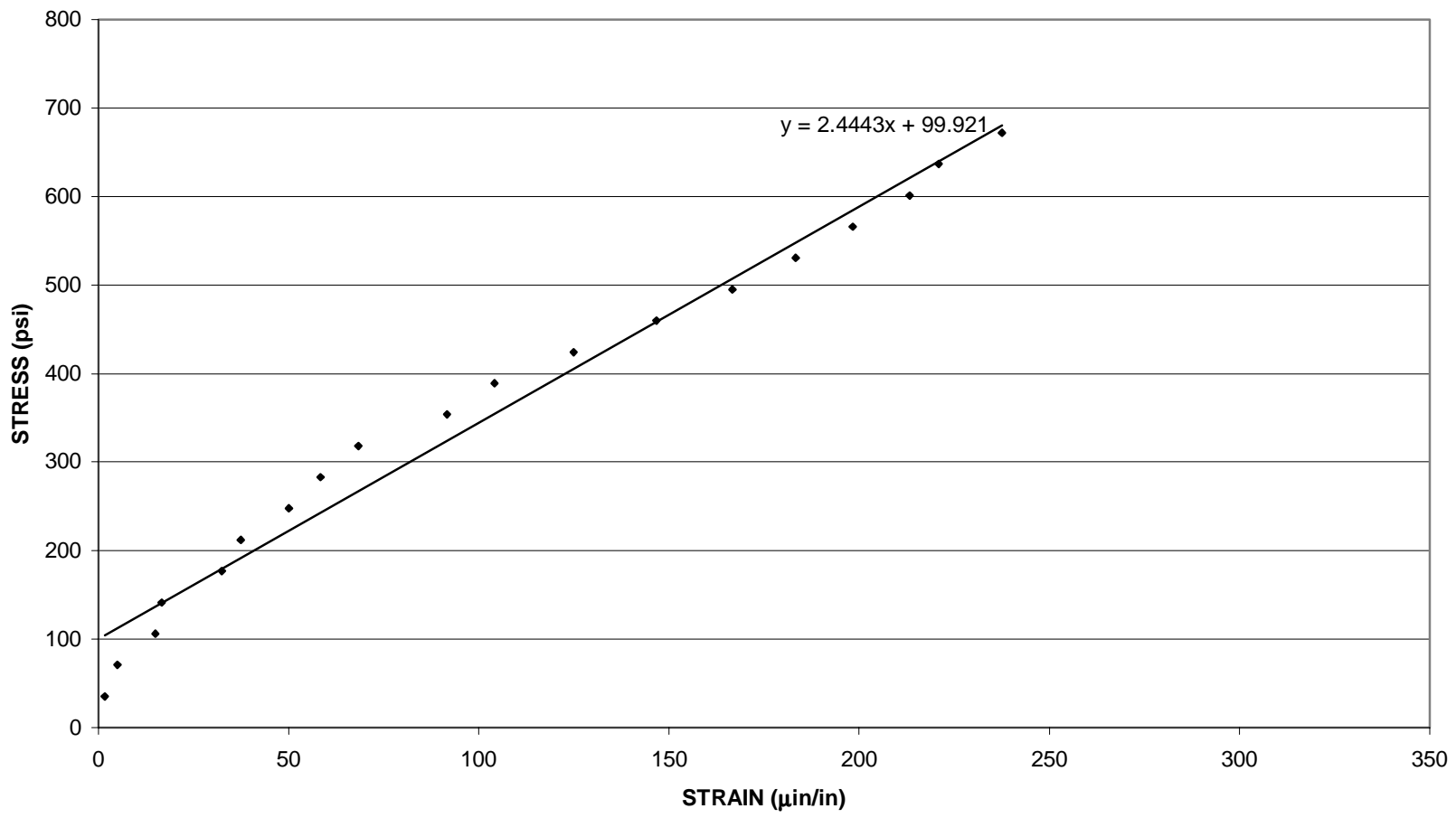

Figure A2: July 1999 early-age Dial Gage tests 
Stress-Strain Curve on 28 day cylinder

Cylinder 2W

Danville, PA mix design Mixed on 07 July 1999

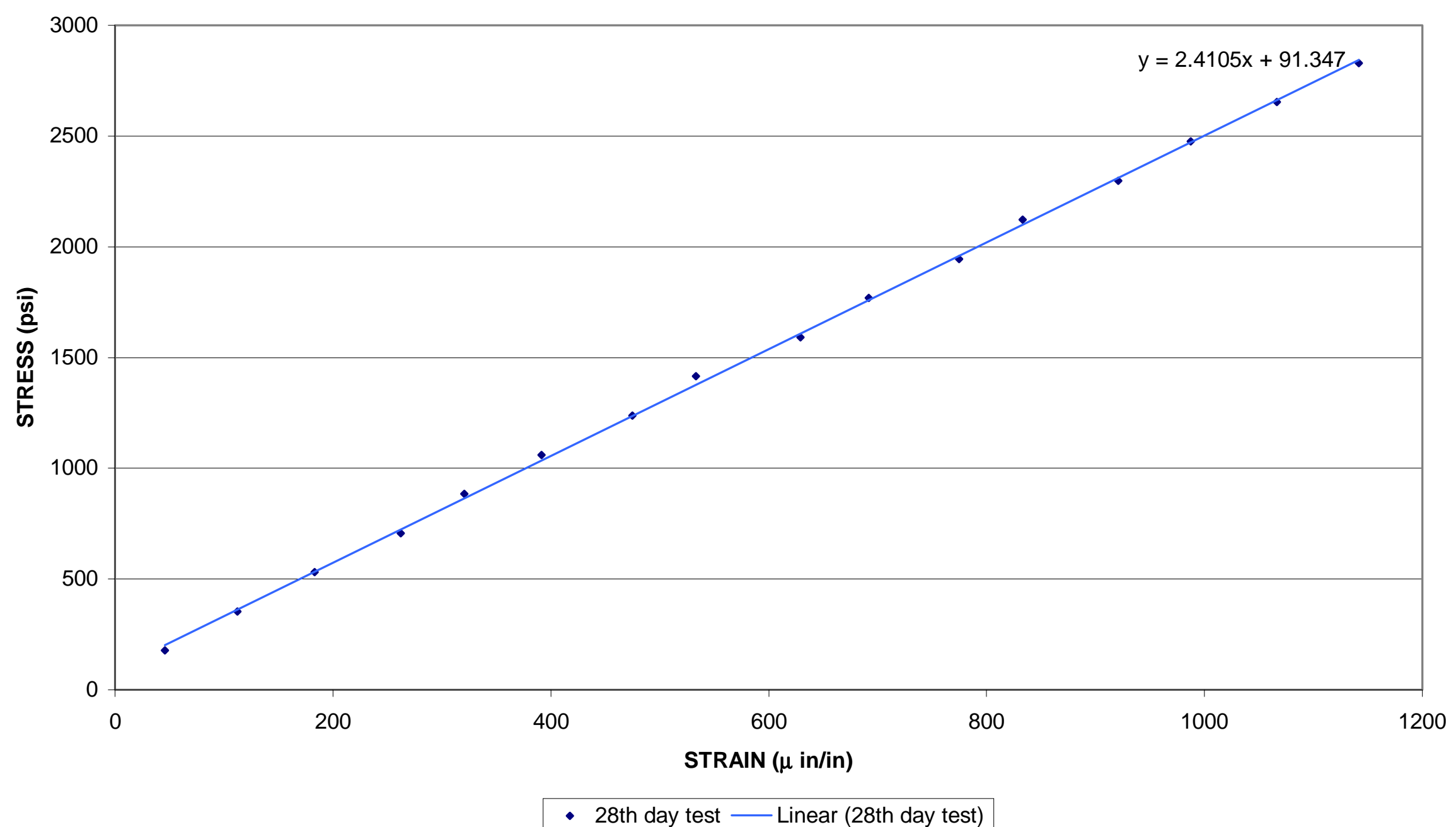

Figure A3: July 1999 28-Day Dial Gage tests 
Stress-Strain Curve on 28 day cylinder

Cylinder 6A

Danville, PA mix design Mixed on 07 July 1999

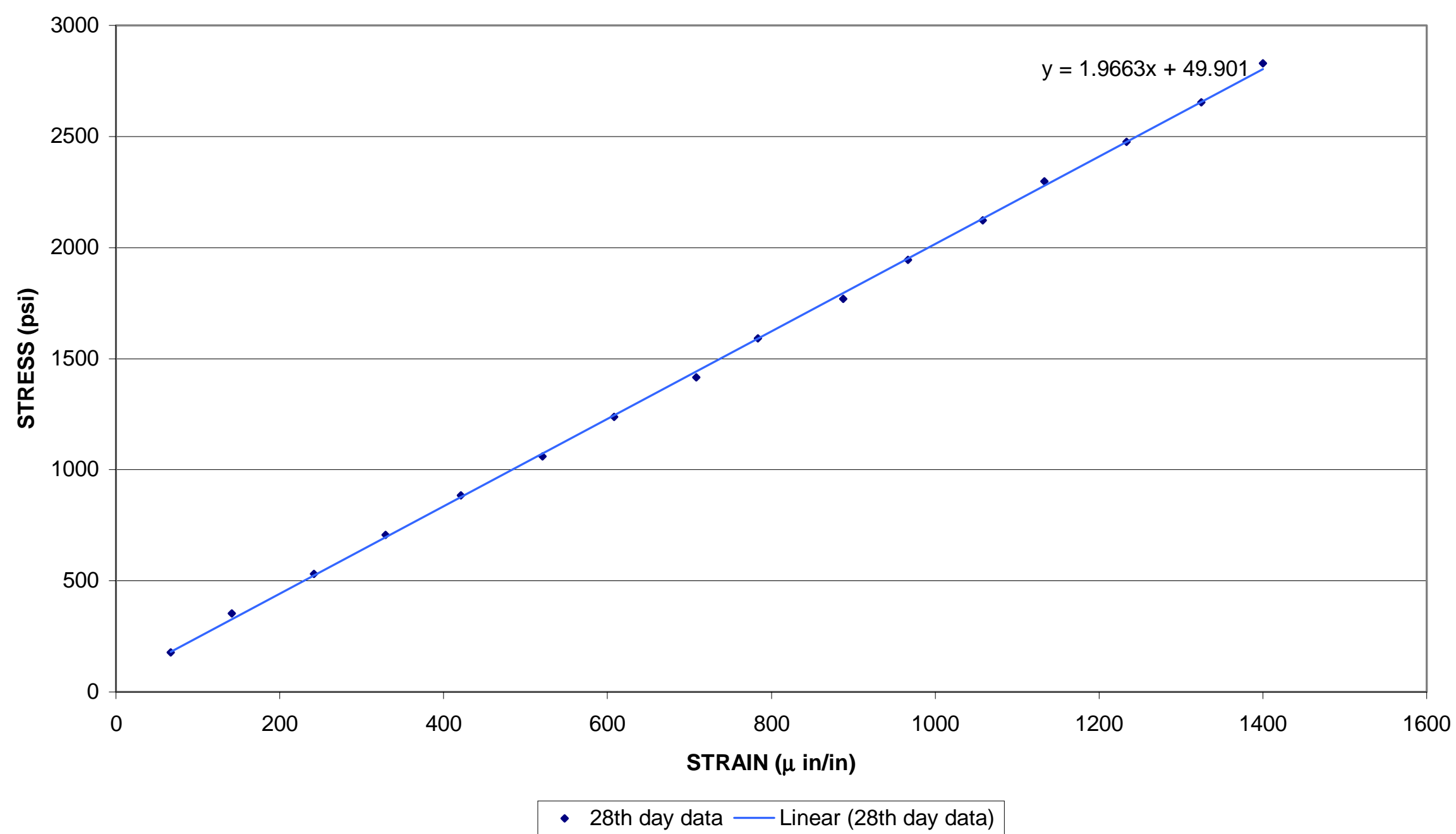

Figure A4: July 1999 28-Day Dial Gage tests, example 2. 
Stress vs. Strain [EM-5 Readings]

22nd-Hour Compression Testing of WV Lab Specimen \#1

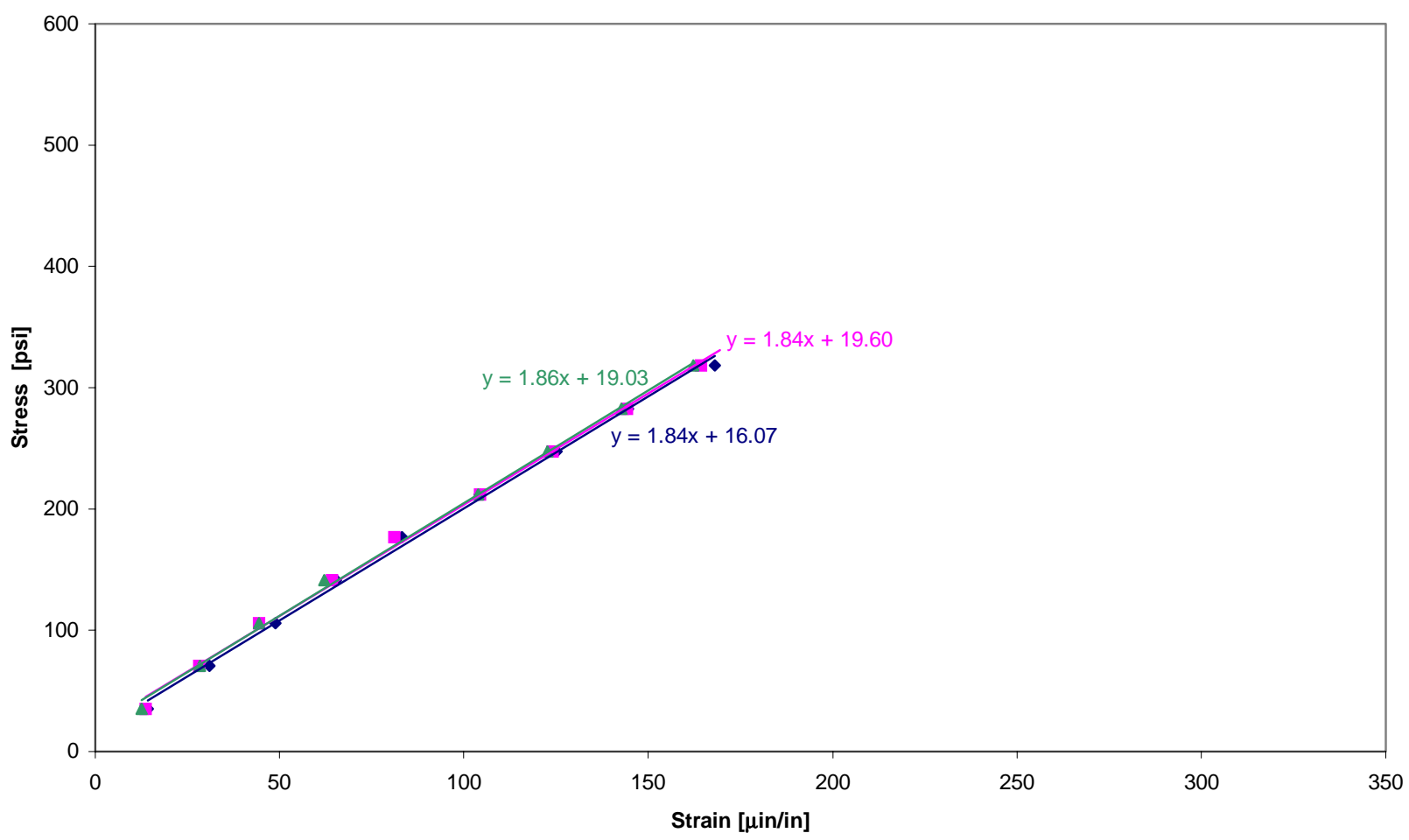

\section{- Test $1 \quad$ Test $2 \quad \Delta$ Test $3 \quad$ Linear (Test 1) — Linear (Test 2) — Linear (Test 3)}

Stress vs Strain [EM-5 Readings]

24th Hour Compression Testing of WV Lab Specimen \#1

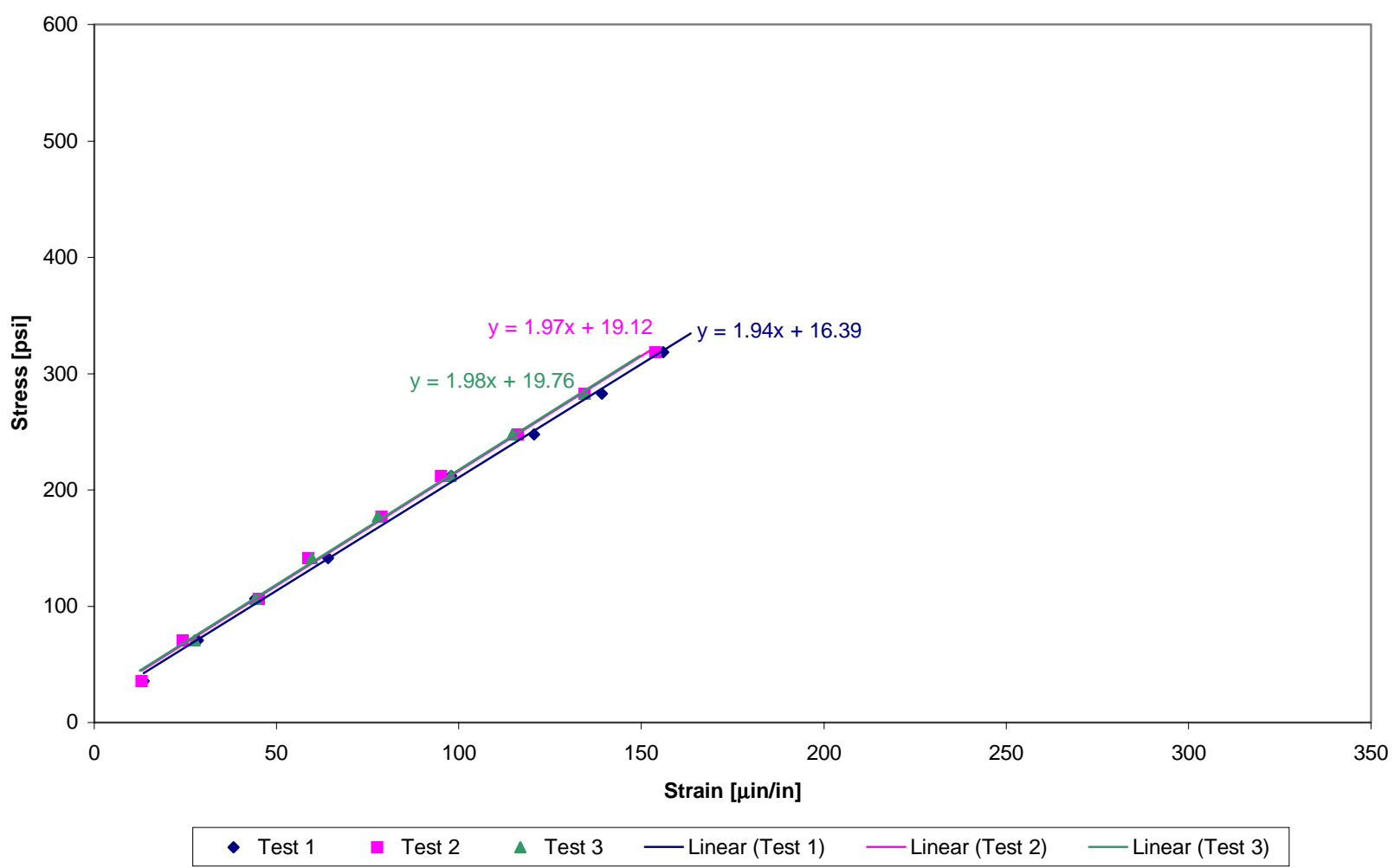

Figure A5: Corridor H Mix, early-age EM-5 tests 
Stress vs. Strain [Dial Gage Readings]

36th Hour Compression Testing of WV Lab Specimen \#1

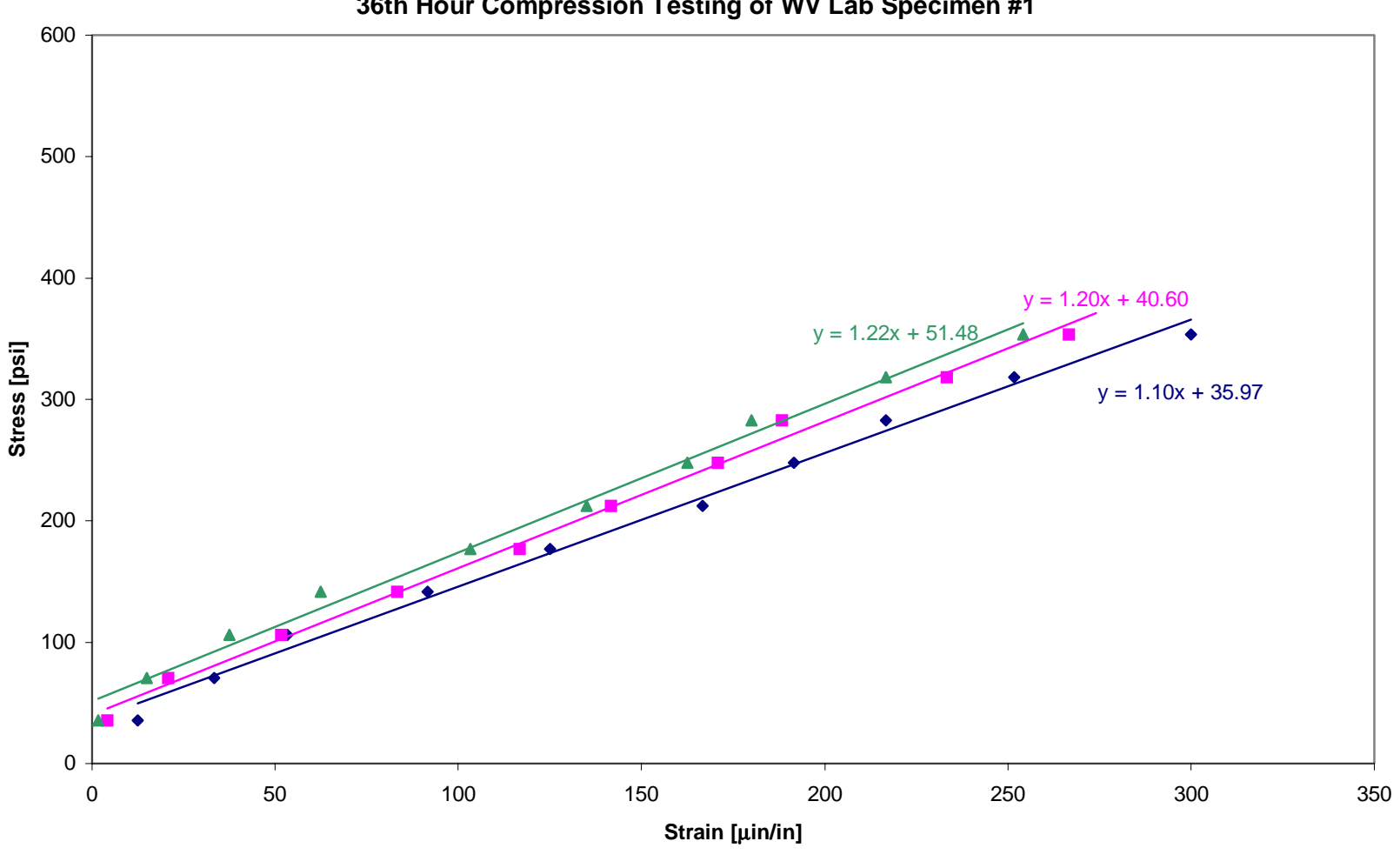

- Test 1 - Test $2 \quad \Delta$ Test $3 \quad$ - Linear (Test 1) — Linear (Test 2) — Linear (Test 3)

Stress vs. Strain [Dial Gage Readings]

48th Hour Compression Testing of WV Lab Specimen \#1

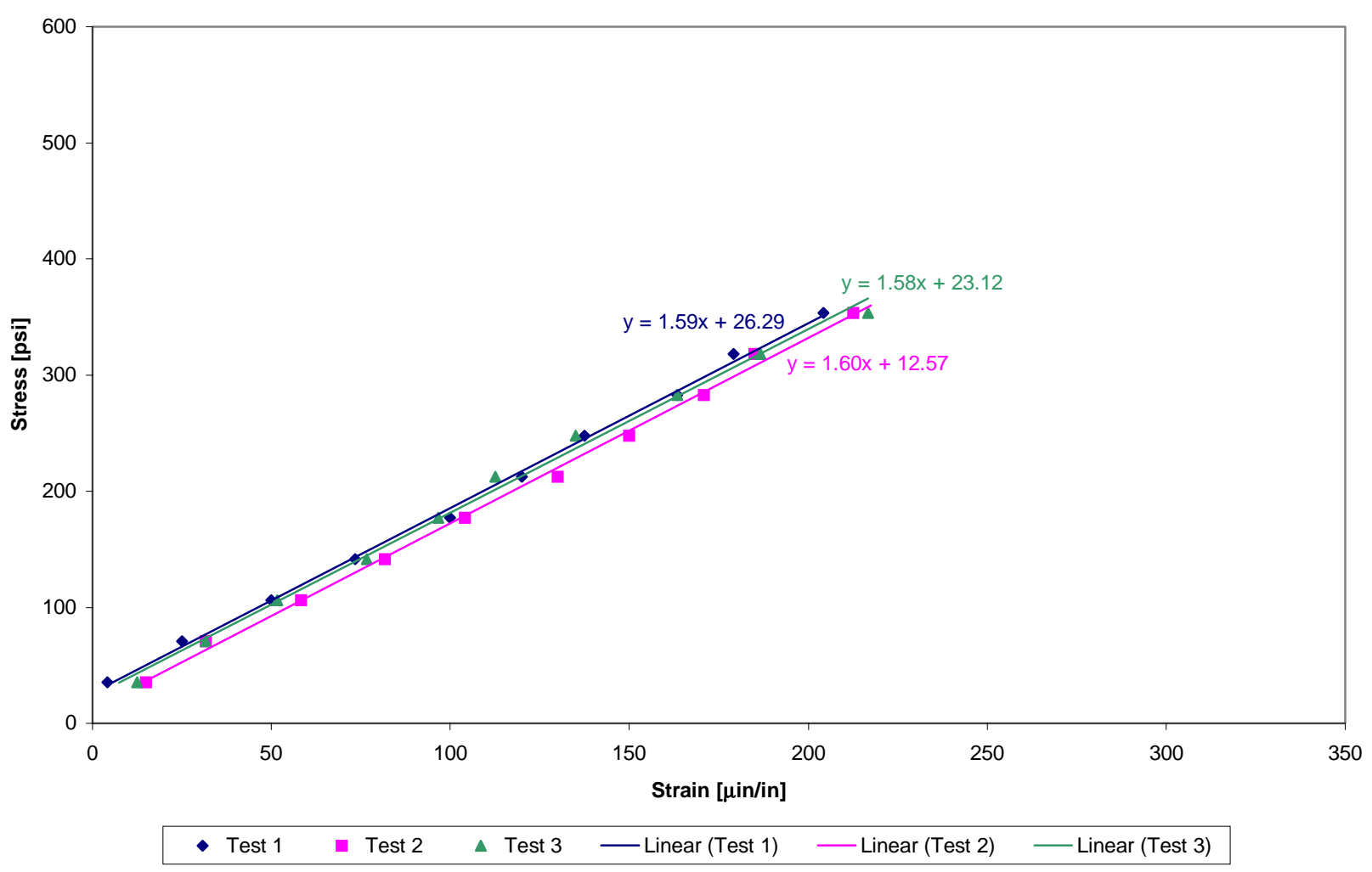

Figure A6: Corridor H Mix, early-age Dial Gage tests 

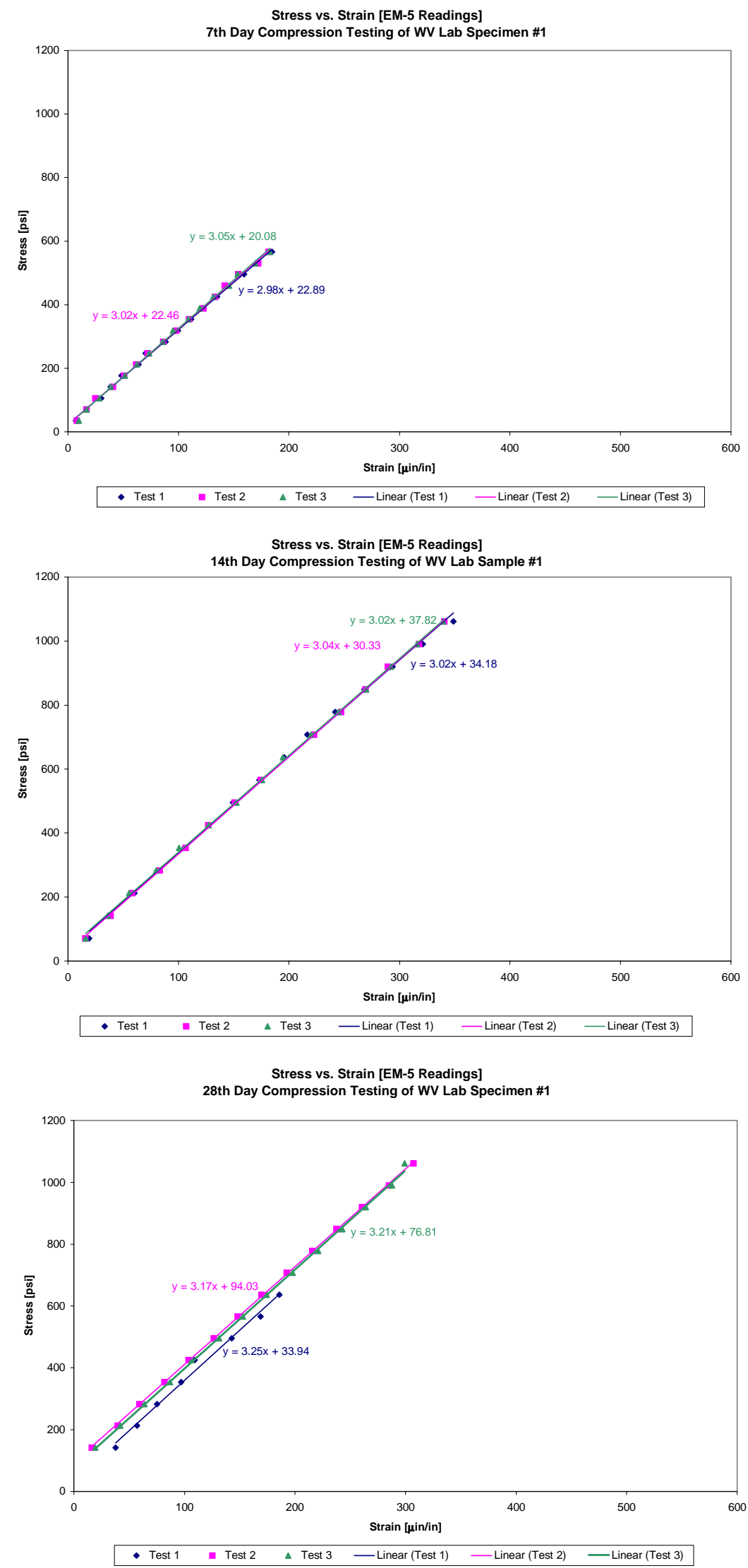

Figure A7: Corridor H Mix, 7, 14 and 28 day EM-5 tests 

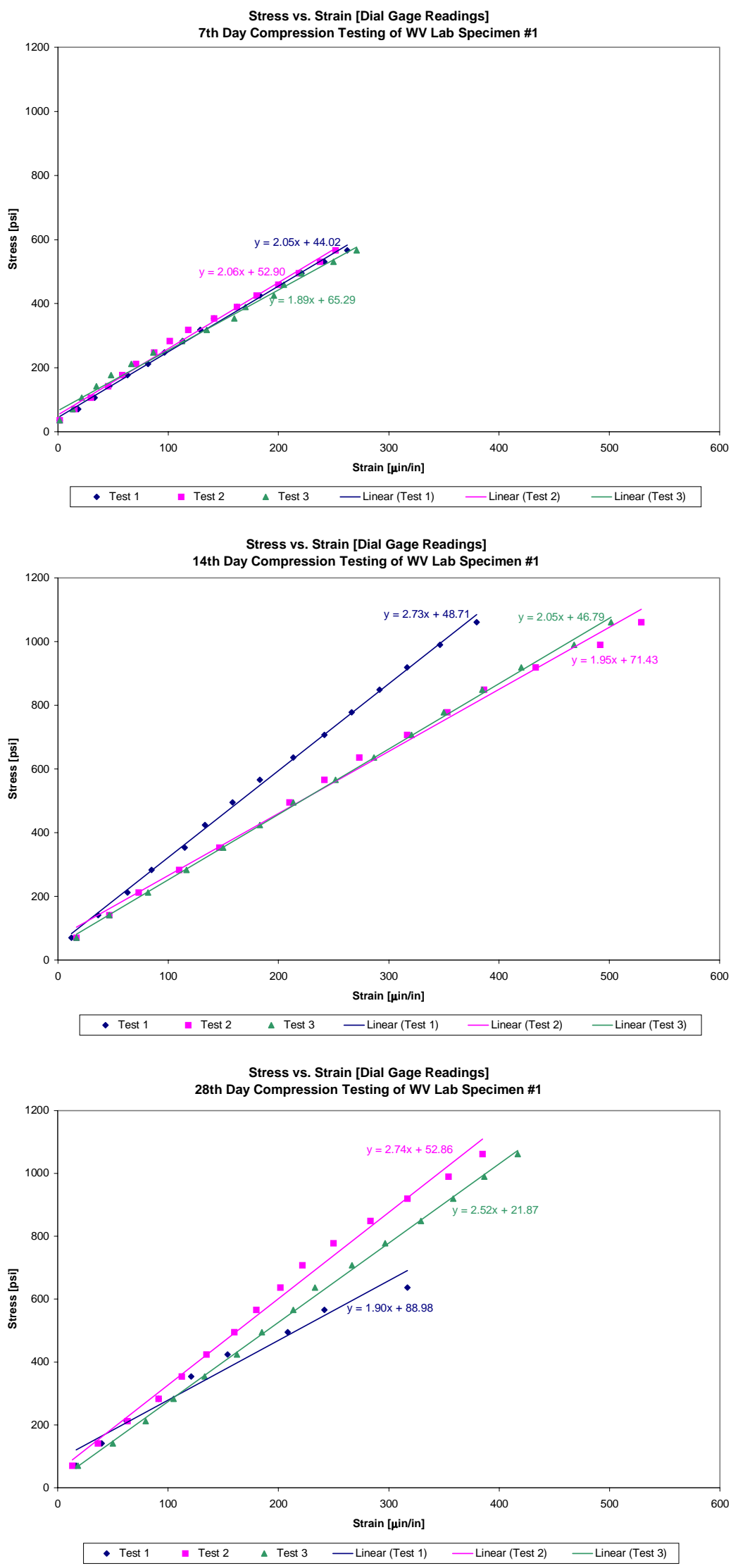

Figure A8: Corridor H Mix, 7, 14 and 28 day Dial Gage tests 